CHORD BEARING CAPACITY IN LONG-SPAN TUBULAR TRUSSES

by

Brian M. Kozy

B.S. in Civil Engineering, The Pennsylvania State University, 1995

M.Eng. in Civil Engineering, The Pennsylvania State University, 1996

\author{
Submitted to the Graduate Faculty of \\ School of Engineering in partial fulfillment \\ of the requirements for the degree of
}

Doctor of Philosophy

University of Pittsburgh

2004 


\section{UNIVERSITY OF PITTSBURGH \\ SCHOOL OF ENGINEERING}

This dissertation was presented

by

Brian M. Kozy

It was defended on

December 3, 2004

and approved by

Jeen-Shang Lin, Sc.D, Associate Professor

Morteza A.M. Torkamani, Ph.D., Associate Professor

Patrick Smolinski, Ph.D., Associate Professor

Kent A. Harries, Ph.D., Assistant Professor

Christopher J. Earls, Ph.D., Associate Professor, Department Chair Dissertation Director 


\title{
CHORD BEARING CAPACITY IN LONG-SPAN TUBULAR TRUSSES
}

\author{
Brian M. Kozy, Ph.D. \\ University of Pittsburgh, 2004
}

Existing design specifications used in North America and Europe do not directly treat the general limit state of local collapse of tubular truss chords at bearing supports; although these specifications do consider the very specific case related to chord wall resistance under concentrated loads applied through simple gusset plate or tubular branch connections. The lack of general and robust treatment of chord bearing strength represents an unsatisfactory situation given the fact that very large reaction forces are often applied locally to the ends of chord members with slender cross-sections in long-span overhead highway sign trusses. A number of these structures in the U.S. have been shown to be inadequate for this limit state; a situation precipitating costly retrofits, construction delays, and motorist safety concerns.

This dissertation research is aimed at quantifying the bearing strength of circular chords in long, simple-span tubular trusses. Two (2) full-scale experimental tests were conducted at the University of Pittsburgh as part of the current research effort. In addition, a parametric study based on the finite element (FE) method is also carried out. The nonlinear FE modeling techniques are first validated against the experimental testing results and then employed in a parametric study whose results are reported on herein. The current study reveals that the bearing strength is influenced by the geometry of the bearing region including any adjacent intermediate truss member(s), the nature of loading, and the material properties. Using a semi-empirical approach, general capacity equations for predicting the ultimate bearing strength are developed. Capacity equations are developed for axial loading (P), moment (M), and interaction of both $(\mathrm{P}+\mathrm{M})$. 


\section{TABLE OF CONTENTS}

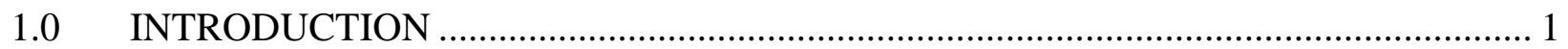

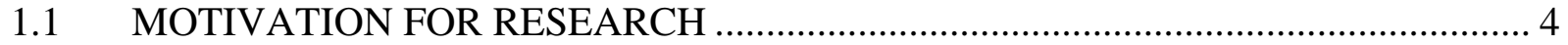

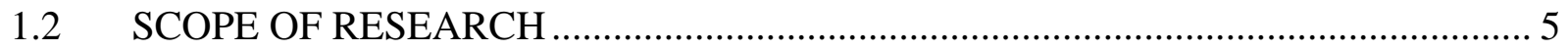

2.0 REVIEW OF EXISTING SPECIFICATIONS AND RESEARCH …............................. 7

$2.1 \quad$ PROCEDURES FOR ANALYSIS AND DESIGN................................................... 9

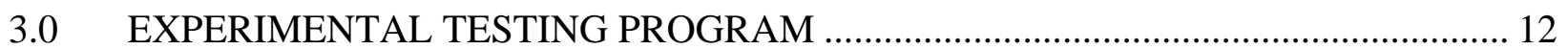

3.1 DESCRIPTION OF TEST SPECIMEN AND SETUP ............................................... 12

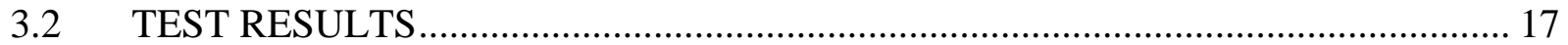

4.0 APPROXIMATE METHODS FOR PREDICTING CAPACITY ……............................ 24

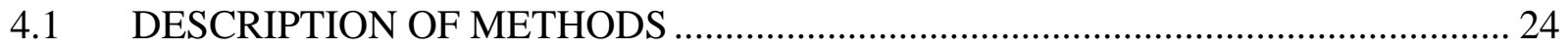

4.1.1 Method 1: Modified application of AISC HSS Specification Section 8 ............... 24

4.1.2 Method 2: Modified application of AISC HSS Specification Section 9 ............... 27

4.1.3 Method 3: Modified application of CIDECT Design Guide ................................. 29

4.1.4 Method 4: Modified application of AWS Section 2.24 ........................................ 30

4.1.5 Additional Notes .............................................................................................. 31

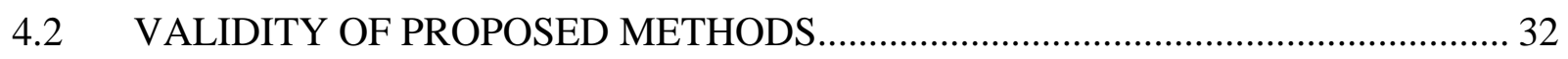

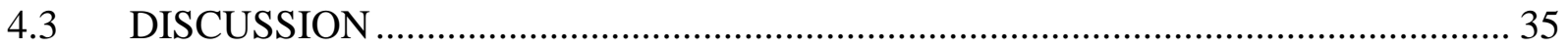

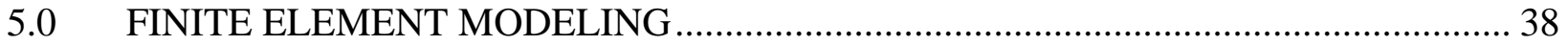

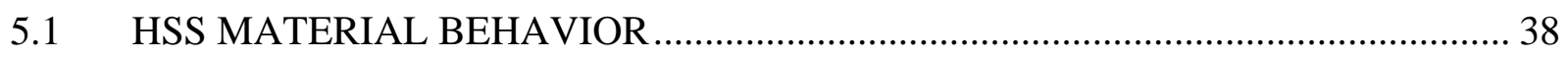

5.1.1 Standard Mill Practice..................................................................................... 38

5.1.2 Specifications .............................................................................................. 39

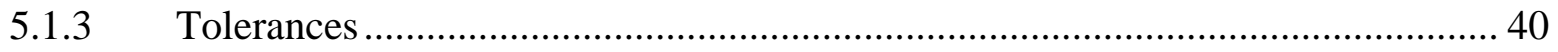

5.1.4 Residual Stresses......................................................................................... 40

5.1.5 Coupon Testing................................................................................................ 42

5.2 FINITE ELEMENT MODELING TECHNIQUES ..................................................... 42 
5.2.1 Boundary Conditions and Loading …………….................................................. 43

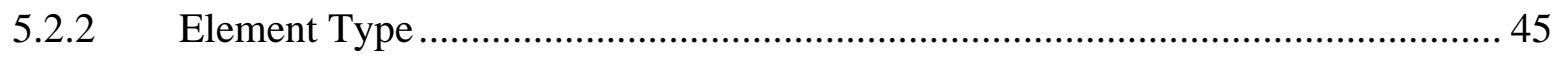

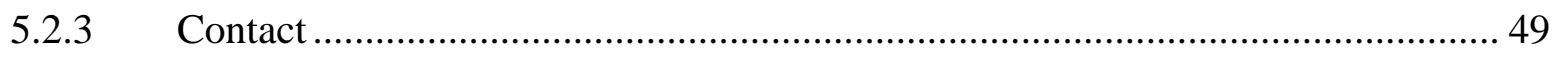

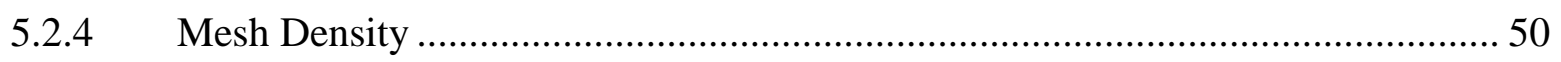

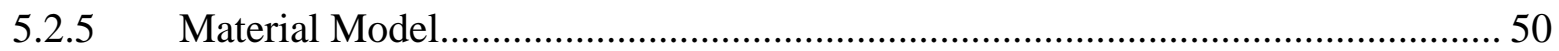

5.3 VERIFICATION OF FINITE ELEMENT ANALYSIS TECHNIQUES ..................... 52

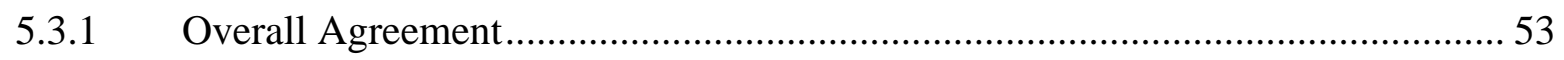

5.3.2 Agreement in Displacements ....................................................................... 53

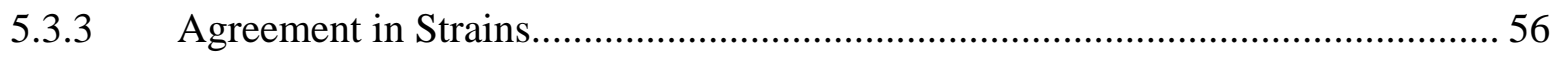

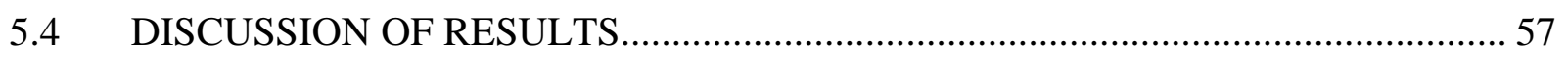

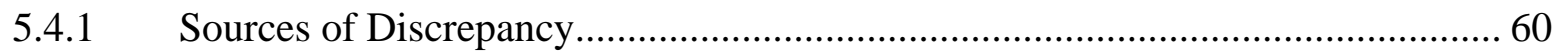

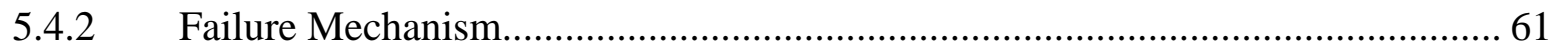

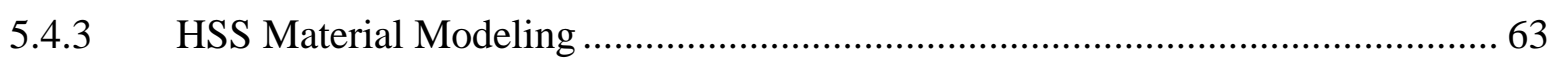

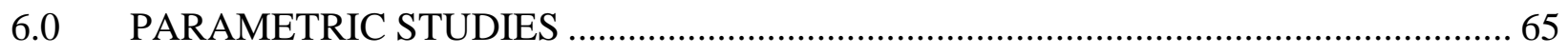

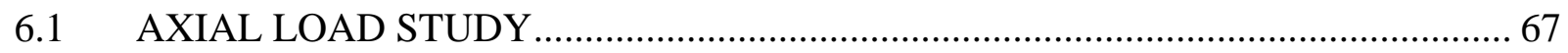

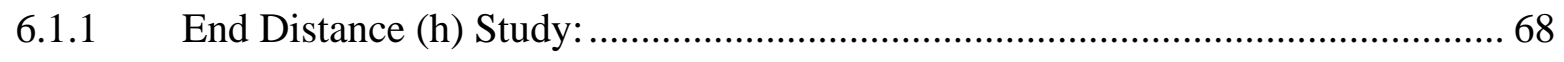

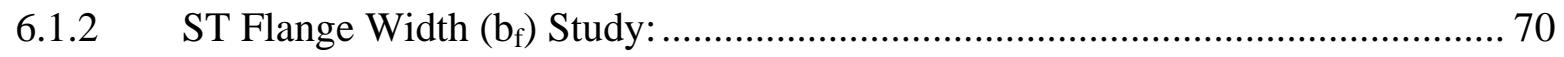

6.1.3 HSS Chord Diameter (D) Study ……………............................................... 71

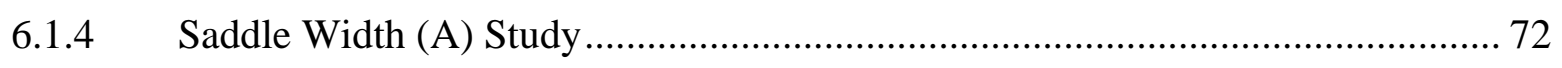

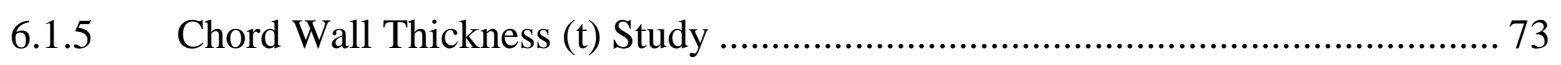

6.1.6 Chord Yield Strength (Fy) Study ........................................................................ 74

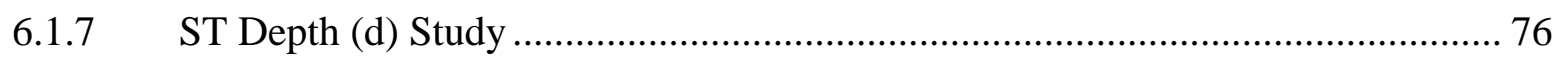

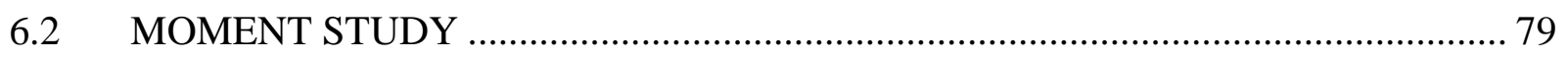

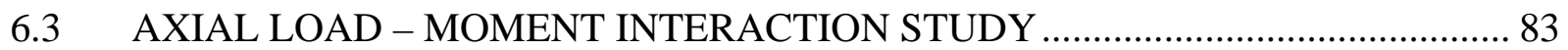

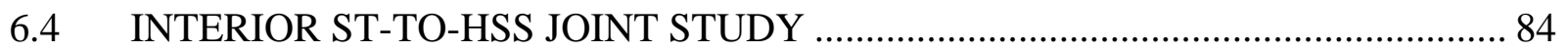

7.0 DEVELOPMENT OF NEW BEARING CAPACITY EQUATIONS ............................... 86

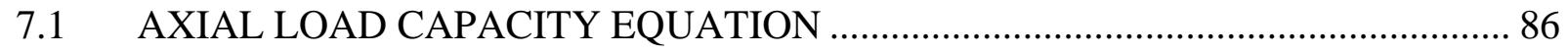

7.2 MOMENT CAPACITY EQUATION …………….................................................... 94

7.3 AXIAL LOAD - MOMENT INTERACTION EQUATION ……………………......... 95

7.4 INTERIOR ST-TO-HSS JOINT CAPACITY …………………………………........ 96

8.0 STRUCTURAL RELIABILITY CONSIDERATIONS ……………………................ 98 


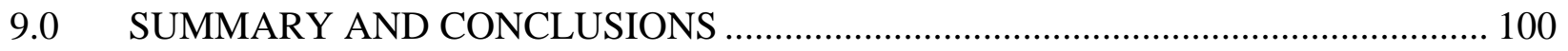

10.0 RECOMMENDATIONS FOR FUTURE RESEARCH............................................ 103

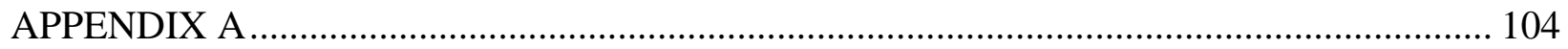

LOAD-DEFLECTION DATA FROM AXIAL LOAD STUDY FEM ANALYSES............ 104

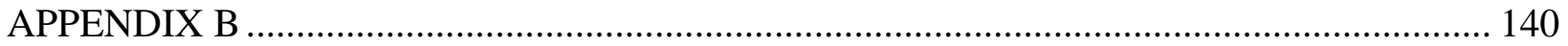

LOAD-DEFLECTION DATA FROM MOMENT STUDY FEM ANALYSES.................. 140

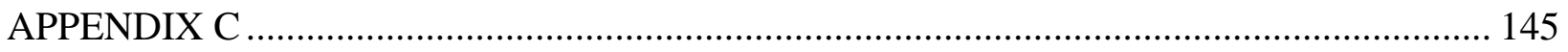

LOAD-DEFLECTION DATA FROM INTERACTION STUDY FEM ANALYSES.......... 145

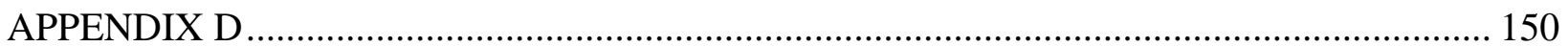

LOAD-DEFLECTION DATA FROM ST-TO-HSS JOINT STUDY FEM ANALYSES. ... 150

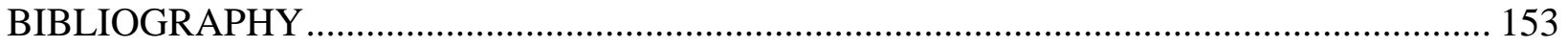




\section{LIST OF TABLES}

Table 4-1: Accuracy of Approximate Methods ..................................................................... 35

Table 5-1: Summary of Shell Elements Considered ............................................................. 47

Table 6-1: Summary of Parametric Study Results for Axial Load ......................................... 78

Table 6-2: Summary of Parametric Study results for applied moment ................................... 82

Table 7-1: Quadratic Function Constants for Axial Load Capacity Equation............................ 89

Table 7-2: Linear Function Constants for Axial Load Capacity Equation ............................... 90 


\section{LIST OF FIGURES}

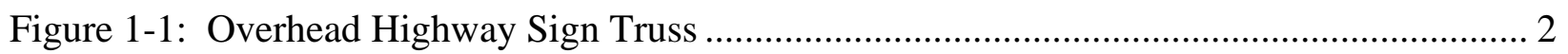

Figure 1-2: Failure of a Tubular Truss Bearing.................................................................... 5

Figure 1-3: Tubular Truss Bearing Configuration Under Investigation. ........................................ 6

Figure 3-1: Schematic of Experimental Test Setup.................................................................... 13

Figure 3-2: Material Response of Steels Used in Test Specimens. .............................................. 15

Figure 3-3: Rosette strain gauge locations on chord wall............................................................ 15

Figure 3-4: Photographs of Experimental Test Specimens........................................................... 18

Figure 3-5: Experimental displacement measurements for Specimen \#1..................................... 19

Figure 3-6: Experimental displacement measurements for Specimen \#2..................................... 19

Figure 3-7: von Mises stresses in chord wall for Specimen \#1 ................................................... 22

Figure 3-8: von Mises stresses in chord wall for Specimen \#2 …………………....................... 23

Figure 4-1: Concentrated Force Distributed Transversely............................................................ 25

Figure 4-2: Concentrated Force Distributed Longitudinally ...................................................... 25

Figure 4-3: HSS-to-HSS Truss Connection ............................................................................. 27

Figure 4-4: Yield Line Mechanisms for ST and Equivalent HSS Branch Members.................... 28

Figure 4-5: WT-to-HSS Joint Covered by CIDECT.............................................................. 29

Figure 5-1: Formed-from-round process for HSS manufacturing ............................................... 39

Figure 5-2: Residual stresses in fabricated round tubular members (Toma and Chen 1979)...... 41

Figure 5-3: Finite element model with von Mises stress contours. ................................................ 44

Figure 5-4: Effect of element formulation on predicted response .................................................. 48

Figure 5-5: Coupon test results from HSS chord steel ............................................................... 51

Figure 5-6: Deformed shape comparison: (a)(b) dimpling at ST and (c)(d) ovalization at end .. 54

Figure 5-7: Load-deflection response comparison at applied load (DCDT 1) .............................. 55

Figure 5-8: Load-deflection response comparison at HSS end (DCDT 3) .................................... 55 
Figure 5-9: Maximum principal strain comparison at gauge location 3....................................... 58

Figure 5-10: Maximum principal strain comparison at gauge location 5 ................................... 58

Figure 5-11: Maximum principal strain comparison at gauge location 9 9.................................... 59

Figure 5-12: Maximum principal strain comparison at gauge location 14................................ 59

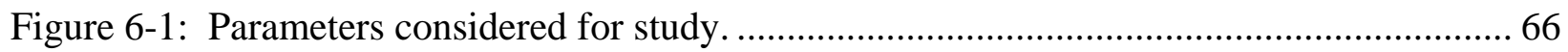

Figure 6-2: Axial load-deflection response for varying end distance (h) ..................................... 69

Figure 6-3: Axial load - deflection Response for varying ST flange width (bf)........................... 70

Figure 6-4: Axial load - deflection response for varying chord diameter (D) ............................ 72

Figure 6-5: Axial load - deflection response for varying saddle width (A)................................. 73

Figure 6-6: Axial load - deflection response for varying chord wall thickness (t) ....................... 74

Figure 6-7: Axial load - deflection response for varying chord yield strength (Fy).................... 75

Figure 6-8: Axial Load - Deflection Response for varying ST depth (d).................................... 77

Figure 6-9: Von Mises Stress Contours for applied moment. ...................................................... 79

Figure 6-10: Parameters considered for Moment Study............................................................... 81

Figure 6-11: Moment-Rotation Response for Applied Moment................................................... 81

Figure 6-12: Axial load-deflection response with corresponding applied moment....................... 84

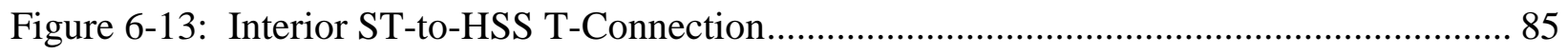

Figure 6-14: Interior ST-to-HSS Cross-Connection ..................................................................... 85

Figure 6-15: Axial load-deflection response for interior ST joints.............................................. 85

Figure 7-1: Yield Line Failure Mechanism for Bearing Connection Region ............................... 87

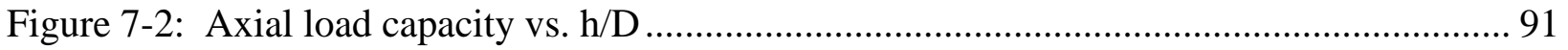

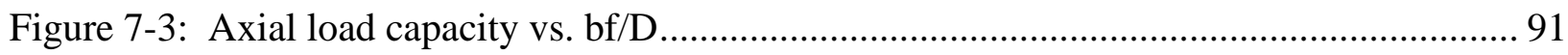

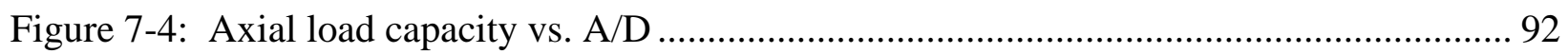

Figure 7-5: Axial load capacity vs. chord wall thickness (t) ....................................................... 92

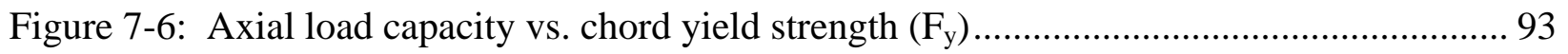

Figure 7-7: Moment capacity vs. plate depth (d) ....................................................................... 95

Figure 7-8: Axial load - moment interaction.................................................................................. 96 


\section{ACKNOWLEDGEMENT}

All of the glory and honor be unto God, the Creator of the universe and the Redeemer of mankind. I pray our understanding of science will only shrink the great divide between us! 


\subsection{INTRODUCTION}

Tubular members, or Hollow Structural Shapes (HSS) as they have come to be known, possess a very efficient cross-section for the resistance of compressive and torsional stresses as a result of their closed, symmetrical geometry. A given HSS member has both a smaller surface area and greater torsional rigidity relative to a comparable open section member of the same weight. Although the material cost is higher for the grades of steel typically specified for hollow sections, this increased cost is typically offset by the lower construction weight deriving from greater structural efficiency, the smaller coating area required for corrosion protection (paint or galvanizing) due to the enclosed nature of the section, and the reduction in fabrication cost by the application of simple joints without stiffening elements. Combine this with the pleasing aesthetics of the HSS, and one can see why tubular members are quickly gaining popularity in structural applications. In particular, the circular HSS has become the member of choice in applications that involve wind, water, or wave loading due to its low drag coefficient. Common structures that utilize the circular HSS include offshore platforms, space trusses in buildings and stadiums, and overhead highway sign structures. A specific design aspect of the last of these applications has motivated the current research. However, the findings will be of interest to researchers and engineers working with many types of tubular structures.

For the proper functioning of the surface transportation system, signage is required to alert the motoring public to changes in interstate topology, weather conditions, traffic patterns, and for other informational purposes. Along heavily traveled segments of the interstate system in urban areas, the roadway is particularly wide so as to accommodate the required number of travel lanes needed to address heavy regional traffic volumes. As a result of this, highway signs frequently must span great distances to provide the motorist with needed information without introducing the danger associated with the occurrence of intermediate supports on medians or other locations adjacent to the roadway. A structural system frequently employed within the U.S. for this purpose is the tubular truss (see Figure 1-1). 
The typical overhead sign structure consists of a set of columns, or towers, that serve as supports for elevated bridging upon which signage is attached. The bridging typically is a tubular latticework, where longitudinal HSS chord members are positioned in a triangular or square orientation and multiple smaller "branch" members compose the lacing that attaches the HSS chords to one another. The connections of the lacing members to the HSS sections are typically proportioned such that the lines of action of all forces introduced into a given connection region intersect at the same work point; thus supporting an analytical approximation that the bridging is a space truss with pinned joints.

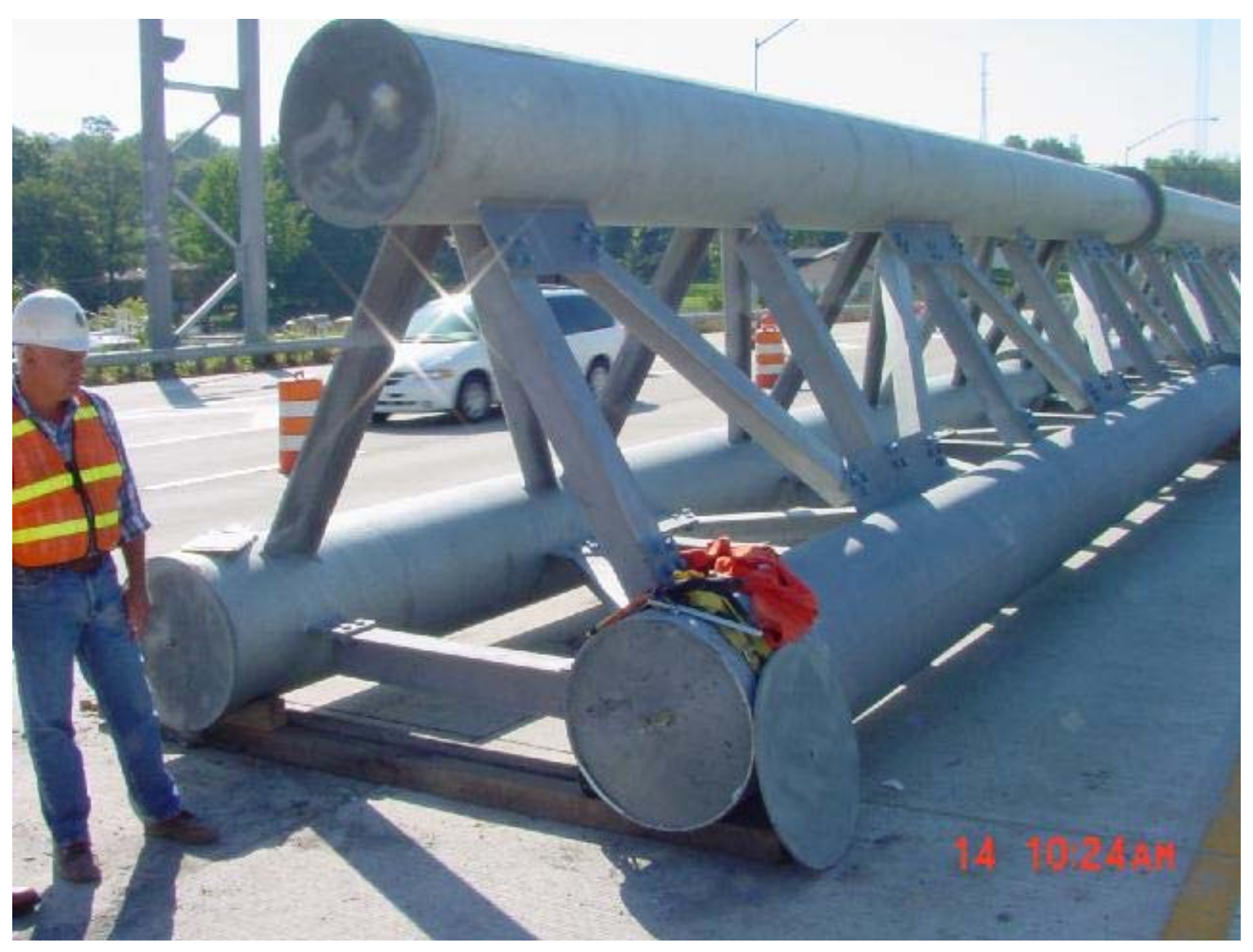

Figure 1-1: Overhead Highway Sign Truss 
One of the primary challenges in designing any safe, cost-effective tubular structure is in the detailing of the connections. Typical connections can be simple HSS-to-HSS connections, connections between an open (rolled) section and an HSS, or connections made through gusset plates. The latter two of these are sometimes referred to as "plate-type" connections. For the specialized case of a truss, the connections usually consist of one or more smaller branch members that are attached to a continuous chord that passes through the connection work point. These truss joints can be classified as a T-Connection, Y-Connection, Cross-Connection, or a KConnection depending on the geometry. For design, special attention must be given to ensure that the connection does not fail by way of punching shear rupture, chord wall plastification, general collapse, or by some other local failure mechanism. The behavior of HSS-to-HSS connections has been researched and is well understood, but less work has been done in the area of plate-type HSS connections.

Typically in the design of long-span tubular trusses such as those as those found in overhead highway sign structures, the desire is to have chord members with a large radius of gyration (larger diameter with thinner walls) so as to increase axial compressive resistance while at the same time reducing member weight. However, such an approach as this usually leads to a trade-off since joint capacities are most likely reduced due to the decreased capacity in thin chord walls. As modern structures "push the envelope" on span lengths, the design of the connections quickly becomes a critical component to the overall design.

The bearing connection region where an overhead sign truss is attached to the uprights or towers is no exception. This region is susceptible to similar mechanisms of failure as interior tubular connections due to the very large reaction forces resulting from dead loads as well as the action of environmental forces from wind, ice, etc. The general attachment between the towers and main truss typically occurs through the ends of the HSS chord sections seated directly on a steel bearing surface. It is the performance of this connection region that is the focus of this research. 


\subsection{MOTIVATION FOR RESEARCH}

Most of the research and published specifications for the design of tubular steel structures has been initiated by the oil industry. Thousands of large tubular steel structures have been built for offshore oil drilling and production over the last fifty years, and the safety and economy of these unique structures has been the driving factor behind most of the research that exists today. In contrast, the long-span tubular truss for overhead highway signs is a relatively new structural form. In the evolution of the modern overhead sign truss, much of the research from the offshore industry has been adapted to this application. However, there exists many issues that are specific to sign trusses such as loading, stability, corrosion, fatigue, etc., which have required additional research. Since structural engineering is often based somewhat on trial-and-error, special attention must always be paid to potential failure modes that may be manifested when designing a new structural system. The bearing connection region in long-span tubular trusses is a prime example of this.

Unlike the typical offshore steel "jacket” platform, the overhead sign truss is a simplespan structure in which the global reaction forces are applied transversely at the truss ends. Thus, this new structural form embodies a unique feature that may have been overlooked by existing research upon which existing related specifications are based. Unfortunately, this was confirmed by a structural failure that occurred outside of Philadelphia, Pennsylvania in August 2000 (see Figure 1-2). The structure was a new slender tubular truss with a span of $180 \mathrm{ft}$; one of the largest constructed by the state of Pennsylvania. During final erection, the chord ends were crushed at the bearing supports under the action of self-weight dead load alone.

A forensic investigation revealed that a poor connection detail was ultimately the cause of failure in this case. The detail called for the chord ends to be seated on a simple flat bearing surface, which is now known to possess a very low bearing capacity. However, it cannot be fully blamed on the engineer of record since this failure mode had not been observed previously and also, none of the relevant design specifications even treated the mode exhibited in the sign structure in question. In response to this, a more rigorous understanding of the mechanics associated with bearing connection regions in long-span tubular trusses is sought in order that economical and reliable design provisions may be prescribed. 


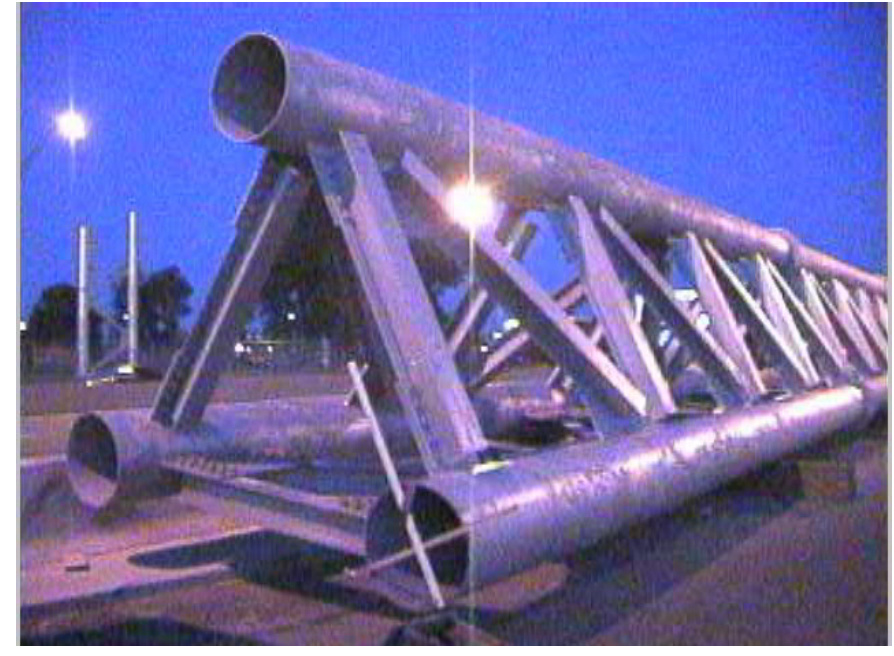

(a)

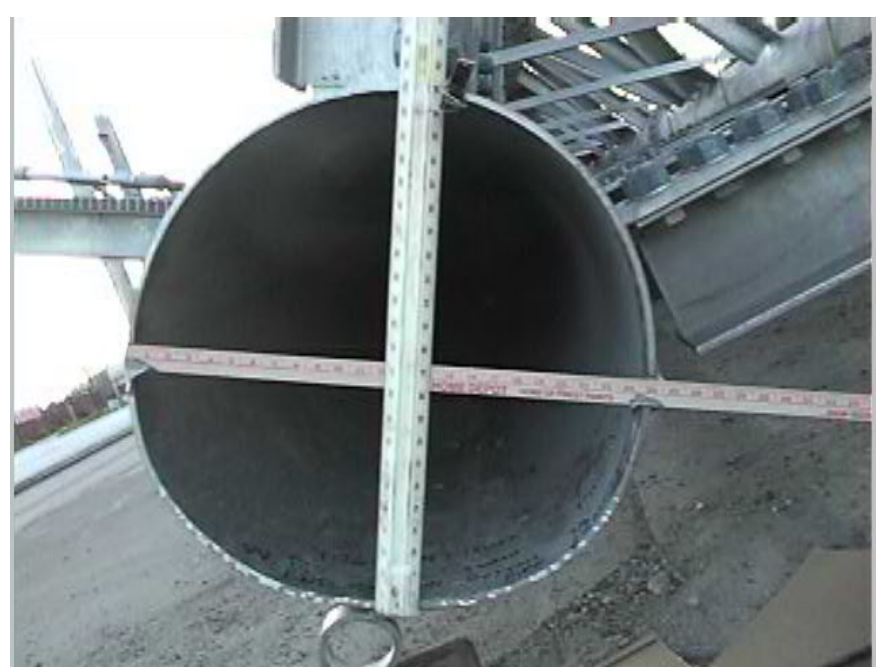

(b)

Figure 1-2: Failure of a Tubular Truss Bearing.

\subsection{SCOPE OF RESEARCH}

The focus of this research work concerns bearing regions in long-span trusses composed of tubular members in the context of U.S. design practice. Specifically, a connection detail involving curved steel saddle bearings and a Structural Tee (ST) connected directly to a largediameter circular Hollow Structural Section (HSS) chord near its open end is considered (see Figure 1-3). For simple-span HSS trusses, the primary load path for the reaction force developed at the support is from the bearing, through the chord, and directly into the first intermediate vertical member. Therefore, the overall connection capacity is influenced by all of these member proportions and their spacing with respect to one another. It must be noted that this region is being investigated locally without involving the global behavior of the entire truss (i.e. the more complicated member internal forces resulting from effects of the structural system surrounding the connection detail are not considered). The assumption is that the effects of such additional 
internal forces are of small magnitude and hence will not significantly influence the local limit states under investigation. In considering this simplified loading condition, it is noted that while some research has been done on local concentrated loads applied to HSS walls through gusset plates, very little work has been done on loads applied directly through the ends of an open rolled sections. No previous work has been found in the literature concerning the cases of saddle-type bearings located at truss chord ends or an ST bearing directly on a circular HSS chord.

This current research is based on the application of sophisticated nonlinear finite element modeling techniques as well as full-scale experimental testing for the quantification of truss end bearing connection capacities. The nonlinear finite element modeling techniques employ experimentally verified strategies (previously verified against available relevant tests on tubular structures found in the literature as well as those tests carried out as part of the current research) and form the cornerstone for parametric studies carried out in support of the formulation of the newly proposed design equations presented herein and aimed at predicting bearing strength in tubular trusses. The full-scale tests carried out as part of the current research were executed using geometric configurations identified as being most susceptible to chord bearing failure.

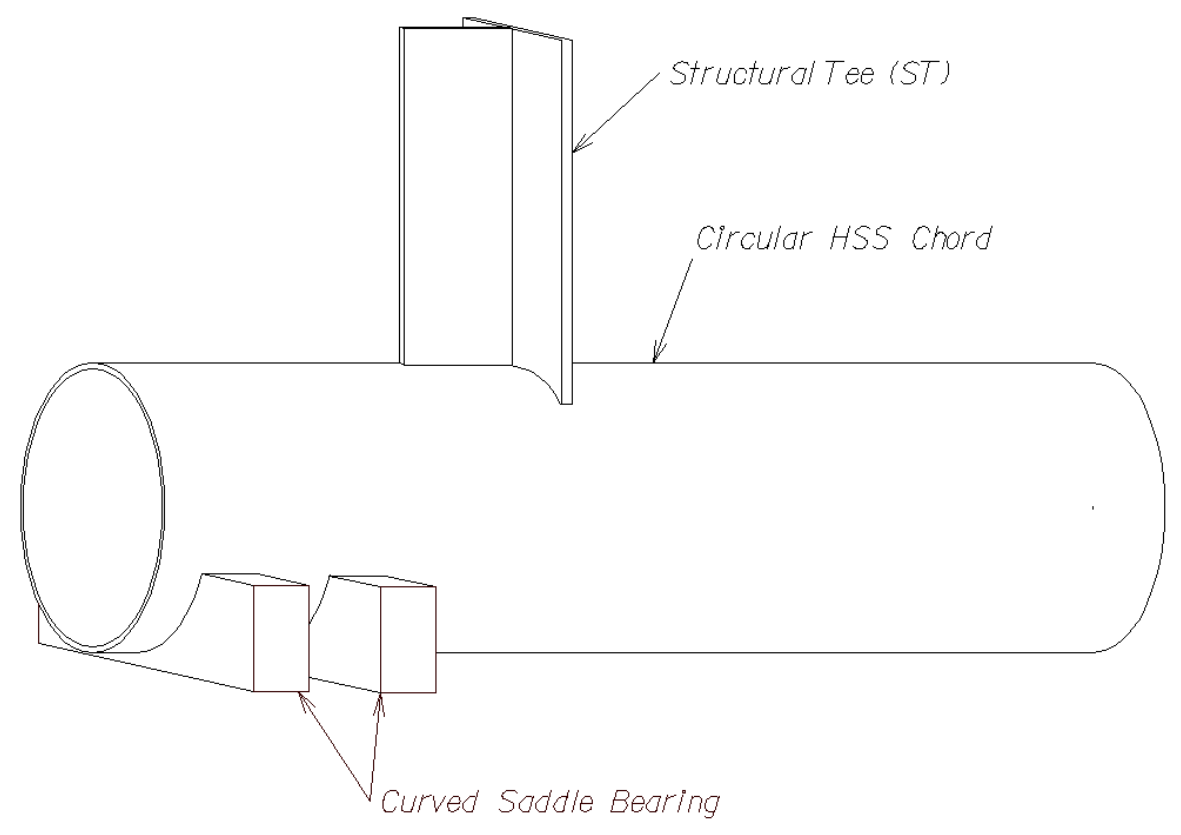

Figure 1-3: Tubular Truss Bearing Configuration Under Investigation. 


\subsection{REVIEW OF EXISTING SPECIFICATIONS AND RESEARCH}

The governing specification for the design of highway overhead sign structures in the US is the Standard Specifications for Structural Supports for Highway Signs, Luminaires and Traffic Signals, $4^{\text {th }}$ Edition (AASHTO 2001). Currently, this specification does not address the capacity of tubular connections or bearings at all; a potentially serious omission since joint related limit states often control the overall structural capacity (Li and Earls 2002). The design engineer must look beyond this omission and recognize the need for checking joint strengths by consulting other specifications for guidance. American specifications that do address connection capacities in tubular structures are the Load and Resistance Factor Design Specification for Steel Hollow Structural Sections (AISC 2000), which can be found in Part 16 of AISC LRFD Manual $3^{\text {rd }}$ Edition (AISC 2001), and AWS D1.1 Structural Welding Code - Steel (AWS 2004). Also, more detailed guidance and examples are provided in the AISC Hollow Structural Sections Connection Manual (AISC 1997a).

The AISC Hollow Structural Sections Connections Manual (AISC 1997a) is the definitive American design manual representing the state-of-the-art in hollow structural section connection design and detailing. This manual treats specific design topics related to: dimensions and properties of HSS members; welding practice; issues related to bolting; simple shear connections; moment connections; tension and compression connections; cap plates, base plate, and column splices; and welded truss connections. In addition, the manual contains the Specification for the Design of Steel Hollow Structural Sections (AISC 1997b), which deals specifically with HSS design issues related to: material properties; loads and load combinations; effective net area for tension members; local plate buckling; limiting slenderness ratios; and design for tension, compression, flexure, shear, torsion, combined loading, and the localized effects of various type of transverse loading scenarios; weld design; truss connection design; and fabrication requirements. 
The AISC Hollow Structural Sections Connections Manual (AISC 1997a) has a Canadian counterpart in the CISC Hollow Structural Section Connections and Trusses Design Guide (Packer and Henderson 1997). This Canadian Manual treats many of the same topics of its American counterpart as well as several additional topics such as: material property and crosssectional geometric definitions; standard truss design; standard truss welded connections; nonstandard truss design; multiplanar welded connections; HSS-to-HSS moment connections; bolted HSS connections; fabrication, welding, and inspection; beam to HSS column connections; trusses and base plates to HSS connections; plate to HSS connections; HSS welded connections subjected to fatigue loading; and standard truss examples.

While it may appear from the forgoing that the Canadian and American HSS manuals are very similar, this would be an incorrect conclusion to draw. The American HSS manual (AISC 1997a) is constructed to be consistent with the format and fundamental approach contained in all other AISC design manuals and as such takes a much more general approach to the promulgation of design guidelines. In contrast, the Canadian HSS manual (Packer 1997) is much more focused on the specific design case of the HSS truss. Most of the Canadian manual is focused to support the design of variations on the HSS truss form.

To discuss the state-of-art knowledge in steel HSS construction, it would be a mistake not to also consider work that is being done outside of North America. Both the Canadian and American HSS specifications have adopted significant material from the European Comite International pour le Developpement et l'Etude de la Construction Tubulaire (CIDECT). Founded in 1962, CIDECT is an international organization of major HSS manufacturers that was formed to combine all the resources worldwide from industry, universities, and other national and international bodies for research and application of technical data, development of simple design and calculation methods and dissemination of the results of research (Wardenier et al.. 1991). CIDECT has technical and research activities ongoing in many areas of HSS construction including: buckling behavior of columns and trusses, bending strength of members, static strength of welded and bolted joints, and fatigue resistance of joints. Most germane to the current discussion on circular HSS connections is CIDECT's publication Design Guide for Circular Hollow Section (CHS) Joints Under Predominantly Static Loading (Wardenier et al.. 1991). This publication contains capacity equations for many of the same HSS connections addressed in the Canadian and American specifications, but it also provides data for many other 
types of joints which will prove valuable for predicting the bearing capacity of circular HSS chord members; the focus of the present work.

\subsection{PROCEDURES FOR ANALYSIS AND DESIGN}

The analysis and design of connections in tubular structures is a very complex problem in general. Many different analytical methods have been applied to address this problem including elastic shell theory, the finite element method, the method of cutting sections, and plastic yield line analysis. However, these analytical methods are often cumbersome or computationally expensive. Thus, researchers and engineers have tended toward the use of experimental methods, which can address the full range of behavior from the elastic to the ultimate limit state. The following paragraphs give a brief overview of the various methods applied to the solution of this difficult problem; a more detailed description of each can be found in Marshall (1992).

The first level of analysis that can be conducted on a tubular connection is elastic analysis. Elastic analysis can be important in fatigue design, in which the localized stresses are typically desired. Closed form solutions for elastic stresses in cylindrical shells have been developed for many simple, symmetric loading conditions (Young 1989), however even the simplest case requires a complex solution. Some tubular connections can be approximated using these simple understood cases, but direct theoretical solutions for common connection details are impractical due the curved geometry and complex stress fields, and are generally not attempted.

Another method utilized for the calculation of elastic stresses in tubular member connection details is the finite element method, which includes thin shell finite elements or 3dimenensional isoparametric continuum finite elements. Thin shell finite element analysis is based on constructing a mesh at the mid-surface of the plate components with the throughthickness direction being implied within the formulation, which works well for analyzing stresses away from discontinuities such as a weld toe. 3-D isoparametric continuum elements provide a solid element to model the finite thickness of the shells, which avoid the paradoxical results that are sometimes obtained from "surface" stresses at the mid-plane intersection in thinshell analysis (Marshall 1992). Researchers have used these methods with success, but typically consulting engineers from industry are not equipped for this type of analysis. 
The next types of analysis that are conducted on tubular connections are limit state methods. The most common approach used for developing capacity equations for HSS connections is the method of cutting sections, often called the "ring model." This method involves analysis of a unit strip or slice through the HSS chord using simple plastic analysis, i.e. the yield line method. Then, the effective width of the ring (length along the HSS chord) is estimated or determined using empirical test data. The ring model approach is found throughout the literature (Kurobane, et al. 1976) (Kurobane, 1981) (Wardenier, 1982) and is the basis for many of the HSS capacity equations in the current specifications.

Another limit state method applied to the analysis of tubular connections is the yield line method, which is based on the upper bound theorem of plasticity. The general approach is to assume a rigid plastic failure mechanism, and compute the load level at which internal work due to yielding equals the external work due to the applied loads (Marshall 1992). This method has been used with success for the formulation of capacity equations in symmetric tubular box connections (Kosteski and Packer, 2003), in which a kinematically admissible collapse mechanism can be developed using simple geometric considerations. For circular HSS connections, the yield line method was applied by Soh et al. (2000), but it is generally not the preferred method due to the associated complex geometry of the failure mechanisms.

Inelastic finite element analysis is another method applied to study of tubular connections. Clough (1965) described the finite element stiffness method in terms of the following steps: (1) Express element internal displacements in terms of assumed deformation patterns which approximate behavior of the continuum, are more or less compatible at the element boundaries and whose magnitude is given by generalized coordinates, one for each degree of freedom, (2-4) Express both nodal displacements and internal strains in terms of the same generalized coordinates and deformation patterns, (5) Evaluate internal stresses from the internal strains, with material characteristics represented by the stress-strain matrix, (6) In generalized coordinates, integrate over the element volume to compute internal virtual work due to internal stresses an strains, compute external work due to nodal forces and displacements; and equate these to extract the element stiffness, (7) Transform to the desired nodal point stiffness matrix for each element. The process is repeated for all the elements to assemble the global stiffness matrix for the whole structure. For linear structures, this is solved by matrix inversion of numerically equivalent methods. However, for solving non-linear problems an additional sub- 
procedure is required, for which two principal methods are used: incremental loading and intermediate equilibrium iteration. Because inelastic finite element analysis involves complex numerical procedures, the modeling techniques (mesh size and layout, element selection, material descriptions, and solution strategy) should be carefully calibrated and benchmarked against reliable experimental results (Marshall 1992).

When none of the previous analytical methods can be applied, then the last resort is to conduct model testing on the tubular connection. Modal tests can be used to study the elastic stresses, ultimate strength limit state, and the fatigue behavior, and are considered by most to be the most reliable way for verifying capacity. However, experimental testing can be relatively expensive as compared to computerized simulations. 


\subsection{EXPERIMENTAL TESTING PROGRAM}

The experimental research program is aimed at quantifying the physical response of the bearing connection region in long-span tubular sign trusses. The given connection detail selected for study is based on U.S. design practice which is considered susceptible to bearing failure (i.e. a detail with a slender chord cross-section). The scope of the current experimental work is threefold: to determine the capacity of a particular truss bearing configuration through physical testing, to evaluate the accuracy of existing provisions for predicting the bearing capacity of tubular truss chords; and to produce a data set of physical testing results for the purposes of validating nonlinear finite element modeling techniques to be used for the parametric studies.

\subsection{DESCRIPTION OF TEST SPECIMEN AND SETUP}

The basis for the geometry of the specimens considered in the experimental tests is the Standard Drawings for Bridge Construction [and Design] developed and maintained by the Pennsylvania Department of Transportation (PennDOT). In these standards, the bearing configuration selected for consideration can be found in many of the long-span highway sign structure truss details. In an effort to maintain reasonable geometric parameters for testing, the experimental specimens are proportioned to exactly match the design and details emanating from BD-644M and BC744M (PennDOT 2003a,b) for the case of a tri-chord truss spanning greater than $197 \mathrm{ft}$; which calls for three (3) - 1/2 in. x 26 in. diameter HSS chords laced together with ST10x48 intermediate members.

At the truss ends, the first ST intermediate (branch) member is oriented vertically and thus is normal to the sidewall of the HSS chord, and the chord end is seated in a curved saddle 
bearing assembly in close proximity to the ST. As a result of the ST orientation, and the fact that this location is highly stressed from the reaction forces, PennDOT chose to detail the ST to bear directly upon the HSS chord side wall through a full-penetration welded connection. In order to simulate this connection condition in the laboratory set-up, two curved saddles were proportioned and positioned within a specially built load frame whose proportions were consistent with those called out in BD-744M (PennDOT 2003b). In general, the schematic testing condition depicted in Figure 3-1 was adhered to in the design of the specimens and load frame. Two (2) specimens having the same dimensions and loading conditions were tested in order that repeatability of results within the testing program might be ascertained.

Fully nonlinear shell finite element based models of potential specimen geometries and the general testing configuration were first constructed and analyzed using ABAQUS (ABAQUS 2003) as a means of identifying proportions that permitted economy in material and fabrication costs while at the same time preserving the integrity of the structural response and failure modes germane to the current work. In the end, the 26 in. circular HSS component of the specimens

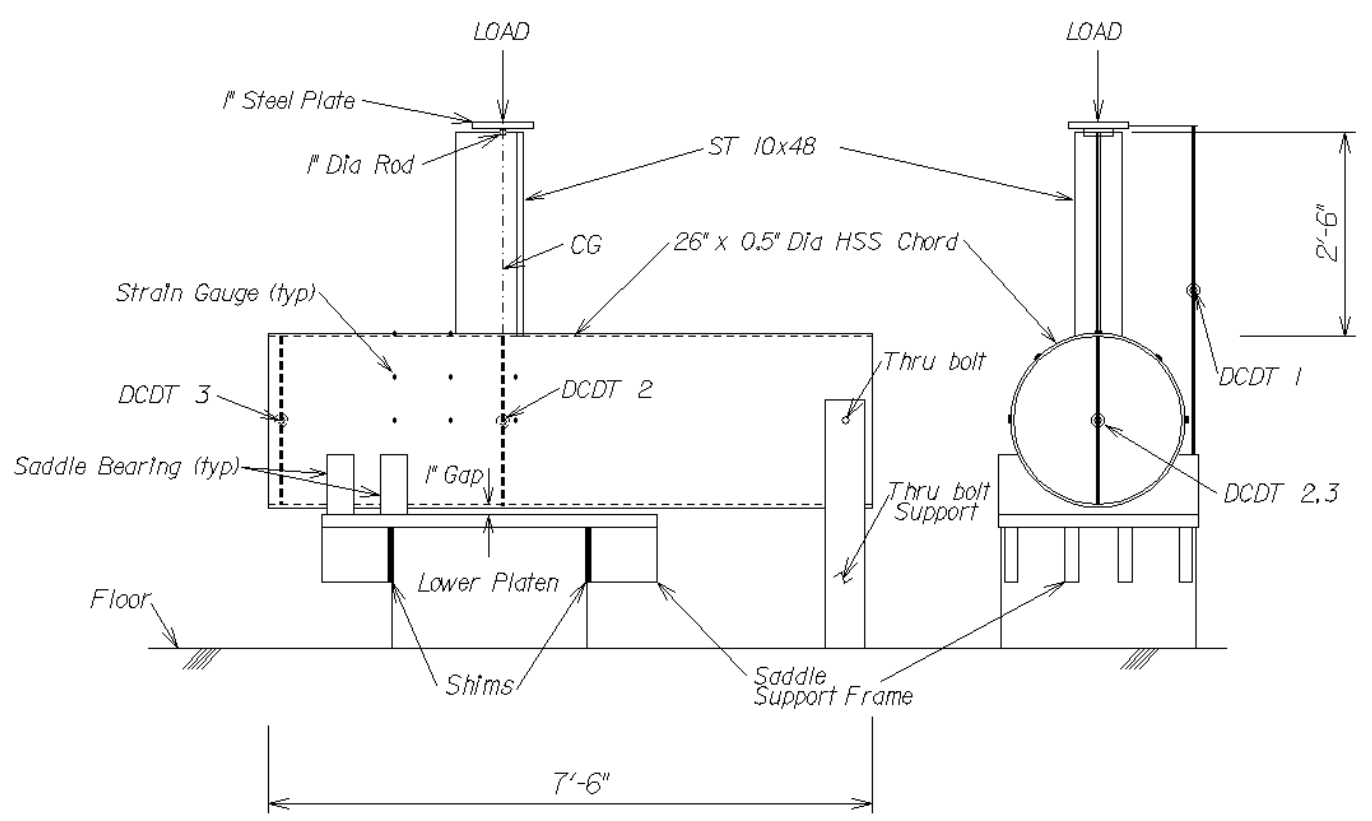

Figure 3-1: Schematic of Experimental Test Setup. 
was selected to be $7 \mathrm{ft}-6$ in. long and the ST10x48 was specified to be $2 \mathrm{ft}-6$ in. long (as shown in Figure 3-1). The HSS length was selected to provide a sufficiently long specimen such that continuity effects of adjacent HSS material would be preserved (i.e. the specimen had to be long enough to capture the local effects of continuity in HSS sidewall provided by the $197 \mathrm{ft}+$ long piece as would be used in the field). The finite element models indicated that the $7 \mathrm{ft}-6$ in. length would be more than adequate for this purpose. Another consideration impacting on the selection of the HSS specimen length was related to the desire to have the end of the circular HSS bear firmly against the saddles and not "lift-off" as a result of pivoting around the support of an excessively short HSS section. Finite element modeling indicated that the $7 \mathrm{ft}-6 \mathrm{in}$. HSS length was sufficient to ensure realistic kinematics in the test. Similarly, the length of the ST10x48 specified was arrived at through finite element modeling that indicated $2 \mathrm{ft}-6 \mathrm{in}$. of member length would be sufficient to attenuate local effects from the point load applied to the top of the ST member by the loading frame actuator (i.e. 2 ft-6 in. was sufficient for St. Venant's principle to take effect and disperse stress concentrations at the load point). In terms of boundary conditions on the circular HSS, at the end away from the saddle, a single thru-bolt was positioned close to the end of the HSS end in order to serve as a "pinned end." The grade of steel used for the HSS was ASTM A53 Grade B and the steel used for the ST10x48 was ASTM A709 Grade 50. The general behvaior of the material stress-strain response obtained from coupon tests are shown in Figure 3-2.

In order to compare the experimental test results to the finite element modeling results, the strains at certain critical points on the HSS section needed to be accurately measured. After reviewing the preliminary finite element models of the specimen geometries considered herein, it was decided that three rows of strain rosettes on the HSS section were required to capture the needed information. The first row fell directly over the saddle closest to the ST; the third was directly under the ST, aligned with the center of the flange; the second row of rosettes was oriented at the midpoint between the two. Five rosettes were circumferentially placed in each row, one at each 90 and 45 degree angular position around the outside of the cross-section, and one located at the top of the HSS section as seen in Figure 3-3. The third rosette row, located under the ST, did not have a rosette on top since the ST occupied the required location for 


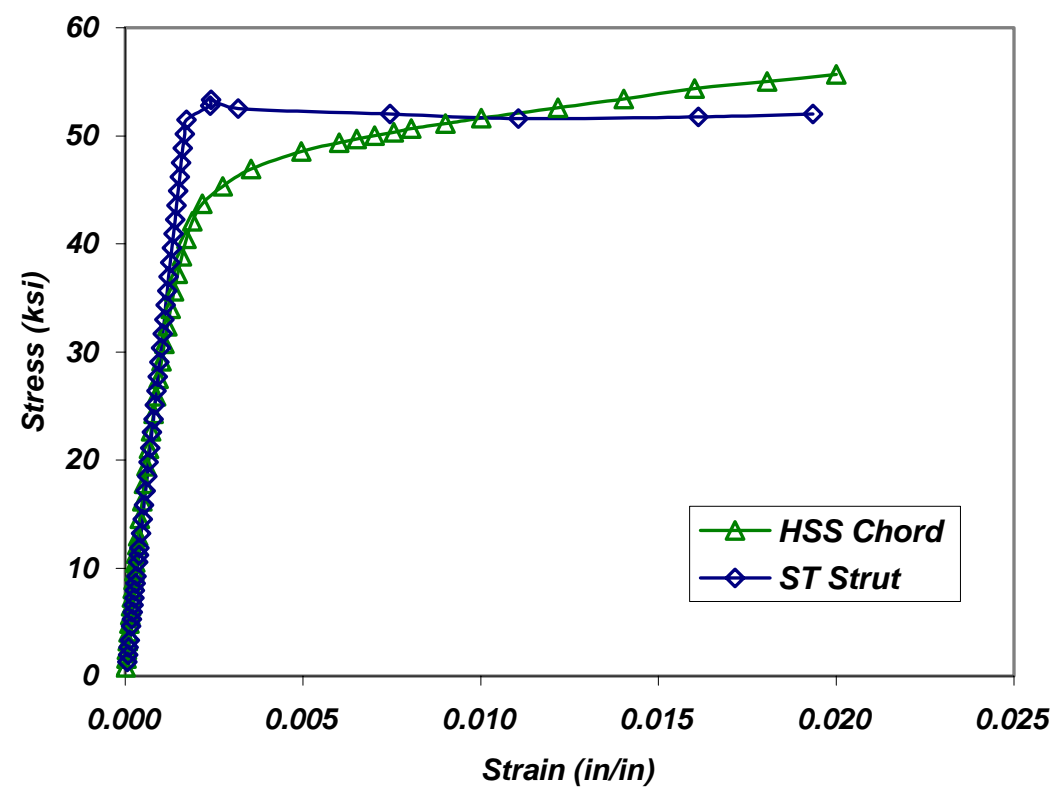

Figure 3-2: Material Response of Steels Used in Test Specimens.
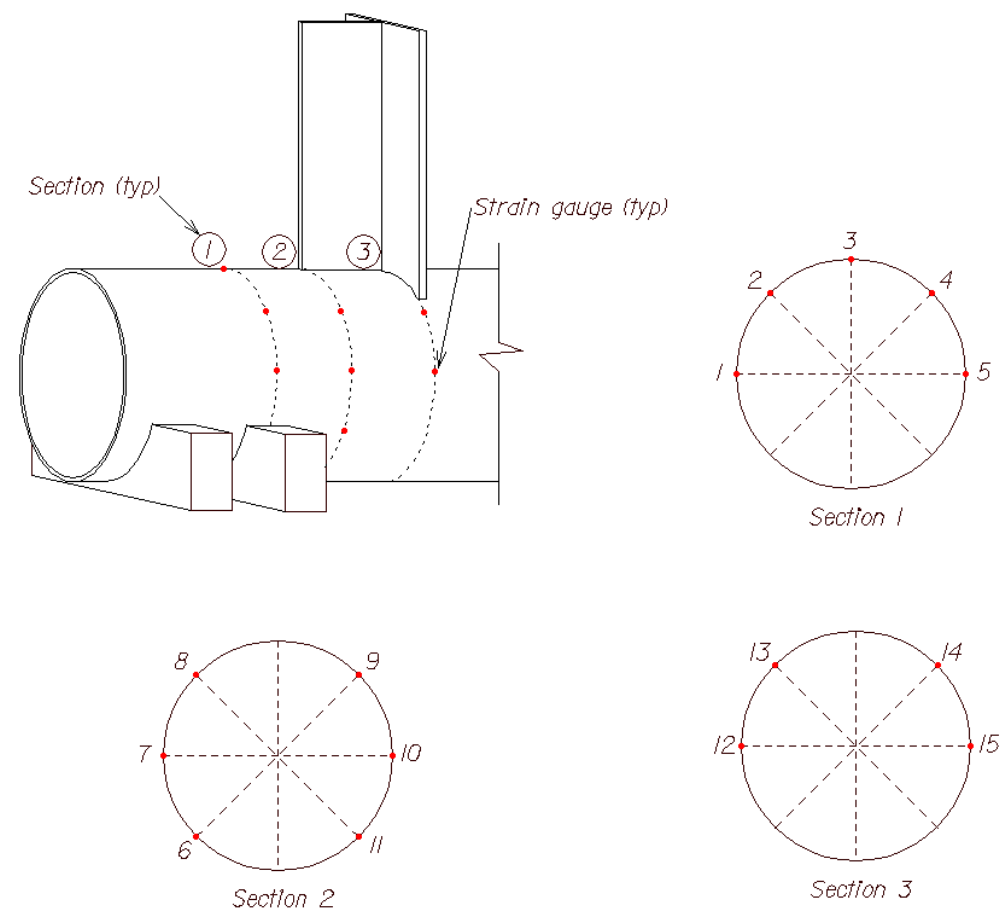

Figure 3-3: Rosette strain gauge locations on chord wall 
installation. Three uniaxial strain gauges were also placed at the midpoint of the ST on each of the flange tips as well as on the web tip to measure the strains in the ST section.

In an effort to monitor deformations and cross-sectional distortion, three displacement transducers (DCDTs), identified as DCDT 1, 2, and 3 were used to measure displacements at different locations as shown in Figure 3-1. The locations were selected to reveal the portion of the overall specimen deformation that results from local wall distortion and the portion that results from global bending. The DCDT 1 , was mounted externally to a bar that was attached to the lower platen of the loading frame, which served as a ground (fixed) point. This DCDT extended to the upper platen of the testing machine and thus it measured the total displacement including both global and local deformation effects within the specimen (i.e. both overall bending of the chord and ovalization of the chord cross-section). The DCDT 2 was positioned inside the HSS directly under the flange-web junction of the ST. This DCDT measured the relative displacement of the top and bottom walls of the HSS, which is the deflection due to local wall distortion (ovalization) under the ST. The final DCDT 3 was oriented in a similar fashion to DCDT 2 inside the HSS, but in this case at the open end of the HSS over the saddles. The results of DCDT 3 will reveal if any ovalization occurs at the open end, thus indicating to what extent the applied load is dispersed longitudinally.

As previously mentioned, the load was applied to the top of the ST using an actuator. The load was applied in 5 kip increments, which were held for approximately two minutes as the instrumentation was scanned and recorded using a computer controlled data acquisition system. In order to ensure minimal eccentricities at the point of load application, a semicircular notch was cut into the stem of the ST directly at the centroid of the cross section where load application occurred. A steel plate with a 1 in. diameter rod (which fit directly into the notch) welded to the center was positioned into the notch; the load cell bore on the plate as the actuator applied the load. In this way, any incidental moment was released and not transmitted to the load cell. 


\subsection{TEST RESULTS}

The two (2) full-scale experimental tests were conducted in the Watkins-Haggart Structural Engineering Laboratory at the University of Pittsburgh in August 2003 (see Figure 3-4). The load versus deflection responses as recorded by DCDT 1, 2, and 3 for both experimental tests are shown in Figure 3-5 and Figure 3-6. The complete test data including the raw strain gauge results is available in the report by Boyle and Earls (2004). Based on the deflection data alone, there are a number of important observations that can be made.

Both tests were completed without any significant problems. However, during the testing of Specimen \#1, the thru-bolt at the right end yielded due to a bending overstress. Approximately midway through the test, the bolt began to sag, allowing the HSS end to drop slightly (less than 0.25 in.). This allowed the HSS chord to rotate, and thus caused some undesired eccentricity (and moment) to be applied to the joint. The test was continued until failure, but it is believed that the ultimate load was reduced somewhat by the additional moment introduced into the ST as a result of the slight sagging associated with the thru-bolt. For Specimen \#2, the thru-bolt size was increased and stiffening bars were added to decrease the span length for the bolt. As a result, the second test was completed without any plastic deformation of the thru-bolt. This is apparent by observing the smooth shape of the loaddeflection plot for Specimen \#2 as compared to Specimen \#1.

Upon review of the DCDT measurements of both tests, it is observed that the majority of the displacement is due to local distortion or ovalization of the HSS cross-section. This is apparent by observing the small difference in the measured displacements of DCDT 1 and DCDT 2 at any load. Recall that DCDT 1 measured the total displacement at the ST including both global and local deformation effects within the specimen and DCDT 2 measured the local deformation only. Since the difference between these two measurements remains relatively small for all loads, this indicates that there is little global deformation. This makes sense physically since the ST and saddles are in such close proximity and the internal moment arm generated between these two elements is quite small when considered from a practical standpoint. 


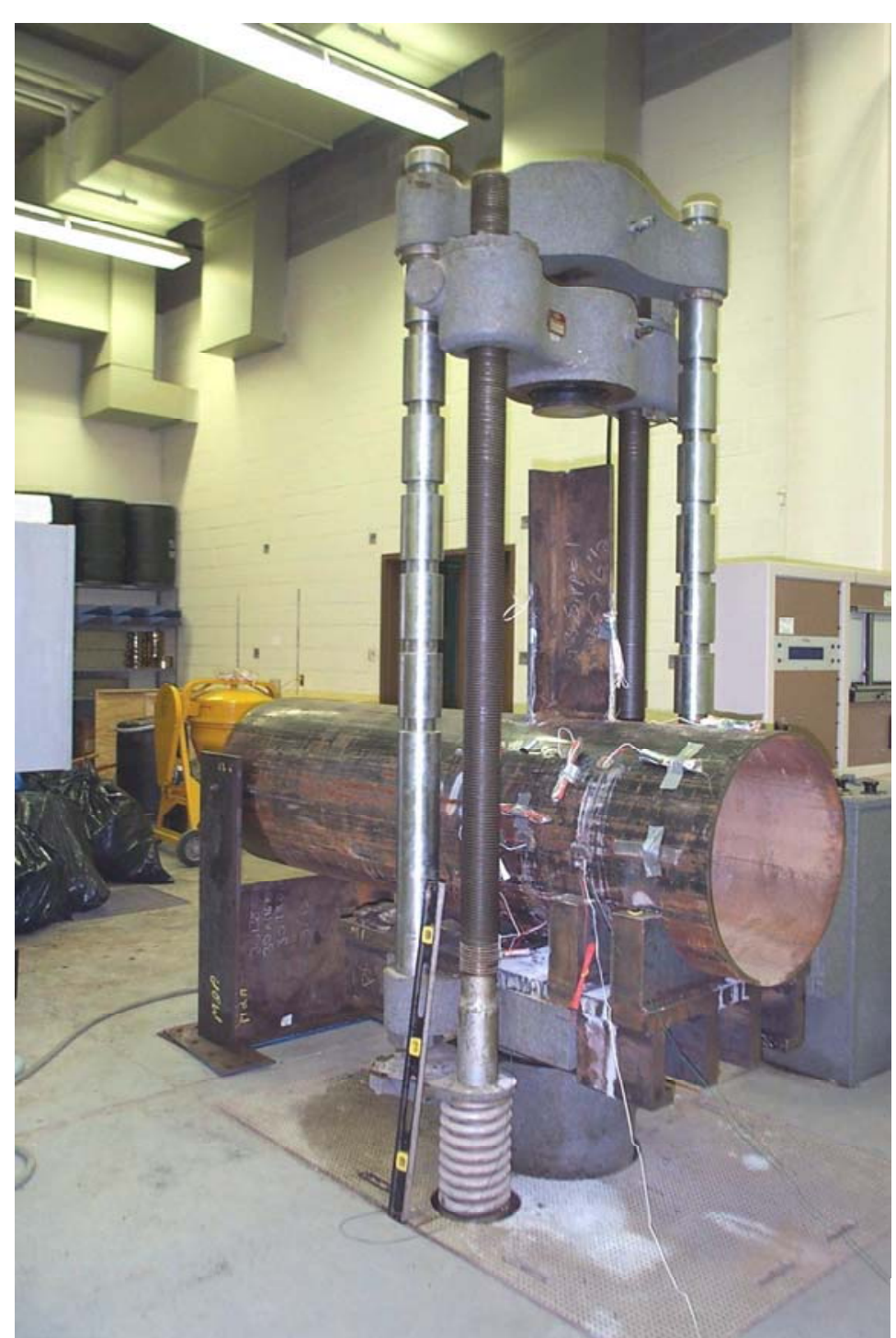

(a)

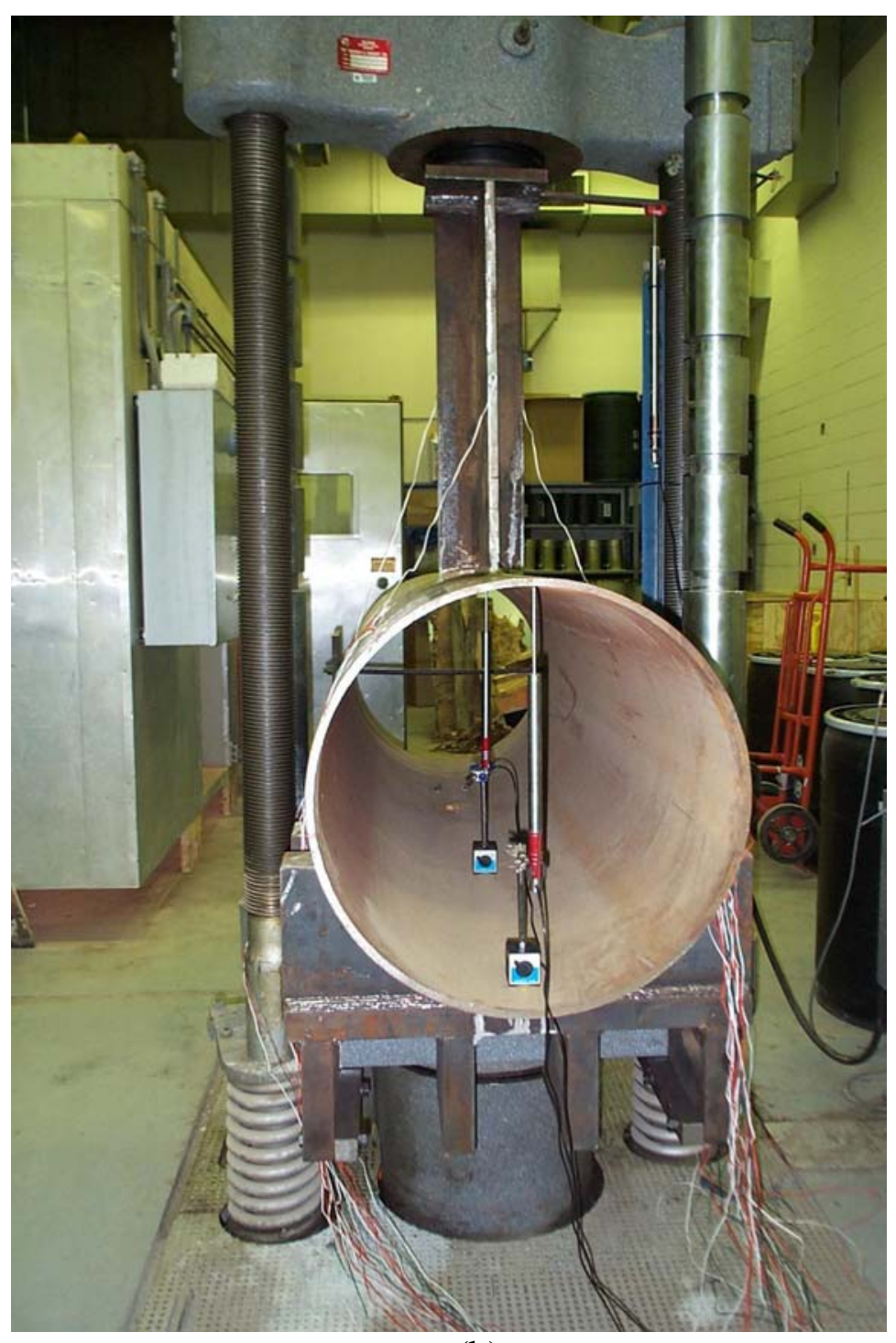

(b)

Figure 3-4: Photographs of Experimental Test Specimens 


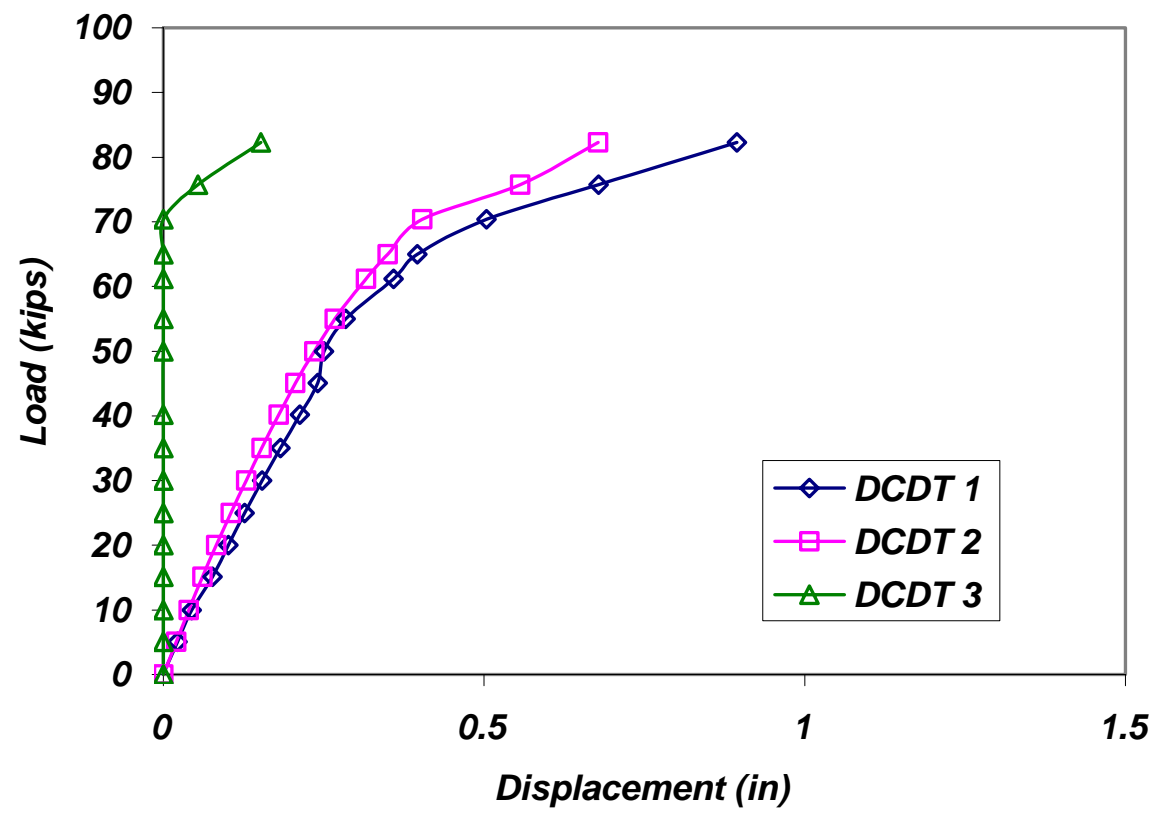

Figure 3-5: Experimental displacement measurements for Specimen \#1.

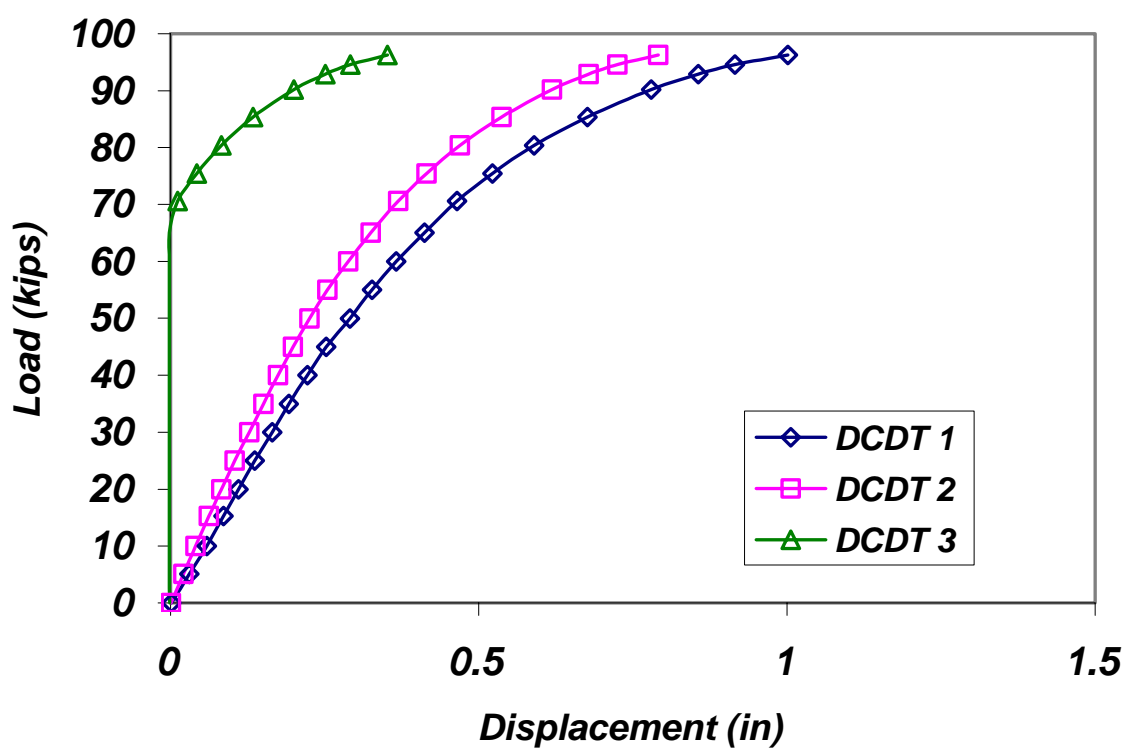

Figure 3-6: Experimental displacement measurements for Specimen \#2. 
The next observations made are relevant to the various limit states of failure for the bearing region. Three response features in the load-deflection response are identified that may be of importance in standard design practice. They are: 1) the yield load, $\mathrm{P}_{\mathrm{y}} 2$ ) the ultimate load, $\mathrm{P}_{\mathrm{u}}$ and 3) the nominal capacity load, $\mathrm{P}_{\mathrm{n}}$.

By analyzing the measurements of DCDT 1 and DCDT 2, it appears that both specimens began to yield at a load of approximately 40 kips. This is the load at which the non-linear behavior appears to have initiated in the load deflection response, but a precise value is difficult to ascertain from the experimental data set since the loading was increased in 5 kip increments. Based on observations of the specimens during testing, it was noted that this yielding occurred in the HSS wall adjacent to each ST flange tip in the form of small “dimples.” Depending on the structural application, this dimpling may not be considered objectionable. Since this yielding occurs at such a low load level and there is so much reserve capacity in the joint beyond this load, it is likely to be too costly to design the connection to prevent any yielding whatsoever.

The ultimate load of this connection is significantly higher than the yield load: Specimen \#1 achieved an ultimate load of 82 kips and Specimen \#2 achieved an ultimate load of 96 kips. As mentioned previously, during testing of Specimen \#1 a small moment was believed to be introduced in the specimen due to shifting occurring at the pin - support end; it is suspected that this reduced the ultimate load for the test. Therefore, it is believed that the ultimate capacity should be considered as 96 kips rather than the average of the two tests until further testing is conducted. It should be noted that 96 kips is consistent with the ultimate load predicted by FEM analysis (see Chapter 5.0).

For defining the nominal capacity for the purposes of design in the context of LRFD, some judgment must be exercised. AISC has formulated many of its provisions so that a deformation limit state is not exceeded at service loads (AISC 1997a). A similar approach might be applied to the present results by analyzing the DCDT 3 response, which is located at the open end of the HSS. At the open end, no distortion was observed as the load increased through most of the test. But when the load reached 70 kips, the deflection began to increase quickly at the open end of the HSS adjacent to the saddles and the ultimate load for the specimen was realized soon after this point. This indicates that a collapse mechanism began to form at a load of 70 kips and the stability of the failure mechanism was in question once the open end began to deform. It 
should also be noted that this behavior was observed to be repeatable across both tests. In the context of preventing excessive deformations, the point of initiation of the collapse mechanism might be considered as the nominal capacity. This is a slightly different approach than that utilized by AISC, but it may be warranted due to the apparent unstable nature of the failure. This is discussed further in Chapter 8.

For analysis of the strain gauge data, conversion to equivalent von Mises stresses is one way to quickly assess the mechanical response within the HSS chord. These are shown graphically for each gauge location in Figure 3-7 and Figure 3-8. From these plots, it can be seen that location 3 is subject to the largest state of stress, with locations 13 and 14 close behind. Noting that the yield stress of the HSS steel is $47 \mathrm{ksi}$ reveals that the additional locations experiencing yield are: 1, 5, 8, and 9. These yielded locations will be considered within the context of the verification portion of the finite element modeling as discussed in Section 5.3. Despite the minor incident that occurred at the pinned end support in Specimen \#1, it is encouraging to note that the stress histories for the strain rosettes are still very consistent between the two tests (i.e. Specimen \#1 and \#2). 


\section{Specimen \#1 Von Mises Stresses}

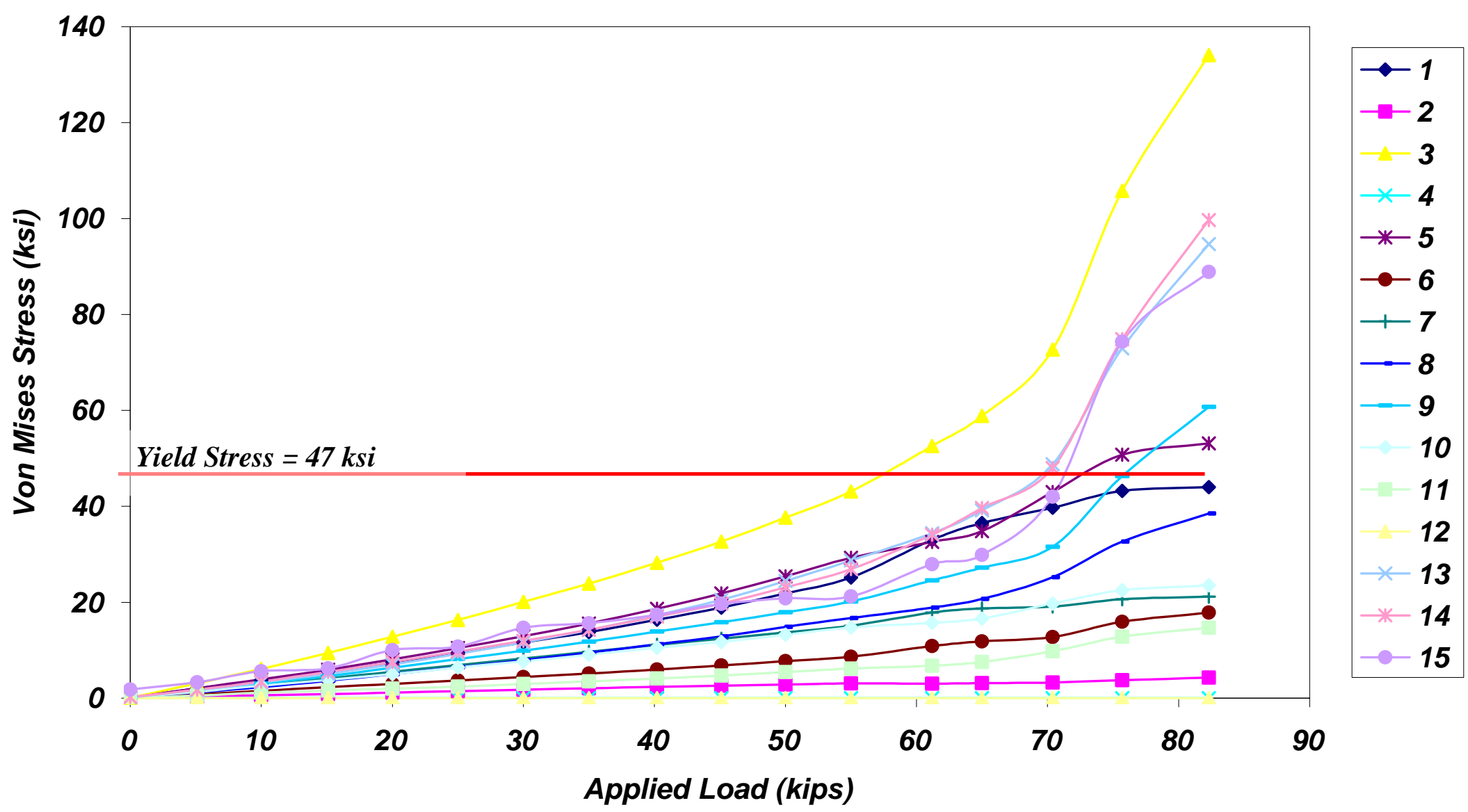

Figure 3-7: von Mises stresses in chord wall for Specimen \#1 
Specimen \#2 Von Mises Stresses

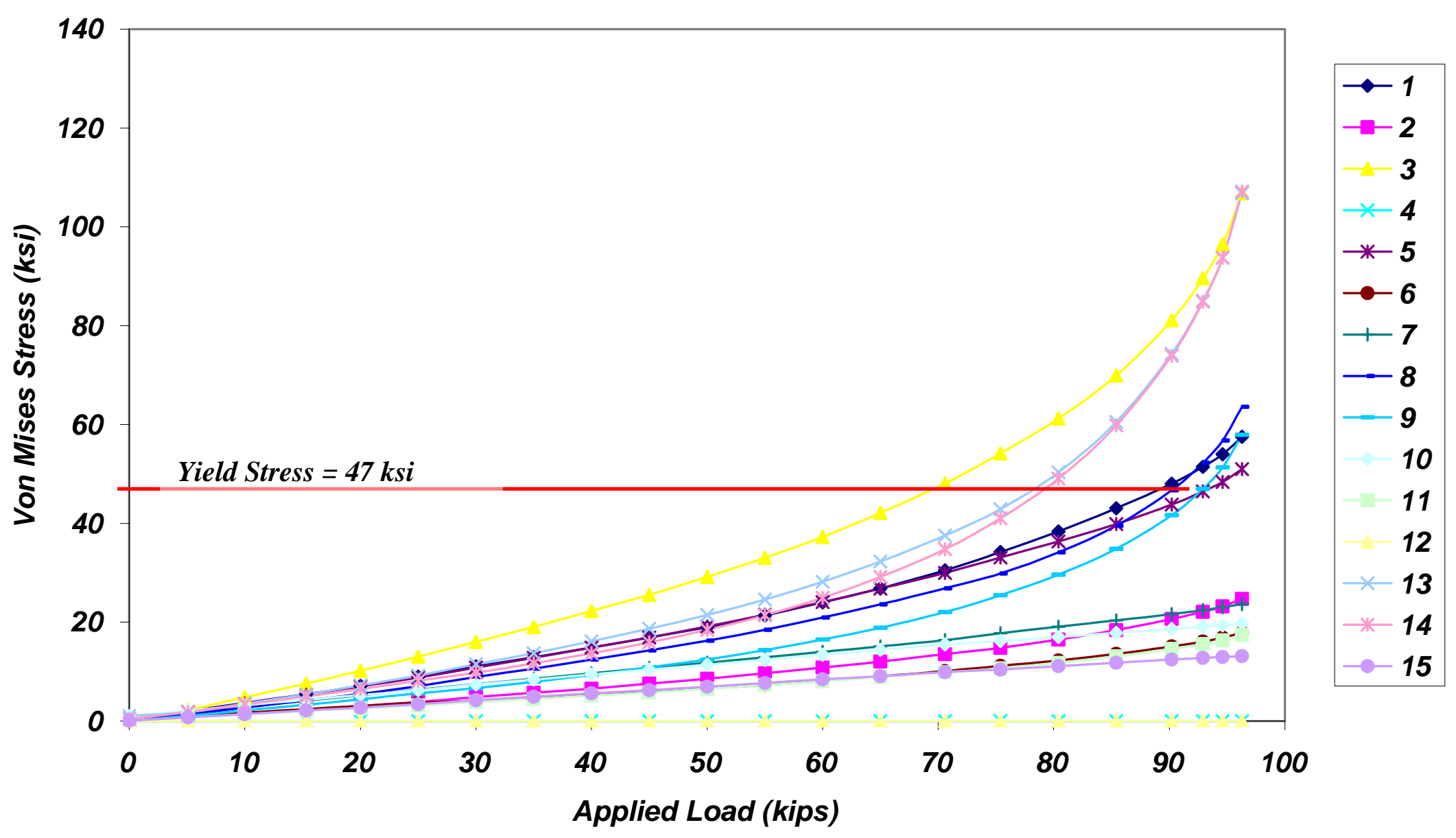

Figure 3-8: von Mises stresses in chord wall for Specimen \#2 


\subsection{APPROXIMATE METHODS FOR PREDICTING CAPACITY}

As mentioned previously, none of the referenced publications in the literature specifically address the bearing capacity in circular HSS truss chords. However, research has been done, and capacity equations published, for many HSS connections that are related (to various degrees) to this particular case of interest. An attempt is made to identify existing provisions that are based on a similar failure mode that governs for this bearing configuration, and that could be adapted for the purposes of estimating the chord bearing capacity.

The proposed methods are based on the assumption that the ST-to-chord joint is the "weak link" in the system and that overall capacity is governed by this detail alone. That is, the saddle bearings are assumed to adequately transfer the reaction force to the chord without compromising the overall capacity and the failure mode takes place in the chord wall locally at the ST. However, in applying this assumption it is quickly noted that even the ST joint itself is not covered directly by existing specifications; and thus, existing provisions must be adapted further. All the methods described below are based on the limit state of plastic flexural collapse of the chord wall, which is consistent with the observed failure mode in the experimental test specimens.

\subsection{DESCRIPTION OF METHODS}

\subsubsection{Method 1: Modified application of AISC HSS Specification Section 8}

In Section 8 of the LRFD HSS specification (AISC 2000), capacity equations are provided for the case of a concentrated force applied to an unstiffened HSS wall through a single bearing plate. To utilize these provisions, the ST member could be analyzed as two individual plates; 
one transverse and one longitudinal to the HSS axis. Section 8.1 addresses the case of a Concentrated Force Distributed Transversely at the Center of the HSS Face, and Section 8.2 addresses the case of a Concentrated Force Distributed Longitudinally at the Center of the HSS Face (see Figure 4-1 and Figure 4-2). These provisions may be applied by assuming that the ST connection will have a total capacity equal to the transverse plate capacity plus the longitudinal plate capacity, or direct superposition of the capacities. (Since this approach neglects any interaction between the two plates, this will prove to be unconservative; as will be discussed later.)

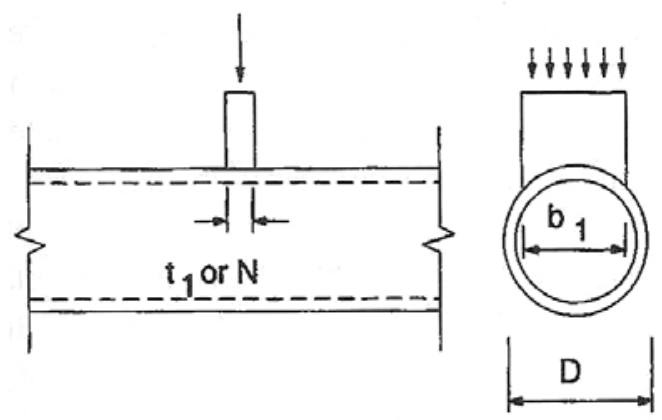

Figure 4-1: Concentrated Force Distributed Transversely (Copyright $\odot$ AISC, Inc. Reprinted with permission. All rights reserved.)
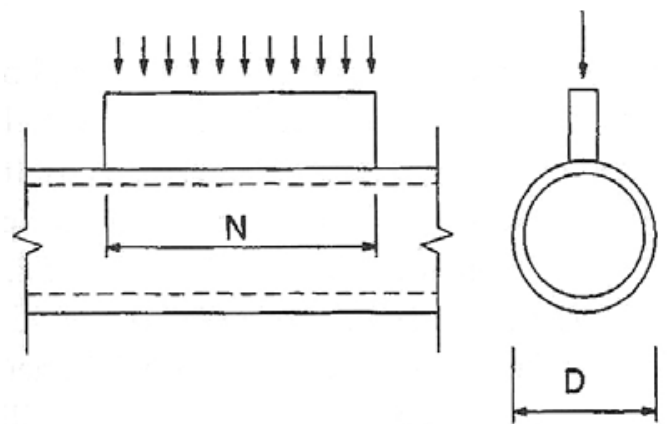

Figure 4-2: Concentrated Force Distributed Longitudinally

(Copyright $\odot$ AISC, Inc. Reprinted with permission. All rights reserved.) 
Using this approach, the capacity of the transverse component (flange) is first calculated using the provision for a circular HSS subjected to a uniformly distributed transverse line load as shown in Section 8.1 (and reproduced below as Equation 4-1):

$$
R_{n}=\frac{5 F_{y} t^{2}}{1-0.81 b_{1} / D} Q_{f}
$$

where,

$$
\begin{aligned}
& b_{1} \equiv \text { the width of the ST flange } \\
& Q_{f} \equiv 1.0 \text { for tension in the HSS (for compression see eqn. 8.1-1 in AISC (2000)) } \\
& F_{y} \equiv \text { specified minimum yield strength of the HSS } \\
& t \equiv \text { HSS Chord wall thickness } \\
& D \equiv \text { HSS Chord diameter }
\end{aligned}
$$

Similarly for the longitudinal component (stem), the capacity is based on the provision for a circular HSS subjected to a uniformly distributed longitudinal line load as shown in Section 8.2 (and reproduced here as Equation 4-2):

$$
R_{n}=5 F_{y} t^{2}(1+0.25 N / D) \cdot Q_{f}
$$

where,

$$
\begin{aligned}
& N \equiv \text { the depth of the ST } \\
& Q_{f} \equiv 1.0 \text { for tension in the HSS (for compression see eqn. 8.1-1 in AISC (2000)) } \\
& F_{y} \equiv \text { specified minimum yield strength of the HSS } \\
& t \equiv \text { HSS Chord wall thickness } \\
& D \equiv \text { HSS Chord diameter }
\end{aligned}
$$

Both of these equations (including the subsequent equation for $Q_{f}$ ) are identical to the “Factored Connection Resistance” equations presented in table 11.2 of the Canadian HSS manual (Packer 1997) and the “Design Strength” equations shown in Figure 25 (Types XP-1 and XP-2) of the CIDECT Design Guide (Wardenier et al. 1991). Unlike the American LRFD specification, the Canadian manual also provides additional insight for consideration of a cruxiform detail, which is an X-shaped open section with plates in both the longitudinal and transverse directions. It states that since the transverse plate connection is so much stronger than 
the longitudinal one, the cruxiform variation is not considered to be significantly stronger than the simple transverse connection (Packer 1997). Applying this same logic to the case of an ST would suggest that a reasonable conservative estimate of the capacity could be obtained by considering the transverse plate component only. However, it should be noted that this is based on the assumption the longitudinal component is smaller or of similar size to the transverse component (Wardenier 1982). This notion will be further investigated in light of the experimental test results and calculations.

\subsubsection{Method 2: Modified application of AISC HSS Specification Section 9}

A second type of joint that is similar to the ST connection, and for which published data is available, is the HSS-to-HSS Truss Connection (see Figure 4-3). This case is well researched and capacity equations are published in all of the previously mentioned references: American, Canadian, and CIDECT. Although at first glance it would seem that a ST and HSS are not very similar in geometry, the limit state that governs the capacity of both joints is chord wall plastification. Both the ST and HSS will actually generate similar yield line mechanisms at failure of the chord wall (see Figure 4-4).

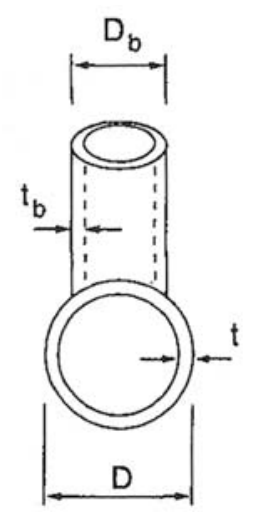

Figure 4-3: HSS-to-HSS Truss Connection

(Copyright $\odot$ AISC, Inc. Reprinted with permission. All rights reserved.) 


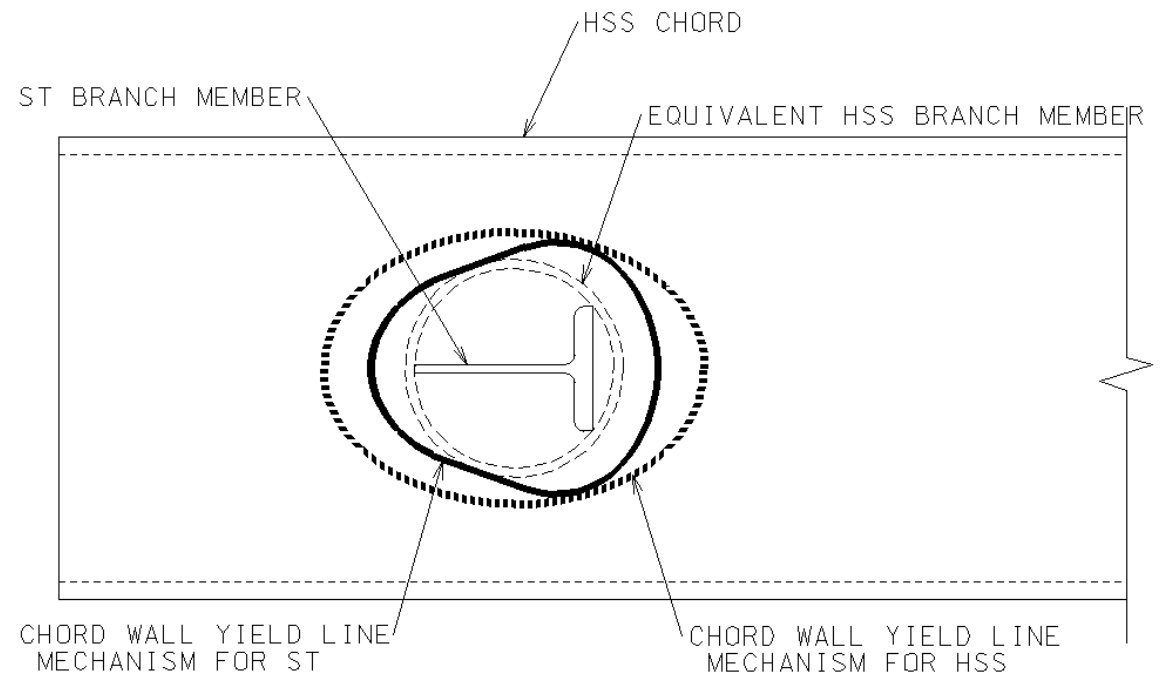

Figure 4-4: Yield Line Mechanisms for ST and Equivalent HSS Branch Members

The provisions that apply to axially loaded circular HSS-to-HSS Truss connections are published in Section 9.4 of the LRFD HSS specification (AISC 2000). Under subsection 2b, for branches with axial loads under the limit state of chord wall plastification, the capacity equation is given as:

$$
P_{n} \sin \theta=t^{2} F_{y}\left(6 \pi \cdot \beta \cdot Q_{q}\right) \cdot Q_{f}
$$

where,

$$
\begin{aligned}
& \theta \equiv \text { Angle between the branch and chord } \\
& \beta \equiv \text { Branch Diameter / Chord Diameter } \\
& Q_{q} \equiv \text { see Eqn. 9.4-3 in (AISC 2000) } \\
& Q_{f} \equiv \text { see Eqn. 9.4-3 in (AISC 2000) }
\end{aligned}
$$

In this case, the ST flange width $b_{\mathrm{f}}$ should be used as the equivalent HSS branch diameter. 


\subsubsection{Method 3: Modified application of CIDECT Design Guide}

A third HSS joint that is similar to the ST connection for which published data is available is the case of a wide flange I-shape end-connected to a circular HSS (see Figure 4-5). This case is covered only in the CIDECT Design Guide (Type XP-4), where a capacity equation is provided. The capacity equation for this case combines Equations (4-1) and (4-2) to yield the following (recast in LRFD format):

$$
P_{n}=\frac{5 F_{y} t^{2}}{1-0.81 \cdot b_{f} / D} \cdot(1+0.25 \cdot d / D) \cdot Q_{f}
$$

Intuitively, a joint with a W shape branch member should yield a higher capacity than an ST member of the same depth due to the simple fact that there are two flanges (not just one as in an ST) oriented transversely to the HSS axis. And as stated previously, the Canadian manual suggests that transverse plate components have the greatest effect on the overall strength of the connection. However, the case of a W shape connected to a circular HSS may actually behave like the ST connection more than the case of a concentrated load applied through a single transverse plate; as will be seen subsequently. As noted for the HSS-to-HSS joint, the geometry of the chord wall yield lines at failure for both the W and ST joints should be similar.
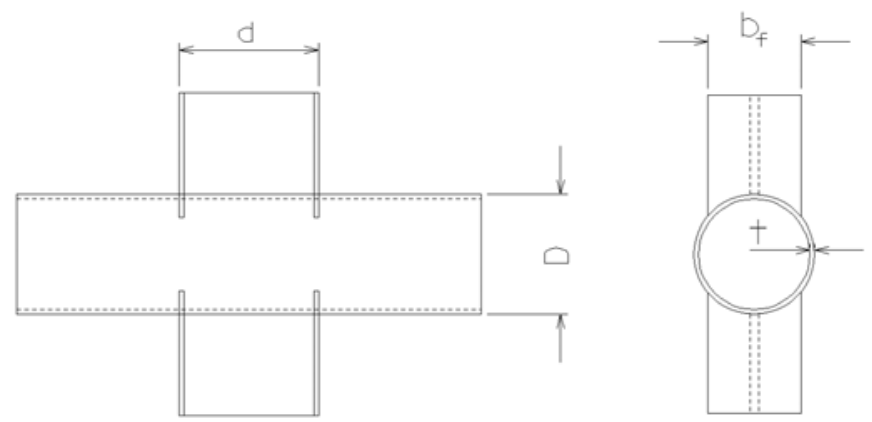

Figure 4-5: WT-to-HSS Joint Covered by CIDECT 


\subsubsection{Method 4: Modified application of AWS Section 2.24}

Another approach to defining the capacity of the ST joint is in terms of punching shear in the chord wall. At first glance, one may argue that punching shear is not the limit state observed in the experimental tests, which is true in an academic sense. However, the term "punching shear" is used somewhat loosely in the context of tubular connection design. The actual failure mechanism involves a complex combination of local shell bending, warping, arching, and large deflection membrane effects and some researchers have chosen to quantify this in terms of a punching shear failure (Marshall, 1992). This approach is the basis for the provisions in AWS Section 2.24 (AWS 2004) and it is based on an applied stress approach. That is, the acting punching shear stress is first calculated by:

$$
V_{p}=\tau \cdot f_{n} \sin \theta
$$

where:

$$
\begin{gathered}
\tau \equiv \text { branch thickness/chord diameter } \\
f_{n} \equiv \text { nominal stress in branch member }
\end{gathered}
$$

However, it should be noted that for an open, plate-type branch member such as an ST, the punching shear area is doubled due to the fact that each plate component must punch through two (2) planes of the chord wall (i.e. double shear). Thus, the acting punching shear stress is cut in half in this case. Next, AWS specifies that the punching shear stress shall not exceed the allowable punching shear stress given by:

$$
V_{p}=Q_{q} \cdot Q_{f} \cdot F_{y} /(0.6 \gamma)
$$

where $\gamma \equiv$ chord radius / chord thickness

By setting these two equations equal to each other, substituting P/A for $\mathrm{f}_{\mathrm{n}}$, applying the double shear multiplier, and solving for $\mathrm{P}$ produces the following equation for axial load capacity: 


$$
P_{n}=2 \cdot Q_{q} \cdot Q_{f} \cdot F_{y} \cdot A /(0.6 \cdot \gamma \cdot \tau)
$$

\subsubsection{Additional Notes}

It should be noted that there are a number of limits of applicability listed in Section 9.4 (2a) of the LRFD HSS specification (AISC 2000) that should be considered. Most relevant to the ST joint are the limits on wall stiffness and the limit on width ratio. The limit on wall stiffness states that the ratio of diameter to wall thickness must be less than or equal to 50 for chords and branches in T-, Y-, and K-connections and less than or equal to 40 for chords of Crossconnections. Members that exceed this limit would be classified as thin-walled sections. The limit on width ratio states that the ratio of branch diameter to chord diameter be within the range: $0.2<\mathrm{D}_{\mathrm{b}} / \mathrm{D}<1.0$.

These limits are specified since some of the published limit state expressions (or their calibrations) are partly empirical. Although the design recommendations have been developed based on many experimental tests and related research that has been carried out worldwide, the formulas may not be reliable outside the parametric range for which they have been validated (AISC 1997a). Thus, it is prudent to use a set of parameter limits that reflect the bounds of most test results.

It is interesting to note that many of the experimental tests that are the basis for the capacity equations described above were conducted in the 1960's and early 1970's in different locations throughout the world. These tests were compiled and used to formulate the equations in 1976 by Y. Kurobane at Kumamoto University (Kurobane, et al. 1976) and the equations have remained mostly unchanged since that time. Equation (4-1) is based on a mere three (3) tests, all using a chord diameter of 6.5 in. Equation (4-2) is based on only eleven (11) tests with chord diameters of 4 in. and 4.5 in. Equation (4-4) is based on only six (6) tests with chord diameters of 6.5 in. and 4.5 in. Equation (4-3) is based on fifty-nine (59) tests with chord diameters of 4 in. to 18 in. Thus, it can be justifiably hypothesized that the range of usefulness for these equations may not include cases where extrapolations to geometries of more than two times the tested dimensions are considered. 
It should also be noted that for all capacity calculations described above, a design wall thickness " $t$ " is needed. When the actual wall thickness is not known, a value of 0.93 times the nominal thickness is permitted to be used as recommended by AISC (AISC 2000). This recommendation arises out of the fact that the American Society of Testing Materials (ASTM) permits the wall thickness in HSS fabrication to be as much as $10 \%$ below the nominal thickness.

\subsection{VALIDITY OF PROPOSED METHODS}

To assess the validity of the proposed methods, the various capacity equations have been applied to the geometry of the experimental test and these theoretical results are then compared to the results obtained from the experimental testing program reported on in Chapter 3. The relevant detail geometry that is considered in the application of the capacity equations is the diameter, thickness, and material strength of the HSS chord and the section dimensions for the ST10x48. This data is summarized below:

\begin{tabular}{ll} 
ST $10 \times 48$ & HSS Chord \\
\hline$b_{f}=7.2 ”$ & D $=26 ”$ \\
$t_{f}=0.92 ”$ & $t=0.50 ”$ \\
$d=10.15 ”$ & $F_{y}=47 \mathrm{ksi}^{*}$ \\
$t_{w}=0.8 ”$ & *from coupon test results \\
A $=14.1 \mathrm{in}^{2}$ &
\end{tabular}

To apply the proposed equations to the experimental test, some assumptions will have to be made. The first assumption is with respect to the $Q_{f}$ factor, which is relevant to all proposed methods. Since the ST is slightly offset in the longitudinal direction from the saddle support below, some flexural stress will develop in the HSS causing tension in the bottom face and compression in the top face. Compression in the chord wall at the ST will likely cause some reduction in the joint capacity. However, due to the close proximity of the ST and saddle, most of the load will likely be transferred by direct shear, or so-called "deep beam” action. Thus, it 
seems reasonable to neglect any capacity reduction resulting from bending stress and assume $Q_{f}$ $=1.0$.

The second assumption to be made is whether this connection should be classified as a Tconnection or a Cross-Connection, which is relevant to Method 2. The AISC HSS specification states that when the branch load is equilibrated by beam shear in the chord member, the connection shall be classified as a T-Connection, but when the branch load is transmitted through the chord member and is equilibrated by branch members on the opposite side, the connection shall be classified as a Cross-Connection (AISC 2000). Unfortunately, the tested configuration falls somewhere in between these two ideals, as mentioned before. Due to the close proximity of the ST and saddle bearing below, it seems reasonable to assume that most of the load is transferred directly through the HSS by shearing action with little bending stress developing. Thus, the connection might be seen to behave more like a cross-type connection.

Before applying the proposed methods, the limits of applicability mentioned in the previous section should also be considered in light of the test specimen geometry. First, the limit on wall stiffness ratio is 40 for cross connections as specified in the LRFD HSS Specification (AISC 2000). This ratio for the test specimens is $26 / 0.5=52$, which is, in fact, slightly outside of the specified limit. Second, the width ratio should fall within the specified limits of 0.2 to 1.0 (AISC 2000). Utilizing the ST flange width $\left(\mathrm{b}_{\mathrm{f}}\right)$ as the branch diameter yields a width ratio of $7.2 / 26=0.28$, which is within the specified limit. Although the wall stiffness ratio has been exceeded, this does not disqualify the use of the provisions as proposed. The limits are merely being considered to evaluate how the specimen geometry compares to joint configurations studied previously.

Utilizing these assumptions and the known geometry, the capacity of the bearing detail in the experimental test has been calculated using the proposed methods developed earlier:

Method 1: Applying the provision for a concentrated force distributed transversely at the center of the HSS Face (Equation 4-1) yields:

$$
R_{n}=\frac{5(47 k s i)\left(0.5^{\prime \prime} \cdot 0.93\right)^{2}}{1-0.81\left(7.2^{\prime \prime}\right) /\left(26^{\prime \prime}\right)}(1.0)=66 k i p s
$$


Applying the provision for a concentrated force distributed longitudinally at the center of the HSS Face (Equation 4-2) yields:

$$
R_{n}=5(47 k s i)\left(0.5^{\prime \prime} \cdot 0.93\right)^{2}\left(1+0.25\left(10.15^{\prime \prime}\right) /\left(26^{\prime \prime}\right)\right) \cdot(1.0)=56 k i p s
$$

Method 2: To apply the provision for a HSS-to-HSS truss connection, the $Q_{q}$ factor must first be calculated using LRFD Equation 9.4-3:

$$
Q_{q}=\left(\frac{1.7}{2.4}+\frac{0.18}{\left(7.2^{\prime \prime} / 26^{\prime \prime}\right)}\right) \cdot(1.0)^{0.7(2.4-1)}=1.36
$$

The capacity is now calculated using Equation 4-3 as follows:

$$
P_{n}(1.0)=\left(0.5^{\prime \prime} \cdot 0.93\right)^{2}(47 k s i)\left(6 \pi \cdot\left(7.2^{\prime \prime} / 26^{\prime \prime}\right) \cdot(1.36)\right) \cdot(1.0)=72 k i p s
$$

Method 3: Applying the provision for a W-to-HSS joint (Equation 4-4) yields:

$$
P_{n}=\frac{5(47 \mathrm{ksi})\left(0.5^{\prime \prime} \cdot 0.93\right)^{2}}{1-0.81\left(7.2^{\prime \prime}\right) /\left(26^{\prime \prime}\right)} \cdot\left(1+0.25 \cdot\left(10.15^{\prime \prime}\right) /\left(26^{\prime \prime}\right)\right) \cdot(1.0)=72 \mathrm{kips}
$$

Method 4: Applying the punching shear provision (Equation 4-7) yields:

$$
P_{n}=2 \cdot(1.36) \cdot(1.0) \cdot(47 \mathrm{ksi}) \cdot\left(14.1 \mathrm{in}^{2}\right) /\left(0.6 \cdot\left(13^{\prime \prime} / 0.5^{\prime \prime}\right) \cdot\left(0.79^{\prime \prime} / 0.5^{\prime \prime}\right)\right)=73 \mathrm{kips}
$$

The theoretical results from each proposed method along with the experimental results are summarized in Table 4-1. 
Table 4-1: Accuracy of Approximate Methods

\begin{tabular}{|cc|cccc|}
\hline \multicolumn{2}{|c|}{ Experimental } & \multicolumn{4}{|c|}{ Theoretical } \\
\hline Nominal & Ultimate & Method 1 & Method 2 & Method 3 & Method 4 \\
$70 \mathrm{k}$ & $96 \mathrm{k}$ & $66 \mathrm{k} / 56 \mathrm{k}$ & $72 \mathrm{k}$ & $72 \mathrm{k}$ & $73 \mathrm{k}$ \\
\hline
\end{tabular}

\subsection{DISCUSSION}

In comparing the experimental and theoretical results, it is important to note that there is a fundamental assumption in using the proposed methods for predicting the capacity of the bearing in this geometric configuration. All of the existing specifications that were used in the development of the proposed methods were based on research done on a typical interior joint with a continuous chord member (i.e. not near an end). However, the vicinity of the connection to the open end of the HSS chord has influenced the geometry of the yield line failure mechanism observed experimentally and so too then, the overall capacity based on observations of the test data. Without further investigation, it is unknown to what extent the open end has affected the capacity of the joint. However, it is also pointed out that ovalization of the open end did not develop until load level of greater than $75 \%$ of ultimate capacity were achieved; an observation somewhat refuting the notion of significant effects being present. In any case, it can be surmised that the open end can only serve to reduce the capacity from that of an interior connection detail as compared to the capacity at an interior location.

For the bearing detail under consideration, the flange of the ST member was located a distance $33 \mathrm{in}$. from the end of the HSS, or a distance of 5/4 x D. If the proposed methods are shown to be accurate for this geometry, they will most likely underestimate the capacity of another joint with an end distance greater than this. Similarly, the proposed methods will likely overestimate the capacity of joints located in closer proximity with the open end. The parametric studies, using validated modeling strategies, are used to explore this point further in Chapter 6.0. 
Method 1: The theoretical capacity predicted by Method 1 is 66 kips for the transverse component (flange plate) and 56 kips for the longitudinal component (stem plate). As mentioned above, the recommendation given the Canadian HSS manual is that only the transverse component should be considered in this case. Applying this notion to the ST joint yields a net theoretical capacity of 66 kips, which agrees well with the nominal capacity of 70 kips (within 6\%) and provides a safety margin of 1.45 with respect to the ultimate capacity (not including the material yield bias). Adding the capacities of the individual components by direct superposition would result in a net theoretical capacity of $122 \mathrm{kips}$, which is a significant overestimate of the nominal capacity, and therefore considered inaccurate in this case.

Although superposition of the individual plate component capacities is unconservative for calculating the nominal capacity, it may apply to the calculation of the ultimate capacity. This recognizes that there is some increase in the ultimate connection capacity attributable to the presence of the longitudinal plate component. However, direct superposition once again overestimates the ultimate capacity of 96 kips obtained from the experimental results by a significant margin (27\%). Assuming that the transverse plate component dominates the overall capacity as before, then it may be reasonable in this case to add the transverse component capacity plus a fraction of the longitudinal component capacity. Using a somewhat arbitrary $50 \%$ factor on the longitudinal plate component yields a theoretical capacity of $66+(0.50 \times 56)$ = 94 kips, which compares well with the experimental results.

Method 2: The capacity predicted by Method 2 is 72 kips, which agrees with the nominal capacity from the experimental results (to within $3 \%$ ). This method provides a safety margin of 1.33 with respect to the ultimate capacity (not including the material yield bias). It should be mentioned that there is significant motivation for using Method 2 since it is the most portable of all the proposed methods. That is, it can be applied to many different connection geometries such as T-, Y-, K-, and Cross-connections, and it also treats the case wherein the branch member(s) experience flexure in addition to axial load. However, since the current testing has only considered the axially loaded $90^{\circ}$ cross-connection, extending this method to other connection types should be done with care. 
Method 3: The capacity predicted by Method 3 is 72 kips, which agrees with the nominal capacity from the experimental results (to within 3\%). This method provides a safety margin of 1.33 with respect to the ultimate capacity (not including the material yield bias). As described earlier, this method is based on the CIDECT provision for a wide-flange connection, which is similar to the ST joint being studied except for the additional flange. This seems to imply that the additional flange does not significantly increase the overall strength of the joint.

Method 4: The capacity predicted by Method 4 is 73 kips, which also agrees with the nominal capacity from the experimental results (to within 4\%) and provides a safety margin of 1.31 with respect to the ultimate capacity (not including the material yield bias). This indicates that the punching shear approach produces similar results in this case.

In summary, all of the proposed approximate methods provide a safe estimate of the bearing capacity as compared to the experimental results. However, the safety margins may be considered too low depending on the nature of loading, consequences of failure, etc. This is discussed further in Chapter 8. 


\subsection{FINITE ELEMENT MODELING}

\subsection{HSS MATERIAL BEHAVIOR}

Since the failure of the bearing region involves a concentrated load which essentially "crushes" the HSS chord, the overall response of the connection is very sensitive to the HSS material behavior. If the HSS material is not modeled correctly, then agreement between the experimental and finite element analysis results will be poor. Therefore, a number of issues relevant to HSS members and their potential influence on the steel material behavior are discussed below.

\subsubsection{Standard Mill Practice}

A common method for manufacturing circular steel HSS members, and the method used for the manufacture of the test specimen chords, is the "formed-from-round" process. This involves conversion of a flat steel plate into an HSS through a series of forming operations. As illustrated in Figure 5-1, a flat strip of steel plate is bent continuously around its longitudinal axis to form an open-seam round by passing it through a progressive set of rolls. The resulting open-seam round is then closed with a continuous longitudinal weld. After welding, the section is cooled and then run through an additional set of sizing rolls to achieve the desired final shape (AISC, 1997a). This is important to note since the cold working in these operations causes changes in stress-strain behavior from the basic steel material properties. A metal which has undergone a severe amount of deformation, as in rolling or drawing, will develop a preferred orientation, or "texture," in which certain crystallographic planes, or mechanical fibers, tend to orient 
themselves in a preferred manner with respect to the direction of maximum strain (Dieter, 1986). Researchers confirmed that this effect can be significant in tubular members by comparing the stress-strain behavior in steels from tubular columns with and without annealing (Popov et al.. 1979).

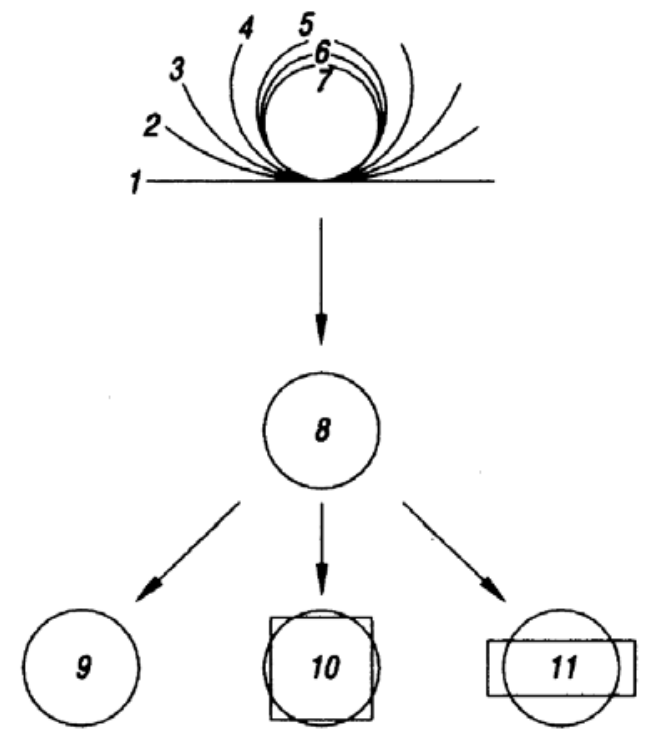

Figure 5-1: Formed-from-round process for HSS manufacturing (Copyright $\odot$ AISC, Inc. Reprinted with permission. All rights reserved.)

\subsubsection{Specifications}

The HSS chords used in the test specimens were manufactured under ASTM A53: Standard Specification for Pipe, Steel, Black and Hot-Dipped, Zinc-Coated, Welded and Seamless. This specification is intended for mechanical and pressure applications and is also acceptable for ordinary uses in steam, water, gas, and air lines. It is suitable for welding, and suitable for forming operations involving coiling, bending, and flanging. However, ASTM A53 is not necessarily meant for structural applications in buildings and bridges as is the more common ASTM A500 Standard Specification for Cold-Formed Welded and Seamless Carbon Steel Structural Tubing in Rounds and Shapes. ASTM A53 Grade B was selected since this is the 
material specification used in Pennsylvania for fabrication of overhead sign trusses. The specification tensile requirements are as follows:

Min. Yield Strength $=35 \mathrm{ksi}$

Min. Tensile Strength $=60 \mathrm{ksi}$

\subsubsection{Tolerances}

Variations in geometric dimensions from the nominal values specified for the HSS members can have a significant affect on the behavior of the structure under investigation. The tolerances for fabrication of tubular members in general are not stringent as compared to similar open rolled structural shapes, and ASTM A53 is even more forgiving to manufacturers. The permissible variations as per ASTM A53 that should be noted are as follows:

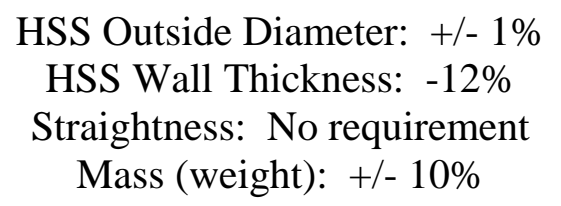

As a result of these generous tolerances, most HSS manufacturers tend to produce undersized sections, but still within the specification limits (Packer and Henderson, 1997). Since connection capacity in tubular structures is typically a function of HSS wall thickness squared, the structural safety index can be very sensitive to this geometric property. As a result, the AISC HSS Specification (AISC, 2000) states that a design wall thickness of 0.93 times the nominal thickness should be used for design calculations.

\subsubsection{Residual Stresses}

Residual stresses in HSS members most commonly arise from the cooling effects after hot finishing, from the welding processes employed, or by the prevention of spring-back introduced during forming operations (Galambos, 1998). Recalling the numerous forming and welding operations that a steel plate must be subjected to for creation of a tubular section by the formed- 
from-round method, it can be seen why significant residual stresses can develop. As a result of these operations, the exact shape of the stress-strain curve, the proportional limit, and the yield strength of tubular members are rather unpredictable (Galambos, 1998). Measurements on members fabricated for a column testing program (Chen and Ross, 1977) gave the longitudinal and through-thickness circumferential residual stress patterns shown in Figure 5-2. These patterns and general magnitudes have been confirmed by other researchers (Prion and Birkemoe, 1988). The distributions show that significant residual stresses develop in tubular members; approaching $35 \%$ of the yield stress $\sigma_{\mathrm{y}}$ in the circumferential direction and $100 \%$ of the yield stress in the longitudinal direction. It is noted that while the longitudinal residual stresses vary based on the distance from the seam weld, the circumferential residual stresses were found to be nearly the same in all locations around the perimeter (Toma and Chen, 1979).

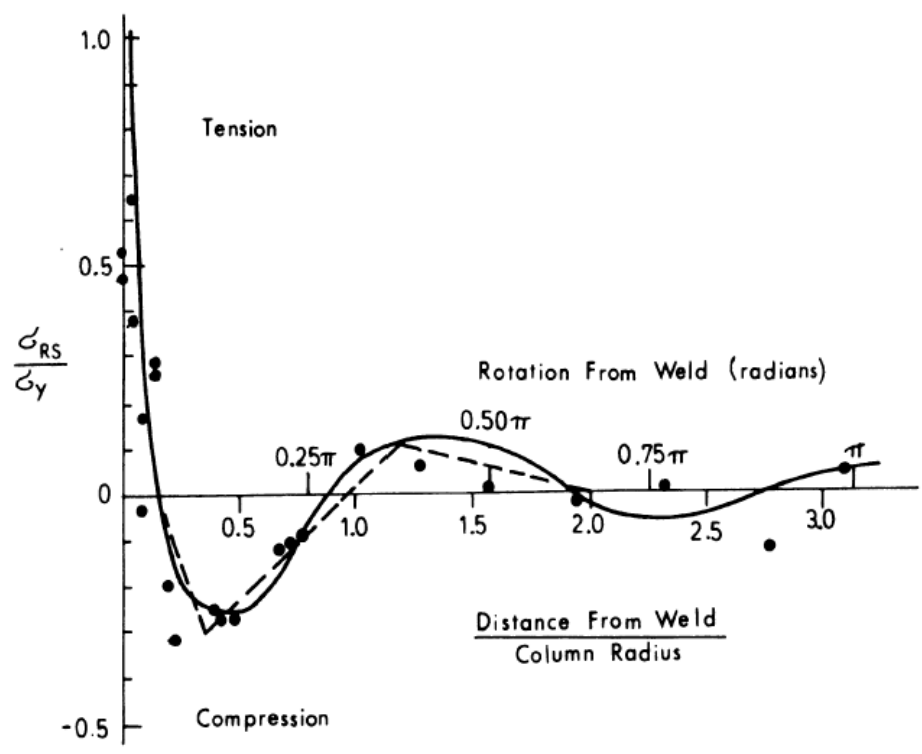

(a) Longitudinal Residual Stress Distribution Obtained from Method of Sectioning

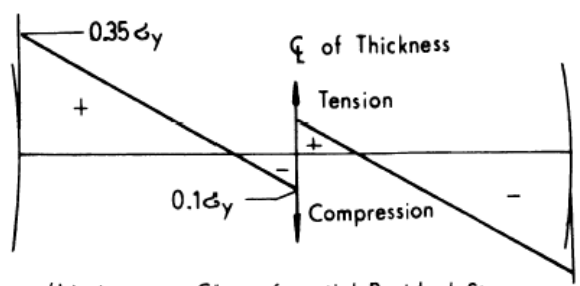

(b) Average Circumferential Residual Stress

Pattern

Figure 5-2: Residual stresses in fabricated round tubular members (Toma and Chen 1979)

(Copyright $\odot$ ASCE. Reprinted with permission. All rights reserved.) 


\subsubsection{Coupon Testing}

Determining the mechanical properties of steel in HSS members can be problematic. Conventional coupon tests are possible for the longitudinal direction (with some machining of the coupon), but not for the transverse direction due to the circular cross-section. To conduct a transverse tensile test (as per ASTM A370 Standard Test Methods and Definitions for Mechanical Testing of Steel Products), a ring must be cut from the specimen and then flattened. However, these test specimens require normalization due to this additional treatment of the material being tested.

One of the unique features in the mechanical behavior of steels from tubular members is that the stress-strain response becomes nonlinear at low stresses and the yield point is typically not well defined as compared to conventional rolled steels. Toma and Chen attributed this to the residual stresses present in tubular members and subsequently they developed the concept of the Effective Young's Modulus for describing the material response, for which a variable modulus is used to describe the slope of the complete stress-strain curve (Toma and Chen, 1979). In this approach, the effective modulus is a function of the applied stress, the yield stress, and an initial yield stress, which results from the residual stresses present.

\subsection{FINITE ELEMENT MODELING TECHNIQUES}

The techniques employed for the finite element modeling are based on the techniques that were developed and validated by Li and Earls for earlier work on HSS connections (Li and Earls, 2002). Consistent with this earlier work, the current research employs dense meshes of nonlinear shell finite elements positioned at the mid-surface of the constituent plate components for each of the structural members comprising the connection under investigation. The application of shell elements in this fashion permits the actual three-dimensional geometry of the structure to be replicated in physically meaningful way. 
Since the finite element models are to be used as the vehicle by which the response characteristics of multiple HSS truss connection geometries are to be quantified, it is important to ensure the robustness and viability of the modeling strategies adopted in the present work. As a means of validating the current modeling techniques, they are first applied to the case of two full-scale experimental specimens tested as part of the current research effort. Favorable agreement between the modeling results of these specimens and the laboratory results are obtained. A detailed discussion of this comparison follows in a subsequent section of the current paper.

Since the potential for steel yielding and localized buckling effects are present, the finite element modeling approach adopted considers both geometric and material non-linearities within the context of an incremental analysis. Thus, a Riks-based solution approach (ABAQUS 2003) is employed to capture both the intermediate loading steps leading up to the ultimate load as well as the response in the unstable (un-loading) region of the equilibrium path. The completed model of the experimental test in its deformed configuration at the ultimate load, and with the von Mises stress contours displayed, in a magnified state, is shown in Figure 5-3.

\subsubsection{Boundary Conditions and Loading}

For the boundary conditions and loading, there are a number of important features of the model that should be discussed. First, the interface between the saddles and the HSS is modeled as a fully pinned surface (i.e. every node at the interface between the HSS and the saddle is constrained against any translation). Thus, the HSS cannot separate from the saddle bearings or slide within the saddles. This is clearly an idealization of the true physical boundary condition, but was nonetheless found to be accurate (see discussion on contact below). At the opposite end of the specimen two (2) discrete pinned support conditions are imposed on the shell element mesh of the HSS to simulate a thru-bolt support condition that is consistent with that used in the experimental testing. Finally, the unconnected end of the ST member, at the point of load application, is prevented from any lateral translation; consistent with the physical boundary condition in the test specimens. In addition, loading is imposed on the model through the application of a concentrated force applied at the centroid of the ST cross-section. 

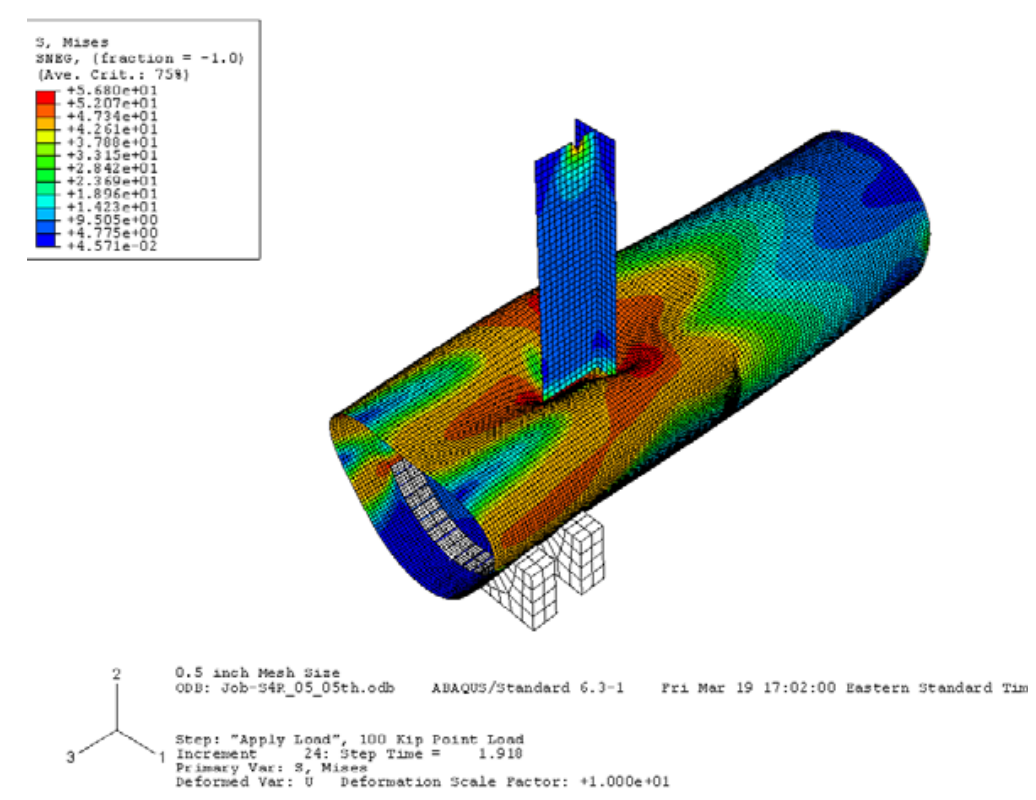

(a)
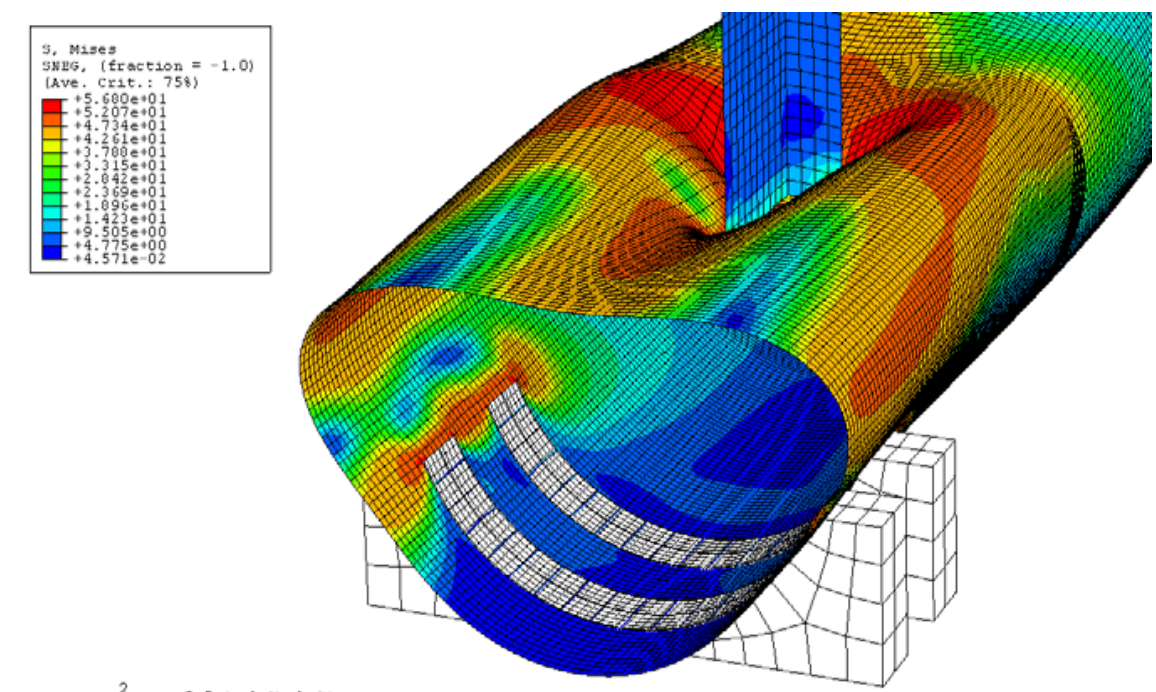

0.5 1nch Meah $512 e$
ODB: Job-84R_OS_OSth.odb

Fri Mar 19 17:02:00 gastern standard Time 2004

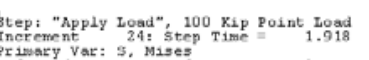

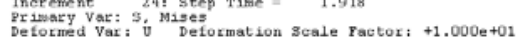

Figure 5-3: Finite element model with von Mises stress contours. 


\subsubsection{Element Type}

Since this structure consists of relatively thin components (some with curvature) subjected to primarily flexural and membrane stresses, the shell element is deemed to be the most appropriate finite element for use in the modeling. In general, the failure mechanism involved in this type of connection is seen to involve a plastic collapse of the HSS chord wall as a result of the formation of a system of well-defined yield lines. While it is that the structural element formulation employed in shell element formulations is well suited to capturing this type of behavior, it should be noted that the regions of the HSS chord in the vicinity of the ST are also observed to be subjected to large local transverse shear stresses as the applied load is transferred from the ST to the chord; a condition where even the most robust shell formulation may experience difficulties.

In choosing the specific shell element to be used in the modeling, several different types from the ABAQUS library are considered initially: S4, S4R, S8R, and STRI3. All of these shell elements utilize 6 degrees of freedom (DOF) at each node (3 translational and 3 rotational), but each is somewhat different in terms of its formulation, integration, and/or interpolation.

The shell formulation refers to the mathematical theory used to define the element's behavior. Shell problems generally fall into one of two categories: thin shell problems and thick shell problems. For a detailed discussion on different shell formulations, as well as proper integration order for the integration of their stiffness matrices, the reader is referred to the book by Bathe (1996). What follows now is a very superficial discussion meant only as a summary of relevant concepts used in the present work. Thick shell problems assume that the effects of transverse shear deformation are important to the solution at hand. Thin shell problems, on the other hand, assume that transverse shear deformation is small enough to be neglected. Thin shell elements provide solutions to shell problems that are adequately described by classical (Kirchhoff) shell theory, thick shell elements yield solutions for structures that are best modeled by shear flexible (Mindlin) shell theory. The STRI3 shell in ABAQUS is a thin shell element, the S8R is a thick shell, and the S4 and S4R are general-purpose shell elements. In ABAQUS, socalled "general purpose" shell elements are considered valid for use in both thick and thin shell problems. 
It should be noted that in the S4R shell, changes in the cross-section thickness, as a function of membrane strains and material definition are considered. This capability can be important in nonlinear analyses where large strains accompany large rotations. The membrane kinematics are based on an assumed-strain formulation that provides accurate solutions to many loading conditions, including in-plane bending behavior (ABAQUS, 2003).

The shell integration refers to the number of discrete points within each element that are utilized to calculate the internal strain energy in the deformed configuration. Shell elements can be either fully integrated (e.g. S4, STRI3) or use reduced integration (e.g. S4R, S8R). For full integration, the standard Gauss quadrature is employed which results in four (4) integration points for a quadrilateral and three (3) integration points for a triangular element. For reduced integration, only a single integration point is used for each of these elements. Reduced integration elements are attractive because they reduce computational expense while providing a means for mitigating shear locking effects which become pronounced when shear deformable shell formulations are used in situations where the through-thickness dimension is small. However, reduced integration elements often exhibit another numerical problem called hourglassing, in which the element can deform in certain ways with the internal strain energy remaining zero. Thus, fully integrated elements are recommended for conditions where greater solution accuracy is desired, or for problems where in-plane bending is expected (ABAQUS, 2003). In all cases, five (5) Simpson integration points through the element thickness are utilized.

The shell interpolation refers to the displacement functions that are assumed in the element formulation for describing the deformed shape between the element nodes. In the context of our present discussion, the interpolation order is either linear or quadratic. Quadratic elements are more accurate on a per element basis; however their use comes at an increased computational expense since additional nodes are required to adequately describe their shape.

A summary of the different shell elements considered and their respective features is shown in Table 5-1.

As part of the current research effort, an evaluation of element performance within the context of the current problem is undertaken. To complete this evaluative effort, analyses of the subject problem are conducted utilizing each of the four (4) elements identified in Table 5-1 and the model response characteristics are compared in the context of load-deflection response (see 
Figure 5-4). For each of the finite element analyses, the geometry, boundary conditions, loading, and material model are identical. However, the finite element meshes vary slightly as a result of differences in elemental node layout. This is important to note since the solution is dependent upon the mesh density (\# elements / unit area) as discussed below. To properly assess the relative performance of the four (4) shell elements, the mesh density is doubled for the STRI3 model and halved for the S8R model (as compared with the 4 node quadrilateral shell mesh). This results in the same number of nodes and DOFs for all four models.

Table 5-1: Summary of Shell Elements Considered

\begin{tabular}{|l|c|c|c|c|}
\hline $\begin{array}{l}\text { ABAQUS } \\
\text { Name }\end{array}$ & \#Nodes/El & Formulation & Integration & Interpolation \\
\hline S4 & 4 & Gen. Purpose & Full & Linear \\
\hline S4R & 4 & Gen. Purpose & Reduced & Linear \\
\hline S8R & 8 & Thick & Reduced & Quadratic \\
\hline STRI3 & 3 & Thin & Full & Linear \\
\hline
\end{tabular}

In general, it can be seen that the load-displacement response is very similar for all the element types. As expected theoretically, all models predict the same result in the elastic range. It is not until well into the plastic range where some subtle differences arise. It is observed that the general-purpose shell elements (S4, S4R) show a slightly higher peak load than the two special purpose elements (S8R, STRI3) by approximately 2\%. This is likely due to the consideration of finite membrane strains (greater than 1\%) in the S4 and S4R formulations. During the analyses, strains of greater than $1 \%$ were observable in regions of the mesh where yield lines formed. In addition, since the HSS chord is subjected to compressive hoop stress as the load travels from the ST to the saddles, the shell thickness will increase by the Poisson effect as inelastic deformation occurs. This increase in thickness will have a strengthening effect on 


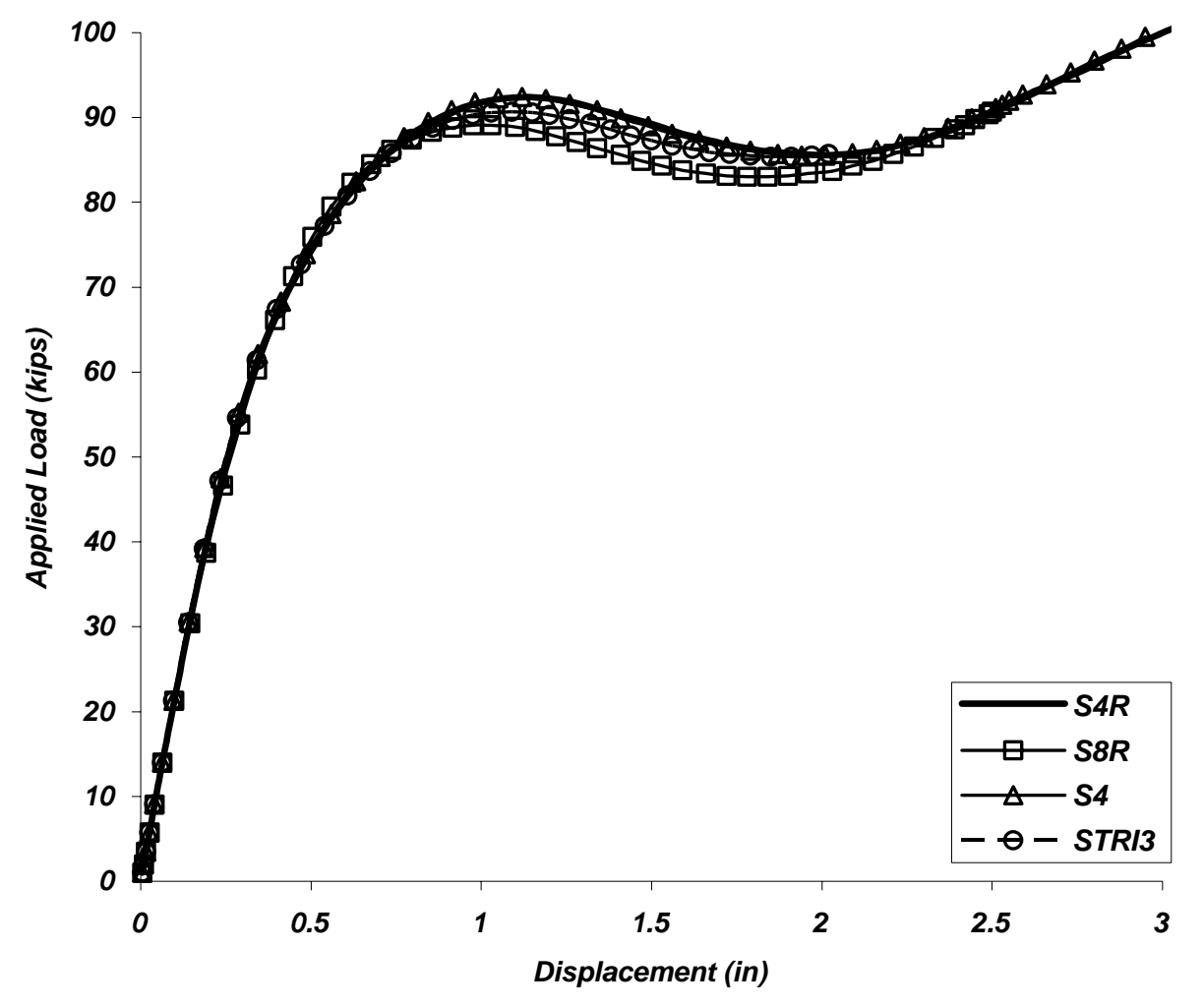

Figure 5-4: Effect of element formulation on predicted response

the yield line failure mechanism since the flexural strength (plastic moment capacity) is a function of the wall thickness. This strengthening effect was confirmed by performing a subsequent analysis with $v=0$, for which the capacity was reduced to nearly the same value as that given by the STRI3.

The second observation to make is that the S4 and S4R models predict nearly the same response throughout. This indicates that the reduced integration does not have a significant impact on the solution, which is good news since the run time is less for the S4R model.

The last observation is that the two special purpose elements (S8R, STRI3) predict similar responses even though the S8R is based on a thick shell formulation and the STRI3 is based on a thin shell formulation. This indicates that the problem is truly a thin shell problem, 
since reduced integrated thick shell elements like the S8R can have limited success solving a thin shell problem. The converse is not typically true for elements formulated for thin shell applications.

Based on this investigation, the S4R nonlinear, finite strain, general-purpose quadrilateral shell element from the ABAQUS element library is selected. A single integration point is used in this particular element, so computational expense is relatively low. Also, since consideration of finite membrane strains may be important to the behavior the structure under investigation, the S4R is the preferred choice. Furthermore, researchers have found the S4R element to produce reliable results for modeling of similar steel plate-type structures (Li and Earls, 2002), (Thomas and Earls, 2003), (Greco and Earls, 2003).

\subsubsection{Contact}

Frequently, stresses developing at contacting interfaces between structural components in a system may prove to dominate an analysis. Such intense stress states may admit the possibility for interfacial slip, separation, and/or sliding as a result of stress concentrations, load redistribution, or other local mechanism. Therefore, there may be a danger that using a simplified modeling approach in the treatment of interfacial behavior will lead to errors in the prediction of ultimate strength. Contact modeling is typically avoided in day-to-day structural engineering analysis due to the computational expense associated with such considerations. However, since the geometry of the structure under investigation involves a flexible shell structure bearing against a rigid curved surface, it is difficult to exercise engineering judgment regarding the potential effects of contact in this case. Therefore, an analysis is performed with a true contact interaction (separation and sliding allowed) at the interface between the HSS chord and the saddle bearings. For this analysis, the saddle bearings are modeled as analytical rigid bodies. That is, they are considered to be infinitely stiff. This approximation is acceptable since any deformation of the saddles is negligible and will have almost no affect on the capacity of the system.

The contact analysis results indicate that while some minor localized sliding may occur between the HSS and the saddles, uplift does not occur as a result of the compressive nature of the loading. More importantly, the ultimate load determined by contact analysis is within $1 \%$ of 
the load when using the simplified boundary condition (but at significant increased cost in terms of analysis time). Thus, the simplified (fully pinned) boundary condition is deemed acceptable for the HSS/saddle interface.

\subsubsection{Mesh Density}

In development of the final modeling techniques (i.e. S4R element in a mesh pinned at the saddle), a mesh convergence study is performed employing S4R element sizes of 2 in., 1 in., $1 / 2$ in., and $1 / 4$ in. It is determined that the accuracy of the solution is improved as the mesh size is refined, but the improvement between $1 / 2$ in. and $1 / 4$ in. is insignificant in comparison to the increased run time. Thus, the recommended element size for the S4R element is $1 / 2$ in., which is used throughout the model.

\subsubsection{Material Model}

Since the global failure mechanism observed involves plastification of the chord wall into welldefined yield lines exhibiting large strains (i.e. greater than 1\%), the material model that is used to describe how the structural components will deform is vital to obtaining accurate overall results. Unfortunately, the material behavior, as opposed to geometry, loading and boundary conditions, is where the greatest uncertainties lie.

The basic form of the material definition utilized is consistent with that of a von Mises metal plasticity model and an associated plastic flow rule. In general, metals resist a portion of a large externally applied load through the development of an elastic strain potential. The remaining portion of the external work is then dissipated through the action of internal plastic work. For the case of mild steel, the primary mechanism for this plastic flow occurs along slip planes. This slipping coincides with atomic structural imperfections such as crystal dislocations and sites of non-metallic impurities in the metallic grains.

The foundation of the von Mises theory is the assumption that metallic materials resist all hydrostatic stress in an elastic fashion. Thus, only the deviatoric components of the stress state are associated with the initiation and propagation of plastic flow, which has been confirmed 
experimentally for most common metals (ABAQUS, 2003). This assumption leads to the development of a yield function or yield surface, which defines the limit of purely elastic response as well as the direction of plastic flow for 3D stress states. The assumed direction of plastic flow is the same as the direction of the outward normal to the yield surface, which is often referred to as associated flow. Associated flow models are useful for materials in which dislocation motion provides the fundamental mechanisms of plastic flow (ABAQUS, 2003). To define the material for the finite element analysis model, only the uniaxial behavior need be employed; ABAQUS will use this data to generate the required von Mises yield surface in 3D stress space.

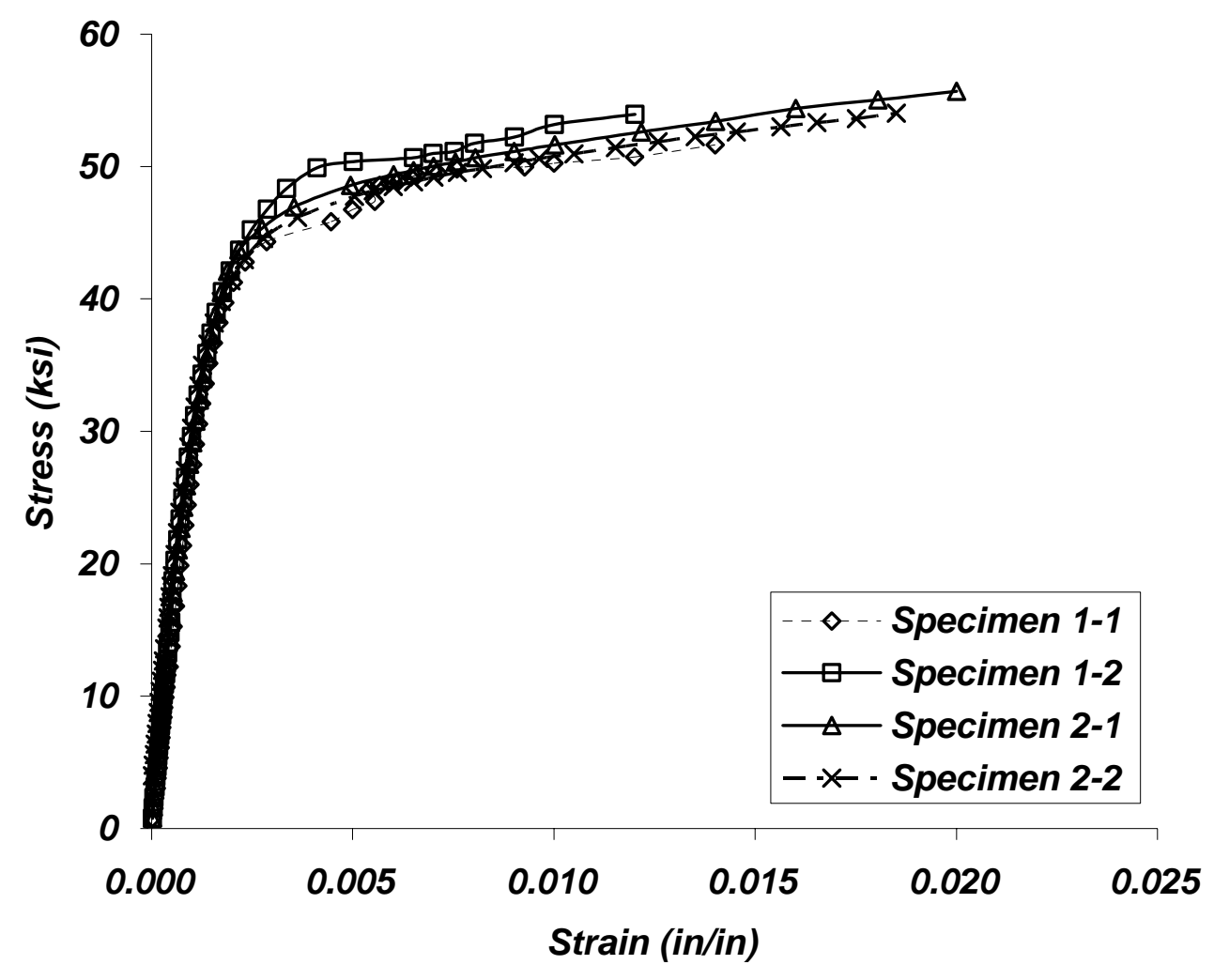

Figure 5-5: Coupon test results from HSS chord steel 
For the uniaxial material definition, coupon test results from the actual test specimens are used. Two (2) coupons were cut and tested from each of the HSS chords in the test specimens, yielding a total of four (4) tests, which are all shown in Figure 5-5. Due to difficulties in machining coupons in the transverse direction of the HSS (see discussion above), only coupons from the longitudinal direction were taken. To utilize the coupon test data for the material model definition, it is assumed that the steel is isotropic, linear-elastic with isotropic plastic hardening and rate and temperature independence. That is, the response is assumed to be linear up to a discrete yield point, after which plastic (permanent) deformation occurs as described by a work hardening curve with no influence from temperature or strain rate. The elastic modulus is determined to be $21,000 \mathrm{ksi}$, and the yield point is established utilizing the standard $0.2 \%$ offset method to be $47 \mathrm{ksi}$. The work hardening curve is defined by using a piecewise linear function developed from the actual measured coupon test data. It should be noted that for large deformation finite element analysis, "engineering” stress and strain must be converted to "true” stress and strain using the following relationships:

$$
\begin{gathered}
\varepsilon_{\text {true }}=\ln \left(1+\varepsilon_{\text {eng }}\right) \\
\sigma_{\text {true }}=\sigma_{\text {eng }}\left(1+\varepsilon_{\text {eng }}\right)
\end{gathered}
$$

The results from Equations (5-1) and (5-2) are then included in the ABAQUS input deck in order that a failure surface may be constructed in three dimensional stress space.

\subsection{VERIFICATION OF FINITE ELEMENT ANALYSIS TECHNIQUES}

To verify that the modeling techniques are producing accurate results, a full simulation of the experimental testing, carried out at as part of this research, is performed and the analytical results

are compared to the experimental measurements. Specifically, the deflections recorded by the displacement transducers (DCDTs) and the strains measured by the rosette gauges installed on the surface of the HSS chord wall are compared to the finite element analysis results.

The DCDT measurements that are used for the verification are designated as DCDT 1 and DCDT 3 from the experimental test data (see Figure 3-1). The DCDT 1 measured the total 
displacement at the point of load application (including both global and local deformation effects within the specimen) and the DCDT 3 measured the local deformation (ovalization) of the HSS cross section at the open end.

Strains measured with rosette gauges on the surface of the HSS chord wall are also used for verification of the finite element analysis modeling techniques. These gauges were positioned uniformly along the circumference of the HSS chord in three (3) sections between the ST and saddle bearings. The gauge locations and their respective numbers are shown in Figure 3-3.

\subsubsection{Overall Agreement}

First, the overall specimen behavior and response is discussed in the context of the observed evolution in the failure modes. As noted in the observations of the experimental results at failure, dimples form in the HSS wall around the ST flange tips and the open end of the HSS deforms into an oval shape (Boyle and Earls, 2004). A deformed shape consistent with this description is also predicted by the finite element analysis simulation (see Figure 5-6). In addition, a number of rosette gauges indicate yielding in the HSS chord wall during testing: 1,3 , $5,8,9,13$, and 14 . In general, these locations of yielding are consistent with the yield line patterns as discernable in the exhibited von Mises stress contours presented in Figure 5-3. In general, these initial observations indicate that the same basic mechanisms of failure are being captured.

\subsubsection{Agreement in Displacements}

Next, the displacements from the finite element analysis and experimental results are compared. By studying the global deflection at the point of load application in Figure 5-7, it can be seen that the agreement between the experimental results and finite element modeling results appears to be favorable at this location. Recall that this is the DCDT 1 measurement discussed previously. The elastic stiffness (initial slope of the load-deflection curves) is consistent and the peak loads from the finite element analysis and experimental results of Specimen \#2 are within 4\% (92.4 kip 


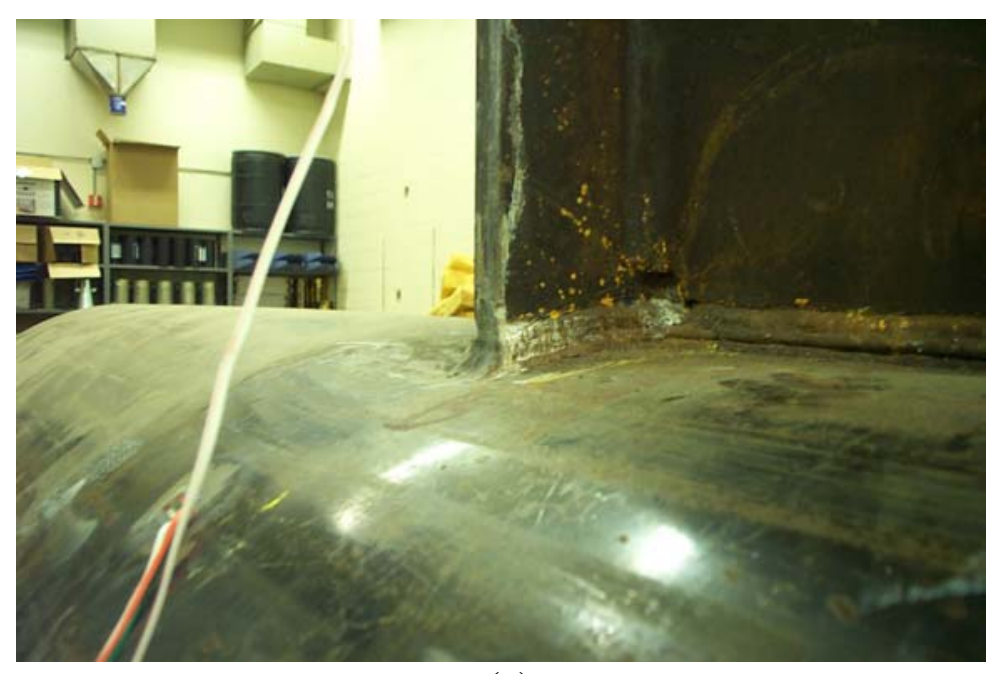

(a)

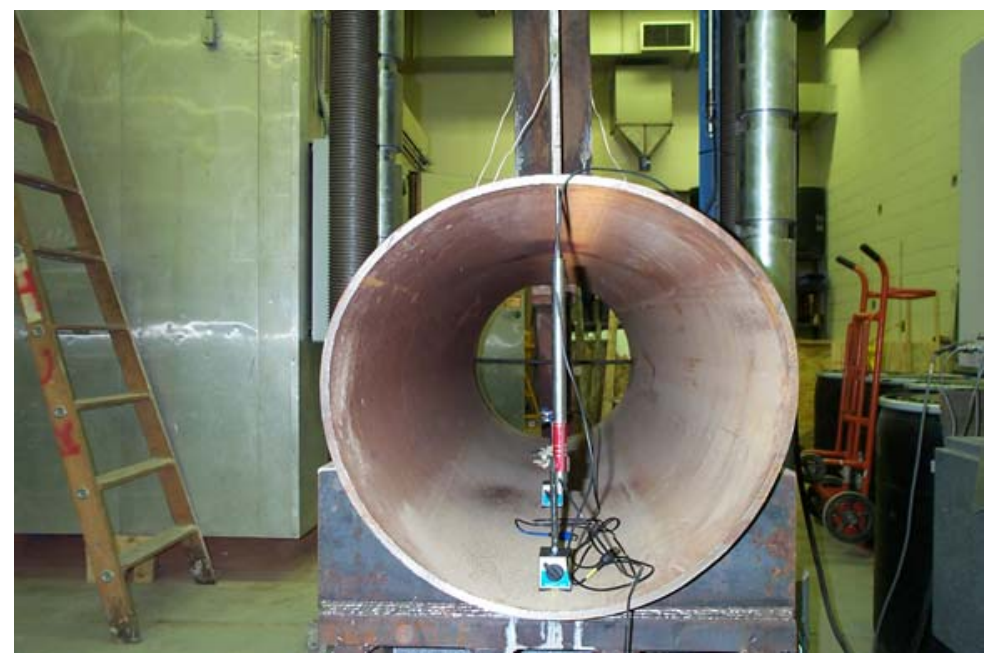

(c)

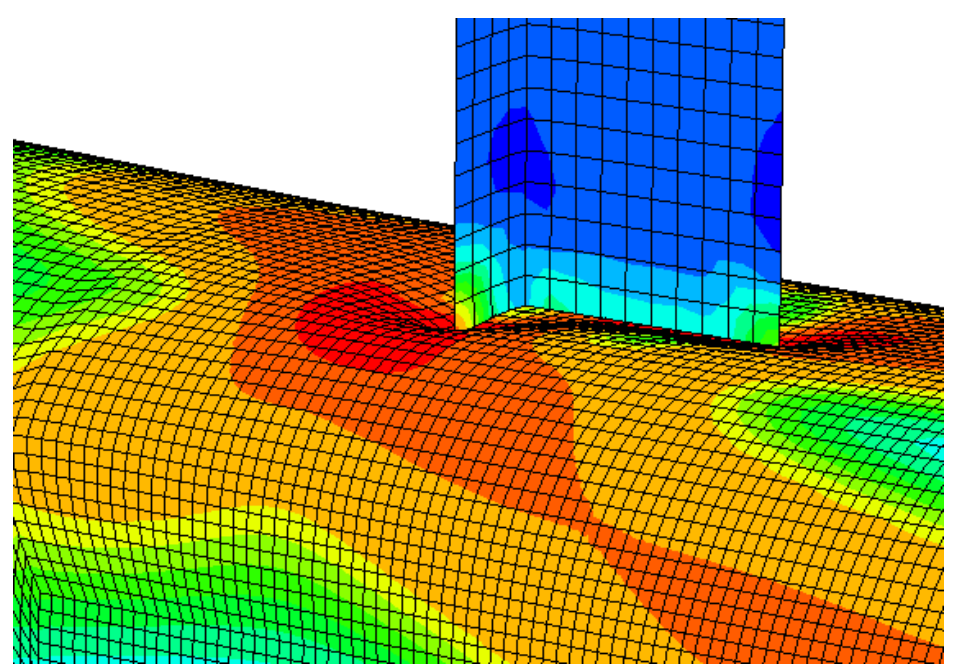

(b)

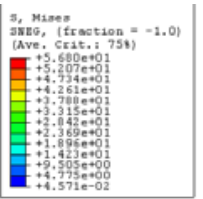

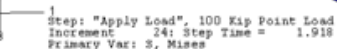

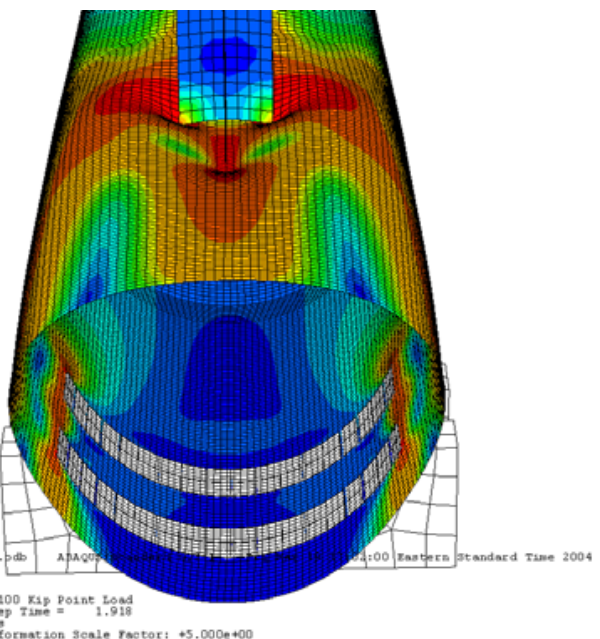

(d)

Figure 5-6: Deformed shape comparison: (a)(b) dimpling at ST and (c)(d) ovalization at end 


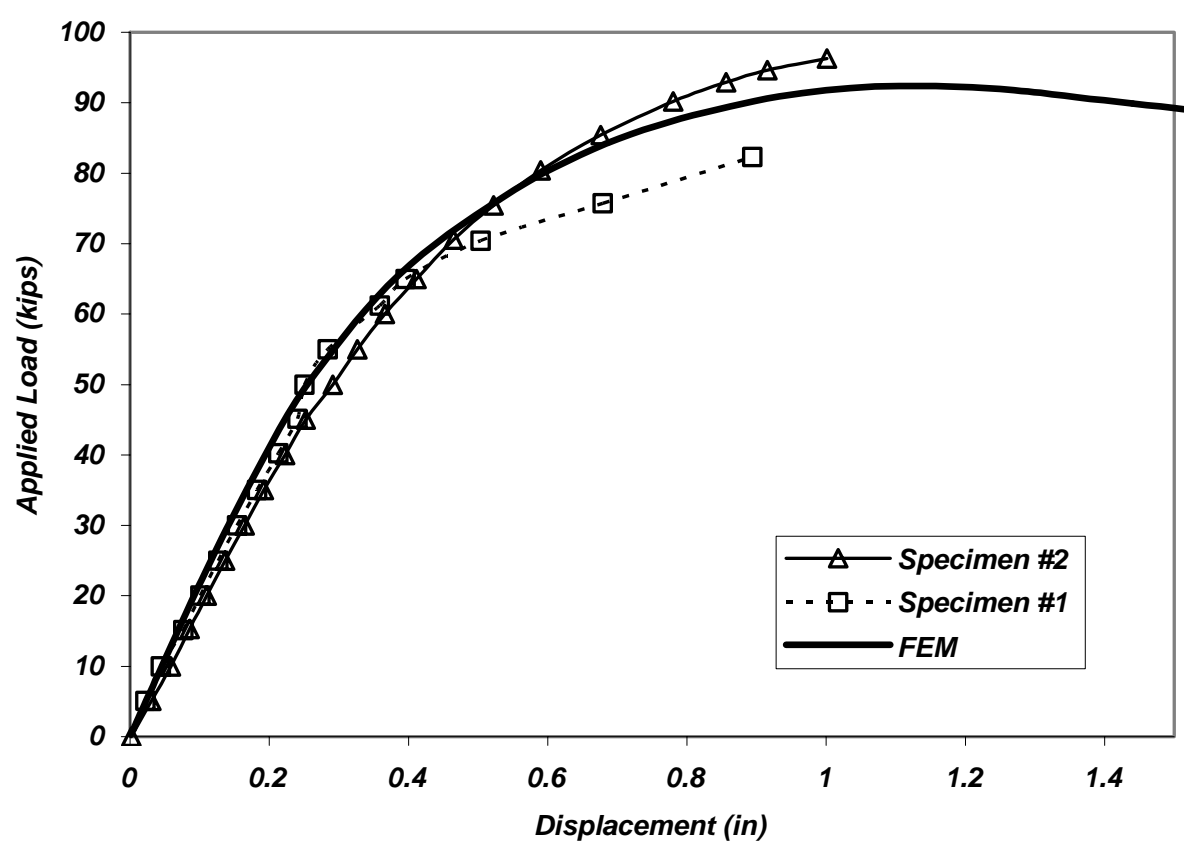

Figure 5-7: Load-deflection response comparison at applied load (DCDT 1)

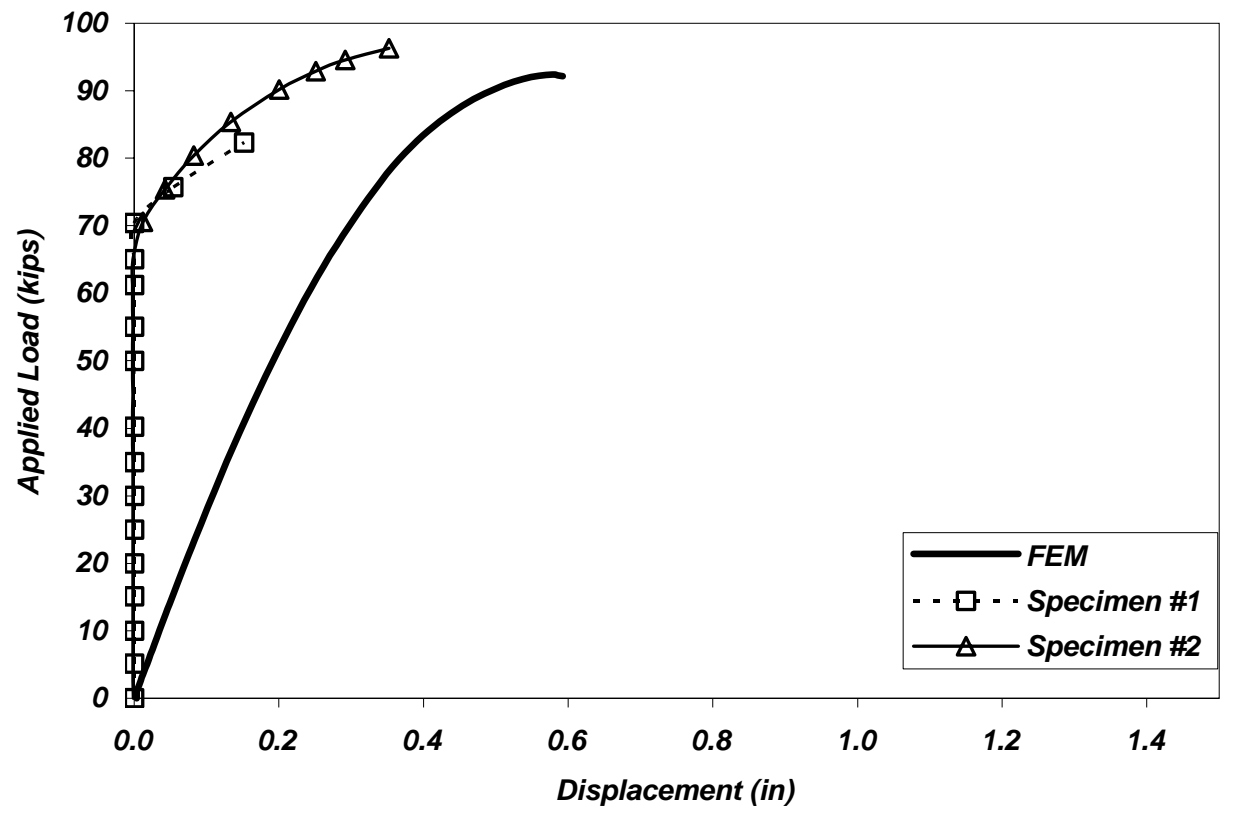

Figure 5-8: Load-deflection response comparison at HSS end (DCDT 3) 
vs. 96.3 kips). For Specimen \#1, the peak load was slightly less which is attributed to the problem in the testing noted earlier. It is also noted that these ultimate loads occur at nearly the same deflection; this may be important if one desired to use a deflection criterion for defining the nominal capacity in a design context. One minor difference to note is that the finite element analysis predicts a slightly softer response in the inelastic range; i.e. the load above 60 kips. This results in a slightly lower ultimate load predicted by finite element analysis as compared to the experiment, but still within a small percentage of the total load.

Additionally, the displacements at the open end of the HSS are compared (see Figure 5-8). Since this location is 33 in. away from the ST strut, the deflection here gives an indication as to what extent the applied load is dispersed longitudinally in the chord wall. Interestingly, both experiments showed no movement until a load of 70 kips, at which point the open end closed quickly. In contrast, this response is not predicted by the finite element analysis. The finite element analysis results indicate a gradual (smooth) increase in deflection from the beginning of load application up to a maximum of deflection of $0.6 \mathrm{in}$. Since similar responses were observed in both experimental tests, it cannot be attributed to the incident that occurred in testing of Specimen \#1. This is discussed further below.

\subsubsection{Agreement in Strains}

Since strains are the actual measured data from the gauges (and thus do not require any additional assumptions regarding material mechanical behavior), comparisons based on these measures represent the most direct approach for determining agreement between the models and the physical tests (as opposed to stresses). However, strains are often difficult to correlate between experiments and analysis since strain is defined at an idealized point in space. This type of measurement is a simple matter for a computer model based on the finite element method, but in a real physical test, the strain rosettes tend to be quite large in size and thus the strain measurements are effectively being averaged over significant gauge lengths in the lab testing. Also, strain measurements tend to be very sensitive to the residual stresses and variations in the thickness in the base material. 
The locations considered in this portion of the comparison in results are all the locations where yielding of the HSS wall occurs; these locations tend to exhibit large magnitudes of strain, which are more useful for comparison purposes. Since rosettes 1,8 , and 13 are mirror locations about the centerline of the HSS to rosettes 5, 9, and 14 respectively, symmetry is exploited and only one-half of the instrument readings are considered. It should be noted that the mirror locations all showed similar behavior to their associated rosette on the opposite side. This indicates that the experimental loading and response was symmetric; with no significant out-ofplane bending or twisting of the specimen.

The comparisons of the principal strains at the four (4) yielded locations are shown graphically in Figure 5-9 through Figure 5-12. By studying the figures, it can be seen that the finite element analysis and experimental strains agree very well at rosettes 3 and 14 . The initial slope of the curves, the load at which the curves become nonlinear, and the strain magnitude at the peak load are all relatively consistent. Of all the rosettes, these two locations exhibited the largest magnitude of total strain: in the range of 3500-4500 microstrains (the uniaxial yield strain is approximately 2200 microstrains). Large strains are expected here since rosette 3 is located at the apex of the HSS adjacent to the ST web where a yield line is well defined. Large strains are also expected at rosette 14 since this is in close proximity to the ST flange tip where significant dimpling was observed to occur in the experimental specimens during testing. For rosettes 5 and 9, the comparisons are slightly less favorable, but are still very reasonable. The less favorable agreement observed between modeling results and physical testing results is likely due to the fact that the magnitudes of the strains are smaller than those observed at 3 and 14 , and so any discrepancies are more pronounced in terms of gross percentages of measured response.

\subsection{DISCUSSION OF RESULTS}

Overall, the agreement between the finite element analysis results and the experimental tests is favorable. The finite element analysis simulation results support the general observations made during the testing. In addition, the displacement and strain measurements taken from the 


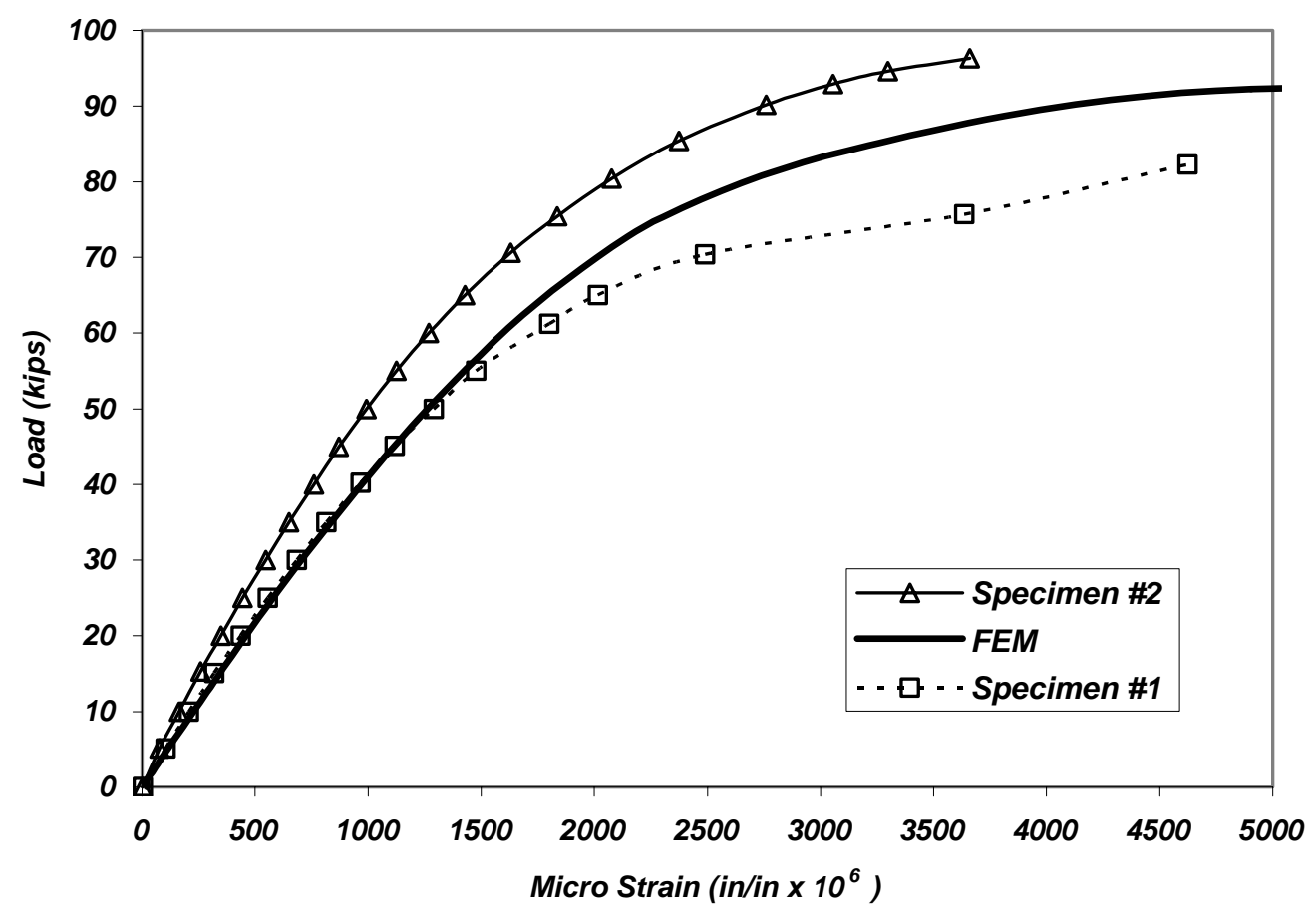

Figure 5-9: Maximum principal strain comparison at gauge location 3

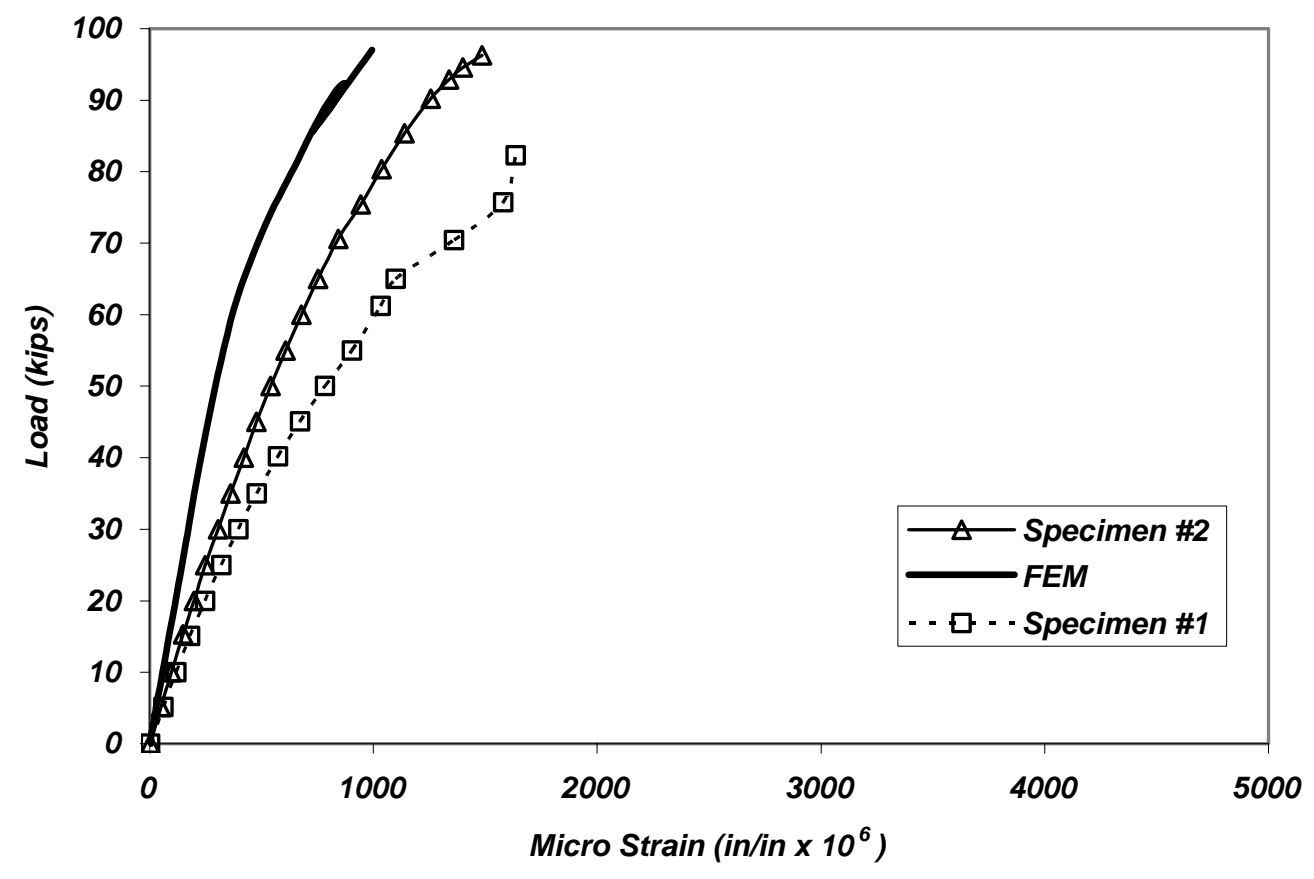

Figure 5-10: Maximum principal strain comparison at gauge location 5 


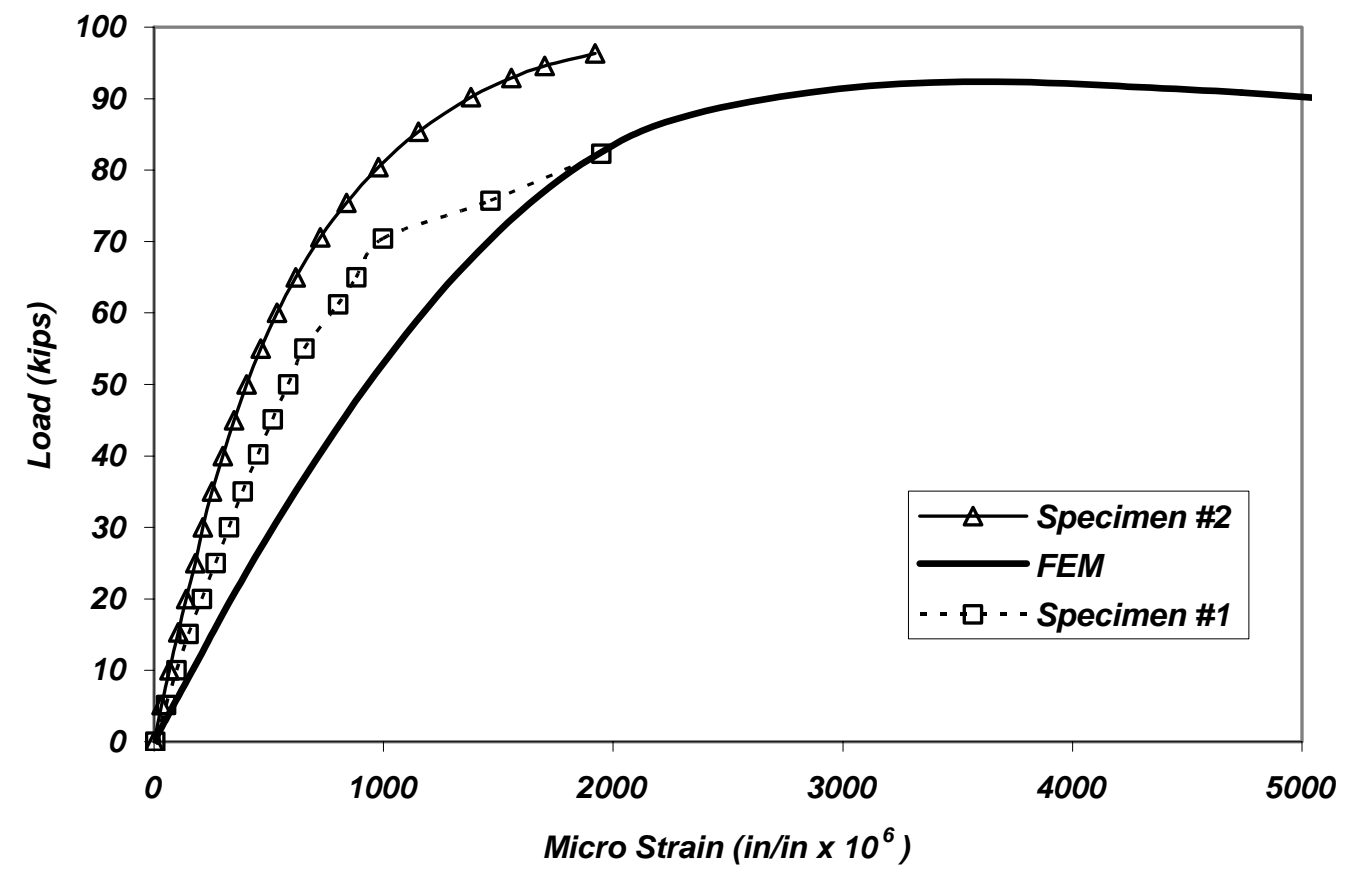

Figure 5-11: Maximum principal strain comparison at gauge location 9

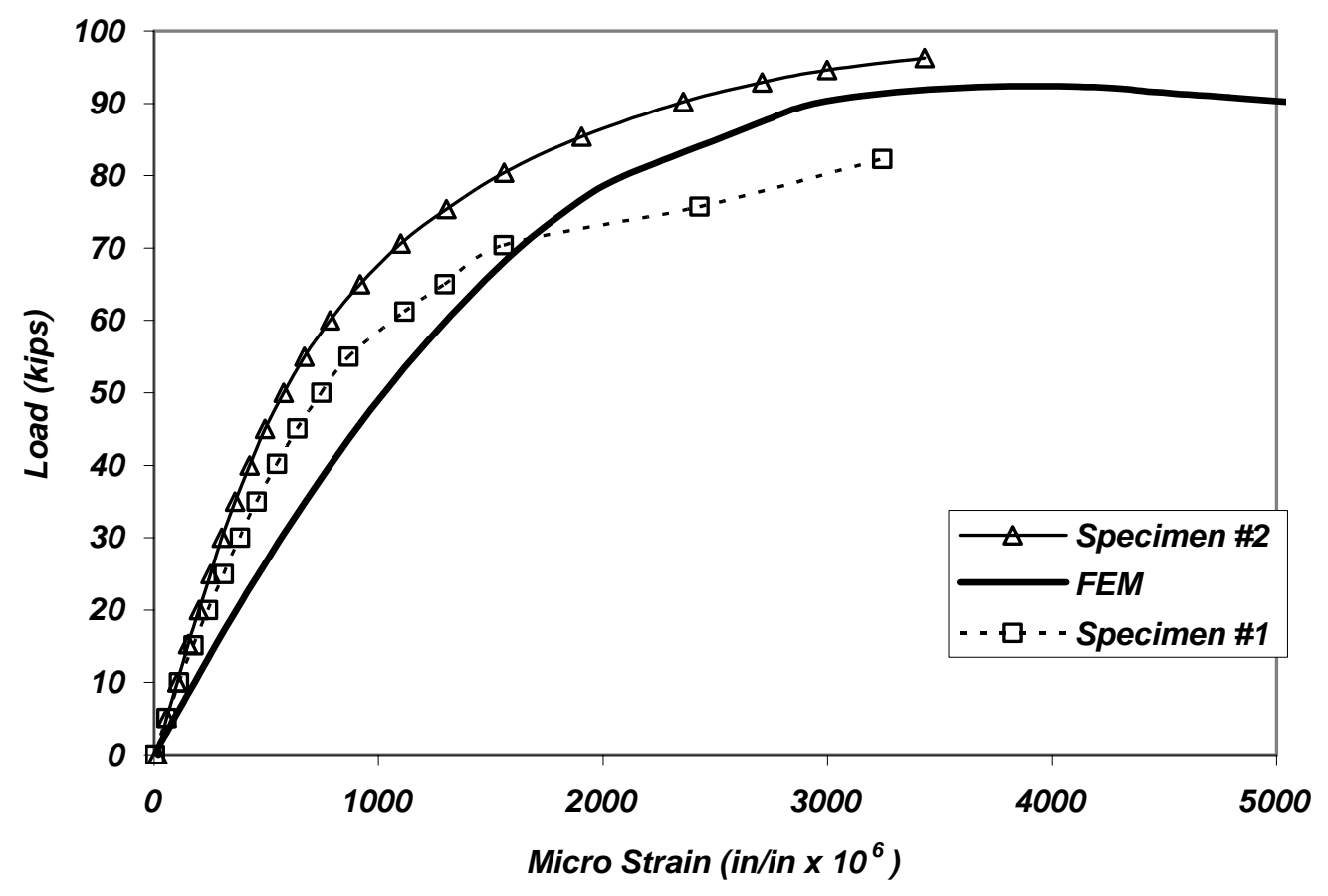

Figure 5-12: Maximum principal strain comparison at gauge location 14 
specimens are mostly consistent with the analytical results. Thus, it is concluded that the finite element analysis techniques employed herein are valid for analysis of the structure under investigation. However, from this research, a number of issues with regard to finite element analysis of tubular steel structures have arisen which are discussed in more detail below.

\subsubsection{Sources of Discrepancy}

The potential sources of discrepancies between the finite element analysis and experimental results are: physical variations in HSS wall thickness, diameter, mass, and residual stresses as discussed previously. However, since actual measurements of these properties were not taken from of the specimens, it is difficult to ascertain their exact influence. These items will be discussed in a general sense by assuming that the magnitudes are consistent with other manufactured HSS members; in light of the tolerance values specified by ASTM A53. It is pointed out right away that, in general, the strains computed using the finite element method are less accurate than the nodal displacements in the context of a given mesh. This is due to the fact that the displacements are nodal quantities that are solved for directly in each equilibrium iteration. In contrast, the stresses are obtained from engineering theories applied at the midsurface Gauss points and subsequently extrapolated out to the nodal locations. As a result of this extrapolation, the strains predicted with the finite element model are somewhat less accurate than the displacements predicted with the same model.

As discussed previously, the strain measurements on the chord wall surface are very sensitive to residual stresses and local variations in wall thickness. Residual stresses will result in a change in the localized yielding response and could cause a global redistribution of the applied loads in the form of shift in the trajectories of the yield line patterns. Note that in the present discussion, the strains are compared in terms of principal strain, which means that both longitudinal and transverse residual stresses will influence the onset of yielding. However, from the figures, it is observed that there are not significant differences in the yielding behavior. That is, the initiation of nonlinear behavior is relatively consistent between finite element analysis and the experiments. The differences that exist are more in terms of overall magnitude at a given load, which is more attributable to a yield line shift. If the actual yield lines deviate from the 
theoretical patterns, this would have a more significant impact on the strain magnitude at discrete gauge locations.

Variations in wall thickness will also result in a change in the extreme fiber strain as compared to the idealized finite element analysis model, which uses the nominal thickness. By considering the linear strain distribution from fundamental flexural theory, the strain for a given elemental curvature is directly proportional to the distance from neutral axis. Thus, a 10\% variation in wall thickness (as per ASTM) would result in a 10\% variation in extreme fiber strain. This may partially explain the differences in strain magnitude between finite element analysis and the experiments, but some differences are much larger than this.

The most significant difference found in the comparison of finite element analysis versus the experimental results is in the displacement response at the open end of the HSS chord. As discussed previously, the open end in the physical test specimens showed no deformation until a load of $70 \mathrm{k}$ was attained. In contrast a gradual distortion of the open end was observed in the finite element models. This difference in response is likely not the result of a modeling issue since the other displacements and strains compare so well. Also, it cannot be attributed to residual stresses and/or dimensional tolerances from the HSS chord manufacturing processes, since neither would have such a dramatic influence on how the applied load is dispersed longitudinally in the chord wall.

Since the experimental researchers noted that a moment was present in the ST strut and that shims for the load frame became loose and fell out during testing of both specimens (Boyle and Earls 2004), it is likely that there existed some unknown flexibility and/or restraint in the testing setup which would be a deviation from the ideal boundary conditions used in the analytical modeling.

\subsubsection{Failure Mechanism}

The mechanism of failure for this structure is an example of a yield line collapse mechanism in which well-defined plastic hinge lines develop in the HSS chord walls, causing instability at a critical load. This is defined as the point at which the tangent stiffness (slope of the loaddeflection curve) equals zero. The yield lines exhibit a geometry that is somewhat complex due to the nature of the problem. However, based on the good agreement between finite element 
analysis and the experiments in terms of global load-deflection response, the salient features of the governing failure mechanism appear to be captured sufficiently well in the analytical modeling.

The present discussion now shifts focus to two specific points: 1) the stiffness after yielding, and 2) the magnitude of the ultimate load; both of these are related to residual stresses in the HSS chord. The residual stresses present can affect both the mechanism geometry (i.e. shifting of the yield lines) and the onset of yielding. Based on Figure 5-2, the longitudinal residual stresses in an HSS member may approach the yield stress in the vicinity of the welded seam. Although this is significant in terms of magnitude, the yield line mechanism for this structure consists mostly of lines oriented longitudinally. Such yield line orientations are not significantly impacted by longitudinal residual stresses in terms of unit strength. However, the longitudinal weld seam might cause a shift in the yield line location. Since any deviation from the ideal (theoretical) mechanism will have a net strengthening effect and result in a higher capacity, this would explain the slightly larger experimental ultimate load.

In contrast, the transverse residual stresses directly influence the net unit capacity of the longitudinal yield lines. From Figure 5-2, the circumferential residual stress distribution is nearly linear, and resembles the stress distribution from simple flexural theory. Thus, the residual stress can be thought of as a residual moment of approximate magnitude $\mathrm{M}_{\text {residual }}=\sigma \mathrm{S}$, where $\sigma=0.35 \sigma_{\mathrm{y}}$ and $\mathrm{S}$ is the section modulus per unit length of chord wall. For this structure, the residual moment is calculated:

$$
M_{\text {residual }}=(0.35 \cdot 47 \mathrm{ksi}) \cdot\left(1 " \cdot\left(0.5^{\prime \prime}\right)^{2} / 6\right)=0.685 \mathrm{k} \cdot \mathrm{in} / \mathrm{in}
$$

From simple plastic section analysis, the plastic moment resistance of the chord wall per unit length is $\mathrm{F}_{\mathrm{y}} \mathrm{t}^{2} / 4$ which yields:

$$
M_{p}=(47 \mathrm{ksi}) \cdot(0.5 ")^{2} / 4=2.94 \mathrm{k} \cdot \mathrm{in} / \mathrm{in}
$$

Thus, there exists a residual moment that is $0.685 / 2.94=23 \%$ of the plastic moment resistance, which could have a stiffening or softening effect depending on the direction of the applied 
flexure. It must be noted that this residual moment will affect the onset of yielding and the inelastic response for the collapse mechanism, but it will not affect the ultimate load since plastic moment resistance is independent of residual stress. Thus, the circumferential residual stress might explain the difference in tangent stiffness observed in the inelastic range.

\subsubsection{HSS Material Modeling}

As discussed previously, modeling of the HSS material is where the greatest uncertainties lie. It is likely that the steel in the test specimens contained residual stresses and was somewhat textured as a result of the manufacturing processes; but these internal properties are difficult to quantify for the purposes of analytical modeling. Thus, neither was utilized in the material definition for the finite element analysis model. However, it is believed that both may have contributed to observed differences in predicted versus observed responses throughout the verification study.

To transform a flat plate into a circular tube, significant circumferential strains will result. Based on the assumption of plane sections remaining plane from fundamental flexural theory, a plate of thickness " $\mathrm{t}$ " bent into a curve of radius " $\mathrm{R}$ " will have extreme fiber strains given by the relationship $\varepsilon=\mathrm{t} / 2 \mathrm{R}$. For the test specimen chords, this results in maximum strains of $\varepsilon=(0.5$ in.) $/ 2(13$ in. $)=0.0192 \mathrm{in} / \mathrm{in}$, which is over ten times the yield strain $\varepsilon_{\mathrm{y}}$. Thus, it is likely that some level of texturing has occurred and the properties of the steel are different in the longitudinal and transverse directions. However, coupon tests were conducted in the longitudinal direction only, and thus the significance of the texturing could not be quantified precisely, but it was clear that the longitudinal elastic modulus was somewhat less that the 29,000 ksi typically ascribed to steel.

In defining the material model, the von Mises metal plasticity model is utilized, which assumes that the stress-strain response is linear up to a discrete yield point. However, in

studying the coupon test data closely it is observed that the material response is nonlinear throughout the elastic range, which is consistent with the findings of Toma and Chen (1979), but even more pronounced. To minimize the error from this linear approximation, an average elastic modulus of 21,000 ksi was specified for the model, as opposed to the initial tangent value of 
29,000 ksi, as a means for considering the nonlinear elastic response exhibited by the A53 Grade B used in the HSS chord members being considered herein. 


\subsection{PARAMETRIC STUDIES}

Now that the verification of the finite element modeling techniques is complete, parametric studies can be reliably conducted for formulation of generalized capacity equations for bearing connection regions in tubular trusses. The goal of this portion of the present work is to develop equations that predict the capacity of the bearing connection for the following:

1) the action of an axial load/reaction force (P)

2) the action of a locally applied moment (M)

3) combined axial load and moment

A number of parameters are identified as potentially influencing the strength of the bearing region in resisting axial forces and/or moments; these are studied individually to quantify their impact. The parameters identified are shown in Figure 6-1 and summarized below:

$\begin{array}{ll}\text { Chord Diameter }(\mathrm{D}) & \text { Chord Wall Thickness }(\mathrm{t}) \\ \text { ST Flange Width }\left(\mathrm{b}_{\mathrm{f}}\right) & \text { ST Depth }(\mathrm{d}) \\ \text { Chord Yield Strength }\left(\mathrm{F}_{\mathrm{y}}\right) & \text { End Distance }(\mathrm{h}) \\ \text { Saddle Width }(\mathrm{A}) & \text { Saddle Length }(\mathrm{B})\end{array}$

For each parameter study, a minimum of four (4) variations are analyzed using FEM analysis. For each variation, the ultimate capacity is determined by studying the load-deflection response. The range of values that is considered for each parameter study is arrived at based on practical limits from existing specifications and/or anticipated construction practice. Four (4) variations for each parameter are considered sufficient so long as the same failure mechanisms are being captured in each case. 
In defining the parameter ranges for the study, it is determined that although variations in the saddle length or saddle position along the longitudinal axis of the HSS chord could have a small influence on the overall bearing capacity, it will not be considered in this study. BC-744 calls for two (2) - 4 in. thick saddles positioned precisely at $12 \mathrm{in}$. from the end of the HSS chord to their centerline (PennDOT, 2003b). However, for modeling purposes these have been simplified into one monolithic saddle of length "B". Since it is unknown at this time what saddle configurations with respect to the HSS end and/or the ST may be considered in the future, practical variations in this parameter cannot be developed. As long as the saddle is proportioned sufficiently long and positioned within reasonable proximity to the ST strut, the impact of Saddle Length (B) on the overall capacity will be minimal.

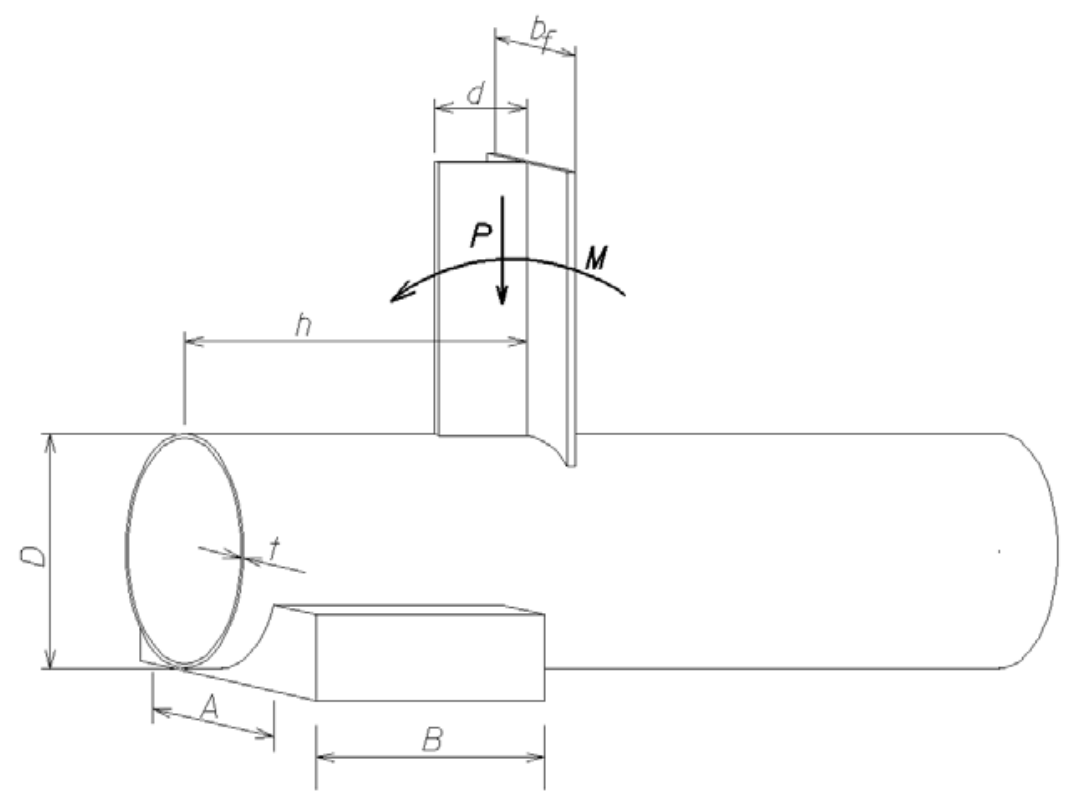

Figure 6-1: Parameters considered for study. 


\subsection{AXIAL LOAD STUDY}

As discussed previously, the primary load path for the reaction force in the bearing connection under investigation extends from the saddle assembly, through the chord, and directly into the first intermediate member (in this case an upright ST member). This was the basis for the load in the experimental tests being applied axially through the ST strut and resisted at the saddles; in order to simulate the loading present in a real tubular truss bearing connection.

The applied load is compressive since overhead sign trusses are typically simple-span structures with the bearings in compression. Coincidentally, most existing provisions for other HSS connections are based on the compressive capacity, not tensile. Research has shown that HSS joints loaded in tension generally have a higher ultimate load capacity than those loaded in compression (Wardenier, 1982). For simplicity, researchers and code-writing bodies have typically based HSS capacity equations on the compressive resistance only, which is somewhat conservative for tensile loading. That same approach will be adopted for this research; and thus all axial loads will be applied in compression.

The next issue that must be addressed is the definition of capacity. Usually, capacity in tubular connections is defined using either a deflection criterion or a strength criterion depending on the application. In Chapter 4, the definition of "nominal capacity" was introduced due to the apparent unstable failure exhibited in the experimental test specimens. However, the finite element results of Chapter 5 showed that the connection contains significant reserve strength after the initial peak load. For the bearing region under investigation, as the applied load is increased from the start, the initial response is shown to be linear (see Figure 5-7). At some point, the structure begins to yield, as evident from the non-linear response. Load and deformation continue to increase until the load reaches a peak value, and then the load softens as deformation continues to increase. After more deformation, another resisting mechanism engages and the structure recovers; eventually resisting a much higher load than the initial peak load. Based on this behavior, either a deflection criterion or a strength criterion could be applied. But since it is difficult to develop a deflection criterion that is applicable to all HSS bearing configurations, the initial peak load is selected as the capacity of the system. At this load, the deflections are not considered excessive, as opposed to the $2^{\text {nd }}$ peak in the load-history after 
recovery. Thus, for all analyses performed in the parametric study for axial load, the first peak in load-deflection response is utilized as the capacity.

As the starting point for each study, the "benchmark case” is considered. The benchmark case is based primarily on the geometry of the experimental tests, thus being fully verified against physical testing. From this benchmark, different parameter variations are explored as needed, but these subsequent configurations still remain reasonably similar to the benchmark case. Except for the parameter "D” as will be shown below, the benchmark case is typically in the middle of all the parametric variations considered. This is not possible for the " $\mathrm{D}$ " study since HSS diameters greater than 26 in. are not of concern.

\subsubsection{End Distance (h) Study:}

Since the primary failure mechanism extends to the open end of the HSS chord, as indicated by strain and deflection measurements from the experimental tests and the stress contours from the FEM simulation, it is apparent that the open end will influence the strength of the bearing connection region. Therefore, its impact on the overall capacity must be assessed. To accomplish this, six (6) configurations are analyzed with the dimension "h" varied from 6 in. to 39 in. (0.25D to $1.5 \mathrm{D})$ and the remaining parameters held constant. The study parameters are summarized as follows:

\begin{tabular}{ll} 
h values: & Constants: \\
\hline 6” & $\mathrm{D}=26 ”$ \\
$13 ”$ & $\mathrm{~b}_{\mathrm{f}}=7.2 ”$ \\
26” *Benchmark case & $\mathrm{d}=10.15 ”$ \\
$33 ”$ & $\mathrm{t}=0.5 ”$ \\
$39 ”$ & $\mathrm{~F}_{\mathrm{y}}=47 \mathrm{ksi}$ \\
& $\mathrm{A}=24.1 ”$ \\
& $\mathrm{~B}=\mathrm{h}-2 ”$
\end{tabular}

As mentioned previously, the saddle length and longitudinal position are not considered as parameters for study and therefore were to remain constant throughout all studies. However, maintaining the same saddle length while varying the location of the ST (dimension " $h$ ") would be problematic for this study. If the ST is moved away from the saddle, then bending is 
introduced into the HSS chord due to the eccentricity between the ST axial load and the reaction force at the saddle. This bending negatively affects the capacity of the system and it becomes more pronounced as the eccentricity increases. To prevent this, the saddle width (B) is specified as a constant $2 \mathrm{in}$. less than the ST flange position (h) for all variations. That is, the inside face of the saddle is always positioned at a dimension of $\mathrm{h}-2 \mathrm{in}$. from the end. This ensures that the same eccentricity exists (although minimal) for all configurations.

The load-deflection results from each FEM analysis are shown in Figure 6-2. As expected, the axial capacity of the bearing region is increased as the end distance (h) of the ST is increased. However, note that the response for $h=33$ in. is the same as the response for $h=39$ in. This indicates that the open end no longer influences the failure mechanism once the ST is located at a distance 33 in. (1.27D) or more from the end.

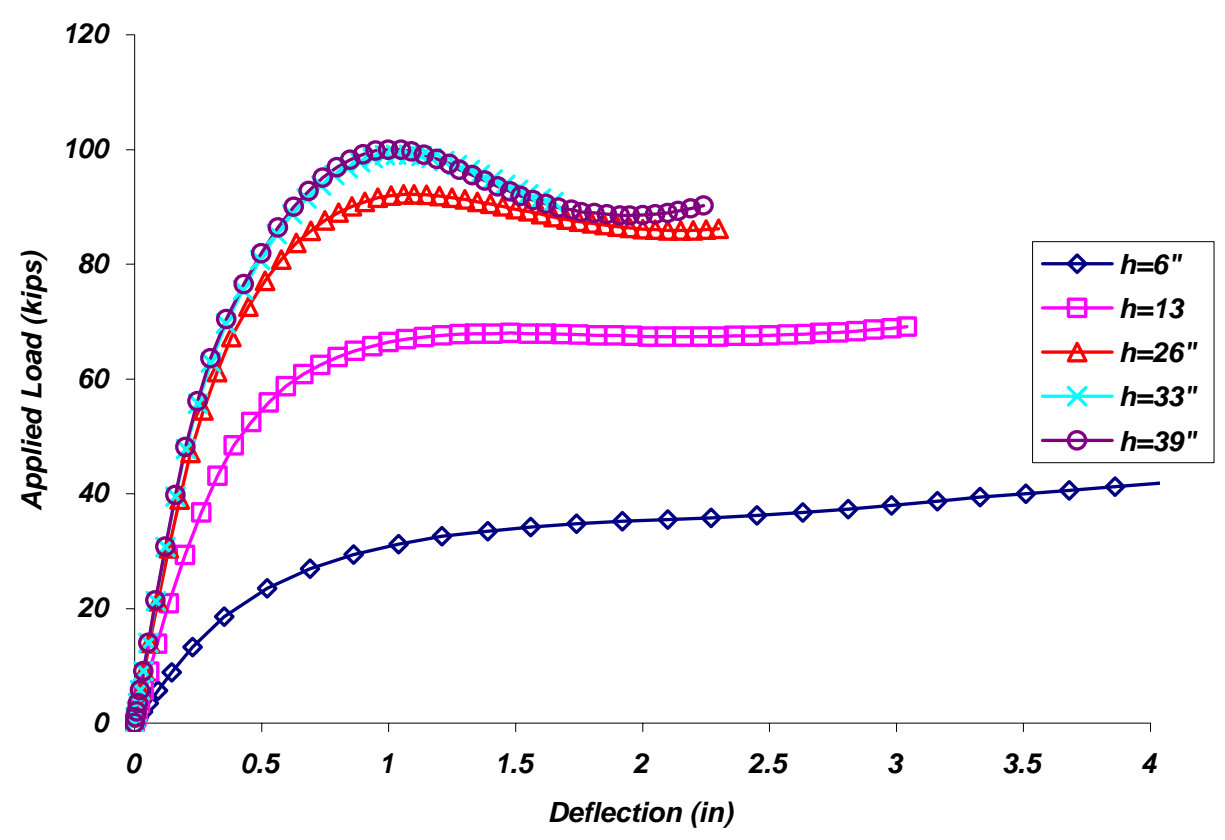

Figure 6-2: Axial load-deflection response for varying end distance (h) 


\subsubsection{ST Flange Width $\left(b_{f}\right)$ Study:}

By observing the yield line patterns indicated by the FEM stress contours in Figure 5-3, it is apparent that the ST flange width will also have an influence on the primary failure mechanism. For this study, five (5) configurations are analyzed with the dimension " $\mathrm{b}_{\mathrm{f}}$ " varied from 0 in. (no flange) to 15.6 in. (0.6D) and the remaining parameters held constant. The case of $\mathrm{b}_{\mathrm{f}} / \mathrm{D}=0.6$ is a practical limit that is consistent with existing published specifications. The study parameters are summarized as follows:

\begin{tabular}{|c|c|}
\hline$\underline{\mathrm{b}}_{\mathrm{f}}$ values: & Constants: \\
\hline $0 ”$ & $\mathrm{D}=26 ”$ \\
\hline $3.9 ”$ & $h=26 ”$ \\
\hline 7.2” *Benchmark case & $d=10.15 ”$ \\
\hline 11.7” & $t=0.5^{\prime \prime}$ \\
\hline $15.6 ”$ & $\begin{array}{l}\mathrm{F}_{\mathrm{y}}=47 \mathrm{ksi} \\
\mathrm{A}=24.1 ”\end{array}$ \\
\hline
\end{tabular}

The load-deflection results from each FEM analysis is shown in Figure 6-3. As expected, the axial capacity of the bearing region is increased as the ST flange width $\left(\mathrm{b}_{\mathrm{f}}\right)$ is increased. Note that significant capacity gain can be realized by increasing the flange width to 15.6 in.

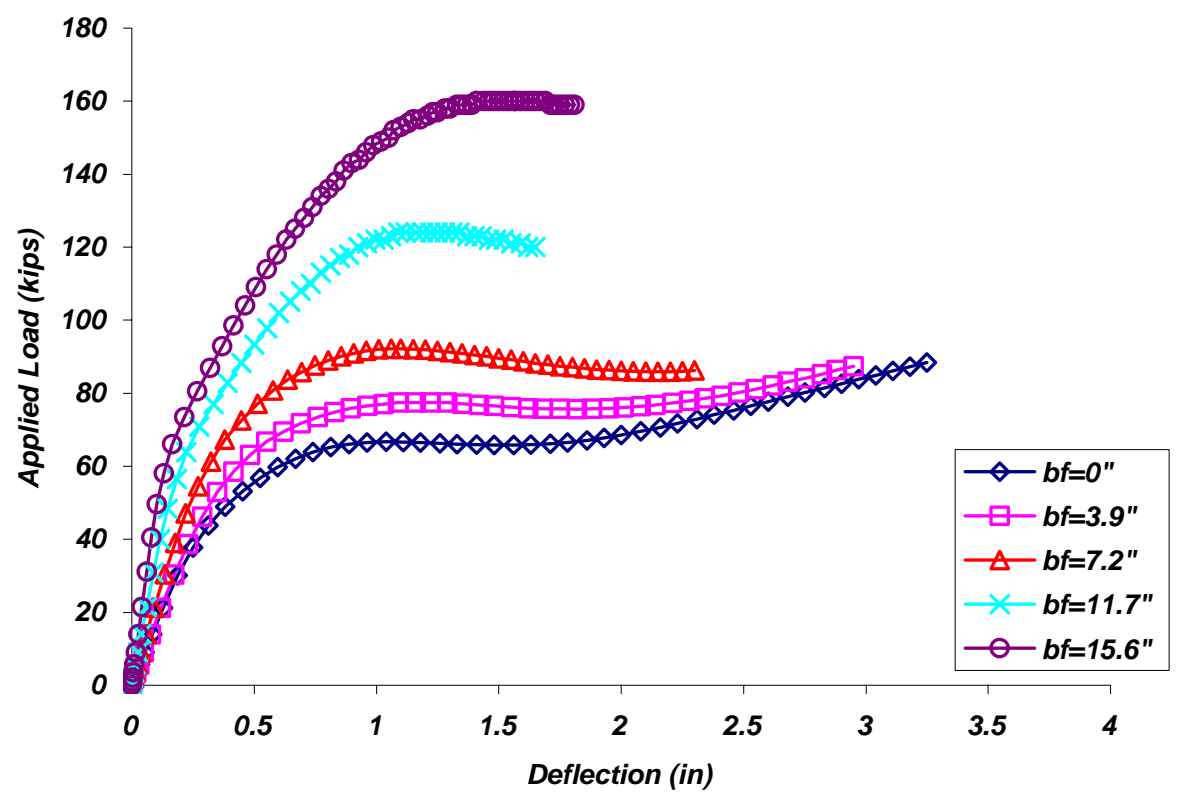

Figure 6-3: Axial load - deflection Response for varying ST flange width (bf) 


\subsubsection{HSS Chord Diameter (D) Study}

For this study, four (4) configurations are analyzed with the chord diameter "D" varied from 10 in. to 26 in. while holding constant the ratios $b_{f} / D, A / D$, and $h / D$ as well as the remaining parameters. The study is conducted in this way since " $\mathrm{D}$ " is a variable that is usually not used explicitly in HSS capacity equations. But rather, it is typically shown within a ratio to another variable (see Eqs (4-1) to (4-4)). In these equations, " $\mathrm{D}$ " is combined with the branch member width to define a parameter ratio $\beta$, which equals $\mathrm{D}$ (branch)/D(chord) for a HSS-to-HSS connection or $b_{1} / D$ for a Concentrated Force Distributed Transversely. Thus, the purpose of this portion of the investigation is to determine whether or not variations in " $\mathrm{D}$ ", if the ratios of $\mathrm{D}$ to other variable remain constant, lead to the same overall connection capacity. The study parameters are summarized as follows:

\begin{tabular}{ll} 
D values: & Constants: \\
\hline $10 ”$ & $\mathrm{~b}_{\mathrm{f}} / \mathrm{D}=0.27$ \\
$14 ”$ & $\mathrm{~h} / \mathrm{D}=1.0$ \\
$20 ”$ & $\mathrm{~d}=10.15 ”$ \\
$26 ”$ *Benchmark case & $\mathrm{t}=0.5 ”$ \\
& $\mathrm{~F}_{\mathrm{y}}=47 \mathrm{ksi}$ \\
& $\mathrm{A} / \mathrm{D}=0.927$ \\
& $\mathrm{~B}=\mathrm{h}-2 ”$
\end{tabular}

The load-deflection results from each FEM analysis is shown in Figure 6-4. As anticipated, the axial capacity of the bearing connection is not significantly affected by variations in $\mathrm{D}$, as long as the ratios of $\mathrm{b}_{f} / \mathrm{D}, \mathrm{h} / \mathrm{D}$ and $\mathrm{A} / \mathrm{D}$ are held constant. There is a slight decrease in capacity as the diameter $\mathrm{D}$ is increased, but since the benchmark case utilizes a diameter $\mathrm{D}=26$ in., then the final capacity equation will be formulated to be slightly conservative for smaller diameters. 


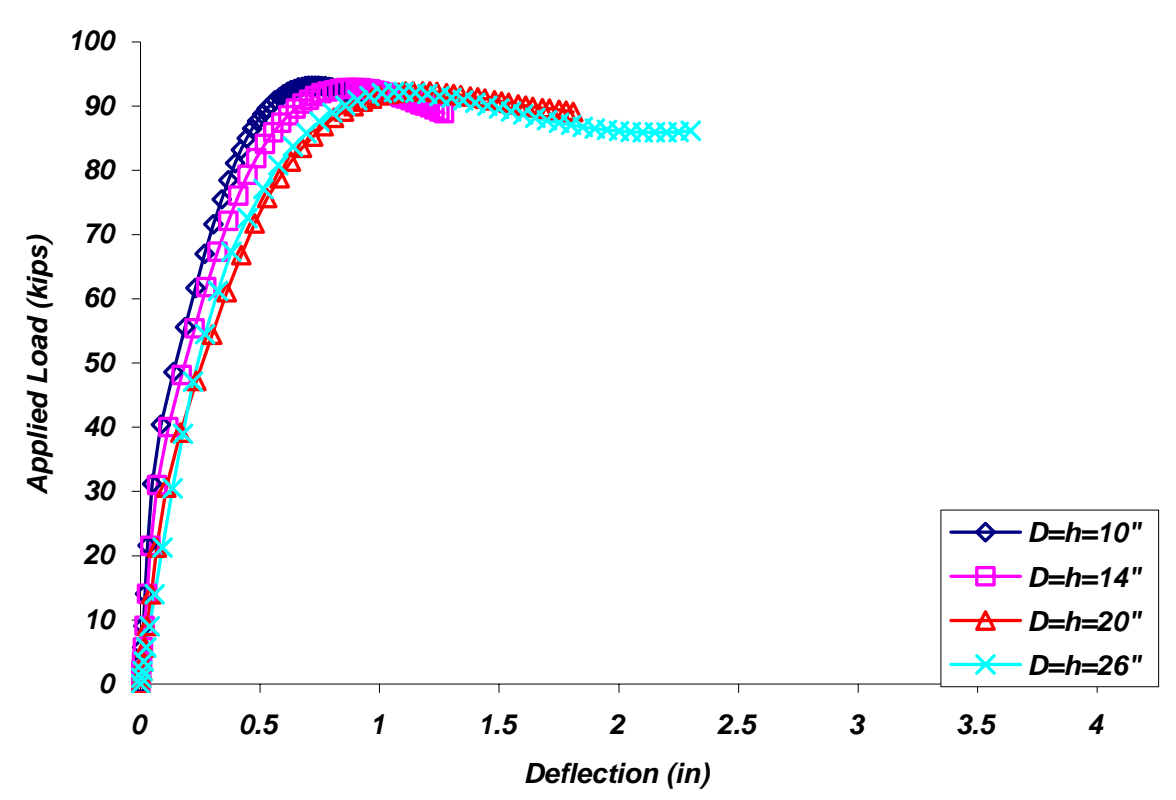

Figure 6-4: Axial load - deflection response for varying chord diameter (D)

\subsubsection{Saddle Width (A) Study}

For this study, five (5) configurations are analyzed with the dimension "A" varied from 0 in. to 26 in. and the remaining parameters held constant. Note that for $A=0$ in., this is the case with no curved saddle bearing (i.e. a single line support) and for $A=26$ in., this is the case in which the saddle covers the entire bottom half of the chord. The study parameters are summarized as follows:

\begin{tabular}{ll} 
A values: & Constants: \\
\cline { 2 - 2 } 0” & $\mathrm{D}=26 ”$ \\
$7.6 ”$ & $\mathrm{~B}=24 ”$ \\
$14.5 ”$ & $\mathrm{~h}=26 ”$ \\
$24.1 ”$ *Benchmark case & $\mathrm{d}=10.15 ”$ \\
$26 ”$ & $\mathrm{t}=0.5 ”$ \\
& $\mathrm{~F}_{\mathrm{y}}=47 \mathrm{ksi}$ \\
& $\mathrm{b}_{\mathrm{f}}=7.2 ”$
\end{tabular}

The load-deflection results from each FEM analysis is shown in Figure 6-5. As expected, the capacity is increased as the saddle width (A) is increased. As mentioned, the case of A $=0$ in. is 
a configuration in which the chord is supported by a single line support rather than a curved bearing surface. Since many in-service bearing details consist of a simple flat plate bearing detail, this case is may be of particular interest to practicing engineers. To accurately model this condition of a round HSS chord bearing on a flat surface, the analysis is conducted with consideration of a true contact interaction between the chord wall and bearing surface. This more sophisticated boundary was not modeled for other parametric models due to its computational expense (see Section 5.2.3).

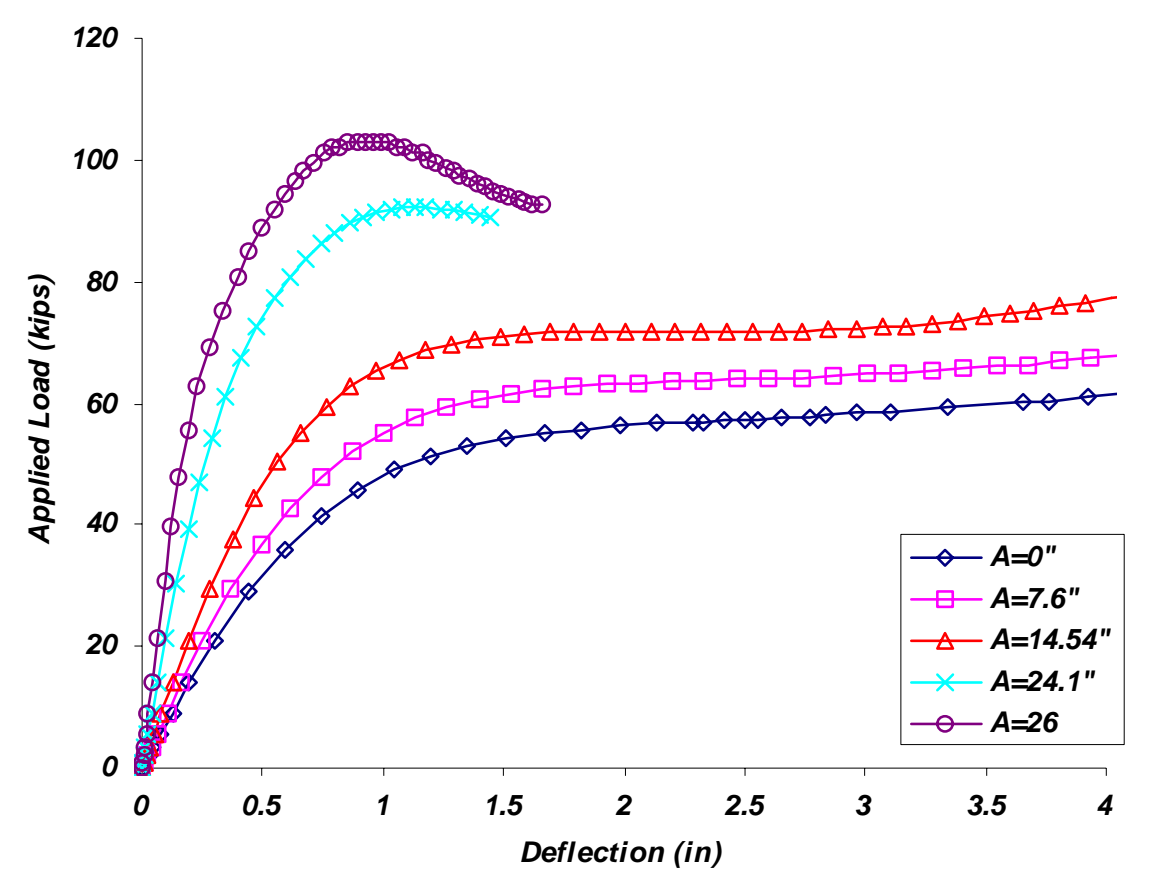

Figure 6-5: Axial load - deflection response for varying saddle width (A)

\subsubsection{Chord Wall Thickness (t) Study}

For this study, four (4) variations are analyzed with the chord wall thickness "t" varied from 3/8 in. to 1 in. (D/70 to D/26) and the remaining parameters held constant. These are selected based on practical limits on HSS members. The study parameters are summarized as follows: 


\begin{tabular}{ll}
$\frac{\text { t values: }}{3 / 8 ”}$ & Constants: \\
\cline { 2 - 2 } $1 / 2 ” *$ Benchmark case & $\mathrm{D}=26 ”$ \\
$3 / 4 ”$ & $\mathrm{~h}=26 ”$ \\
1 ” & $\mathrm{d}=10.15 ”$ \\
& $\mathrm{~F}_{\mathrm{y}}=47 \mathrm{ksi}$ \\
& $\mathrm{A}=24.1 ”$ \\
& $\mathrm{~b}_{\mathrm{f}}=7.2 ”$ \\
& $\mathrm{~B}=24 ”$
\end{tabular}

The load-deflection results from each FEM analysis is shown in Figure 6-6. As expected, increasing the chord wall thickness results in significantly increased capacity.

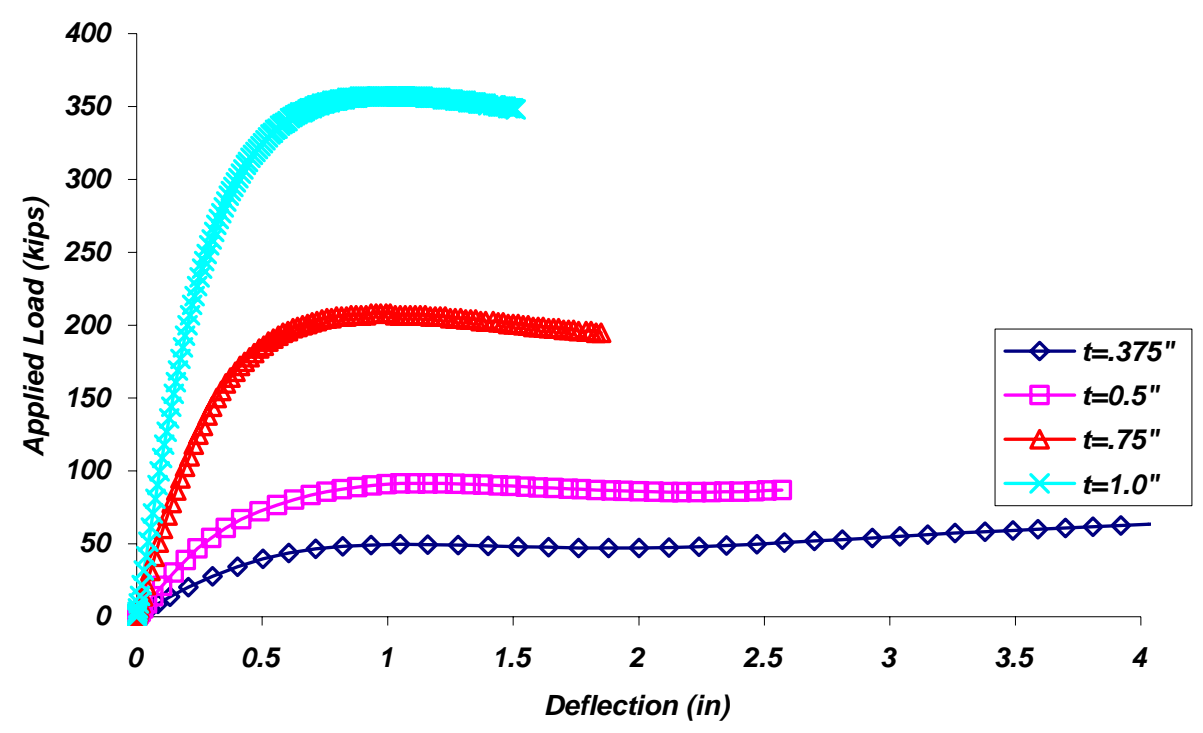

Figure 6-6: Axial load - deflection response for varying chord wall thickness (t)

\subsubsection{Chord Yield Strength (Fy) Study}

For this study, three (3) variations are analyzed with the chord yield strength "Fy" varied from 36 to $60 \mathrm{ksi}$ and the remaining parameters held constant. To maintain consistency, the material models are simplified to a bi-linear reponse in which the ratio of $\sigma_{\mathrm{u}} / \sigma_{\mathrm{y}}$ is held to a constant value 
of 1.25 and the maximum tensile strain $\varepsilon_{\mathrm{u}}$ is specified as $0.0171 \mathrm{in} / \mathrm{in}$ for definition of the plastic hardening for all cases. For this study, only three (3) variations are considered since these steel strengths should envelope most applications in HSS construction. The study parameters are summarized as follows:

\begin{tabular}{ll}
$\underline{F}_{\mathrm{y}}$ values: & Constants: \\
\hline 36 ksi & $\mathrm{D}=26 ”$ \\
$47 \mathrm{ksi}$ *Benchmark case & $\mathrm{h}=26 ”$ \\
$60 \mathrm{ksi}$ & $\mathrm{d}=10.15 ”$ \\
& $\mathrm{t}=0.5 ”$ \\
& $\mathrm{~A}=24.1 ”$ \\
& $\mathrm{~b}_{\mathrm{f}}=7.2 ”$ \\
& $\mathrm{~B}=24 ”$
\end{tabular}

The load-deflection results from each FEM analysis is shown in Figure 6-7. As expected, increasing the chord yield strength results in increased capacity.

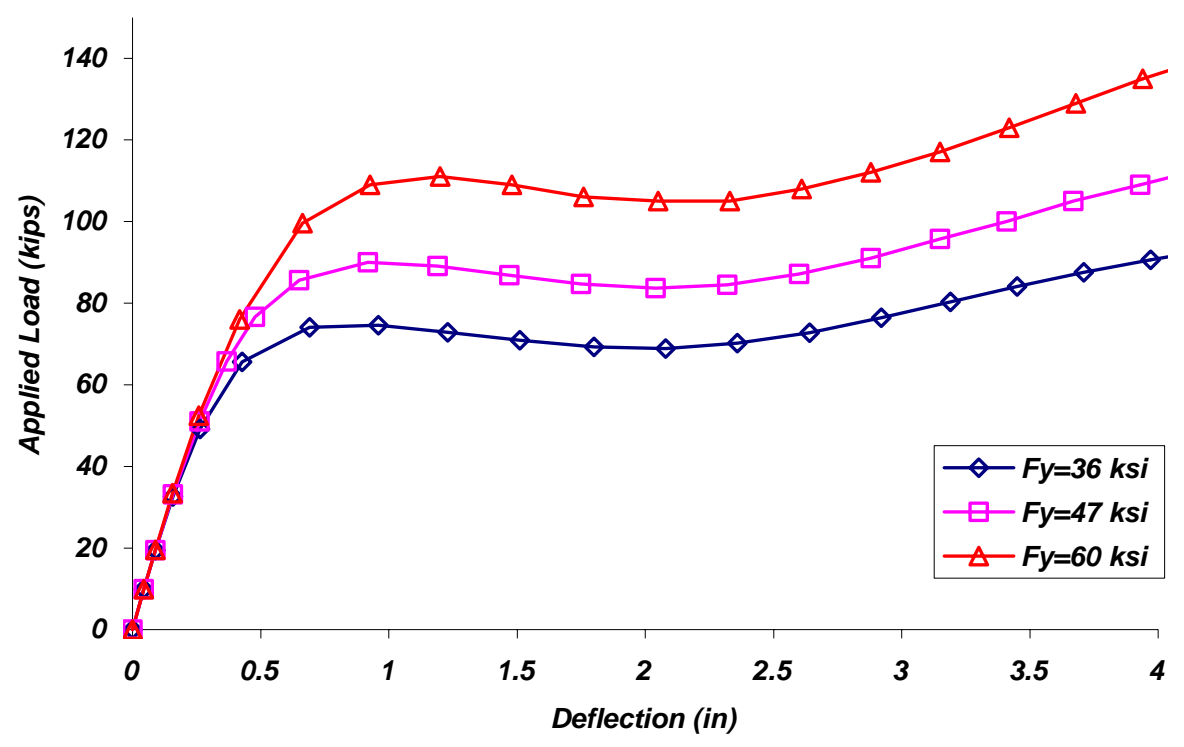

Figure 6-7: Axial load - deflection response for varying chord yield strength (Fy) 


\subsubsection{ST Depth (d) Study}

For this study, three (3) configurations are analyzed with the dimension "d" varied from 0 in. (no stem) to 26 in. (end distance, h) and the remaining parameters held constant. The study parameters are summarized as follows:

\begin{tabular}{ll} 
d values: & Constants: \\
\cline { 2 - 2 } 0” & $\mathrm{D}=26 ”$ \\
$10.15 ”$ *Benchmark case & $\mathrm{h}=26 ”$ \\
$26 ”$ & $\mathrm{~b}_{\mathrm{f}}=7.2 ”$ \\
& $\mathrm{t}=0.5 ”$ \\
& $\mathrm{~F}_{\mathrm{y}}=47 \mathrm{ksi}$ \\
$\mathrm{A}=24.1 ”$ \\
$\mathrm{~B}=24 ”$
\end{tabular}

The load-deflection results from each FEM analysis is shown in Figure 6-8. These responses show that the ST depth (d) does not have a significant impact on the overall capacity as seen by the similar response for the cases of $d=10.15$ in. and $d=26$ in. However, it is also observed that when there is no stem plate $(\mathrm{d}=0)$, a different failure mechanism is manifested. Thus, if there is no stem plate (i.e. a single transverse gusset plate), then the final capacity equation will not apply. As long as the intermediate branch member is an ST shape with a typical stem plate, then the depth (d) will not have a significant influence on the overall capacity. It should be noted that if the ST was rotated by 180 degrees with the stem facing toward the interior of the HSS, then increasing (d) would likely result in an increase of the capacity.

A summary of all the parametric study results for axial load is shown in Table 6-1. Each row lists the parameter values used in the individual FEM analyses and the resulting axial load capacity. Note that the parameter variations for each study group are shown in boldface type. The complete load-deflection data from each FEM analysis is also compiled and presented in Appendix A.

It should be noted that the bearing configuration under investigation includes a curved saddle bearing and a ST intermediate branch member, which may be considered to have limited applicability. Other bearing connection details may contain a flat bearing surface rather than a 
curved saddle bearing, an HSS intermediate branch member rather than an ST, or a branch member connected to the chord using a gusset plate. An attempt has been made to cover these related cases by selecting wide ranges in the parametric study (i.e. $A=0, b_{f}=0, d=0$ ). For an HSS intermediate branch member, the branch diameter can be substituted for the ST flange width $b_{f}$, which will produce a conservative result.

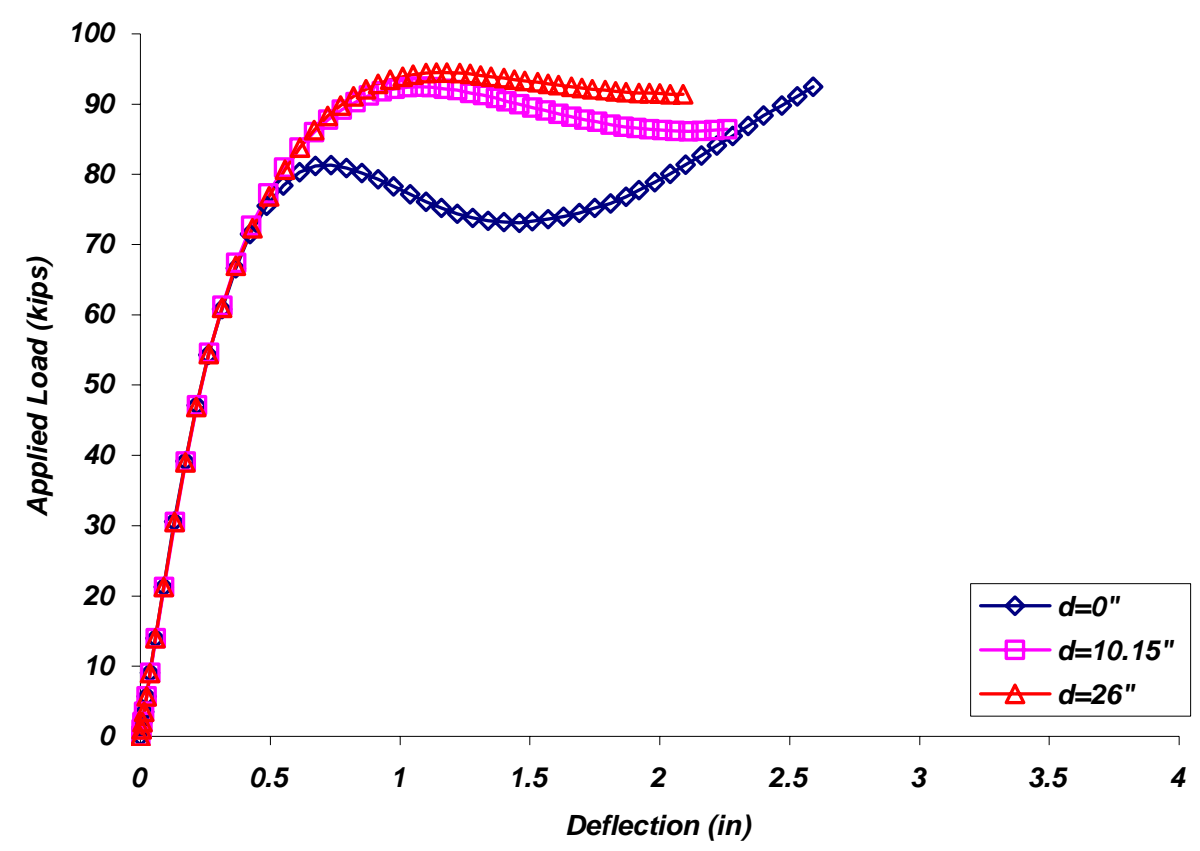

Figure 6-8: Axial Load - Deflection Response for varying ST depth (d) 
Table 6-1: Summary of Parametric Study Results for Axial Load

\begin{tabular}{|c|c|c|c|c|c|c|c|c|c|c|}
\hline$F_{y}$ & $\mathrm{t}$ & d & $D$ & $\mathrm{~h}$ & $h / D$ & A & $A / D$ & $b_{f}$ & $b_{f} / D$ & $\mathrm{P}_{\mathrm{u}}$ \\
\hline ksi & in & in & in & in & - & in & - & in & - & kips \\
\hline 47 & 0.5 & 10.15 & 26 & 6 & 0.231 & 24.1 & 0.927 & 7.2 & 0.277 & 37 \\
\hline 47 & 0.5 & 10.15 & 26 & 13 & 0.500 & 24.1 & 0.927 & 7.2 & 0.277 & 68 \\
\hline 47 & 0.5 & 10.15 & 26 & 26 & 1.000 & 24.1 & 0.927 & 7.2 & 0.277 & 92.2 \\
\hline 47 & 0.5 & 10.15 & 26 & 33 & 1.269 & 24.1 & 0.927 & 7.2 & 0.277 & 99.1 \\
\hline 47 & 0.5 & 10.15 & 26 & 39 & 1.500 & 24.1 & 0.927 & 7.2 & 0.277 & 100 \\
\hline 47 & 0.5 & 10.15 & 26 & 52 & 2.000 & 24.1 & 0.927 & 7.2 & 0.277 & 100 \\
\hline 47 & 0.5 & 10.15 & 26 & 26 & 1.000 & 24.1 & 0.927 & 0 & 0.000 & 66.7 \\
\hline 47 & 0.5 & 10.15 & 26 & 26 & 1.000 & 24.1 & 0.927 & 3.9 & 0.150 & 77.5 \\
\hline 47 & 0.5 & 10.15 & 26 & 26 & 1.000 & 24.1 & 0.927 & 7.2 & 0.277 & 92.2 \\
\hline 47 & 0.5 & 10.15 & 26 & 26 & 1.000 & 24.1 & 0.927 & 11.7 & 0.450 & 124 \\
\hline 47 & 0.5 & 10.15 & 26 & 26 & 1.000 & 24.1 & 0.927 & 15.6 & 0.600 & 160 \\
\hline 47 & 0.5 & 10.15 & 10 & 10 & 1.000 & 9.27 & 0.927 & 2.7 & 0.270 & 93.2 \\
\hline 47 & 0.5 & 10.15 & 14 & 14 & 1.000 & 12.98 & 0.927 & 3.78 & 0.270 & 92.8 \\
\hline 47 & 0.5 & 10.15 & 20 & 20 & 1.000 & 18.54 & 0.927 & 5.4 & 0.270 & 92.3 \\
\hline 47 & 0.5 & 10.15 & 26 & 26 & 1.000 & 24.1 & 0.927 & 7.2 & 0.277 & 92.2 \\
\hline 47 & 0.5 & 10.15 & 26 & 26 & 1.000 & 0 & 0.000 & 7.2 & 0.277 & 55 \\
\hline 47 & 0.5 & 10.15 & 26 & 26 & 1.000 & 7.6 & 0.292 & 7.2 & 0.277 & 63 \\
\hline 47 & 0.5 & 10.15 & 26 & 26 & 1.000 & 14.54 & 0.559 & 7.2 & 0.277 & 71.7 \\
\hline 47 & 0.5 & 10.15 & 26 & 26 & 1.000 & 24.1 & 0.927 & 7.2 & 0.277 & 92.3 \\
\hline 47 & 0.5 & 10.15 & 26 & 26 & 1.000 & 26 & 1.000 & 7.2 & 0.277 & 103 \\
\hline 47 & 0.375 & 10.15 & 26 & 26 & 1.000 & 24.1 & 0.927 & 7.2 & 0.277 & 49.6 \\
\hline 47 & 0.5 & 10.15 & 26 & 26 & 1.000 & 24.1 & 0.927 & 7.2 & 0.277 & 91.5 \\
\hline 47 & 0.75 & 10.15 & 26 & 26 & 1.000 & 24.1 & 0.927 & 7.2 & 0.277 & 208 \\
\hline 47 & 1 & 10.15 & 26 & 26 & 1.000 & 24.1 & 0.927 & 7.2 & 0.277 & 357 \\
\hline 36 & 0.5 & 10.15 & 26 & 26 & 1.000 & 24.1 & 0.927 & 7.2 & 0.277 & 74.6 \\
\hline 47 & 0.5 & 10.15 & 26 & 26 & 1.000 & 24.1 & 0.927 & 7.2 & 0.277 & 90 \\
\hline 60 & 0.5 & 10.15 & 26 & 26 & 1.000 & 24.1 & 0.927 & 7.2 & 0.277 & 111 \\
\hline 47 & 0.5 & 0 & 26 & 26 & 1.000 & 24.1 & 0.927 & 7.2 & 0.277 & 81.3 \\
\hline 47 & 0.5 & 10.15 & 26 & 26 & 1.000 & 24.1 & 0.927 & 7.2 & 0.277 & 92.5 \\
\hline 47 & 0.5 & 26 & 26 & 26 & 1.000 & 24.1 & 0.927 & 7.2 & 0.277 & 94.5 \\
\hline
\end{tabular}




\subsection{MOMENT STUDY}

Since the intermediate members of in-service tubular trusses typically have fixed-end moments present, the current portion of the parametric study is conducted for determining the capacity of the bearing connection under the action of an applied moment. The moment is applied locally to the ST member and resisted by a force couple consisting of: 1) the reaction force at the saddle and 2) an internal "beam" shear force in the HSS chord.

This study is somewhat simplified as compared to the axial load investigation. For an applied moment in the direction of the HSS end, the stress contours at failure are as shown in Figure 6-9. It can be seen that the yield zones are much more concentrated than those observed

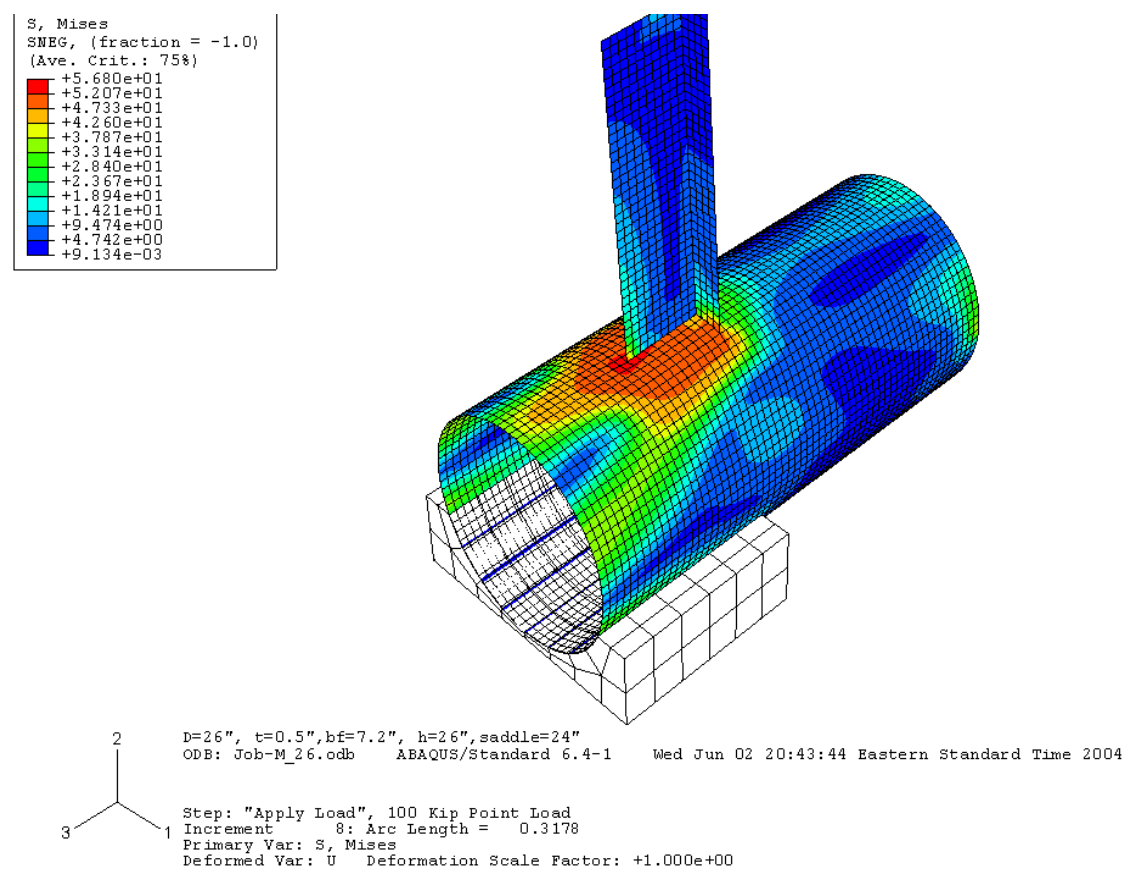

Figure 6-9: Von Mises Stress Contours for applied moment. 
for axial loading. Based on this and by analyzing a number of related configurations, it is determined that the moment capacity of the system is not significantly impacted by the parameters $\mathrm{A}, \mathrm{h}$, or $\mathrm{b}_{\mathrm{f}}$. The failure mechanism occurs in the HSS chord wall locally around the tip of the ST stem and therefore the ST depth "d" essentially controls the capacity. As the depth "d" is increased, the chord wall stresses are reduced; thus increasing capacity.

The second difference from the axial load investigation is in the definition of capacity. Recall that for axial loading, the first peak in the load-deflection response was used as the nominal capacity of the system. For an applied moment, the moment-rotation response is somewhat different. In this case a subtle plateau is observed, but no distinctive peak is present. Therefore, a deformation limit state must be applied. It is decided that a limit will be placed on the rotation of 0.05 radians for determining the capacity. This is approximately the start of the plateau region, after a moderate amount of plastic deformation has occurred in the HSS chord wall.

As with axial loading, the compression case controls over the tension condition. That is, if the moment is applied toward the ST flange with the stem in tension, then a higher capacity will be observed. As before, this will be neglected and all capacities will be based on the ST stem in compression (i.e. moment applied toward the open end). This is reasonable since the fixed-end moments in HSS structures could be in either direction.

Since it is found that $\mathrm{A}, \mathrm{h}$, and $\mathrm{b}_{\mathrm{f}}$ all have a negligible impact on the moment capacity of the system, these components are removed from the study and a simplified structure is used for the analyses (see Figure 6-10). A series of models are constructed with the dimension "d" varied from 5 in. to $30 \mathrm{in}$. and the remaining parameters held constant. They are summarized as follows:

\begin{tabular}{|c|c|}
\hline d values: & Constants: \\
\hline 5” & $\mathrm{D}=26^{\prime \prime}$ \\
\hline $10 "$ & $\mathrm{t}=0.5^{\prime \prime}$ \\
\hline $\begin{array}{l}20 " \\
30 "\end{array}$ & $\mathrm{~F}_{\mathrm{y}}=47 \mathrm{ksi}$ \\
\hline
\end{tabular}

The moment-rotation results from each FEM analysis is shown in Figure 6-11. As expected, the capacity is increased as the plate depth (d) increases. 


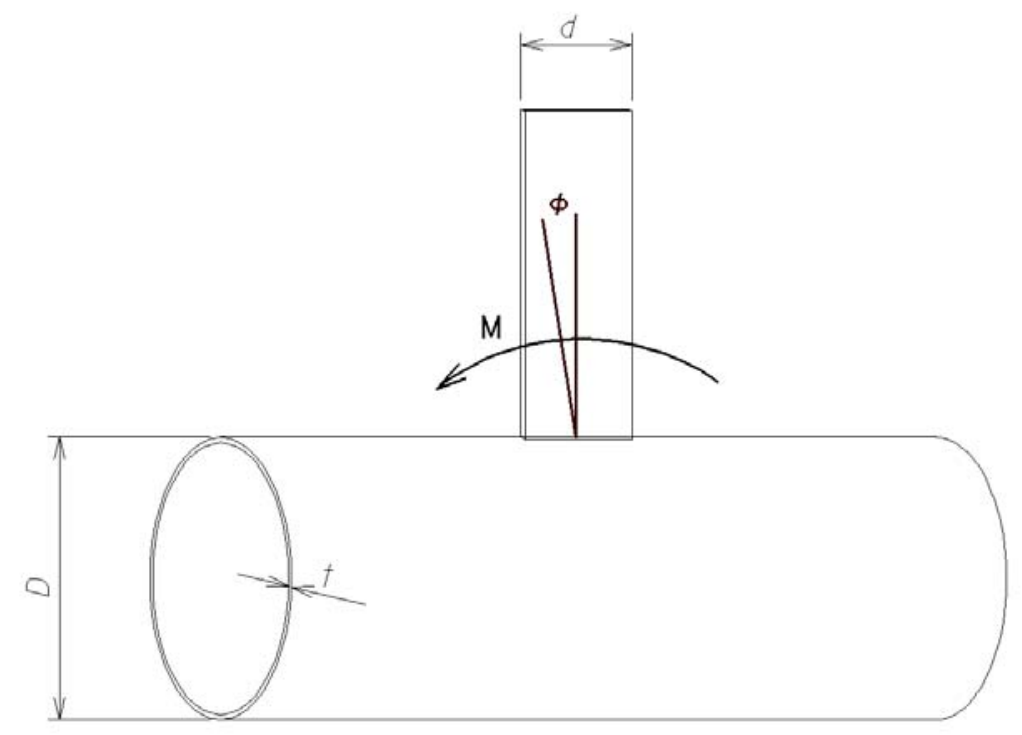

Figure 6-10: Parameters considered for Moment Study.

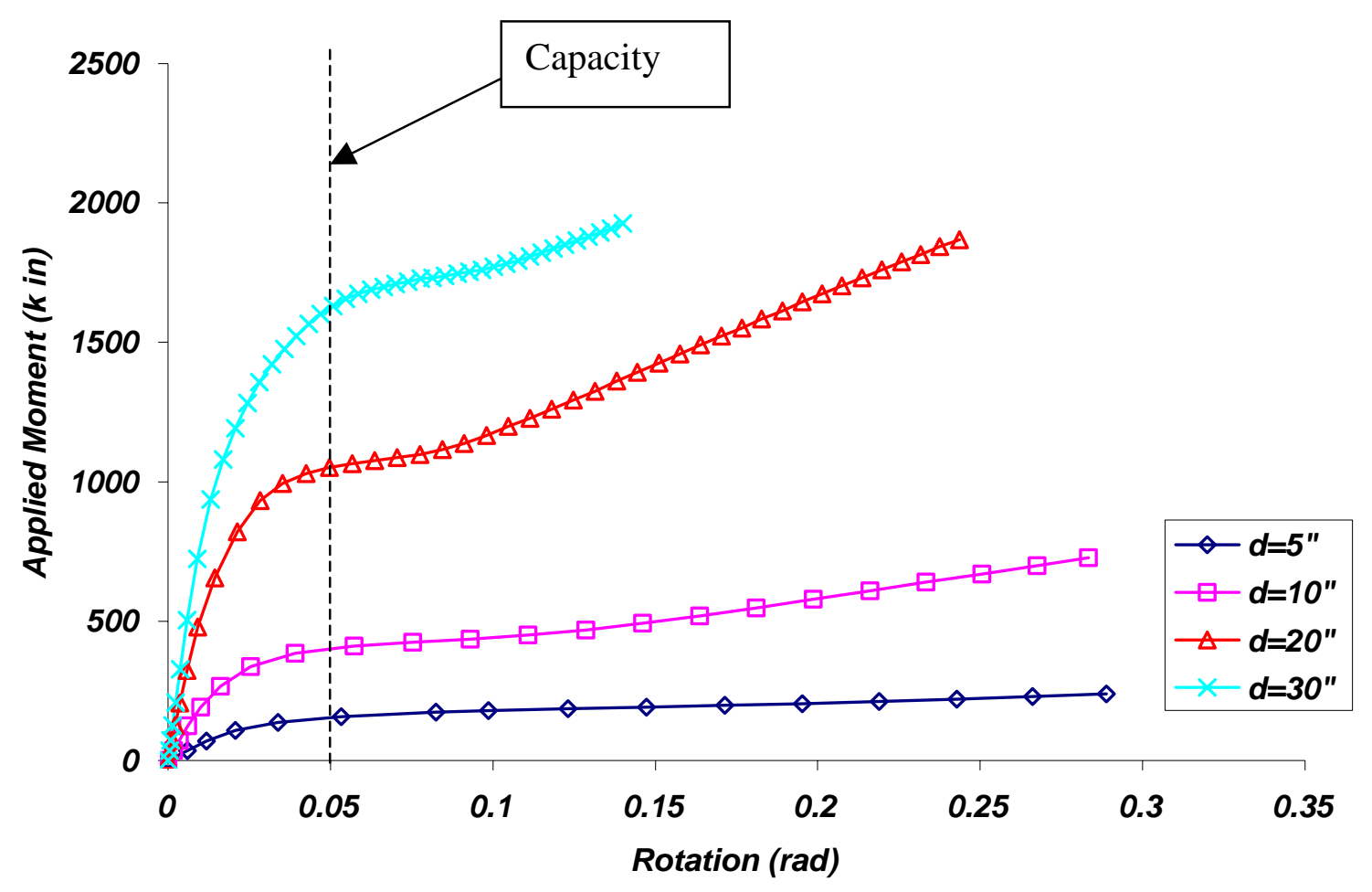

Figure 6-11: Moment-Rotation Response for Applied Moment 
To determine whether the HSS chord diameter influences the moment capacity, three (3) additional configurations are analyzed with $\mathrm{D}=10$ in. They are:

\begin{tabular}{ll} 
d values: & Constants: \\
\cline { 2 - 2 } "” & $\mathrm{D}=10 ”$ \\
$10 ”$ & $\mathrm{t}=0.5 ”$ \\
$20 ”$ & $\mathrm{~F}_{\mathrm{y}}=47 \mathrm{ksi}$
\end{tabular}

For efficiency, it is decided that it is unnecessary to carry out another study on the influence of the parameters $t$ and $F_{y}$, which was done for the axial load study. Since it is known that the failure mechanism is a classic case of a yield line mechanism based on the stress contours observed in Figure 6-9, then the capacity will be directly proportional to $\mathrm{F}_{\mathrm{y}}$ and $\mathrm{t}^{2}$. This will be confirmed in the formulation of the capacity equations in the next chapter.

The results of all analyses are summarized in Table 6-2. Each row lists the parameter values used in the individual FEM analyses and the resulting moment capacity based on the 0.05 radian rotation limit. Note that the parameter variations for each study group are shown in boldface type. The complete load-deflection data from each FEM analysis is also shown in Appendix B.

Table 6-2: Summary of Parametric Study results for applied moment

\begin{tabular}{|c|c|c|c|c|}
\hline$F_{\mathrm{y}}$ & $\mathrm{t}$ & $\mathrm{d}$ & $\mathrm{D}$ & $\mathrm{M}_{\mathrm{u}}{ }^{*}$ \\
\hline $\mathrm{ksi}$ & in & In & in & k in \\
\hline \hline 47 & 0.5 & $\mathbf{5}$ & 26 & 154 \\
\hline 47 & 0.5 & $\mathbf{1 0}$ & 26 & 400 \\
\hline 47 & 0.5 & $\mathbf{2 0}$ & 26 & 1051 \\
\hline 47 & 0.5 & $\mathbf{3 0}$ & 26 & 1624 \\
\hline & & & & \\
\hline 47 & 0.5 & $\mathbf{5}$ & 10 & 198 \\
\hline 47 & 0.5 & $\mathbf{1 0}$ & 10 & 554 \\
\hline 47 & 0.5 & $\mathbf{2 0}$ & 10 & 1498 \\
\hline
\end{tabular}

*Using a 0.05 radian rotation limit. 


\subsection{AXIAL LOAD - MOMENT INTERACTION STUDY}

This study is conducted for quantifying the capacity of the bearing region when subjected to a combined axial load and moment. To begin, it is assumed that the primary demand likely to cause failure of an in-service bearing connection is the axial load. Thus, the general approach is to first apply a constant moment (within the moment capacity) to the joint and then apply the axial load to failure. This will reveal to what extent the axial capacity is reduced by the addition of a fixed-end moment and will be the basis of an interaction capacity equation. Only the benchmark case is considered, and it is assumed that the same capacity interaction applies to other bearing configurations.

For the benchmark case, the moment capacity is found to be 400 kip in (see Table 6-2). To explore the moment interaction range between 0 and 1.0, moment values of $0,100,200,300$, and $400 \mathrm{kip}$ in are considered. As described, the loading is applied in a two-step process: the constant moment is first applied and then the structure is loaded with an axial load to failure with the moment remaining constant. The resulting load-deflection response for each analysis is shown in Figure 6-12.

From the figure, first note that the case of $\mathrm{M}=0$ is the same case considered previously in the Axial Load Study, for which the capacity was determined to be $P_{u}=92.2$ kips. As the moments are introduced for the subsequent cases, the distinct peak in the load-deflection response curve disappears; a behavior consistent with the application of a simple moment observed previously. As before, a deflection limit must be utilized for establishing the capacity. It is decided that the deflection value corresponding to failure of the benchmark case $(M=0)$ will be used as the limit criterion for the subsequent cases. This deflection limit is determined to be 1.3 in. and is identified with a dotted line in Figure 6-12. From the load-deflection data, the remaining axial load capacities are determined to be as follows:

\begin{tabular}{ll}
$M($ k in) & $P_{u}$ (kips) \\
\hline 100 & 87.2 \\
200 & 78.4 \\
300 & 67.9 \\
400 & 56.7
\end{tabular}




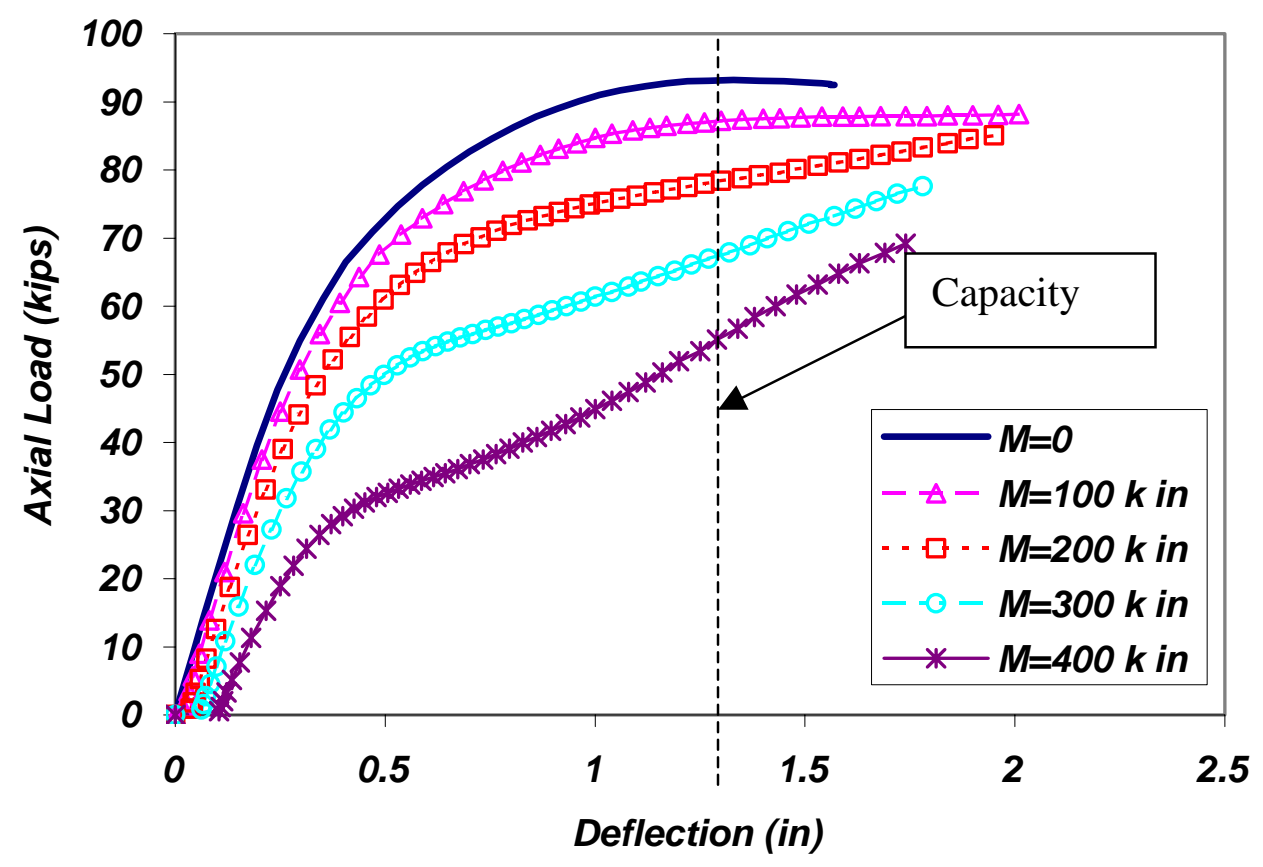

Figure 6-12: Axial load-deflection response with corresponding applied moment

\subsection{INTERIOR ST-TO-HSS JOINT STUDY}

Since no research has been found in the literature for the case of a simple interior ST-to-HSS joint, this case is considered so that recommendations can be made for these types of joints when located at the interior of a primary chord member. Also, the capacity will be compared to that provided by the bearing assembly at the chord end. A full parametric study for this related joint configuration is beyond the scope of this research, but a single case is carried out for the purposes mentioned. To this end, a simple interior ST joint is analyzed in two configurations: 1) T-connection and 2) Cross-connection. In both cases, the branch member is an ST10x48 and the chord member is a 0.5 in. x 26 in. diameter HSS. The resulting von Mises stress contours for each analysis are shown in Figure 6-13 and Figure 6-14 and the load-deflection response for each is shown in Figure 6-15. The results indicate the capacity is 95.4 kips for the T-Connection and 86.2 kips for the Cross-Connection. 

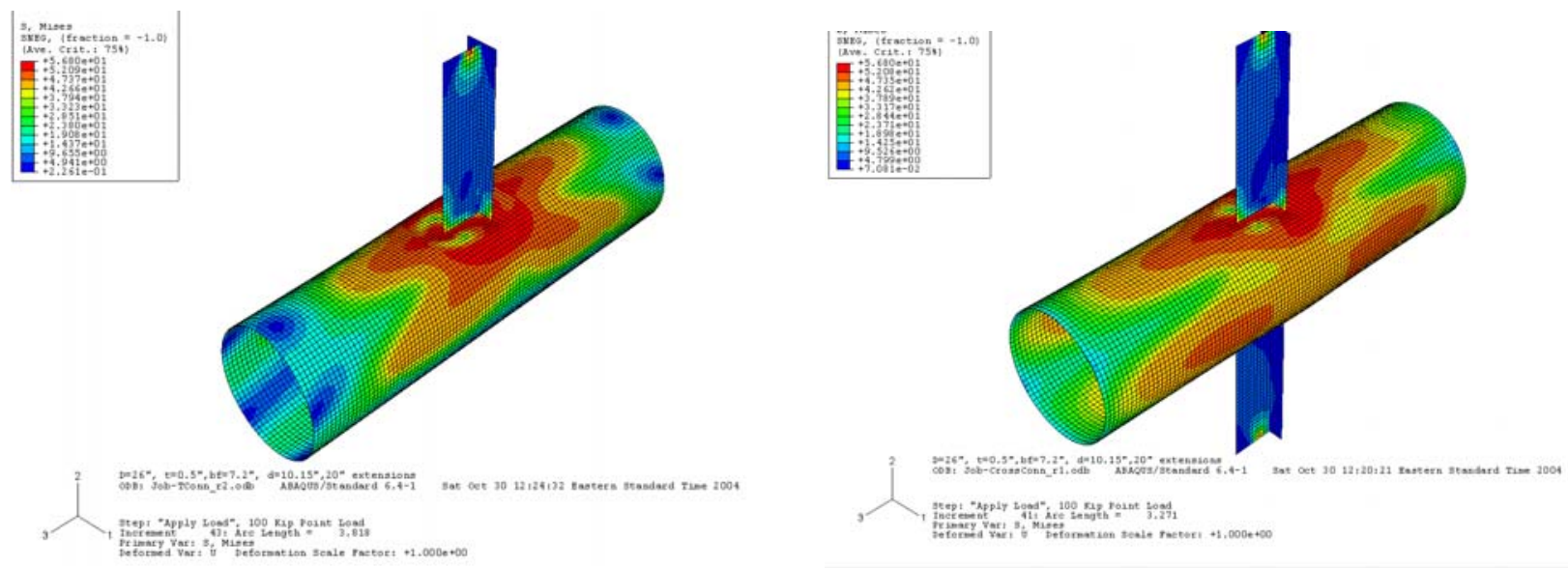

Figure 6-13: Interior ST-to-HSS T-Connection

Figure 6-14: Interior ST-to-HSS Cross-Connection

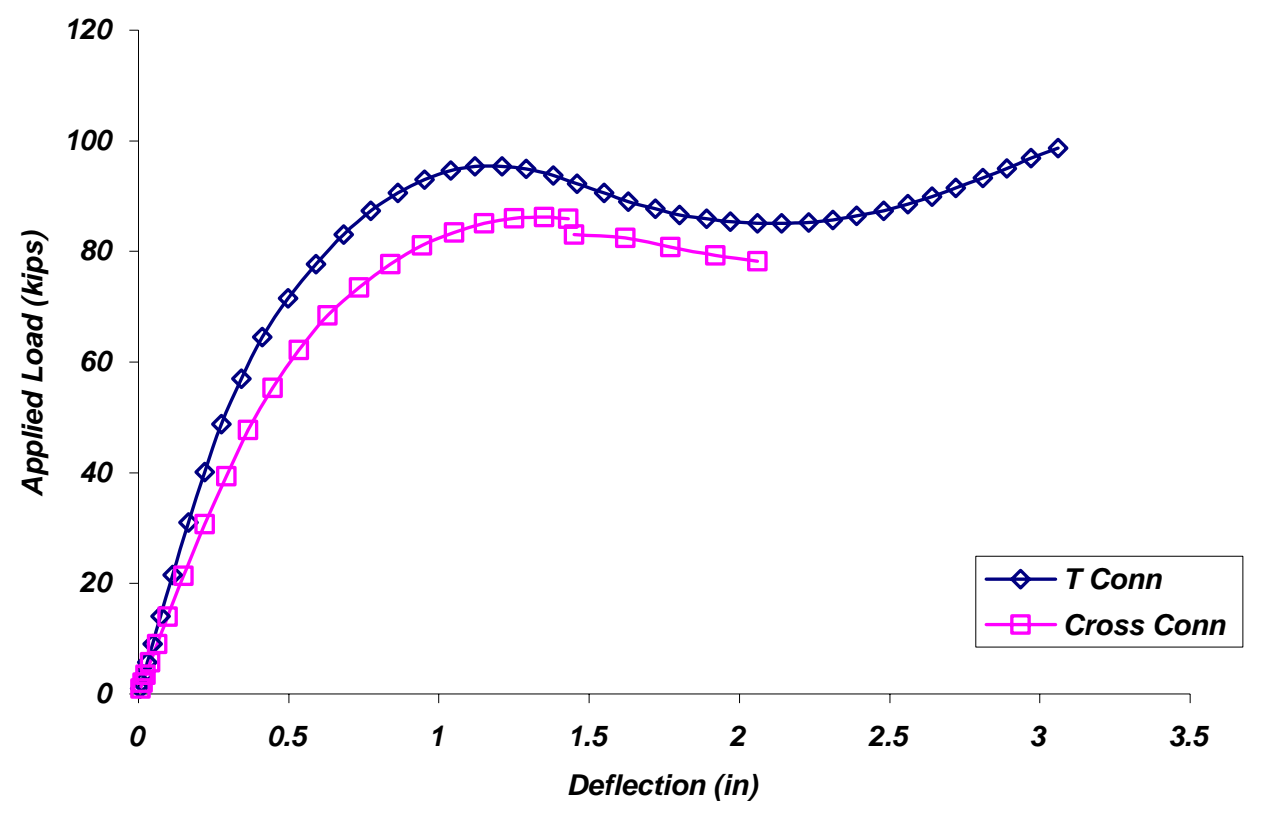

Figure 6-15: Axial load-deflection response for interior ST joints 


\subsection{DEVELOPMENT OF NEW BEARING CAPACITY EQUATIONS}

This chapter describes the development of new capacity equations for predicting the strength of the bearing connection region under the actions of axial force and moment. These equations are developed based on the results from the parametric studies reported on in Chapter 6.

\subsection{AXIAL LOAD CAPACITY EQUATION}

As discussed in Chapter 2, a common approach to developing a theoretical solution to the capacity of a tubular connection is the method of cutting sections, or the "ring model." The limitation of the ring model is that it generally works well only for symmetric connection geometries. For the bearing connection under investigation, there is very little symmetry due to the ST shape and vicinity to the open end of the HSS chord. Li and Earls (2002) applied a form of the ring model to this type of structure, but stopped short of calculating the effective width, which is where symmetry and empirical data is needed for completion of the analysis. For developing a capacity equation, the ring model philosophy will be used in a slightly modified form.

For development of an axial load capacity equation, we begin by studying the stress patterns in the HSS wall at failure (see Figure 7-1). It can be seen that there are yield lines present as indicated by the areas colored red. Based on these yield lines, two (2) distinct regions are identified and their rings are shown; one for the end region and one for the interior region. In the end region, the ring consists of five (5) yield lines: two at the tops of the saddle, one at the 


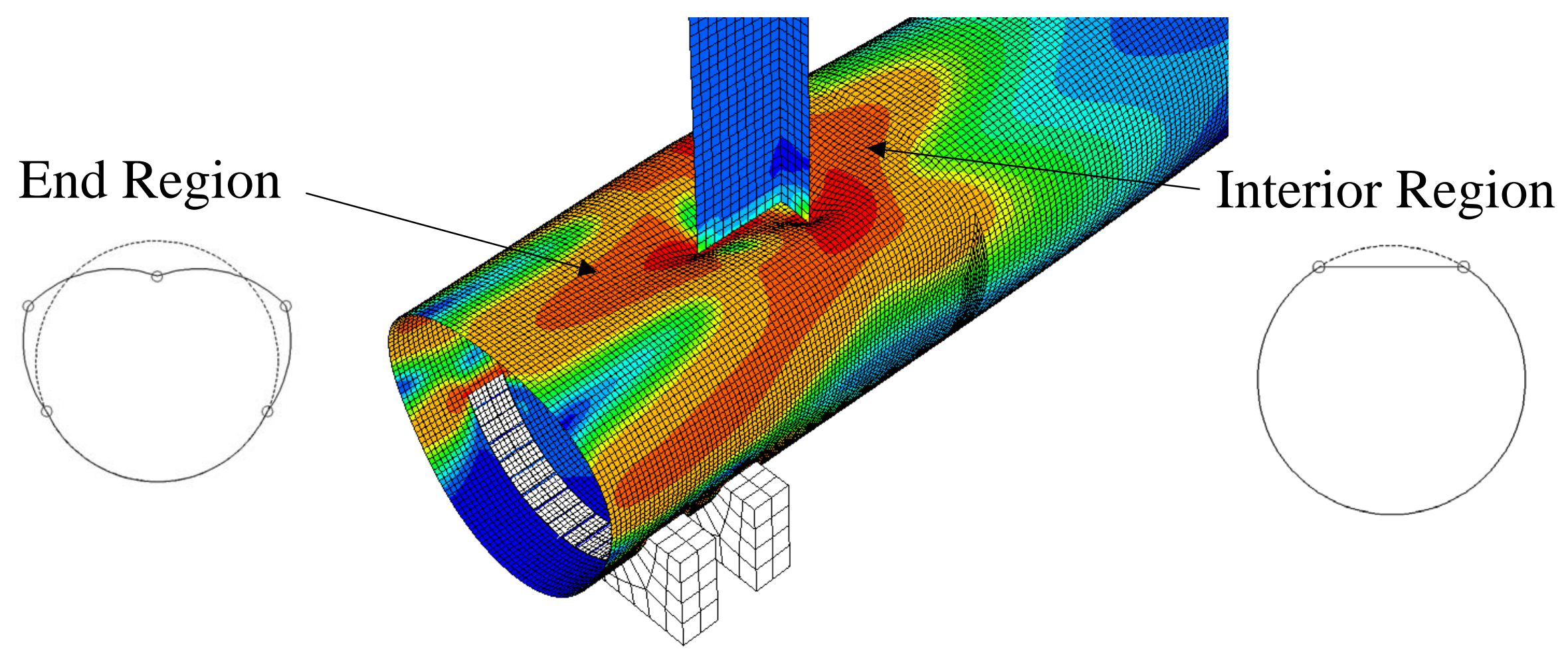

Figure 7-1: Yield Line Failure Mechanism for Bearing Connection Region 
apex of the HSS, and two at approximately midway between. This same ring is present in the entire region between the open end and the stem of the ST. That is, the yield line geometry is uniform throughout this region. This is the mechanism that Li and Earls (2002) proposed as the basis for an earlier version of a capacity equation. There is also a second zone where the ring mechanism is quite different; at the interior region. In this region, there exists essentially only one primary yield line that wraps around the flange of the ST and connects with the yield lines from the end region. These observations are used as the basis for the generalized capacity equation.

Since the observed mechanism of failure involves a distinct pattern of yield lines, it is surmised that the overall capacity will be some function of the unit flexural yield line capacity of the HSS chord wall. Based on simple plastic section analysis, the plastic moment resistance of the chord wall per unit length is equal to $\mathrm{F}_{\mathrm{y}} \mathrm{t}^{2} / 4$. Thus, the final capacity will be directly proportional to $\mathrm{F}_{\mathrm{y}}$ and $\mathrm{t}^{2}$. Based on the two distinct regions observed, it is also theorized that the total capacity will be the capacity of the end region plus the capacity of the interior region. It is further assumed that the end region capacity is influenced only by the parameters $\mathrm{A}$ and $\mathrm{h}$, and the interior region capacity is influenced only by the parameters $b_{f}$ and $h$. By normalizing these parameters to the HSS chord diameter “D”, the basic form of the capacity equation is stated:

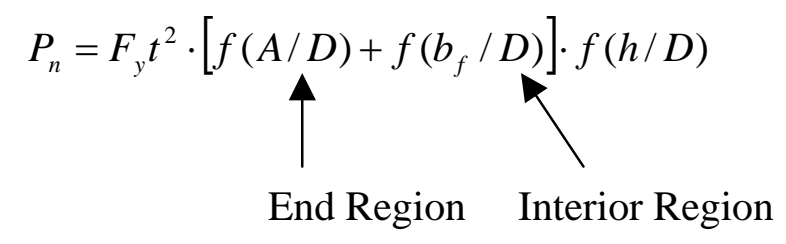

where $f(\alpha)$ are a series of functions to describe the geometry of the yield line mechanism. Assuming that quadratic functions are sufficient for this purpose yields functions of the form:

$$
f(\alpha)=C 1\left[1+C 2(\alpha)+C 3(\alpha)^{2}\right]
$$


where C1, C2, and C3 are constants that are to be determined using regression-type analysis on the parametric study data.

With the basic form of the equation in place and the unknown function constants established, a curve-fit analysis of the parametric study data is performed using a method of least squares. The results are summarized in Table 7-1. Using the quadratic form of the parameter functions yields a total of nine (9) constants that must be determined. However, C1 is unnecessary for both $f(A / D)$ and $f\left(b_{f} / D\right)$ since these constants can be combined with $C 1$ of $f$ (h/D). This reduces the total number of unknown constants to seven (7). While these constants are easily determined, this yields a capacity equation that is somewhat cumbersome for use in an engineering design application. Since combining the three equations from (7-2) into Eq (7-1) is impractical, the designer must calculate the three (3) functional values and then manually plug these into Eq (7-1).

Table 7-1: Quadratic Function Constants for Axial Load Capacity Equation

\begin{tabular}{|c|c|c|c|}
\hline Function & C1 & C2 & C3 \\
\hline $\mathrm{f}(\mathrm{A} / \mathrm{D})$ & - & 1.01 & 2.28 \\
\hline $\mathrm{f}\left(\mathrm{b}_{\mathrm{f}} / \mathrm{D}\right)$ & - & 4.17 & 13.0 \\
\hline $\mathrm{f}(\mathrm{h} / \mathrm{D})$ & 0.161 & 9.48 & -3.48 \\
\hline
\end{tabular}

In an attempt to simplify the capacity equation, reduced linear functions are also considered for $f(\alpha)$. Functions of the same form as Eq (7-2) are once again utilized, but with the quadratic term eliminated:

$$
f(\alpha)=C 1[1+C 2(\alpha)]
$$

As before, $\mathrm{C} 1$ is unnecessary for both $\mathrm{f}(\mathrm{A} / \mathrm{D})$ and $\mathrm{f}\left(\mathrm{b}_{\mathrm{f}} / \mathrm{D}\right)$ since these constants can be combined with $\mathrm{C} 1$ of $\mathrm{f}(\mathrm{h} / \mathrm{D})$. This reduces the total number of unknown constants to four (4). In this case, the same curve-fit solution approach applied previously is not used, since it is desired that the capacity equation predict a conservative value for all parameter ranges, not the mean. The approach taken is to minimize the errors by the method of least squares, while simultaneously 
applying a constraint that the capacity equation cannot produce an unconservative result. This is accomplished by using an optimization tool in Microsoft Excel called Solver $®$. Solver explores all of the possible options for the trial function constants that satisfy the constraints and minimize the residual errors. The resulting function constants are summarized in Table 7-2.

Table 7-2: Linear Function Constants for Axial Load Capacity Equation

\begin{tabular}{|l|c|c|c|}
\hline Function & C1 & C2 & C3 \\
\hline $\mathrm{f}(\mathrm{A} / \mathrm{D})$ & - & 7.23 & - \\
\hline $\mathrm{f}\left(\mathrm{b}_{\mathrm{f}} / \mathrm{D}\right)$ & - & 37.3 & - \\
\hline $\mathrm{f}(\mathrm{h} / \mathrm{D})$ & 0.104 & 2.58 & - \\
\hline
\end{tabular}

In this case, the functions of Eq (7-3) can be combined reasonably with Eq (7-1). By substitution, a stand-alone capacity equation for axial load is formulated:

$$
P_{n}=0.104 \cdot F_{y} t^{2} \cdot\left[2+7.23 \cdot(A / D)+37.3 \cdot\left(b_{f} / D\right)\right] \cdot[1+2.58 \cdot(h / D)]
$$

The nominal axial load capacities predicted by Eq (7-1) and Eq (7-4) along with the capacities obtained from the FEM analyses in the parametric studies are shown graphically in Figure 7-2 through Figure 7-6. It can be seen that Eq (7-1) correlates very well to the FEM results throughout. The simplified Eq (7-4) agrees reasonably well and produces a conservative prediction for capacity in all ranges.

Based on the parametric study results on the parameter "h" (see Table 6-1), it can be seen that the capacity of the bearing region is essentially the same for $\mathrm{h}=33$ in., 39 in., and 52 in. This indicates that if the ST is located at a distance of 33 in. (1.27D) or more, then the open end of the HSS chord no longer influences the capacity of the structure. To account for this, only the 


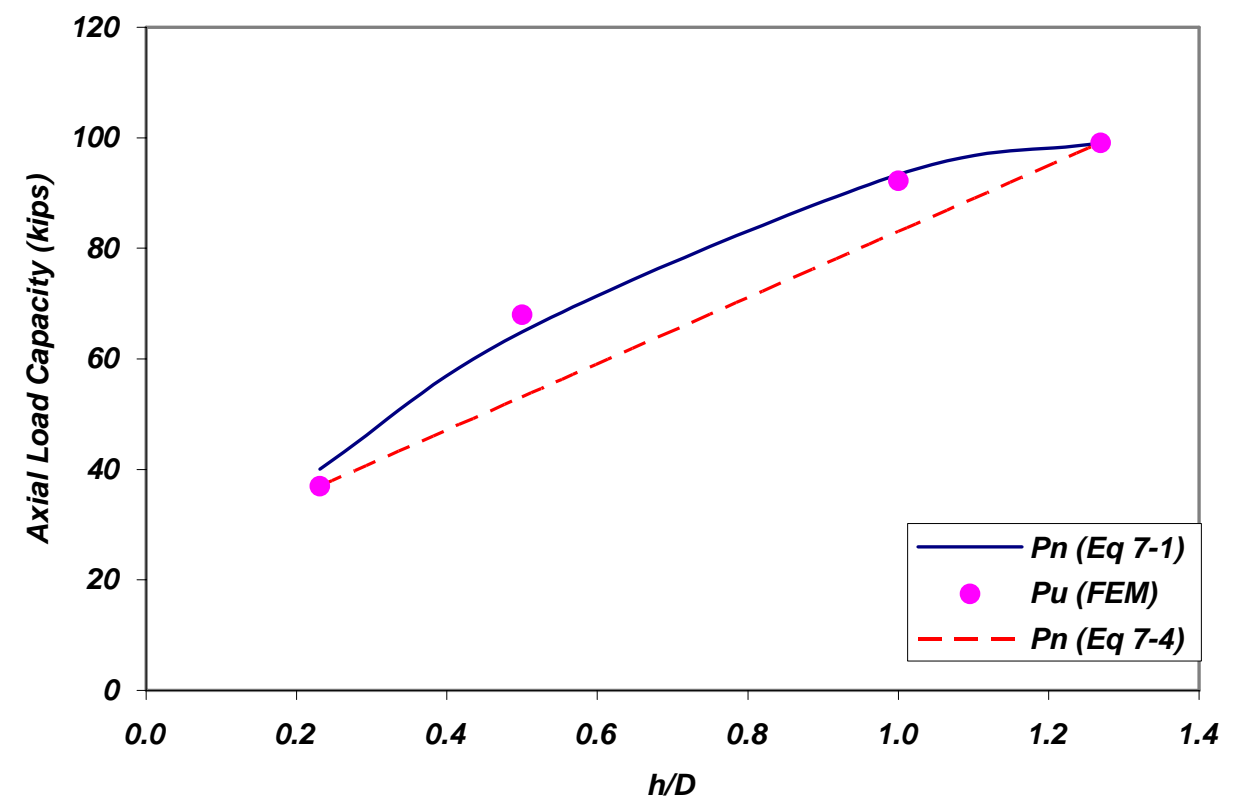

Figure 7-2: Axial load capacity vs. h/D

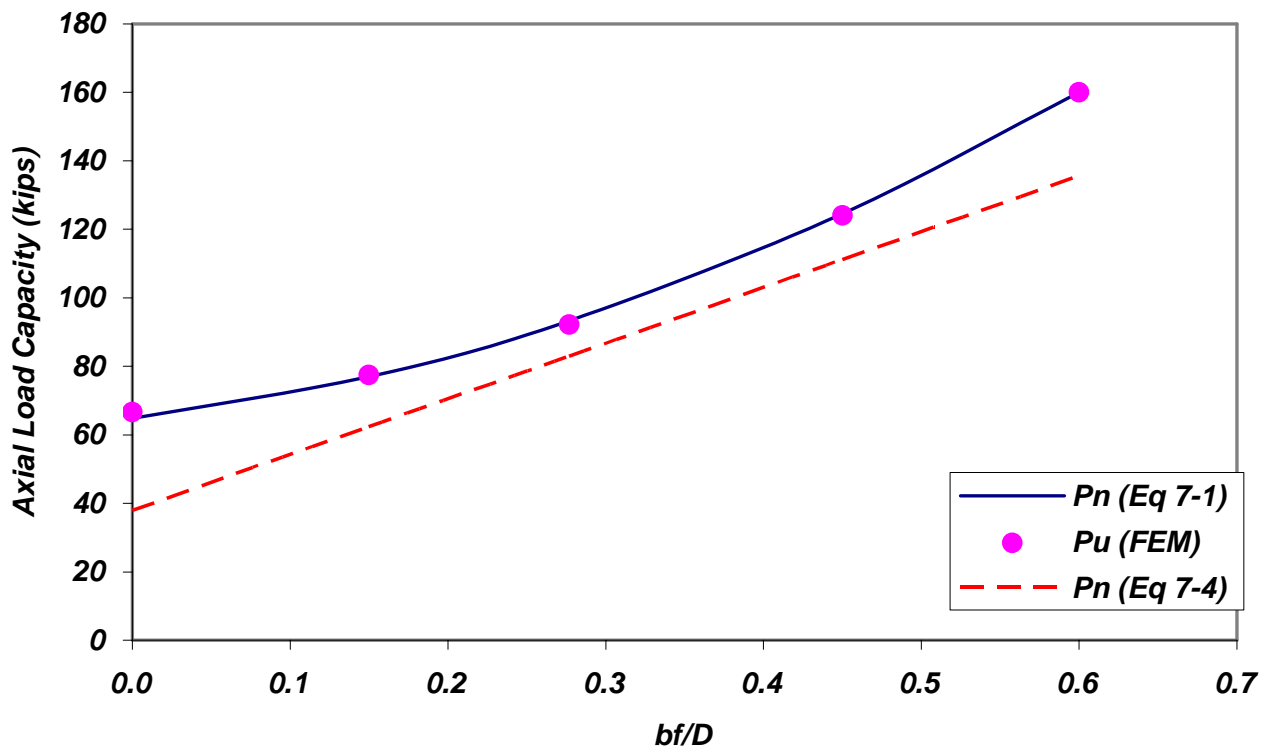

Figure 7-3: Axial load capacity vs. bf/D 


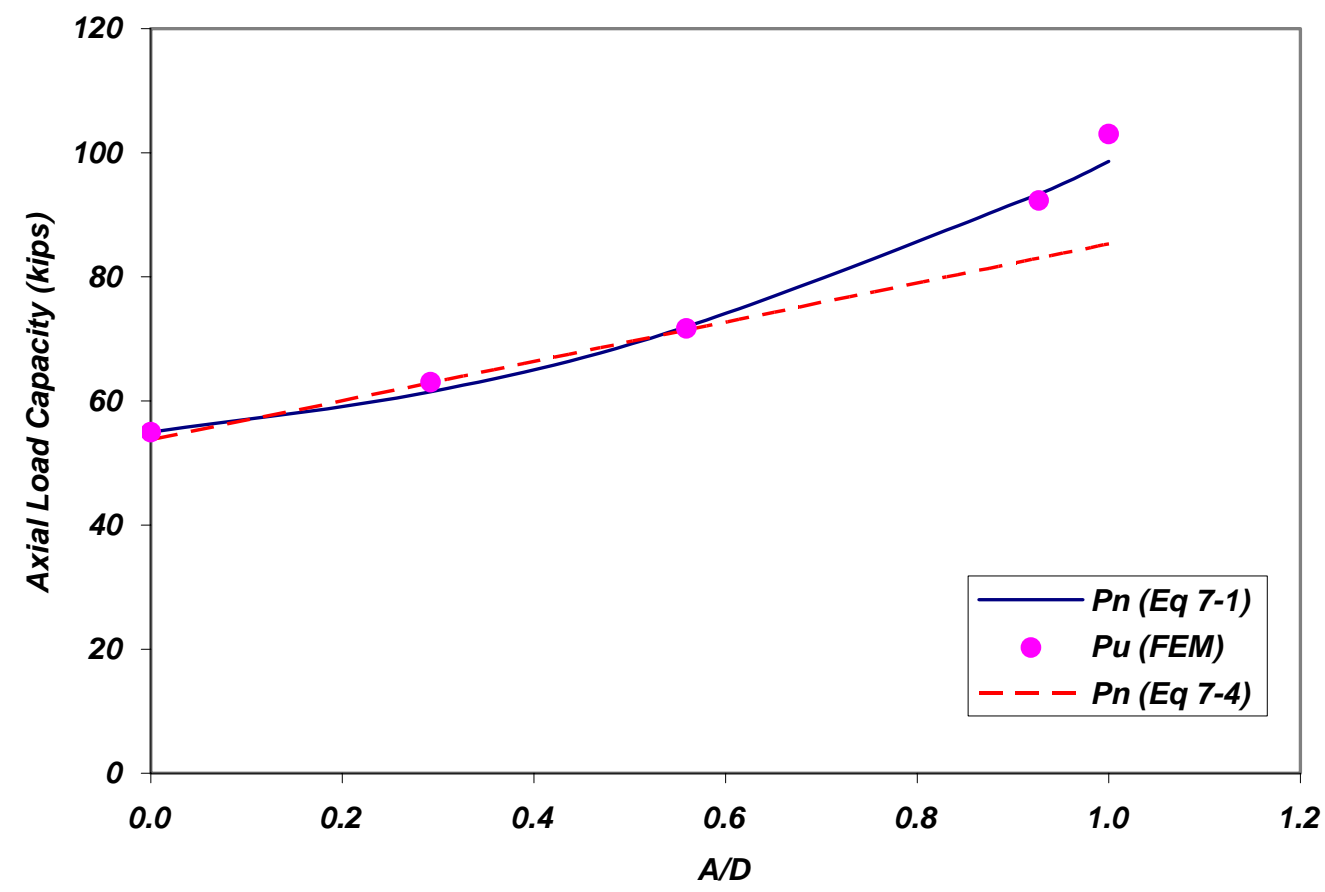

Figure 7-4: Axial load capacity vs. A/D

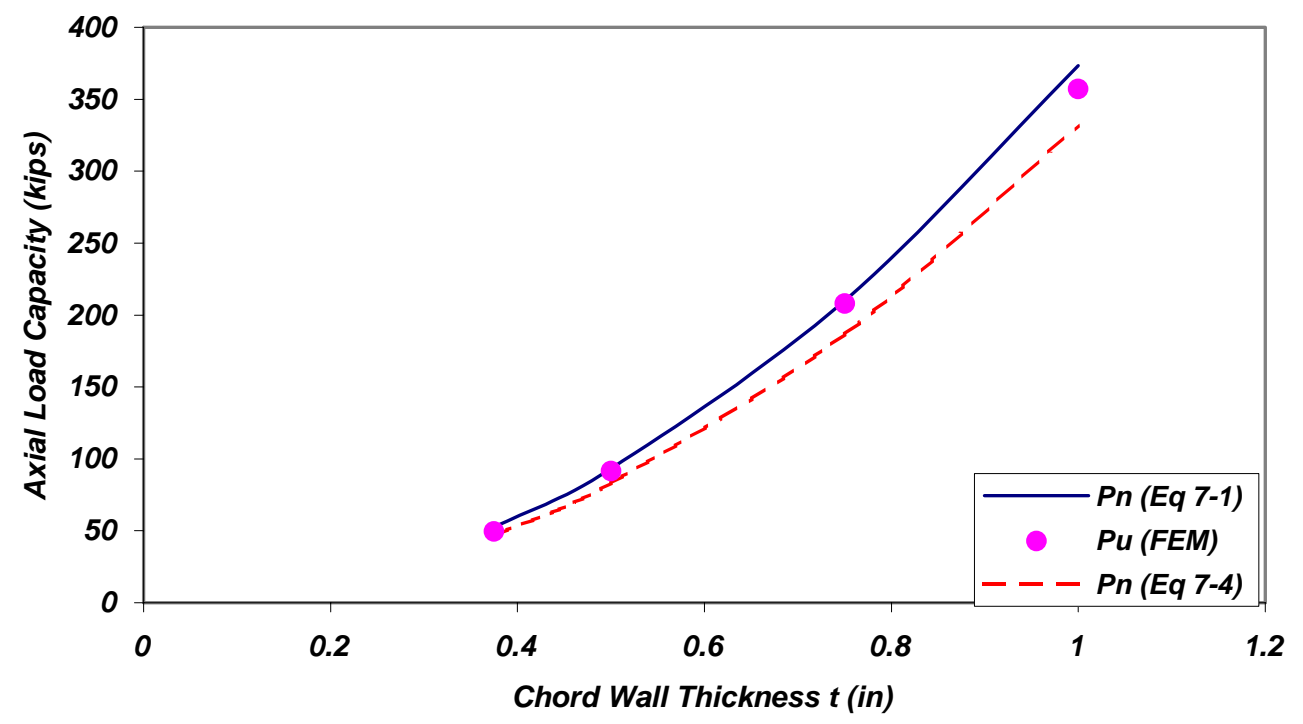

Figure 7-5: Axial load capacity vs. chord wall thickness (t) 


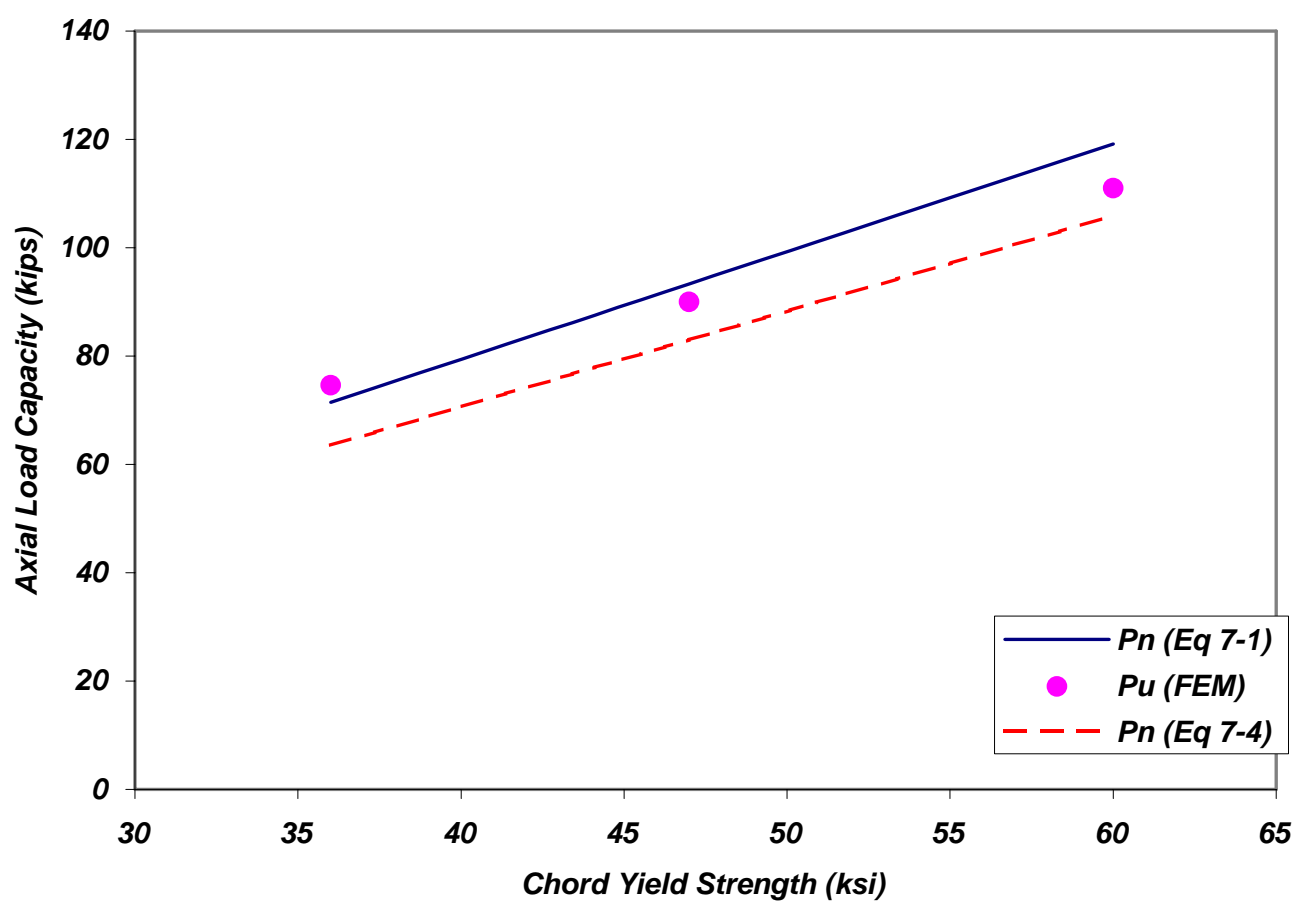

Figure 7-6: Axial load capacity vs. chord yield strength $\left(F_{y}\right)$

values of h less than 33 in. (1.25D) were included in the curve-fit analysis, and subsequent development of the capacity equation. For the case of h greater than $1.25 \mathrm{D}$, then $\mathrm{f}(\mathrm{h} / \mathrm{D})$ is a constant of 1.19 for the quadratic Eq (7-1) and 0.44 for the linear equation (7-4).

The parameter ranges that were studied should be noted, since these are typically used as limits of applicability in specifications. A full range of possible $h$ and A values were studied; no limit exists for these parameters. For the ST flange width $b_{f}$, the range of $0<b_{f} / D<0.6$ was studied, which is consistent with limits in the existing specifications. For the HSS chord diameter "D", values of 10 in. to 26 in. were considered, which should envelope most practical applications. Practical limits were also utilized for $t$, yielding a range for the wall stiffness ratio of $26<\mathrm{D} / \mathrm{t}<69$.

Another notable observation is that the overall capacity is most sensitive to the ST flange width bf, which is apparent by observing the relative magnitudes of the C2 constants in Table 7-1. Thus, an effective way to increase the bearing capacity is to utilize a larger width flange. 


\subsection{MOMENT CAPACITY EQUATION}

In developing a moment capacity equation for the bearing region, the solution is much simpler than the one required for axial loading. As discussed previously, the moment capacity of the system is not significantly impacted by the parameters $A, h$, or $b_{f}$; the stem plate depth of the ST essentially controls the capacity. Based on this finding, existing provisions that address the case of a moment applied to a single longitudinal plate are used and modified as needed. The simple case of a moment applied to a longitudinal plate is addressed in the Canadian HSS Design Guide (Packer and Henderson, 1997) with the following capacity equation (recast into a form that is consistent with the current nomenclature):

$$
M_{n}=5.0 \cdot F_{y} t^{2}(1+0.25 \cdot d / D) \cdot d
$$

The capacity predicted by Eq (7-5) is compared to the results from the analyses performed in the parametric studies (see Figure 7-7). It can be seen that Eq (7-5) predicts a consistently higher capacity than that observed from the FEM analyses, although the general trend of the curve follows the data. Recall that the nominal capacity determined from the analysis results was based on a limit on the rotation of 0.05 radians, which was somewhat subjective. This is likely not the same limit criterion that was used in the formulation of Eq (7-5). To develop an equation that agrees with the limit criterion of 0.05 radians, the constant term in Eq (7-5) is reduced from 5.0 to 3.5 , yielding:

$$
M_{n}=3.5 \cdot F_{y} t^{2}(1+0.25 \cdot d / D) \cdot d
$$


This equation is also compared to the FEM results in Figure 7-7. As shown, by simply adjusting the constant term, Eq (7-6) can be made to agree very well with the capacities indicated by the FEM analyses. It appears that the general form of this equation works for determining moment capacity, but the constant term may need adjustment based on the deformation limit specified by the designer.

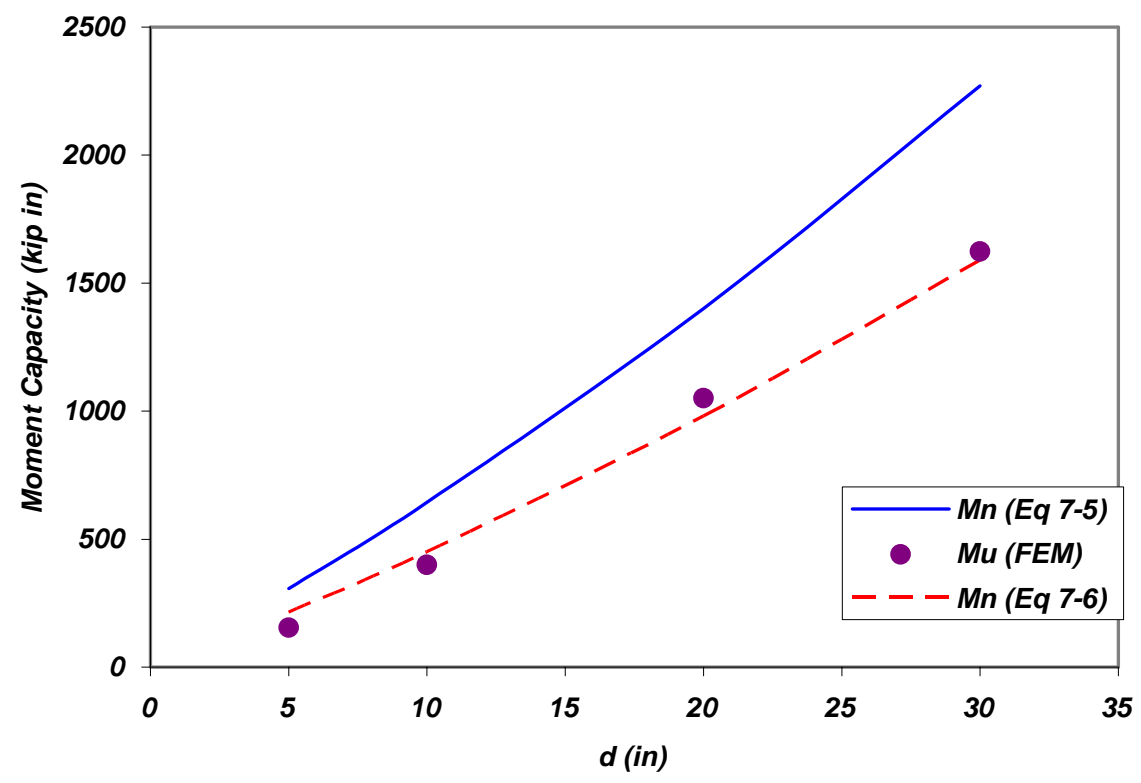

Figure 7-7: Moment capacity vs. plate depth (d)

\subsection{AXIAL LOAD - MOMENT INTERACTION EQUATION}

This section discusses the development of an interaction equation for the combined actions of axial load and moment, which may be present at an in-service bearing connection. The typical forms of interaction equations that are used are either linear or quadratic. Stamenkovic and Sparrow (1983) found that a linear interaction exists for simple HSS-to-HSS T-Connections. However, since a deformation limit has been placed on the moment capacity as described earlier, 
it is determined that a quadratic equation fits the data more reasonably. Thus, the following quadratic interaction equation is proposed:

$$
\left(P / P_{n}\right)^{2}+\left(M / M_{n}\right)^{2} \leq 1.0
$$

where $\mathrm{P}$ and $\mathrm{M}$ are the applied axial force and moment and $\mathrm{P}_{\mathrm{n}}$ and $\mathrm{M}_{\mathrm{n}}$ are the respective capacities. The results from the FEM analyses along with Eq (7-7) are shown in Figure 7-8. It is once again noted that the loading is applied in a non-proportional fashion in that a given moment of imposed and held constant while the axial force is permitted to grow until failure is achieved.

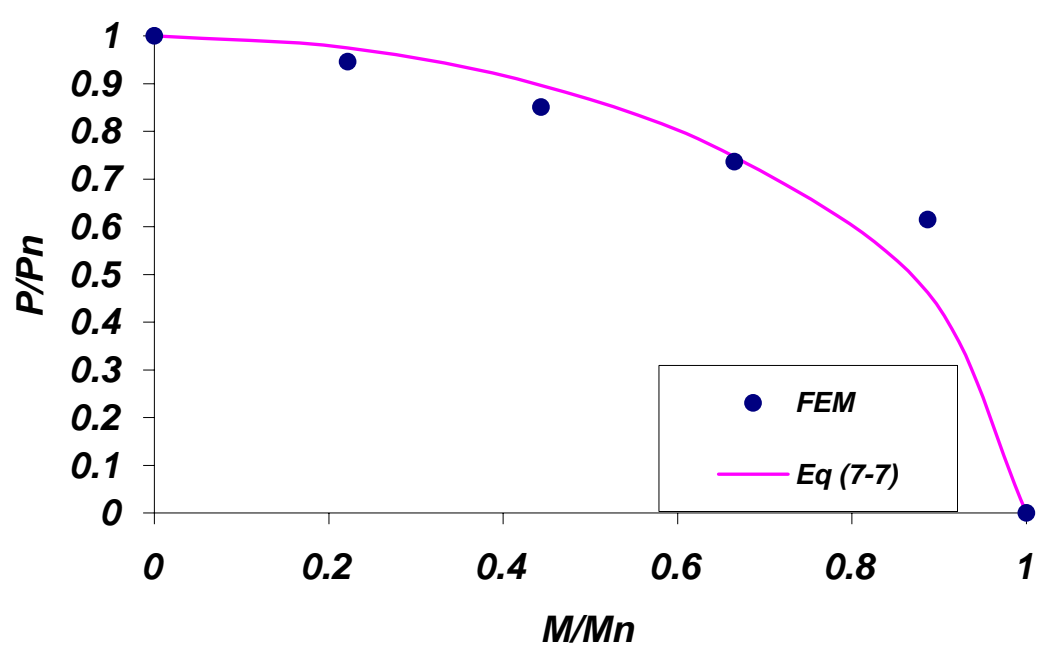

Figure 7-8: Axial load - moment interaction

\subsection{INTERIOR ST-TO-HSS JOINT CAPACITY}

Since a full parametric study has not been conducted for the interior ST-to-HSS joint, a new capacity equation is not developed. However, some general guidance can be offered for addressing these types of joints, if they are located sufficiently far from any chord end region. 
First, it is noted that the capacity of the T-Connection is shown to be 95.4 kips from Figure $6-15$, which is within $3 \%$ of the capacity for the benchmark case considered in the parametric study. Therefore, the notion that the ST-to-HSS joint is the "weak link" in the bearing connection region appears to be supported. Recall that this assumption was the basis of the development of the approximate methods in Chapter 4. Thus, to predict the capacity of an interior ST-to-HSS T-Connection, the methods described in Chapter 4 are applicable. However, these should be used with caution since they have not been fully verified for other geometric configurations.

For the ST-to-HSS Cross-Connection, a different failure mechanism is engaged as evident from the stress contours in Figure 6-14 and the different load-deflection response shown in Figure 6-15. This appears to be the limit state of general collapse that is found throughout the literature, in which the chord cross-section fails by excessive ovalization. Since this limit state is more global in nature, it should be less sensitive to the cross section geometry of the branch member. Thus, it is recommended that the equations as presented in the literature can be applied to this case. In calculating the $\beta$ ratio, the ST flange width $b_{f}$ should be used. 


\subsection{STRUCTURAL RELIABILITY CONSIDERATIONS}

Up to this point, the term "capacity" has been referring to the nominal strength of the connection, with no consideration of variability in geometric properties or material strength. However, in real structures variability in these properties do exist. Therefore, safety must added to the design process using a factor of safety (FS) in the context of an allowable stress design approach (ASD) or load/resistance factors in the context of the load and resistance factor design (LRFD) approach. In tubular connection design, since the capacity equations are typically formulated empirically, safety factors are typically based on statistical analysis of experimental test data.

This research uses experimental testing only to validate finite element modeling techniques, which are subsequently used for a parametric study. Statistical methods are utilized in the formulation of the capacity equations, but this is merely to obtain an accurate curve-fit to the analytical results. A conventional statistical analysis (linear regression, confidence limits, etc.) does not apply in this case since there is no scatter with analytical data other than minor errors introduced from any approximations in the capacity formulation. (Recall from Chapter 7 that the quadratic form of the capacity equations contain minimal errors with respect to the parametric study results and the linear form of the capacity equations contain only minor errors, which always add conservatism) Therefore, we look to related research for making recommendations with regard to safety in the proposed capacity equations.

The literature that addresses structural safety in tubular joint connections most thoroughly is AWS D1.1 Structural Welding Code - Steel (AWS 2004). In the commentary, the database of testing results used for development of the capacity equations of Section 2.24.1.1 for the limit state of ultimate plastic collapse is summarized in Figure C2.9. From the figure, it is observed that the mean SF of 2.44 is provided by the capacity equation. However, it is noted that this is

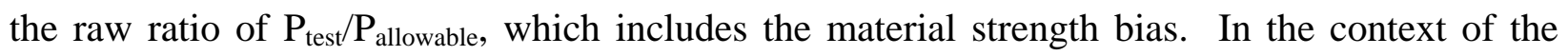
ASD method, the nominal SF that results is 1.8. When used in the context of LRFD, with a 
resistance factor or 0.8 , this is nominally equivalent to the ASD method for structures having $40 \%$ dead load and $60 \%$ service loads (AWS 2004).

For the bearing connection under investigation, the failure mechanism is also a form of plastic collapse, which is consistent with the limit state used as the basis of the safety recommendations in AWS. For this limit state, variations in the material yield strength $\left(F_{y}\right)$ and chord wall thickness (t) will dominate the uncertainty in the overall bearing capacity. That is, small variations (within the fabrication tolerances) in the other variables (D, A, $b_{f}, h$ ) will not have a significant impact on the capacity, and can be considered negligible. Thus, it is recommended that the same $\mathrm{SF}=1.8$ also be used for the capacity equations developed herein until further experimental testing is conducted. 


\subsection{SUMMARY AND CONCLUSIONS}

Existing design specifications used in North America and Europe do not directly treat the general limit state of local collapse of tubular truss chords at bearing supports, while a number of overhead highway sign structures in the U.S. have been shown to be inadequate for this limit state. There are published capacity equations provided for the connection type that is related to the deficient details in question in which a concentrated force is applied to an unstiffened HSS wall through a single gusset plate. Unfortunately, the specification guidance on this related case is based on very limited experimental testing. This dissertation research is aimed at quantifying the bearing strength of circular chords in long, simple-span tubular trusses. The following is a summary of the research findings:

1) Two identical full-scale experimental tests are conducted on the bearing connection region of a long-span tubular highway sign truss proportioned in a fashion that is consistent with U.S. design practice (as a matter of course, this leads to a connection detail which has been observed to be susceptible to bearing failure in field installations). The test specimen consists of a circular HSS chord of 26 in. outer diameter with a $1 / 2$ in. wall thickness and $7 \mathrm{ft}-6$ in. length. The chord is loaded to failure with an axial load applied through an ST10x48 strut connected at 90 degrees and bearing diretly on the HSS side wall through a full penetration weld made at a location 33 in. from the open end of the HSS section. The applied load is resisted by two curved steel "saddle" bearings. The objective of the experimental testing is to simulate the loading conditions present at the bearing region of an in-service long-span tubular truss. The results from these tests indicate that the ultimate bearing capacity is 96 kips for this configuration, but the load cuasing first yield is identified to be 40 kips.

2) Four (4) approximate methods are proposed for predicting the bearing capacity for the detail under investigation based on modified application of existing U.S. and international specifications. All of the proposed approximate methods provide a safe estimate of the bearing 
capacity as compared to the experimental results. However, the safety margins may be considered too low, depending on the application.

3) Finite element modeling techniques are developed and validated using the experimental test results including deflection measurements and strain gauge data. Agreement between the experimentally measured response and the response of the finite element analogs is deemed reasonable to enable a parametric study to proceed. As part of these verified modeling techniques, linearly interpolated, quadrilateral shell elements based on a general-purpose formulation and reduced integration are employed as the primary finite element type for modeling of the structure under investigation. Since the demands on the shell are mostly flexural, this problem could be solved adequately using a simplified thin shell element. However, a general-purpose element that is able to consider finite membrane strains displays a slightly better agreement with experimental results. A simplified boundary condition at the saddle bearings, as opposed to a true contact interaction, is sufficiently accurate for modeling of this structure. Tubular (HSS) members have somewhat loose dimensional tolerances governing their manufacturing and also contain significant residual stresses as a result of the manufacturing processes; both require that analytical modeling of the steel material properties be done with great care. Useful approaches to treating these unique challenges are proven to be successful in the work reported herein.

4) The experimentally verified nonlinear finite element modeling techniques are used to perform a parametric study on all parameters relevant to the overall bearing capacity: $h, b_{f}, A, D$, $\mathrm{t}, \mathrm{F}_{\mathrm{y}}$. Analyses are conducted to observe the following: 1) the bearing capacity of the HSS chord under the action of an axial load/reaction force (P), 2) the flexural capacity of the HSS chord wall under the action of a locally applied moment (M) and 3) the capacity of a combined axial load and moment. The results indicate that the open end of the chord no longer influences the failure mechanism once the intermediate branch member is located at a distance $33 \mathrm{in} .(1.27 * \mathrm{D})$ or more from the end. It is determined that the moment capacity of the connection is not significantly impacted by the parameters $\mathrm{A}$, $\mathrm{h}$, or $\mathrm{b}_{\mathrm{f}}$. 
5) Capacity equations are developed for axial loading (P), moment (M), and interaction of both $(\mathrm{P}+\mathrm{M})$. For axial loading, the global failure mechanism observed in both the experimental tests and the finite element analysis involves a flexural collapse of the HSS chord through plastification of the chord wall into a well-defined yield line mechanism. However, the yield line patterns in this case cannot be described with simple geometry. Thus, quadratic functions are used for formulating the capacity equations, which are solved for by a regressiontype curve-fit procedure. Due to the complexity of the final axial load capacity equations, two (2) equations are developed: one complex version yielding the more accurate capacity prediction and one simplified version for easy design office use. The moment capacity equation is a modified version of an existing published equation based on the deformation limit selected. The interaction behavior can be described in this case by a classic quadratic interaction equation.

6) The bearing configuration considered in this research includes a curved saddle bearing and a ST intermediate branch member, which may be considered to have limited applicability. Other bearing connection details may contain a flat bearing surface rather than a curved saddle bearing, a HSS intermediate branch member rather than an ST, or a branch member connected to the chord using a gusset plate. An attempt has been made to address these related cases by selecting wide ranges in the parametric study (i.e. $A=0, b_{f}=0, d=0$ ). For an HSS intermediate branch member, the branch diameter can be substituted for the ST flange width $b_{f}$, which will produce a conservative result.

7) The parameter ranges that are considered herein are consistent with geometric limits of applicability currently indentified by the dominant design specifications. A full range of possible $\mathrm{h}$ and A values are studied; no limit is needed for these parameters. For the ST flange width $\mathrm{b}_{\mathrm{f}}$, the range of $0<b_{f} / D<0.6$ is studied. For the HSS chord diameter " $D$ ", values of 10 in. to 26 in. are considered, which should envelope most practical applications. Practical limits are also utilized for $\mathrm{t}$, yielding a range for the wall stiffness ratio of $26<\mathrm{D} / \mathrm{t}<69$. 


\subsection{RECOMMENDATIONS FOR FUTURE RESEARCH}

Based on the scope of this research, the following recommendations for further study are made:

1) Additional experimental testing should be conducted to further validate the proposed capacity equations. Also, instrumentation of in-service trusses should be conducted to verify the load paths and stress fields present in the bearing connection region.

2) Further statistical analysis should be conducted for quantifying the structural safety provided by the bearing connection studied. As part of this, applied loading in overhead sign structures should be studied with respect to reaction forces such that the safety index can be evaluated for the contextual basis at issue.

3) A survey of different bearing connection details utilized throughout the world should be conducted and any necessary modifications to the proposed capacity equations should be explored.

4) This research is focused on the limit state of ultimate plastic collapse and is not concerned with magnitudes of elastic stresses. However, it is noted that "hot spot" stresses do exist in the chord wall at the tips of the ST flange. The potential for low-cycle and high-cycle fatigue problems at these locations should be investigated.

5) For slender chord bearing connections, stiffening measures should be designed and analyzed, especially for flat-plate bearing details. 


\section{APPENDIX A}

\section{LOAD-DEFLECTION DATA FROM AXIAL LOAD STUDY FEM ANALYSES.}

This appendix presents the status report (.STA) files from the FEM analyses using ABAQUS, which shows in detail the incremental load-deflection data used for determination of the bearing connection capacity in the parametric study. A concentrated load (P) is applied to the CG of the ST and the deflection of this point is monitored. Column 7 of the .STA file reports the Load Proportionality Factor (LPF) and Column 9 reports the DOF monitor. The applied load specified for all models is 100 kips, thus the load at a given increment equals LPF x 100 kips. The capacity load/deflection for each analysis is shown in boldface type.

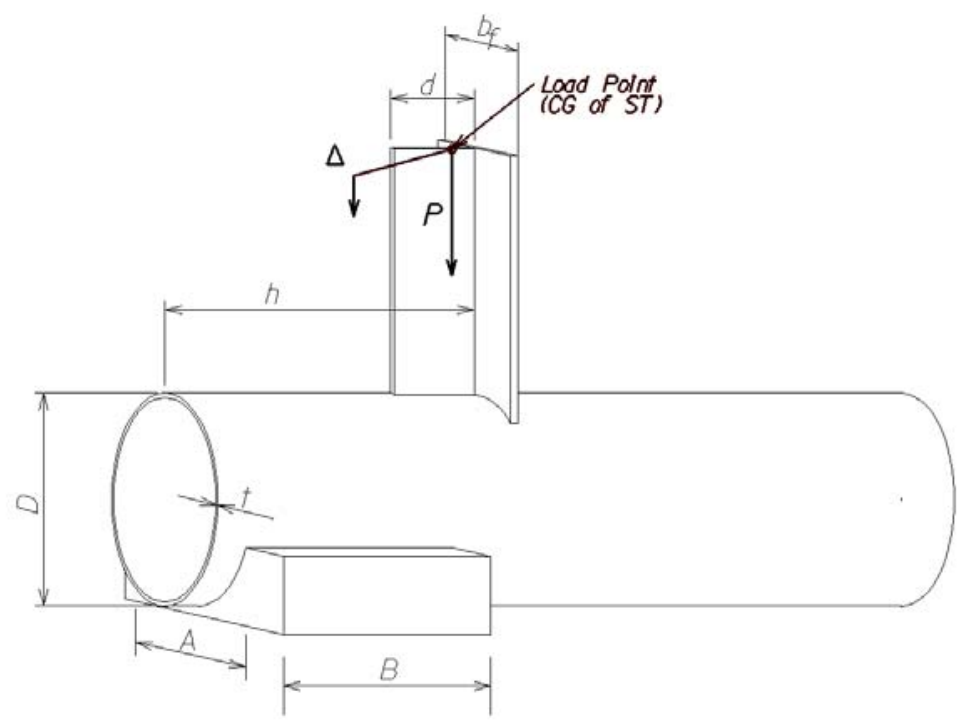

Figure A 1 
h Study: $h=6^{\prime \prime}$

$F y=47 \mathrm{ksi}, t=0.5^{\prime \prime}, D=26^{\prime \prime}, b f=7.2^{\prime \prime}, d=10.15^{\prime \prime}, A=24.1^{\prime \prime}, B=4 "$

ABAQUS VERSION 6.4-1

DATE 01-May-2004 TIME 09:19:55

SUMMARY OF JOB INFORMATION:

MONITOR NODE: 5251 DOF : 2

STEP INC ATT SEVERE EQUIL TOTAL

TOTAL ITERS

\begin{tabular}{rrrrr}
1 & 1 & 1 & 0 & 2 \\
1 & 2 & 1 & 0 & 2 \\
1 & 3 & 1 & 0 & 2 \\
1 & 4 & 1 & 0 & 2 \\
1 & 5 & 1 & 0 & 3 \\
1 & 6 & 1 & 0 & 3 \\
1 & 7 & 1 & 0 & 4 \\
1 & 8 & 1 & 0 & 4 \\
1 & 9 & 1 & 0 & 3 \\
1 & 10 & 1 & 0 & 4 \\
1 & 11 & 1 & 0 & 3 \\
1 & 12 & 1 & 0 & 4 \\
1 & 13 & 1 & 0 & 4 \\
1 & 14 & 1 & 0 & 4 \\
1 & 15 & 1 & 0 & 4 \\
1 & 16 & 1 & 0 & 5 \\
1 & 17 & 1 & 0 & 4 \\
1 & 18 & 1 & 0 & 4 \\
1 & 19 & 1 & 0 & 4 \\
1 & 20 & 1 & 0 & 4 \\
1 & $\mathbf{2 1}$ & $\mathbf{1}$ & 0 & 5 \\
\hline 1 & 22 & 1 & 0 & 4
\end{tabular}

FREQ

$\begin{array}{cccc}\text { STEP } & \text { INC OF } & \text { DOF } & \text { IF } \\ \text { TIME/LPF } & \text { TIME/LPF } & \text { MONITOR } & \text { RIKS }\end{array}$

$\odot . \odot \odot 997$

$\odot .009969$

$-0.0160$

$\odot .0199$

0.009903

$-0.0320$

0.0346

0.01474

$-0.0559$

0.0565

๑. 02186

$-0.0919$

0.0885

$\odot .03201$

0.133

0.04449

0.186

0.05315

$\odot .235$

0.04932

$\odot .269$

0.03378

0.02459

0.312

$\odot .01816$

0.01360

$\odot .009607$

0.335

0.006852

$-0.146$

$-0.228$

$-0.353$

$-0.521$

$-0.691$

$-0.863$

$\odot .335$

0.005555

0.348

0.004301

$-1.04$

$-1.21$

$\odot .004301$

0.355

0.003073

$\odot .004039$

0.362

0.367

$\odot .004899$

$-1.39$

$-1.56$

$-1.74$

$-1.92$

$-2.10$

-2.27
-2.45

2.63

0.373

0.005972

0.380

0.006741

$-2.81$

0.387

0.007040

$-2.98$

$\odot .394$

$\odot .007297$

3.16

0.400

$\odot .006389$

$-3.33$

0.406

005881

0.412

0.005930

$-3.68$

0.418

.006052

$-3.86$

0.424

$\odot .005987$

$-4.03$

0.430

0.005675

$-4.21$

0.435

0.005510

$-4.38$

0.441

0.005376

$-4.55$

0.446

0.005340

0.451

0.005244

$-4.90$

0.456

. . 005228

0.462

$\odot .005239$

$-5.25$

0.467

.005236

$-5.42$

0.472

0.005288

$-5.59$

0.478

.005317

$-5.76$

$\odot .005263$

$-5.93$

0.483

$\odot .005364$

$-6.10$

0.494

$\odot .005499$

$-6.28$

0.499

$\odot .005601$

$-6.45$

0.505

๑. 005672

0.511

0.005687

$-6.79$

0.516

0.005725

$-6.96$

0.522

$\odot .005806$

$-7.13$

0.528

.005876

$-7.30$

0.534

$\odot .005905$

$-7.46$

0.540

0.005849

$-7.63$

0.546

$\odot .005822$

$-7.80$

0.551

0.005857

$-7.97$

0.557

0.005920

$-8.13$

0.563

$\odot .006011$

$-8.30$

0.570

. . 006166

0.576

$\odot .006350$

$-8.63$

0.582

006546

$-8.80$

0.589

$\odot .006664$

$-8.96$

0.596

๑. 006814

$-9.12$

0.603

$\odot .006950$

0.610

$\odot .007085$

$-9.45$

0.617

$\odot .007223$

$-9.77$ 


$\begin{array}{llllllllll}1 & 63 & 1 & 0 & 4 & 4 & 0.625 & 0.007383 & -9.93 & \mathrm{R} \\ 1 & 64 & 1 & 0 & 4 & 4 & 0.632 & 0.007557 & -10.1 & \mathrm{R} \\ 1 & 65 & 1 & 0 & 4 & 4 & 0.640 & 0.007793 & -10.3 & \mathrm{R} \\ 1 & 66 & 1 & 0 & 4 & 4 & 0.648 & 0.008008 & -10.4 & \mathrm{R} \\ 1 & 67 & 1 & 0 & 4 & 4 & 0.656 & 0.008238 & -10.6 & \mathrm{R} \\ 1 & 68 & 1 & 0 & 4 & 4 & 0.665 & 0.008441 & -10.7 & \mathrm{R} \\ 1 & 69 & 1 & 0 & 5 & 5 & 0.673 & 0.008673 & -10.9 & \mathrm{R} \\ 1 & 70 & 1 & 0 & 4 & 4 & 0.682 & 0.008891 & -11.0 & \mathrm{R} \\ 1 & 71 & 1 & 0 & 4 & 4 & 0.691 & 0.009169 & -11.2 & \mathrm{R} \\ 1 & 72 & 1 & 0 & 4 & 4 & 0.701 & 0.009433 & -11.4 & \mathrm{R} \\ 1 & 73 & 1 & 0 & 4 & 4 & 0.711 & 0.009706 & -11.5 & \mathrm{R} \\ 1 & 74 & 1 & 0 & 4 & 4 & 0.720 & 0.009925 & -11.7 & \mathrm{R} \\ 1 & 75 & 1 & 0 & 4 & 4 & 0.731 & 0.01016 & -11.8 & \mathrm{R} \\ 1 & 76 & 1 & 0 & 4 & 4 & 0.741 & 0.01038 & -12.0 & \mathrm{R} \\ 1 & 77 & 1 & 0 & 4 & 4 & 0.752 & 0.01058 & -12.1 & \mathrm{R} \\ 1 & 78 & 1 & 0 & 4 & 4 & 0.762 & 0.01076 & -12.3 & \mathrm{R} \\ 1 & 79 & 1 & 0 & 4 & 4 & 0.773 & 0.01100 & -12.4 & \mathrm{R} \\ 1 & 80 & 1 & 0 & 4 & 4 & 0.785 & 0.01119 & -12.6 & \mathrm{R}\end{array}$

THE ANALYSIS HAS COMPLETED SUCCESSFULLY 


\begin{tabular}{|c|c|c|c|c|c|c|c|c|c|c|}
\hline ABAQU & $S$ VEF & SION & $N 6.4-1$ & & & & DATE & $30-A p r-20 \odot 4$ & TIME 15: & $27: 09$ \\
\hline SUMMA & RY of & $\mathrm{JOE}$ & B INFORN & MATION : & & & & & & \\
\hline MONIT & $\mathrm{OR} \mathrm{NC}$ & DE : & 5119 & 9 DOF: & 2 & & & & & \\
\hline STEP & INC & ATT & SEVERE & EQUIL & TOTAL & TOTAL & STEP & INC OF & DOF & IF \\
\hline & & & $\begin{array}{l}\text { DISCON } \\
\text { ITERS }\end{array}$ & ITERS & ITERS & $\begin{array}{l}\text { TIME/ } \\
\text { FREQ }\end{array}$ & TIME/LPF & TIME/LPF & MONITOR & RIKS \\
\hline 1 & 1 & 1 & 0 & 2 & 2 & & 0.00998 & $\odot .009984$ & -0.00620 & $\mathrm{R}$ \\
\hline 1 & 2 & 1 & $\odot$ & 2 & 2 & & $\odot .0199$ & $\odot . \odot \odot 9949$ & $-\odot .0124$ & $\mathrm{R}$ \\
\hline 1 & 3 & 1 & $\odot$ & 2 & 2 & & $\odot .0348$ & 0.01486 & -0.0217 & $\mathrm{R}$ \\
\hline 1 & 4 & 1 & $\odot$ & 2 & 2 & & 0.0570 & 0.02216 & -0.0356 & $\mathrm{R}$ \\
\hline 1 & 5 & 1 & $\odot$ & 2 & 2 & & 0.0899 & 0.03295 & $-\odot .0566$ & $\mathrm{R}$ \\
\hline 1 & 6 & 1 & 0 & 2 & 2 & & 0.139 & 0.04875 & -0.0880 & $\mathrm{R}$ \\
\hline 1 & 7 & 1 & $\Theta$ & 3 & 3 & & 0.209 & $\odot .07050$ & -0.135 & $\mathrm{R}$ \\
\hline 1 & 8 & 1 & $\odot$ & 3 & 3 & & 0.293 & 0.08430 & -0.198 & $\mathrm{R}$ \\
\hline 1 & 9 & 1 & $\odot$ & 3 & 3 & & 0.367 & 0.07358 & -0.262 & $\mathrm{R}$ \\
\hline 1 & 10 & 1 & $\odot$ & 4 & 4 & & 0.431 & 0.06417 & -0.326 & $\mathrm{R}$ \\
\hline 1 & 11 & 1 & 0 & 4 & 4 & & 0.484 & 0.05318 & -0.391 & $\mathrm{R}$ \\
\hline 1 & 12 & 1 & $\odot$ & 3 & 3 & & 0.525 & 0.04093 & -0.459 & $\mathrm{R}$ \\
\hline 1 & 13 & 1 & $\odot$ & 3 & 3 & & 0.559 & 0.03333 & -0.528 & $\mathrm{R}$ \\
\hline 1 & 14 & 1 & $\odot$ & 4 & 4 & & 0.587 & 0.02789 & -0.596 & $\mathrm{R}$ \\
\hline 1 & 15 & 1 & $\odot$ & 3 & 3 & & 0.608 & 0.02131 & -0.664 & $\mathrm{R}$ \\
\hline 1 & 16 & 1 & 0 & 3 & 3 & & 0.624 & 0.01661 & -0.732 & $\mathrm{R}$ \\
\hline 1 & 17 & 1 & 0 & 3 & 3 & & 0.638 & 0.01349 & -0.800 & $\mathrm{R}$ \\
\hline 1 & 18 & 1 & 0 & 3 & 3 & & 0.649 & 0.01066 & -0.868 & $\mathrm{R}$ \\
\hline 1 & 19 & 1 & $\odot$ & 4 & 4 & & 0.657 & $\odot .008547$ & -0.937 & $\mathrm{R}$ \\
\hline 1 & 20 & 1 & $\odot$ & 3 & 3 & & 0.664 & $\odot .006944$ & -1.00 & $\mathrm{R}$ \\
\hline 1 & 21 & 1 & 0 & 3 & 3 & & 0.669 & $\odot .005179$ & -1.07 & $\mathrm{R}$ \\
\hline 1 & 22 & 1 & 0 & 3 & 3 & & 0.673 & 0.003745 & -1.14 & $\mathrm{R}$ \\
\hline 1 & 23 & 1 & 0 & 3 & 3 & & 0.676 & $\odot .002746$ & -1.21 & $\mathrm{R}$ \\
\hline 1 & 24 & 1 & $\odot$ & 3 & 3 & & 0.678 & $\odot .001793$ & -1.28 & $\mathrm{R}$ \\
\hline 1 & 25 & 1 & 0 & 3 & 3 & & 0.679 & 0.001132 & -1.34 & $\mathrm{R}$ \\
\hline 1 & 26 & 1 & 0 & 3 & 3 & & 0.679 & 0.0006570 & -1.41 & $\mathrm{R}$ \\
\hline 1 & 27 & 1 & 0 & 4 & 4 & & 0.680 & 0.0001542 & -1.48 & $\mathbf{R}$ \\
\hline 1 & 28 & 1 & 0 & 3 & 3 & & 0.679 & -0.0001839 & -1.55 & $\mathrm{R}$ \\
\hline 1 & 29 & 1 & $\odot$ & 3 & 3 & & 0.679 & $-\odot . \odot \odot \odot 4852$ & -1.62 & $\mathrm{R}$ \\
\hline 1 & 30 & 1 & 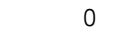 & 4 & 4 & & 0.678 & $-\odot .0 \odot \odot 7228$ & -1.68 & $\mathrm{R}$ \\
\hline 1 & 31 & 1 & 0 & 4 & 4 & & 0.677 & -๑.๑०९8986 & -1.75 & $\mathrm{R}$ \\
\hline 1 & 32 & 1 & 0 & 4 & 4 & & 0.676 & $-\odot .00 \odot 8916$ & -1.82 & $\mathrm{R}$ \\
\hline 1 & 33 & 1 & 0 & 3 & 3 & & 0.676 & $-\odot .0 \odot \odot 7757$ & -1.89 & $\mathrm{R}$ \\
\hline 1 & 34 & 1 & $\odot$ & 3 & 3 & & 0.675 & -๑. .०००6418 & -1.96 & $\mathrm{R}$ \\
\hline 1 & 35 & 1 & 0 & 4 & 4 & & 0.674 & $-\odot .0 \odot \odot 4825$ & -2.02 & $\mathrm{R}$ \\
\hline 1 & 36 & 1 & 0 & 3 & 3 & & 0.674 & $-0.0 \odot \odot 2775$ & -2.09 & $\mathrm{R}$ \\
\hline 1 & 37 & 1 & 0 & 3 & 3 & & 0.674 & $-\odot .0001223$ & -2.16 & $\mathrm{R}$ \\
\hline 1 & 38 & 1 & 0 & 3 & 3 & & 0.674 & $-6.203 e-06$ & -2.23 & $\mathrm{R}$ \\
\hline 1 & 39 & 1 & 0 & 4 & 4 & & 0.674 & $\odot .0001644$ & -2.30 & $\mathrm{R}$ \\
\hline 1 & 40 & 1 & 0 & 4 & 4 & & 0.675 & $\odot .0003723$ & -2.36 & $\mathrm{R}$ \\
\hline 1 & 41 & 1 & $\odot$ & 3 & 3 & & 0.675 & $\odot .0005817$ & -2.43 & $\mathrm{R}$ \\
\hline 1 & 42 & 1 & 0 & 4 & 4 & & 0.676 & $\odot .0008033$ & -2.50 & $\mathrm{R}$ \\
\hline 1 & 43 & 1 & $\odot$ & 4 & 4 & & 0.677 & ๑. 001032 & -2.57 & $\mathrm{R}$ \\
\hline 1 & 44 & 1 & $\odot$ & 4 & 4 & & 0.678 & $\odot .001291$ & -2.64 & $\mathrm{R}$ \\
\hline 1 & 45 & 1 & 0 & 4 & 4 & & 0.680 & $\odot .001480$ & -2.70 & $\mathrm{R}$ \\
\hline 1 & 46 & 1 & 0 & 4 & 4 & & 0.681 & 0.001704 & -2.77 & $\mathrm{R}$ \\
\hline 1 & 47 & 1 & 0 & 4 & 4 & & 0.683 & ๑. 001958 & -2.84 & $\mathrm{R}$ \\
\hline 1 & 48 & 1 & $\odot$ & 4 & 4 & & 0.686 & $\odot . \odot \odot 2285$ & -2.91 & $\mathrm{R}$ \\
\hline 1 & 49 & 1 & $\odot$ & 4 & 4 & & 0.688 & $\odot . \odot \odot 26 \odot 7$ & -2.98 & $\mathrm{R}$ \\
\hline 1 & 50 & 1 & $\odot$ & 4 & 4 & & 0.691 & ๑.0०2939 & -3.04 & $\mathrm{R}$ \\
\hline
\end{tabular}

THE ANALYSIS HAS COMPLETED SUCCESSFULLY 


\begin{tabular}{|c|c|c|c|c|c|c|c|c|c|c|}
\hline ABAQU & $S$ VEF & SION & $N 6.4-1$ & & & & DATE & $30-A p r-20 \odot 4$ & TIME 15: & $27: 09$ \\
\hline SUMMA & RY of & $\mathrm{JOE}$ & B INFORN & MATION : & & & & & & \\
\hline MONIT & $\mathrm{OR} \mathrm{NC}$ & DE : & 5273 & 3 DOF: & 2 & & & & & \\
\hline STEP & INC & ATT & SEVERE & EQUIL & TOTAL & TOTAL & STEP & INC OF & DOF & IF \\
\hline & & & $\begin{array}{l}\text { DISCON } \\
\text { ITERS }\end{array}$ & ITERS & ITERS & $\begin{array}{l}\text { TIME/ } \\
\text { FREQ }\end{array}$ & TIME/LPF & TIME/LPF & MONITOR & RIKS \\
\hline 1 & 1 & 1 & 0 & 2 & 2 & & 0.00999 & $\odot .009989$ & -0.00420 & $\mathrm{R}$ \\
\hline 1 & 2 & 1 & $\odot$ & 2 & 2 & & $\odot . \odot 2 \odot \odot$ & $\odot . \odot \odot 9966$ & $-\odot .00839$ & $\mathrm{R}$ \\
\hline 1 & 3 & 1 & $\odot$ & 2 & 2 & & 0.0349 & 0.01491 & -0.0147 & $\mathrm{R}$ \\
\hline 1 & 4 & 1 & $\odot$ & 2 & 2 & & 0.0571 & 0.02228 & -0.0241 & $\mathrm{R}$ \\
\hline 1 & 5 & 1 & $\odot$ & 2 & 2 & & 0.0904 & 0.03322 & $-\odot .0383$ & $\mathrm{R}$ \\
\hline 1 & 6 & 1 & 0 & 2 & 2 & & 0.140 & 0.04938 & -0.0596 & $\mathrm{R}$ \\
\hline 1 & 7 & 1 & $\Theta$ & 2 & 2 & & 0.213 & $\odot .07297$ & -0.0915 & $\mathrm{R}$ \\
\hline 1 & 8 & 1 & $\odot$ & 3 & 3 & & 0.305 & 0.09256 & -0.134 & $\mathrm{R}$ \\
\hline 1 & 9 & 1 & $\odot$ & 3 & 3 & & 0.390 & 0.08503 & -0.177 & $\mathrm{R}$ \\
\hline 1 & 10 & 1 & $\odot$ & 3 & 3 & & 0.471 & $\odot .08027$ & -0.220 & $\mathrm{R}$ \\
\hline 1 & 11 & 1 & 0 & 4 & 4 & & 0.545 & 0.07460 & -0.270 & $\mathrm{R}$ \\
\hline 1 & 12 & 1 & $\odot$ & 3 & 3 & & 0.612 & 0.06698 & -0.324 & $\mathrm{R}$ \\
\hline 1 & 13 & 1 & $\odot$ & 4 & 4 & & 0.673 & 0.06050 & -0.380 & $\mathrm{R}$ \\
\hline 1 & 14 & 1 & $\odot$ & 4 & 4 & & 0.726 & 0.05318 & -0.448 & $\mathrm{R}$ \\
\hline 1 & 15 & 1 & $\odot$ & 3 & 3 & & 0.771 & $\odot .04553$ & -0.514 & $\mathrm{R}$ \\
\hline 1 & 16 & 1 & 0 & 3 & 3 & & 0.808 & 0.03676 & -0.577 & $\mathrm{R}$ \\
\hline 1 & 17 & 1 & 0 & 3 & 3 & & 0.837 & 0.02842 & -0.637 & $\mathrm{R}$ \\
\hline 1 & 18 & 1 & 0 & 3 & 3 & & 0.858 & 0.02180 & -0.694 & $\mathrm{R}$ \\
\hline 1 & 19 & 1 & $\odot$ & 3 & 3 & & 0.876 & 0.01744 & -0.749 & $\mathrm{R}$ \\
\hline 1 & 20 & 1 & $\odot$ & 3 & 3 & & 0.890 & 0.01400 & -0.803 & $\mathrm{R}$ \\
\hline 1 & 21 & 1 & 0 & 3 & 3 & & 0.901 & 0.01115 & -0.856 & $\mathrm{R}$ \\
\hline 1 & 22 & 1 & 0 & 3 & 3 & & 0.909 & 0.008551 & -0.907 & $\mathrm{R}$ \\
\hline 1 & 23 & 1 & 0 & 3 & 3 & & 0.916 & 0.006230 & -0.958 & $\mathrm{R}$ \\
\hline 1 & 24 & 1 & $\odot$ & 3 & 3 & & 0.920 & $\odot .004084$ & -1.01 & $\mathrm{R}$ \\
\hline 1 & 25 & 1 & 0 & 3 & 3 & & 0.922 & ๑.0๑1866 & -1.06 & $\mathrm{R}$ \\
\hline 1 & 26 & 1 & 0 & 3 & 3 & & 0.922 & 0.0004311 & -1.10 & $\mathbf{R}$ \\
\hline$\overline{1}$ & 27 & 1 & $\theta$ & 3 & 3 & & 0.921 & -0.0009663 & -1.15 & $\bar{R}$ \\
\hline 1 & 28 & 1 & 0 & 3 & 3 & & 0.919 & $-\odot .001942$ & -1.20 & $\mathrm{R}$ \\
\hline 1 & 29 & 1 & $\odot$ & 3 & 3 & & 0.916 & $-\odot .002829$ & -1.25 & $\mathrm{R}$ \\
\hline 1 & 30 & 1 & 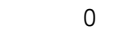 & 3 & 3 & & 0.913 & -0.003470 & -1.30 & $\mathrm{R}$ \\
\hline 1 & 31 & 1 & 0 & 3 & 3 & & 0.909 & $-\odot .003809$ & -1.35 & $\mathrm{R}$ \\
\hline 1 & 32 & 1 & 0 & 3 & 3 & & 0.905 & $-\odot .0 \odot 4116$ & -1.40 & $\mathrm{R}$ \\
\hline 1 & 33 & 1 & 0 & 3 & 3 & & 0.901 & -0.004371 & -1.45 & $\mathrm{R}$ \\
\hline 1 & 34 & 1 & 0 & 3 & 3 & & 0.896 & $-\odot .004506$ & -1.50 & $\mathrm{R}$ \\
\hline 1 & 35 & 1 & 0 & 3 & 3 & & 0.892 & $-\odot .004575$ & -1.55 & $\mathrm{R}$ \\
\hline 1 & 36 & 1 & 0 & 3 & 3 & & 0.887 & $-\odot .004558$ & -1.60 & $\mathrm{R}$ \\
\hline 1 & 37 & 1 & 0 & 3 & 3 & & 0.882 & $-\odot .0 \odot 4462$ & -1.65 & $\mathrm{R}$ \\
\hline 1 & 38 & 1 & 0 & 3 & 3 & & 0.878 & $-\odot .0 \odot 4186$ & -1.70 & $\mathrm{R}$ \\
\hline 1 & 39 & 1 & 0 & 3 & 3 & & 0.874 & -0.003931 & -1.75 & $\mathrm{R}$ \\
\hline 1 & 40 & 1 & 0 & 3 & 3 & & 0.871 & $-\odot .003585$ & -1.80 & $\mathrm{R}$ \\
\hline 1 & 41 & 1 & $\odot$ & 3 & 3 & & 0.868 & -0.003189 & -1.85 & $\mathrm{R}$ \\
\hline 1 & 42 & 1 & 0 & 3 & 3 & & 0.865 & $-\odot . \odot \odot 2726$ & -1.90 & $\mathrm{R}$ \\
\hline 1 & 43 & 1 & 0 & 3 & 3 & & 0.863 & $-\odot . \odot \odot 2286$ & -1.95 & $\mathrm{R}$ \\
\hline 1 & 44 & 1 & $\odot$ & 3 & 3 & & 0.861 & $-\odot .001768$ & -2.00 & $\mathrm{R}$ \\
\hline 1 & 45 & 1 & 0 & 3 & 3 & & 0.860 & $-\odot .001304$ & -2.05 & $\mathrm{R}$ \\
\hline 1 & 46 & 1 & 0 & 4 & 4 & & 0.859 & -0.0006799 & -2.10 & $\mathrm{R}$ \\
\hline 1 & 47 & 1 & 0 & 3 & 3 & & 0.859 & $-5.059 e-05$ & -2.15 & $\mathrm{R}$ \\
\hline 1 & 48 & 1 & $\odot$ & 4 & 4 & & 0.859 & $\odot .00 \odot 4676$ & -2.20 & $\mathrm{R}$ \\
\hline 1 & 49 & 1 & $\odot$ & 3 & 3 & & 0.860 & $\odot .0009563$ & -2.25 & $\mathrm{R}$ \\
\hline 1 & 50 & 1 & $\odot$ & 3 & 3 & & 0.862 & $\odot .001648$ & -2.30 & $\mathrm{R}$ \\
\hline
\end{tabular}

THE ANALYSIS HAS COMPLETED SUCCESSFULLY 


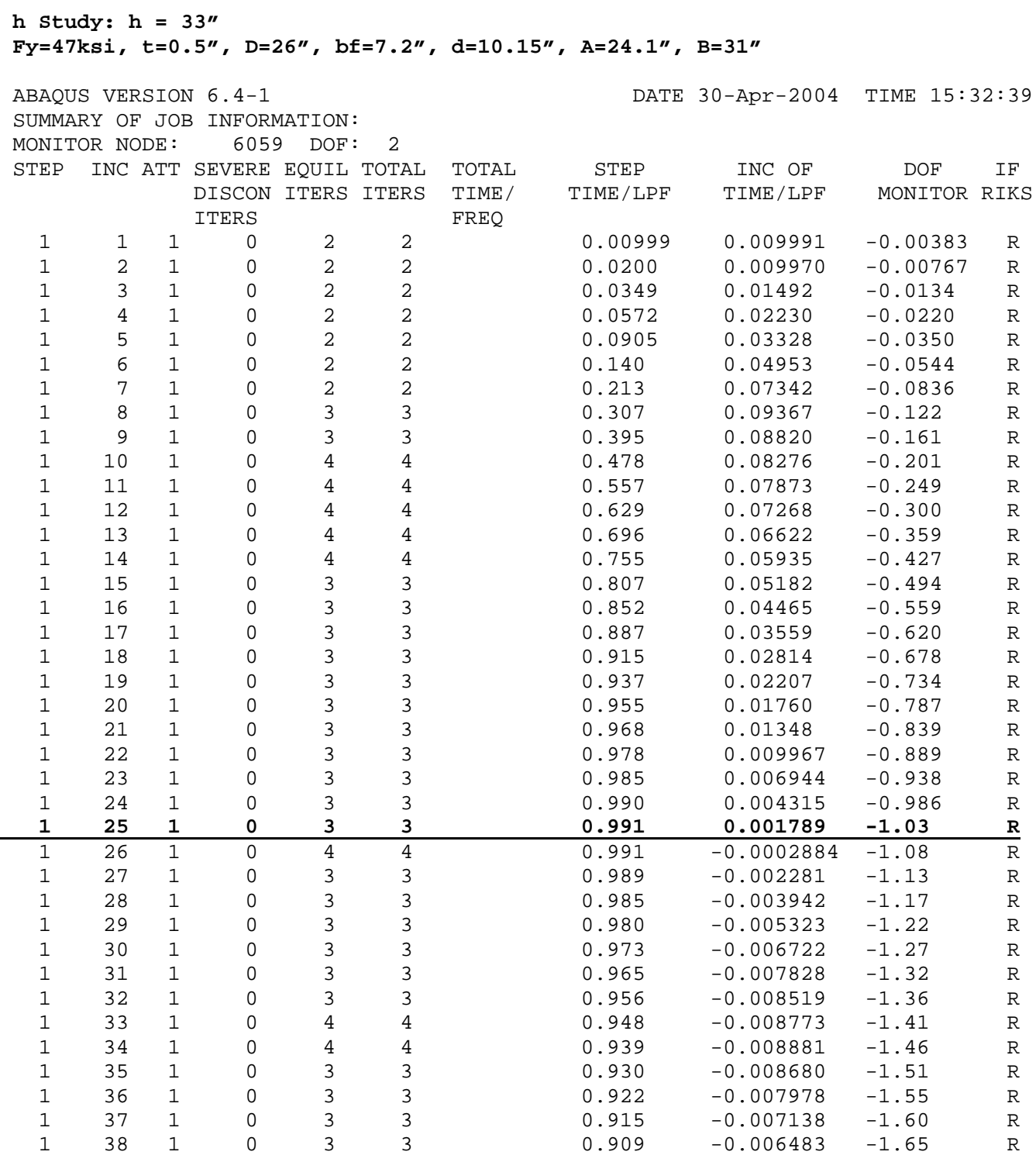




\begin{tabular}{|c|c|c|c|c|c|c|c|c|c|c|}
\hline ABAQU & 5 VER & SION & $N 6.4-1$ & & & & DATE & 01 - Мay - $20 \odot 4$ & TIME $08: 5$ & $53: 09$ \\
\hline SUMMA & RY OF & $\mathrm{JOB}$ & B INFORM & MATION & & & & & & \\
\hline MONIT & $\mathrm{R} N \mathrm{NC}$ & DE : & 7805 & 5 DOF & 2 & & & & & \\
\hline STEP & INC & ATT & SEVERE & EQUIL & TOTAL & TOTAL & STEP & INC OF & DOF & IF \\
\hline & & & $\begin{array}{l}\text { DISCON } \\
\text { ITERS }\end{array}$ & ITERS & ITERS & $\begin{array}{l}\text { TIME/ } \\
\text { FREQ }\end{array}$ & TIME/LPF & TIME/LPF & MONITOR & RIKS \\
\hline 1 & 1 & 1 & $\odot$ & 2 & 2 & & $\odot .00999$ & ๑.0०9991 & $-\odot .00379$ & $\mathrm{R}$ \\
\hline 1 & 2 & 1 & $\odot$ & 2 & 2 & & $\odot .02 \odot \odot$ & $\odot .0 \odot 9972$ & $-\odot .0 \odot 759$ & $\mathrm{R}$ \\
\hline 1 & 3 & 1 & 0 & 2 & 2 & & 0.0349 & ๑.01493 & -0.0133 & $\mathrm{R}$ \\
\hline 1 & 4 & 1 & 0 & 2 & 2 & & 0.0572 & $\odot .02232$ & -0.0218 & $\mathrm{R}$ \\
\hline 1 & 5 & 1 & 0 & 2 & 2 & & $\odot .0905$ & 0.03332 & -0.0346 & $\mathrm{R}$ \\
\hline 1 & 6 & 1 & 0 & 2 & 2 & & 0.140 & $\odot .04961$ & -0.0539 & $\mathrm{R}$ \\
\hline 1 & 7 & 1 & 0 & 2 & 2 & & 0.214 & 0.07361 & -0.0828 & $\mathrm{R}$ \\
\hline 1 & 8 & 1 & 0 & 3 & 3 & & 0.308 & 0.09424 & -0.121 & $\mathrm{R}$ \\
\hline 1 & 9 & 1 & 0 & 3 & 3 & & 0.398 & ๑. 08956 & -0.160 & $\mathrm{R}$ \\
\hline 1 & 10 & 1 & 0 & 4 & 4 & & 0.481 & ๑.08391 & -0.200 & $\mathrm{R}$ \\
\hline 1 & 11 & 1 & 0 & 3 & 3 & & 0.561 & $\odot .08003$ & -0.247 & $\mathrm{R}$ \\
\hline 1 & 12 & 1 & 0 & 3 & 3 & & 0.636 & 0.07442 & -0.299 & $\mathrm{R}$ \\
\hline 1 & 13 & 1 & 0 & 4 & 4 & & 0.704 & $\odot .06771$ & -0.361 & $\mathrm{R}$ \\
\hline 1 & 14 & 1 & 0 & 4 & 4 & & 0.765 & $\odot .06151$ & -0.430 & $\mathrm{R}$ \\
\hline 1 & 15 & 1 & $\odot$ & 3 & 3 & & 0.819 & 0.05364 & -0.499 & $\mathrm{R}$ \\
\hline 1 & 16 & 1 & 0 & 3 & 3 & & 0.864 & 0.04508 & -0.564 & $\mathrm{R}$ \\
\hline 1 & 17 & 1 & 0 & 3 & 3 & & 0.900 & 0.03576 & -0.626 & $\mathrm{R}$ \\
\hline 1 & 18 & 1 & 0 & 3 & 3 & & 0.928 & 0.02882 & -0.685 & $\mathrm{R}$ \\
\hline 1 & 19 & 1 & 0 & 3 & 3 & & 0.951 & $\odot .02281$ & -0.742 & $\mathrm{R}$ \\
\hline 1 & 20 & 1 & 0 & 3 & 3 & & $\odot .969$ & 0.01797 & -0.797 & $\mathrm{R}$ \\
\hline 1 & 21 & 1 & 0 & 3 & 3 & & 0.982 & 0.01326 & -0.849 & $\mathrm{R}$ \\
\hline 1 & 22 & 1 & 0 & 3 & 3 & & 0.992 & 0.009278 & -0.900 & $\mathrm{R}$ \\
\hline 1 & 23 & 1 & 0 & 3 & 3 & & 0.998 & 0.005874 & $-\odot .950$ & $\mathrm{R}$ \\
\hline 1 & 24 & 1 & 0 & 3 & 3 & & 1.00 & 0.002745 & -0.998 & $\mathbf{R}$ \\
\hline 1 & 25 & 1 & $\theta$ & 4 & 4 & & 1.00 & -0.0002220 & -1.05 & $\overline{\mathrm{R}}$ \\
\hline 1 & 26 & 1 & 0 & 3 & 3 & & 0.997 & $-\odot .003068$ & -1.09 & $\mathrm{R}$ \\
\hline 1 & 27 & 1 & 0 & 3 & 3 & & 0.991 & $-\odot .005626$ & -1.14 & $\mathrm{R}$ \\
\hline 1 & 28 & 1 & 0 & 3 & 3 & & 0.984 & $-\odot .007495$ & -1.19 & $\mathrm{R}$ \\
\hline 1 & 29 & 1 & $\odot$ & 3 & 3 & & 0.975 & $-\odot . \odot \odot 8755$ & -1.24 & $\mathrm{R}$ \\
\hline 1 & 30 & 1 & 0 & 4 & 4 & & 0.965 & $-\odot .0 \odot 9691$ & -1.28 & $\mathrm{R}$ \\
\hline 1 & 31 & 1 & 0 & 3 & 3 & & 0.955 & -0.01002 & -1.33 & $\mathrm{R}$ \\
\hline 1 & 32 & 1 & 0 & 3 & 3 & & 0.946 & $-\odot .009836$ & -1.38 & $\mathrm{R}$ \\
\hline 1 & 33 & 1 & 0 & 4 & 4 & & 0.936 & $-\odot .009489$ & -1.43 & $\mathrm{R}$ \\
\hline 1 & 34 & 1 & 0 & 3 & 3 & & 0.927 & $-\odot .008992$ & -1.48 & $\mathrm{R}$ \\
\hline 1 & 35 & 1 & $\odot$ & 3 & 3 & & 0.919 & $-\odot .008275$ & -1.52 & $\mathrm{R}$ \\
\hline 1 & 36 & 1 & 0 & 3 & 3 & & 0.912 & $-\odot .007361$ & -1.57 & $\mathrm{R}$ \\
\hline 1 & 37 & 1 & 0 & 3 & 3 & & 0.905 & $-\odot .006553$ & -1.62 & $\mathrm{R}$ \\
\hline 1 & 38 & 1 & 0 & 3 & 3 & & 0.899 & -0.005612 & -1.67 & $\mathrm{R}$ \\
\hline 1 & 39 & 1 & $\odot$ & 3 & 3 & & 0.895 & $-\odot .004528$ & -1.72 & $\mathrm{R}$ \\
\hline 1 & 40 & 1 & $\odot$ & 3 & 3 & & 0.891 & $-\odot .003430$ & -1.76 & $\mathrm{R}$ \\
\hline 1 & 41 & 1 & $\odot$ & 3 & 3 & & 0.889 & $-\odot .002738$ & -1.81 & $\mathrm{R}$ \\
\hline 1 & 42 & 1 & 0 & 3 & 3 & & 0.887 & -0.002113 & -1.86 & $\mathrm{R}$ \\
\hline 1 & 43 & 1 & 0 & 3 & 3 & & 0.885 & -0.001192 & -1.91 & $\mathrm{R}$ \\
\hline 1 & 44 & 1 & $\odot$ & 3 & 3 & & 0.885 & -๑.๑๑९1871 & -1.95 & $\mathrm{R}$ \\
\hline 1 & 45 & 1 & 0 & 3 & 3 & & 0.886 & $\odot .0005500$ & -2.00 & $\mathrm{R}$ \\
\hline 1 & 46 & 1 & $\odot$ & 3 & 3 & & $\odot .887$ & 0.001400 & -2.05 & $\mathrm{R}$ \\
\hline 1 & 47 & 1 & 0 & 3 & 3 & & 0.889 & $\odot .0 \odot 2238$ & -2.10 & $\mathrm{R}$ \\
\hline 1 & 48 & 1 & 0 & 4 & 4 & & 0.893 & $\odot .003224$ & -2.14 & $\mathrm{R}$ \\
\hline 1 & 49 & 1 & 0 & 3 & 3 & & $\odot .897$ & $\odot .0 \odot 42 \odot 7$ & -2.19 & $\mathrm{R}$ \\
\hline 1 & 50 & 1 & 0 & 3 & 3 & & 0.902 & $\odot .005093$ & -2.24 & $\mathrm{R}$ \\
\hline
\end{tabular}

THE ANALYSIS HAS COMPLETED SUCCESSFULLY 


\begin{tabular}{|c|c|c|c|c|c|c|c|c|c|c|}
\hline ABAQ & $S$ VER & SION & $N 6.4-1$ & & & & DATE & $\odot 1-$ May-2๑๑4 & TIME ๑८: & $56: 16$ \\
\hline SUMM & RY OF & $\mathrm{JOB}$ & B INFORN & MATION & & & & & & \\
\hline MONI & OR NO & DE : & 10197 & 7 DOF & 2 & & & & & \\
\hline STEP & INC & ATT & SEVERE & EQUIL & TOTAL & TOTAL & STEP & INC OF & DOF & IF \\
\hline & & & $\begin{array}{l}\text { DISCON } \\
\text { ITERS }\end{array}$ & ITERS & ITERS & $\begin{array}{l}\text { TIME/ } \\
\text { FREQ }\end{array}$ & TIME/LPF & TIME/LPF & MONITOR & RIKS \\
\hline 1 & 1 & 1 & 0 & 2 & 2 & & 0.00999 & $\odot .009992$ & -0.00383 & $\mathrm{R}$ \\
\hline 1 & 2 & 1 & $\odot$ & 2 & 2 & & $\odot .02 \odot \odot$ & $\odot .0 \odot 9973$ & $-\odot .00765$ & $\mathrm{R}$ \\
\hline 1 & 3 & 1 & $\odot$ & 2 & 2 & & 0.0349 & $\odot .01493$ & $-\odot .0134$ & $\mathrm{R}$ \\
\hline 1 & 4 & 1 & $\odot$ & 2 & 2 & & 0.0572 & 0.02233 & -0.0220 & $\mathrm{R}$ \\
\hline 1 & 5 & 1 & $\odot$ & 2 & 2 & & 0.0906 & 0.03334 & -0.0349 & $\mathrm{R}$ \\
\hline 1 & 6 & 1 & $\odot$ & 2 & 2 & & 0.140 & 0.04966 & -0.0544 & $\mathrm{R}$ \\
\hline 1 & 7 & 1 & $\odot$ & 2 & 2 & & 0.214 & 0.07372 & -0.0835 & $\mathrm{R}$ \\
\hline 1 & 8 & 1 & $\odot$ & 3 & 3 & & 0.309 & 0.09460 & -0.122 & $\mathrm{R}$ \\
\hline 1 & 9 & 1 & $\odot$ & 3 & 3 & & 0.399 & 0.09039 & -0.161 & $\mathrm{R}$ \\
\hline 1 & 10 & 1 & $\odot$ & 4 & 4 & & 0.484 & 0.08482 & -0.202 & $\mathrm{R}$ \\
\hline 1 & 11 & 1 & $\odot$ & 3 & 3 & & 0.565 & ๑. 08101 & -0.250 & $\mathrm{R}$ \\
\hline 1 & 12 & 1 & $\odot$ & 3 & 3 & & 0.639 & 0.07468 & -0.302 & $\mathrm{R}$ \\
\hline 1 & 13 & 1 & $\odot$ & 4 & 4 & & $\odot .707$ & 0.06804 & -0.366 & $\mathrm{R}$ \\
\hline 1 & 14 & 1 & $\odot$ & 4 & 4 & & 0.769 & 0.06142 & -0.436 & $\mathrm{R}$ \\
\hline 1 & 15 & 1 & $\odot$ & 3 & 3 & & 0.823 & 0.05382 & -0.506 & $\mathrm{R}$ \\
\hline 1 & 16 & 1 & $\odot$ & 3 & 3 & & 0.868 & 0.04515 & -0.572 & $\mathrm{R}$ \\
\hline 1 & 17 & 1 & $\odot$ & 3 & 3 & & 0.904 & 0.03578 & -0.635 & $\mathrm{R}$ \\
\hline 1 & 18 & 1 & $\odot$ & 3 & 3 & & 0.932 & 0.02849 & -0.695 & $\mathrm{R}$ \\
\hline 1 & 19 & 1 & $\odot$ & 3 & 3 & & $\odot .955$ & 0.02260 & -0.753 & $\mathrm{R}$ \\
\hline 1 & 20 & 1 & $\odot$ & 3 & 3 & & 0.972 & 0.01710 & -0.808 & $\mathrm{R}$ \\
\hline 1 & 21 & 1 & $\odot$ & 3 & 3 & & 0.984 & 0.01231 & -0.861 & $\mathrm{R}$ \\
\hline 1 & 22 & 1 & $\odot$ & 3 & 3 & & $\odot .992$ & $\odot . \odot \odot 8257$ & -0.912 & $\mathrm{R}$ \\
\hline 1 & 23 & 1 & $\odot$ & 3 & 3 & & $\odot .997$ & $\odot .0 \odot 4523$ & -0.962 & $\mathrm{R}$ \\
\hline 1 & 24 & 1 & 0 & 3 & 3 & & 0.998 & 0.001077 & -1.01 & $\mathbf{R}$ \\
\hline 1 & 25 & 1 & $\theta$ & 4 & 4 & & 0.996 & -0.002162 & -1.06 & $\overline{\mathrm{R}}$ \\
\hline 1 & 26 & 1 & $\odot$ & 3 & 3 & & $\odot .991$ & $-\odot .005127$ & -1.11 & $\mathrm{R}$ \\
\hline 1 & 27 & 1 & $\odot$ & 3 & 3 & & 0.984 & $-\odot .007052$ & -1.16 & $\mathrm{R}$ \\
\hline 1 & 28 & 1 & $\odot$ & 3 & 3 & & 0.975 & -0.008323 & -1.20 & $\mathrm{R}$ \\
\hline 1 & 29 & 1 & $\odot$ & 3 & 3 & & 0.966 & $-\odot .0 \odot 9234$ & -1.25 & $\mathrm{R}$ \\
\hline 1 & 30 & 1 & $\odot$ & 3 & 3 & & $\odot .957$ & $-\odot .0 \odot 9547$ & -1.30 & $\mathrm{R}$ \\
\hline 1 & 31 & 1 & $\odot$ & 3 & 3 & & $\odot .947$ & $-\odot .0 \odot 9616$ & -1.35 & $\mathrm{R}$ \\
\hline 1 & 32 & 1 & $\odot$ & 3 & 3 & & 0.937 & $-\odot .009532$ & -1.40 & $\mathrm{R}$ \\
\hline 1 & 33 & 1 & $\odot$ & 3 & 3 & & 0.928 & -0.009133 & -1.45 & $\mathrm{R}$ \\
\hline 1 & 34 & 1 & $\odot$ & 3 & 3 & & 0.920 & $-\odot .0 \odot 8303$ & -1.50 & $\mathrm{R}$ \\
\hline 1 & 35 & 1 & $\odot$ & 3 & 3 & & 0.913 & $-\odot .007407$ & -1.54 & $\mathrm{R}$ \\
\hline 1 & 36 & 1 & $\odot$ & 3 & 3 & & $\odot .906$ & $-\odot .0065 \odot \odot$ & -1.59 & $\mathrm{R}$ \\
\hline 1 & 37 & 1 & $\odot$ & 3 & 3 & & $\odot .901$ & $-\odot .005546$ & -1.64 & $\mathrm{R}$ \\
\hline
\end{tabular}




\begin{tabular}{|c|c|c|c|c|c|c|c|c|c|c|}
\hline ABAQU & $S$ VER & SION & v 6.4-1 & & & & DATE & $28-A p r-20 \odot 4$ & TIME 20: & $48: 11$ \\
\hline SUMMA & RY OF & $\mathrm{JOB}$ & 3 INFORM & MATION : & & & & & & \\
\hline MONIT & OR NO & EE : & 5649 & 9 DOF: & 2 & & & & & \\
\hline STEP & INC & АTT & SEVERE & EQUIL & TOTAL & TOTAL & STEP & INC OF & DOF & IF \\
\hline & & & $\begin{array}{l}\text { DISCON } \\
\text { ITERS }\end{array}$ & ITERS & ITERS & $\begin{array}{l}\text { TIME/ } \\
\text { FREQ }\end{array}$ & TIME/LPF & TIME/LPF & MONITOR & RIKS \\
\hline 1 & 1 & 1 & $\odot$ & 2 & 2 & & $\odot .0 \odot 999$ & ๑. 009987 & $-\odot .00587$ & $\mathrm{R}$ \\
\hline 1 & 2 & 1 & $\odot$ & 2 & 2 & & $\odot .0199$ & $\odot . \odot \odot 9961$ & $-\odot .0117$ & $\mathrm{R}$ \\
\hline 1 & 3 & 1 & $\odot$ & 2 & 2 & & 0.0348 & $\odot .01489$ & -0.0205 & $\mathrm{R}$ \\
\hline 1 & 4 & 1 & $\odot$ & 2 & 2 & & 0.0571 & 0.02223 & -0.0338 & $\mathrm{R}$ \\
\hline 1 & 5 & 1 & $\odot$ & 2 & 2 & & 0.0902 & 0.03311 & $-\odot .0536$ & $\mathrm{R}$ \\
\hline 1 & 6 & 1 & 0 & 2 & 2 & & 0.139 & 0.04912 & -0.0834 & $\mathrm{R}$ \\
\hline 1 & 7 & 1 & 0 & 3 & 3 & & 0.212 & $\odot .07226$ & -0.128 & $\mathrm{R}$ \\
\hline 1 & 8 & 1 & 0 & 3 & 3 & & 0.301 & 0.08913 & -0.188 & $\mathrm{R}$ \\
\hline 1 & 9 & 1 & 0 & 3 & 3 & & 0.378 & 0.07722 & -0.250 & $\mathrm{R}$ \\
\hline 1 & 10 & 1 & $\odot$ & 4 & 4 & & 0.438 & $\odot .06028$ & -0.314 & $\mathrm{R}$ \\
\hline 1 & 11 & 1 & 0 & 3 & 3 & & 0.489 & ๑. 05103 & -0.381 & $\mathrm{R}$ \\
\hline 1 & 12 & 1 & 0 & 3 & 3 & & 0.532 & 0.04256 & -0.452 & $\mathrm{R}$ \\
\hline 1 & 13 & 1 & 0 & 3 & 3 & & 0.568 & 0.03641 & -0.524 & $\mathrm{R}$ \\
\hline 1 & 14 & 1 & 0 & 3 & 3 & & 0.598 & 0.02947 & -0.596 & $\mathrm{R}$ \\
\hline 1 & 15 & 1 & $\odot$ & 3 & 3 & & 0.621 & 0.02317 & -0.669 & $\mathrm{R}$ \\
\hline 1 & 16 & 1 & 0 & 3 & 3 & & 0.639 & 0.01784 & -0.741 & $\mathrm{R}$ \\
\hline 1 & 17 & 1 & 0 & 3 & 3 & & 0.652 & 0.01321 & -0.814 & $\mathrm{R}$ \\
\hline 1 & 18 & 1 & 0 & 3 & 3 & & 0.660 & $\odot .008379$ & -0.888 & $\mathrm{R}$ \\
\hline 1 & 19 & 1 & 0 & 4 & 4 & & 0.665 & $\odot .004741$ & -0.962 & $\mathrm{R}$ \\
\hline 1 & 20 & 1 & 0 & 3 & 3 & & 0.667 & 0.001658 & -1.04 & $\mathbf{R}$ \\
\hline 1 & 21 & 1 & $\theta$ & 3 & 3 & & 0.666 & -0.0002690 & -1.11 & $\bar{R}$ \\
\hline 1 & 22 & 1 & 0 & 3 & 3 & & 0.665 & $-\odot .001190$ & -1.18 & $\mathrm{R}$ \\
\hline 1 & 23 & 1 & 0 & 3 & 3 & & 0.663 & $-\odot .002362$ & -1.26 & $\mathrm{R}$ \\
\hline 1 & 24 & 1 & 0 & 3 & 3 & & 0.661 & $-\odot .002156$ & -1.33 & $\mathrm{R}$ \\
\hline 1 & 25 & 1 & 0 & 3 & 3 & & 0.659 & -0.001624 & -1.41 & $\mathrm{R}$ \\
\hline 1 & 26 & 1 & 0 & 4 & 4 & & 0.658 & -0.001230 & -1.48 & $\mathrm{R}$ \\
\hline 1 & 27 & 1 & 0 & 4 & 4 & & 0.658 & $6.021 e-05$ & -1.56 & $\mathrm{R}$ \\
\hline 1 & 28 & 1 & 0 & 4 & 4 & & 0.659 & $\odot .001345$ & -1.63 & $\mathrm{R}$ \\
\hline 1 & 29 & 1 & $\odot$ & 4 & 4 & & 0.662 & $\odot .002413$ & -1.71 & $\mathrm{R}$ \\
\hline 1 & 30 & 1 & 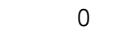 & 3 & 3 & & 0.665 & $\odot .003823$ & -1.78 & $\mathrm{R}$ \\
\hline 1 & 31 & 1 & 0 & 3 & 3 & & 0.671 & $\odot .005406$ & -1.86 & $\mathrm{R}$ \\
\hline 1 & 32 & 1 & 0 & 4 & 4 & & 0.678 & ๑.๑०6883 & -1.93 & $\mathrm{R}$ \\
\hline 1 & 33 & 1 & 0 & 4 & 4 & & 0.686 & ๑.๑๑8260 & -2.00 & $\mathrm{R}$ \\
\hline 1 & 34 & 1 & $\odot$ & 4 & 4 & & 0.696 & ๑.๑०9472 & -2.08 & $\mathrm{R}$ \\
\hline 1 & 35 & 1 & 0 & 4 & 4 & & 0.706 & ๑. 01051 & -2.16 & $\mathrm{R}$ \\
\hline 1 & 36 & 1 & 0 & 4 & 4 & & 0.717 & 0.01119 & -2.23 & $\mathrm{R}$ \\
\hline 1 & 37 & 1 & 0 & 4 & 4 & & 0.729 & 0.01164 & -2.31 & $\mathrm{R}$ \\
\hline 1 & 38 & 1 & 0 & 4 & 4 & & 0.741 & 0.01203 & -2.38 & $\mathrm{R}$ \\
\hline 1 & 39 & 1 & $\odot$ & 4 & 4 & & 0.753 & ๑. .01195 & -2.46 & $\mathrm{R}$ \\
\hline 1 & 40 & 1 & 0 & 4 & 4 & & 0.765 & ๑. 01215 & -2.53 & $\mathrm{R}$ \\
\hline 1 & 41 & 1 & $\odot$ & 4 & 4 & & 0.777 & 0.01227 & -2.60 & $\mathrm{R}$ \\
\hline 1 & 42 & 1 & 0 & 4 & 4 & & 0.790 & $\odot .01231$ & -2.68 & $\mathrm{R}$ \\
\hline 1 & 43 & 1 & $\odot$ & 4 & 4 & & 0.802 & 0.01221 & -2.75 & $\mathrm{R}$ \\
\hline 1 & 44 & 1 & $\odot$ & 4 & 4 & & 0.814 & ๑. 01211 & -2.83 & $\mathrm{R}$ \\
\hline 1 & 45 & 1 & 0 & 4 & 4 & & 0.826 & ๑. 01204 & -2.90 & $\mathrm{R}$ \\
\hline 1 & 46 & 1 & 0 & 4 & 4 & & 0.838 & 0.01187 & -2.97 & $\mathrm{R}$ \\
\hline 1 & 47 & 1 & 0 & 4 & 4 & & 0.849 & ๑. 01165 & -3.04 & $\mathrm{R}$ \\
\hline 1 & 48 & 1 & $\odot$ & 4 & 4 & & 0.861 & ๑. 01157 & -3.11 & $\mathrm{R}$ \\
\hline 1 & 49 & 1 & $\odot$ & 4 & 4 & & 0.873 & 0.01154 & -3.18 & $\mathrm{R}$ \\
\hline 1 & 50 & 1 & $\odot$ & 4 & 4 & & 0.884 & ๑. 01134 & -3.25 & $\mathrm{R}$ \\
\hline
\end{tabular}

THE ANALYSIS HAS COMPLETED SUCCESSFULLY 
bf Study: bf $=3.9^{\prime \prime}$

Fy=47ksi, $t=0.5^{\prime \prime}, \quad D=26^{\prime \prime}, h=26^{\prime \prime}, \quad d=10.15^{\prime \prime}, A=24.1^{\prime \prime}, B=24^{\prime \prime}$

ABAQUS VERSION 6.4-1 SUMMARY OF JOB INFORMATION :

MONITOR NODE: 186 DOF: 2

STEP INC ATT SEVERE EQUIL TOTAL DISCON ITERS ITERS TIME/

FREQ

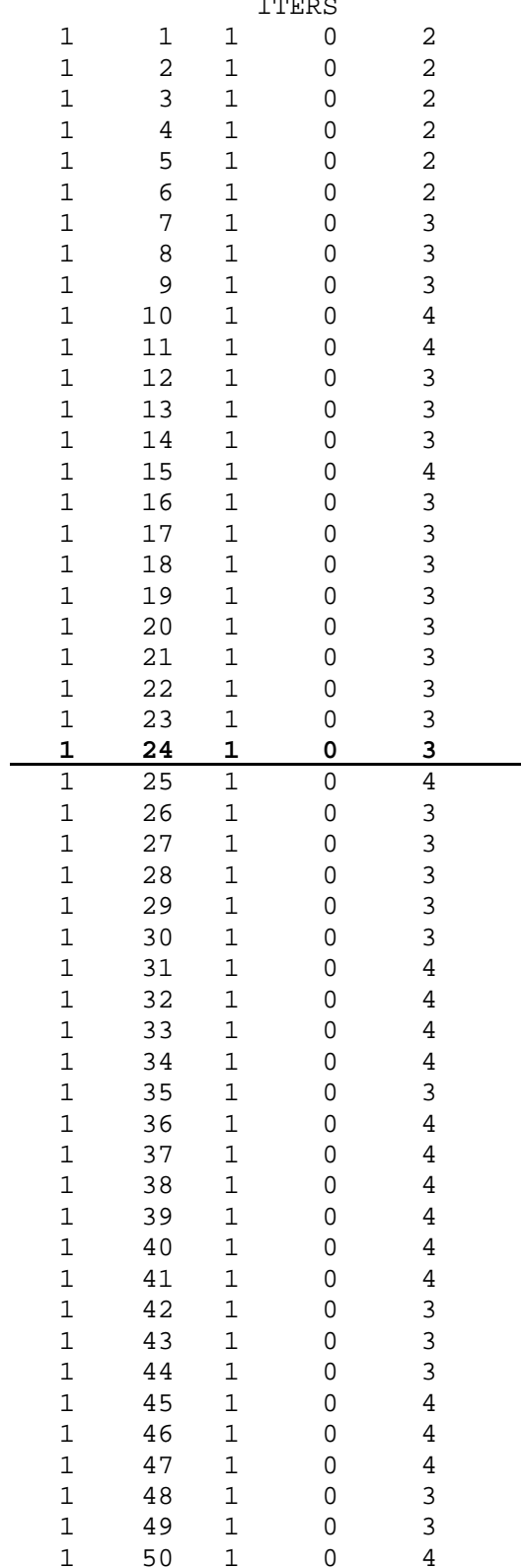

DATE 28-Apr-2004 TIME 20:07:21

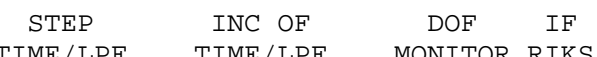

$0.00999 \quad 0.009988-0.00545 \quad R$

$0.0199 \quad 0.009962-0.0109 \quad R$

$0.0348 \quad 0.01490 \quad-0.0191 \quad R$

$\begin{array}{llll}0.0571 & 0.02225 & -0.0314 & R\end{array}$

$0.0902 \quad 0.03314 \quad-0.0498 \quad R$

$\begin{array}{llll}0.139 & 0.04920 & -0.0775 & R\end{array}$

$0.212 \quad 0.07240 \quad-0.119 \quad \mathrm{R}$

$\begin{array}{llll}0.303 & 0.09138 & -0.174 & R\end{array}$

$0.387 \quad 0.08354 \quad-0.230 \quad \mathrm{R}$

$\begin{array}{llll}0.462 & 0.07558 & -0.287 & R\end{array}$

$\begin{array}{llll}0.529 & 0.06663 & -0.349 & R\end{array}$

$\begin{array}{llll}0.585 & 0.05630 & -0.416 & R\end{array}$

$\begin{array}{llll}0.631 & 0.04576 & -0.483 & R\end{array}$

$\begin{array}{llll}0.667 & 0.03624 & -0.550 & R\end{array}$

$\begin{array}{llll}0.695 & 0.02808 & -0.620 & R\end{array}$

$\begin{array}{llll}0.717 & 0.02199 & -0.691 & R\end{array}$

$\begin{array}{llll}0.735 & 0.01719 & -0.761 & R\end{array}$

$\begin{array}{llll}0.748 & 0.01334 & -0.829 & R\end{array}$

$\begin{array}{llll}0.758 & 0.009887 & -0.896 & R\end{array}$

$0.765 \quad 0.007268 \quad-0.963 \quad \mathrm{R}$

$0.770 \quad 0.005072 \quad-1.03 \quad \mathrm{R}$

$0.774 \quad 0.003424 \quad-1.09 \quad \mathrm{R}$

$0.775 \quad 0.001698 \quad-1.16 \quad \mathrm{R}$

$0.775 \quad 1.689 \mathrm{e}-05 \quad-1.22 \quad R$

$\begin{array}{lll}-0.001567 & -1.29 & R \\ -0.002427 & -1.35\end{array}$

$0.768 \quad-0.003087 \quad-1.42 \quad \mathrm{R}$

$\begin{array}{llll}0.765 & -0.003208 & -1.48 & R\end{array}$

$0.762 \quad-0.003139 \quad-1.55 \quad R$

$\begin{array}{llll}0.759 & -0.002555 & -1.62 & R\end{array}$

$\begin{array}{llll}0.757 & -0.001759 & -1.68 & R\end{array}$

$0.757-0.0009671-1.75 \quad$ R

$0.756 \quad-8.882 \mathrm{e}-05 \quad-1.82 \quad \mathrm{R}$

$0.757 \quad 0.0006933-1.88 \quad \mathrm{R}$

$0.759 \quad 0.001676 \quad-1.95 \quad$ R

$0.761 \quad 0.002450 \quad-2.01 \quad \mathrm{R}$

$\begin{array}{llll}0.764 & 0.003235 & -2.08 & R\end{array}$

$\begin{array}{llll}0.768 & 0.003981 & -2.14 & R\end{array}$

$\begin{array}{llll}0.773 & 0.004969 & -2.21 & R\end{array}$

$\begin{array}{llll}0.779 & 0.005765 & -2.28 & R\end{array}$

$0.786 \quad 0.006651 \quad-2.34 \quad$ R

$\begin{array}{llll}0.793 & 0.007584 & -2.41 & R\end{array}$

$\begin{array}{llll}0.802 & 0.008499 & -2.48 & R\end{array}$

$\begin{array}{llll}0.811 & 0.009113 & -2.55 & R\end{array}$

$0.821 \quad 0.009745 \quad-2.62 \quad R$

$\begin{array}{llll}0.831 & 0.01024 & -2.68 & R\end{array}$

$0.841 \quad 0.01047 \quad-2.75 \quad R$

$\begin{array}{llll}0.852 & 0.01065 & -2.82 & R\end{array}$

$\begin{array}{llll}0.863 & 0.01081 & -2.88 & R \\ 0.874 & 0.01082 & -2.95 & R\end{array}$

THE ANALYSIS HAS COMPLETED SUCCESSFULLY 
bf Study: bf $=7.2^{\prime \prime}$

Fy=47ksi, $t=0.5^{\prime \prime}, \quad D=26^{\prime \prime}, h=26^{\prime \prime}, d=10.15^{\prime \prime}, A=24.1^{\prime \prime}, B=24^{\prime \prime}$

ABAQUS VERSION 6.4-1 SUMMARY OF JOB INFORMATION:

MONITOR NODE: 5273 DOF: 2

STEP INC ATT SEVERE EQUIL TOTAL DISCON ITERS ITERS

\begin{tabular}{|c|c|c|c|c|}
\hline & \multicolumn{4}{|c|}{ ITERS } \\
\hline 1 & 1 & 1 & $\odot$ & 2 \\
\hline 1 & 2 & 1 & $\odot$ & 2 \\
\hline 1 & 3 & 1 & $\odot$ & 2 \\
\hline 1 & 4 & 1 & $\odot$ & 2 \\
\hline 1 & 5 & 1 & $\odot$ & 2 \\
\hline 1 & 6 & 1 & $\odot$ & 2 \\
\hline 1 & 7 & 1 & $\odot$ & 2 \\
\hline 1 & 8 & 1 & $\odot$ & 3 \\
\hline 1 & 9 & 1 & $\odot$ & 3 \\
\hline 1 & 10 & 1 & $\odot$ & 3 \\
\hline 1 & 11 & 1 & $\odot$ & 4 \\
\hline 1 & 12 & 1 & $\odot$ & 3 \\
\hline 1 & 13 & 1 & $\odot$ & 4 \\
\hline 1 & 14 & 1 & $\odot$ & 4 \\
\hline 1 & 15 & 1 & $\odot$ & 3 \\
\hline 1 & 16 & 1 & $\odot$ & 3 \\
\hline 1 & 17 & 1 & $\odot$ & 3 \\
\hline 1 & 18 & 1 & $\odot$ & 3 \\
\hline 1 & 19 & 1 & 0 & 3 \\
\hline 1 & 20 & 1 & 0 & 3 \\
\hline 1 & 21 & 1 & 0 & 3 \\
\hline 1 & 22 & 1 & 0 & 3 \\
\hline 1 & 23 & 1 & 0 & 3 \\
\hline 1 & 24 & 1 & 0 & 3 \\
\hline 1 & 25 & 1 & 0 & 3 \\
\hline
\end{tabular}

FREQ

DATE 28-Apr-2004 TIME 20:39:40

STEP INC OF DOF IF

TIME/LPF TIME/LPF MONITOR RIKS

$\begin{array}{llll}0.00999 & 0.009989 & -0.00420 & R\end{array}$

$\begin{array}{llll}0.0200 & 0.009966 & -0.00839 & R\end{array}$

$0.0349 \quad 0.01491 \quad-0.0147 \quad R$

$\begin{array}{lllll}0.0571 & 0.02228 & -0.0241 & R\end{array}$

$0.0904 \quad 0.03322 \quad-0.0383 \quad R$

$\begin{array}{llll}0.140 & 0.04938 & -0.0596 & R\end{array}$

$\begin{array}{llll}0.213 & 0.07297 & -0.0915 \quad R\end{array}$

$\begin{array}{llll}0.305 & 0.09256 & -0.134 & R\end{array}$

$\begin{array}{llll}0.390 & 0.08503 & -0.177 & R\end{array}$

$\begin{array}{llll}0.471 & 0.08027 & -0.220 & R\end{array}$

$\begin{array}{llll}0.545 & 0.07460 & -0.270 & R\end{array}$

$\begin{array}{llll}0.612 & 0.06698 & -0.324 & R\end{array}$

$\begin{array}{llll}0.673 & 0.06050 & -0.380 & R\end{array}$

$\begin{array}{llll}0.726 & 0.05318 & -0.448 & R\end{array}$

$\begin{array}{llll}0.771 & 0.04553 & -0.514 & R\end{array}$

$0.808 \quad 0.03676 \quad-0.577 \quad \mathrm{R}$

$\begin{array}{llll}0.837 & 0.02842 & -0.637 & R\end{array}$

$0.858 \quad 0.02180 \quad-0.694 \quad R$

$0.876 \quad 0.01744 \quad-0.749 \quad \mathrm{R}$

$\begin{array}{lllll}0.890 & 0.01400 & -0.803 & R\end{array}$

$\begin{array}{llll}0.901 & 0.01115 & -0.856 \quad R\end{array}$

$\begin{array}{llll}0.909 & 0.008551 & -0.907 & R\end{array}$

$0.916 \quad 0.006230 \quad-0.958 \quad R$

$\begin{array}{llll}0.920 & 0.004084 & -1.01 & R\end{array}$

$0.922 \quad 0.001866-1.06 \quad \mathrm{R}$

$0.922 \quad 0.0004311-1.10 \quad R$

$\begin{array}{llll}0.921 & -0.0009663 & -1.15 & R \\ 0.919 & -0.001942 & -1.20 & R\end{array}$

$0.916-0.002829-1.25 \quad R$

$\begin{array}{llll}0.913 & -0.003470 & -1.30 & R\end{array}$

$\begin{array}{llll}0.909 & -0.003809 & -1.35 & R\end{array}$

$\begin{array}{llll}0.905 & -0.004116 & -1.40 & R\end{array}$

$\begin{array}{llll}0.901 & -0.004371 & -1.45 & R\end{array}$

$\begin{array}{llll}0.896 & -0.004506 & -1.50 & R\end{array}$

$\begin{array}{llll}0.892 & -0.004575 & -1.55 & R\end{array}$

$0.887-0.004558-1.60 \quad$ R

$0.882 \quad-0.004462 \quad-1.65 \quad R$

$0.878 \quad-0.004186 \quad-1.70 \quad R$

$0.874 \quad-0.003931 \quad-1.75 \quad R$

$\begin{array}{llll}0.871 & -0.003585 & -1.80 & R\end{array}$

$0.868 \quad-0.003189 \quad-1.85 \quad R$

$0.865 \quad-0.002726 \quad-1.90 \quad R$

$0.863-0.002286 \quad-1.95 \quad R$

$\begin{array}{llll}0.861 & -0.001768 & -2.00 & R\end{array}$

$0.860-0.001304 \quad-2.05 \quad R$

$\begin{array}{llll}0.859 & -0.0006799 & -2.10 & R\end{array}$

$\begin{array}{llll}0.859 & -5.059 \mathrm{e}-05 & -2.15 & \mathrm{R}\end{array}$

$\begin{array}{llll}0.859 & 0.0004676 & -2.20 & R\end{array}$

$\begin{array}{llll}0.860 & 0.0009563 & -2.25 & R \\ 0.862 & 0.001648 & -2.30 & R\end{array}$

THE ANALYSIS HAS COMPLETED SUCCESSFULLY 
bf Study: bf $=11.7^{\prime \prime}$

$F y=47 \mathrm{ksi}, t=0.5^{\prime \prime}, D=26^{\prime \prime}, h=26^{\prime \prime}, d=10.15^{\prime \prime}, A=24.1^{\prime \prime}, B=24 "$

ABAQUS VERSION 6.4-1

DATE 28-Apr-2004 TIME 20:34:39

SUMMARY OF JOB INFORMATION:

MONITOR NODE: 186 DOF: 2

STEP INC ATT SEVERE EQUIL TOTAL DISCON ITERS ITERS TIME

TIME/

STEP INC OF DOF IF ITERS

\begin{tabular}{rrrrl}
1 & 1 & 1 & $\odot$ & 2 \\
1 & 2 & 1 & $\odot$ & 2 \\
1 & 3 & 1 & $\odot$ & 2 \\
1 & 4 & 1 & $\odot$ & 2 \\
1 & 5 & 1 & $\odot$ & 2 \\
1 & 6 & 1 & $\odot$ & 2 \\
1 & 7 & 1 & $\odot$ & 2 \\
1 & 8 & 1 & $\odot$ & 3 \\
1 & 9 & 1 & $\odot$ & 3 \\
1 & $1 \odot$ & 1 & $\odot$ & 4 \\
1 & 11 & 1 & $\odot$ & 4 \\
1 & 12 & 1 & $\odot$ & 3 \\
1 & 13 & 1 & $\odot$ & 4 \\
1 & 14 & 1 & $\odot$ & 3 \\
1 & 15 & 1 & $\odot$ & 3 \\
1 & 16 & 1 & $\odot$ & 3 \\
1 & 17 & 1 & $\odot$ & 3 \\
1 & 18 & 1 & $\odot$ & 3 \\
1 & 19 & 1 & $\odot$ & 3 \\
1 & $2 \odot$ & 1 & $\odot$ & 3 \\
1 & 21 & 1 & $\odot$ & 3 \\
1 & 22 & 1 & $\odot$ & 3 \\
1 & 23 & 1 & $\odot$ & 3 \\
1 & 24 & 1 & $\odot$ & 3 \\
1 & 25 & 1 & $\odot$ & 3 \\
1 & 26 & 1 & $\odot$ & 3 \\
1 & 27 & 1 & $\odot$ & 3 \\
1 & 28 & 1 & $\odot$ & 3 \\
1 & 29 & 1 & $\odot$ & 3 \\
1 & $3 \odot$ & 1 & $\odot$ & 3 \\
1 & 31 & 1 & $\odot$ & 3 \\
1 & 32 & 1 & $\odot$ & 3 \\
1 & 33 & 1 & $\odot$ & 3 \\
1 & 34 & 1 & $\odot$ & 3 \\
1 & 35 & 1 & $\odot$ & 3 \\
1 & 36 & 1 & 0 & 3 \\
\hline 1 & 37 & 1 & $\odot$ & 3 \\
1 & 38 & 1 & $\odot$ & 3 \\
1 & 39 & 1 & $\odot$ & 3 \\
1 & $4 \odot$ & 1 & $\odot$ & 3 \\
1 & 41 & 1 & $\odot$ & 3 \\
1 & 42 & 1 & $\odot$ & 3 \\
1 & 43 & 1 & $\odot$ & 3 \\
1 & 44 & 1 & $\odot$ & 3 \\
1 & 45 & 1 & $\odot$ & 3 \\
1 & 46 & 1 & $\odot$ & 3 \\
1 & 47 & 1 & $\odot$ & 3 \\
1 & 48 & 1 & $\odot$ & 3 \\
1 & 49 & 1 & $\odot$ & 3 \\
1 & $5 \odot$ & 1 & $\odot$ & 3 \\
& & & &
\end{tabular}

FREQ

TIME/LPF TIME/LPF MONITOR RIKS

$\begin{array}{llll}0.00999 & 0.009991 & -0.00278 \quad R\end{array}$

$0.0200 \quad 0.009971 \quad-0.00556 \quad R$

$0.0349 \quad 0.01493 \quad-0.00973 \quad R$

$0.0572 \quad 0.02232 \quad-0.0160 \quad R$

$\begin{array}{llll}0.0905 & 0.03332 & -0.0254 & R\end{array}$

$\begin{array}{llll}0.140 & 0.04962 & -0.0395 & R\end{array}$

$\begin{array}{llll}0.214 & 0.07363 & -0.0606 \quad R\end{array}$

$\begin{array}{llll}0.309 & 0.09473 & -0.0884 & R\end{array}$

$\begin{array}{llll}0.400 & 0.09134 & -0.116 & R\end{array}$

$\begin{array}{llll}0.484 & 0.08417 & -0.146 & R\end{array}$

$\begin{array}{llll}0.565 & 0.08055 & -0.183 & R\end{array}$

$\begin{array}{llll}0.639 & 0.07489 & -0.223 & R\end{array}$

$\begin{array}{llll}0.708 & 0.06866 & -0.276 & R\end{array}$

$\begin{array}{llll}0.770 & 0.06212 & -0.334 & R\end{array}$

$\begin{array}{llll}0.828 & 0.05786 & -0.391 & R\end{array}$

$\begin{array}{llll}0.883 & 0.05455 & -0.447 & R\end{array}$

$\begin{array}{llll}0.933 & 0.05074 & -0.501 & R\end{array}$

$\begin{array}{llll}0.978 & 0.04483 & -0.553 & R\end{array}$

$\begin{array}{llll}1.02 & 0.03893 & -0.601 & R\end{array}$

$\begin{array}{llll}1.05 & 0.03352 & -0.647 & R\end{array}$

$\begin{array}{llll}1.08 & 0.02885 & -0.691 & R\end{array}$

$\begin{array}{llll}1.10 & 0.02534 & -0.732 & R\end{array}$

$\begin{array}{llll}1.13 & 0.02261 & -0.773 & R\end{array}$

$\begin{array}{llll}1.15 & 0.02057 & -0.812 & R\end{array}$

$\begin{array}{llll}1.17 & 0.01861 & -0.851 & R\end{array}$

$\begin{array}{llll}1.18 & 0.01643 & -0.889 & R\end{array}$

$\begin{array}{llll}1.20 & 0.01410 & -0.926 & R\end{array}$

$\begin{array}{llll}1.21 & 0.01138 & -0.961 & R\end{array}$

$\begin{array}{llll}1.22 & 0.008924 & -0.995 & R\end{array}$

$\begin{array}{llll}1.22 & 0.007202 & -1.03 & R\end{array}$

$\begin{array}{llll}1.23 & 0.005827 & -1.06 & R\end{array}$

$\begin{array}{llll}1.24 & 0.004536 & -1.09 & R\end{array}$

$\begin{array}{llll}1.24 & 0.003319 & -1.12 & \mathrm{R} \\ 1.24 & 0.002148 & -1.16 & \mathrm{R}\end{array}$

$\begin{array}{llll}1.24 & 0.002148 & -1.16 & R \\ 1.24 & 0.001131 & -1.19 & R\end{array}$

\begin{tabular}{llll}
$\mathbf{1 . 2 4}$ & $\mathbf{0 . 0 0 0 3 3 8 1}$ & $\mathbf{- 1 . 2 2}$ & $\mathbf{R}$ \\
\hline 1.24 & -0.0003163 & -1.25 & $\mathrm{R}$
\end{tabular}

$\begin{array}{llll}1.24 & -0.0009330 & -1.28 & R\end{array}$

$\begin{array}{llll}1.24 & -0.001612 & -1.31 & R\end{array}$

$\begin{array}{llll}1.24 & -0.002111 & -1.34 & R\end{array}$

$\begin{array}{llll}1.23 & -0.002554 & -1.37 & R\end{array}$

$\begin{array}{llll}1.23 & -0.002932 & -1.40 & R \\ 1.23 & -0.003209 & -1.43 & R\end{array}$

$\begin{array}{llll}1.23 & -0.003209 & -1.43 & R\end{array}$

$\begin{array}{llll}1.22 & -0.003533 & -1.46 & \mathrm{R} \\ 1.22 & -0.003775 & -1.49 & \mathrm{R}\end{array}$

$\begin{array}{llll}1.22 & -0.004004 & -1.52 & R\end{array}$

$\begin{array}{llll}1.21 & -0.004166 & -1.55 & R\end{array}$

$\begin{array}{llll}1.21 & -0.004300 & -1.59 & R\end{array}$

$\begin{array}{llll}1.20 & -0.004411 & -1.62 & \mathrm{R} \\ 1.20 & -0.004469 & -1.65 & \mathrm{R}\end{array}$

THE ANALYSIS HAS COMPLETED SUCCESSFULLY 
bf Study: bf $=15.6^{\prime \prime}$

$F y=47 \mathrm{ksi}, t=0.5^{\prime \prime}, D=26^{\prime \prime}, h=26^{\prime \prime}, d=10.15^{\prime \prime}, A=24.1^{\prime \prime}, B=24 "$

ABAQUS VERSION 6.4-1

DATE 28-Apr-2004 TIME 22:56:00 SUMMARY OF JOB INFORMATION:

MONITOR NODE: 186 DOF: 2

STEP INC ATT SEVERE EQUIL TOTAL

$\begin{array}{lllll} & & & & \\ \text { TIME/ } & \text { TIME/LPF } & \text { TIME/LPF } & \text { MONITOR } & \text { RIKS }\end{array}$

ITERS

\begin{tabular}{|c|c|c|c|c|}
\hline 1 & 1 & 1 & 0 & 2 \\
\hline 1 & 2 & 1 & 0 & 2 \\
\hline 1 & 3 & 1 & 0 & 2 \\
\hline 1 & 4 & 1 & $\odot$ & 2 \\
\hline 1 & 5 & 1 & 0 & 2 \\
\hline 1 & 6 & 1 & 0 & 2 \\
\hline 1 & 7 & 1 & $\odot$ & 2 \\
\hline 1 & 8 & 1 & 0 & 2 \\
\hline 1 & 9 & 1 & 0 & 3 \\
\hline 1 & 10 & 1 & $\odot$ & 4 \\
\hline 1 & 11 & 1 & $\Theta$ & 4 \\
\hline 1 & 12 & 1 & $\odot$ & 4 \\
\hline 1 & 13 & 1 & 0 & 4 \\
\hline 1 & 14 & 1 & 0 & 3 \\
\hline 1 & 15 & 1 & $\odot$ & 3 \\
\hline 1 & 16 & 1 & 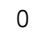 & 3 \\
\hline 1 & 17 & 1 & $\odot$ & 3 \\
\hline 1 & 18 & 1 & $\theta$ & 3 \\
\hline 1 & 19 & 1 & 0 & 3 \\
\hline 1 & 20 & 1 & $\odot$ & 3 \\
\hline 1 & 21 & 1 & $\odot$ & 3 \\
\hline 1 & 22 & 1 & $\odot$ & 3 \\
\hline 1 & 23 & 1 & 0 & 3 \\
\hline 1 & 24 & 1 & 0 & 3 \\
\hline 1 & 25 & 1 & $\odot$ & 3 \\
\hline 1 & 26 & 1 & $\odot$ & 3 \\
\hline 1 & 27 & 1 & 0 & 3 \\
\hline 1 & 28 & 1 & 0 & 3 \\
\hline 1 & 29 & 1 & 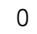 & 3 \\
\hline 1 & 30 & 1 & 0 & 3 \\
\hline 1 & 31 & 1 & 0 & 3 \\
\hline 1 & 32 & 1 & 0 & 3 \\
\hline 1 & 33 & 1 & 0 & 3 \\
\hline 1 & 34 & 1 & 0 & 3 \\
\hline 1 & 35 & 1 & 0 & 3 \\
\hline 1 & 36 & 1 & 0 & 3 \\
\hline 1 & 37 & 1 & 0 & 3 \\
\hline 1 & 38 & 1 & 0 & 3 \\
\hline 1 & 39 & 1 & 0 & 3 \\
\hline 1 & 40 & 1 & 0 & 3 \\
\hline 1 & 41 & 1 & 0 & 3 \\
\hline 1 & 42 & 1 & $\odot$ & 3 \\
\hline 1 & 43 & 1 & 0 & 3 \\
\hline 1 & 44 & 1 & 0 & 3 \\
\hline 1 & 45 & 1 & 0 & 3 \\
\hline 1 & 46 & 1 & 0 & 3 \\
\hline 1 & 47 & 1 & 0 & 3 \\
\hline 1 & 48 & 1 & 0 & 3 \\
\hline 1 & 49 & 1 & 0 & 2 \\
\hline 1 & 50 & 1 & 0 & 3 \\
\hline 1 & 51 & 1 & $\Theta$ & 3 \\
\hline 1 & 52 & 1 & $\odot$ & 2 \\
\hline 1 & 53 & 1 & 0 & 2 \\
\hline 1 & 54 & 1 & 0 & 3 \\
\hline 1 & 55 & 1 & $\odot$ & 2 \\
\hline 1 & 56 & 1 & 0 & 3 \\
\hline 1 & 57 & 1 & 0 & 3 \\
\hline 1 & 58 & 1 & $\theta$ & 3 \\
\hline 1 & 59 & 1 & 0 & 4 \\
\hline 1 & 60 & 1 & 0 & 3 \\
\hline 1 & 61 & 1 & 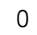 & 3 \\
\hline 1 & 62 & 1 & 0 & 3 \\
\hline
\end{tabular}

FREQ

TIME/LPF

$0.00999 \quad 0.009993 \quad-0.00191 \quad R$

$0.0200 \quad 0.009976 \quad-0.00383 \quad R$

$\begin{array}{lll}0.0349 & 0.01494 & -0.00670 \quad R\end{array}$

$0.0573 \quad 0.02235 \quad-0.0110 \quad R$

$\begin{array}{llll}0.0906 & 0.03339 & -0.0175 & R\end{array}$

$0.140 \quad 0.04978 \quad-0.0271 \quad R$

$\begin{array}{llll}0.214 & 0.07400 & -0.0417 \quad R\end{array}$

$0.311 \quad 0.09624 \quad-0.0608 \quad R$

$\begin{array}{llll}0.405 & 0.09387 & -0.0799 & R\end{array}$

$0.496 \quad 0.09104 \quad-0.102 \quad R$

$\begin{array}{llll}0.581 & 0.08567 & -0.131 & R\end{array}$

$\begin{array}{llll}0.661 & 0.08001 & -0.165 & R\end{array}$

$\begin{array}{llll}0.735 & 0.07370 & -0.215 & R\end{array}$

$\begin{array}{llll}0.805 & 0.07004 & -0.268 & R\end{array}$

$\begin{array}{llll}0.869 & 0.06443 & -0.320 & R\end{array}$

$\begin{array}{llll}0.928 & 0.05905 & -0.369 & R\end{array}$

$\begin{array}{llll}0.985 & 0.05651 & -0.416 & R\end{array}$

$\begin{array}{llll}1.04 & 0.05399 & -0.463 & R\end{array}$

$\begin{array}{llll}1.09 & 0.05065 & -0.508 & R\end{array}$

$\begin{array}{llll}1.14 & 0.04694 & -0.551 & R \\ 1.18 & 0.04299 & -0.593 & R\end{array}$

$\begin{array}{llll}1.22 & 0.03783 & -0.632 & R\end{array}$

$\begin{array}{llll}1.25 & 0.03361 & -0.668 & R\end{array}$

$\begin{array}{llll}1.28 & 0.03107 & -0.704 & R\end{array}$

$\begin{array}{llll}1.31 & 0.02893 & -0.739 & R\end{array}$

$\begin{array}{llll}1.34 & 0.02637 & -0.772 & R\end{array}$

$\begin{array}{llll}1.36 & 0.02446 & -0.805 & R\end{array}$

$\begin{array}{llll}1.38 & 0.02268 & -0.836 & R\end{array}$

$\begin{array}{llll}1.41 & 0.02125 & -0.867 & R \\ 1.43 & 0.01989 & -0.898 & R\end{array}$

$\begin{array}{llll}1.43 & 0.01980 & -0.898 & R \\ 1.44 & 0.01846 & -0.929 & R\end{array}$

$\begin{array}{llll}1.46 & 0.01717 & -0.959 & R\end{array}$

$\begin{array}{llll}1.48 & 0.01581 & -0.988 & R \\ 1.49 & 0.01458 & -1.02 & R\end{array}$

$\begin{array}{llll}1.49 & 0.01458 & -1.02 & R\end{array}$

$\begin{array}{llll}1.50 & 0.01305 & -1.05 & R \\ 1.52 & 0.01153 & -1.07 & R\end{array}$

$\begin{array}{llll}1.53 & 0.01058 & -1.10 & R\end{array}$

$\begin{array}{llll}1.54 & 0.009693 & -1.13 & R\end{array}$

$\begin{array}{llll}1.55 & 0.009005 & -1.15 & R\end{array}$

$\begin{array}{llll}1.55 & 0.008097 & -1.18 & \mathrm{R} \\ 1.56 & 0.006952 & -1.21 & \mathrm{R}\end{array}$

$\begin{array}{llll}1.57 & 0.006154 & -1.23 & R\end{array}$

$\begin{array}{llll}1.57 & 0.006154 & -1.23 & \mathrm{R} \\ 1.57 & 0.005552 & -1.25 & \mathrm{R}\end{array}$

$\begin{array}{llll}1.58 & 0.004976 & -1.28 & R\end{array}$

$\begin{array}{llll}1.58 & 0.004328 & -1.30 & R\end{array}$

$\begin{array}{llll}1.59 & 0.003786 & -1.33 & R\end{array}$

$\begin{array}{llll}1.59 & 0.003229 & -1.35 & R\end{array}$

$\begin{array}{llll}1.59 & 0.002649 & -1.37 & R\end{array}$

$\begin{array}{llll}1.59 & 0.002226 & -1.39 & \mathrm{R}\end{array}$

$\begin{array}{llll}1.60 & 0.001901 & -1.41 & R\end{array}$

$\begin{array}{llll}1.60 & 0.001495 & -1.44 & R \\ 1.60 & 0.001142 & -1.46 & R\end{array}$

$1.60 \quad 0.001142 \quad-1.46 \quad \mathrm{R}$

$\begin{array}{llll}1.60 & 0.0008745 & -1.48 & R \\ 1.60 & 0.0006017 & -1.50 & R\end{array}$

$1.60 \quad 0.0004027-1.52 \quad R$

$1.60 \quad 0.0002054-1.54 \quad \mathrm{R}$

$\begin{array}{llll}1.60 & 1.846 \mathrm{e}-05 & -1.56 & \mathrm{R} \\ 1.60 & -0.0001949 & -1.57 & \mathrm{R}\end{array}$

$\begin{array}{llll}1.60 & -0.0003778 & -1.59 & R\end{array}$

$1.60-0.0005166-1.61 \quad R$

$\begin{array}{llll}1.60 & -0.0006529 & -1.63 & R\end{array}$

$1.60 \quad-0.0008757-1.65$ 


$\begin{array}{llllllllll}1 & 63 & 1 & 0 & 3 & 3 & 1.60 & -0.001023 & -1.67 & \mathrm{R} \\ 1 & 64 & 1 & 0 & 3 & 3 & 1.60 & -0.001216 & -1.69 & \mathrm{R} \\ 1 & 65 & 1 & 0 & 3 & 3 & 1.59 & -0.001371 & -1.71 & \mathrm{R} \\ 1 & 66 & 1 & 0 & 3 & 3 & 1.59 & -0.001504 & -1.73 & \mathrm{R} \\ 1 & 67 & 1 & 0 & 3 & 3 & 1.59 & -0.001607 & -1.75 & \mathrm{R} \\ 1 & 68 & 1 & 0 & 3 & 3 & 1.59 & -0.001703 & -1.77 & \mathrm{R} \\ 1 & 69 & 1 & 0 & 3 & 3 & 1.59 & -0.001783 & -1.79 & \mathrm{R} \\ 1 & 70 & 1 & 0 & 3 & 3 & 1.59 & -0.001881 & -1.81 & \mathrm{R}\end{array}$

THE ANALYSIS HAS COMPLETED SUCCESSFULLY 


\begin{tabular}{|c|c|c|c|c|c|c|c|c|c|c|}
\hline \multicolumn{11}{|c|}{ D Study: $D=10^{\prime \prime}, h=10^{\prime \prime}, \quad b f=2.7^{\prime \prime}, A=9.27^{\prime \prime}, B=8 "$} \\
\hline ABAQU & $S$ VER & SIOI & N $6.4-1$ & & & & DATE & $23-A p r-2004$ & TIME 10: & $54: 39$ \\
\hline SUMMA & & $\mathrm{JOH}$ & B INFORN & MATION & & & & & & \\
\hline MONIT & OR NO & DE : & 142 & 2 DOF & 2 & & & & & \\
\hline STEP & INC & ATT & SEVERE & EQUIL & TOTAL & TOTAL & STEP & INC OF & DOF & IF \\
\hline & & & $\begin{array}{l}\text { DISCON } \\
\text { ITERS }\end{array}$ & ITERS & ITERS & $\begin{array}{l}\text { TIME/ } \\
\text { FREQ }\end{array}$ & TIME/LPF & TIME/LPF & MONITOR & RIKS \\
\hline 1 & 1 & 1 & $\odot$ & 2 & 2 & & 0.0100 & $\odot .0 \odot 9995$ & -0.00134 & $\mathrm{R}$ \\
\hline 1 & 2 & 1 & $\odot$ & 2 & 2 & & $\odot .0200$ & $\odot .009985$ & -0.00269 & $\mathrm{R}$ \\
\hline 1 & 3 & 1 & 0 & 2 & 2 & & $\odot .0349$ & ๑.01496 & $-\odot .0 \odot 470$ & $\mathrm{R}$ \\
\hline 1 & 4 & 1 & $\odot$ & 2 & 2 & & $\odot .0573$ & $\odot .02240$ & $-\odot .00772$ & $\mathrm{R}$ \\
\hline 1 & 5 & 1 & $\odot$ & 2 & 2 & & $\odot .0909$ & 0.03352 & -0.0123 & $\mathrm{R}$ \\
\hline 1 & 6 & 1 & $\odot$ & 2 & 2 & & 0.141 & 0.05008 & -0.0191 & $\mathrm{R}$ \\
\hline 1 & 7 & 1 & $\odot$ & 2 & 2 & & 0.216 & 0.07468 & -0.0292 & $\mathrm{R}$ \\
\hline 1 & 8 & 1 & $\odot$ & 5 & 5 & & $\odot .312$ & $\odot .09660$ & $-\odot .0484$ & $\mathrm{R}$ \\
\hline 1 & 9 & 1 & $\odot$ & 5 & 5 & & $\odot .4 \odot 4$ & ๑. 09164 & $-\odot .0861$ & $\mathrm{R}$ \\
\hline 1 & 10 & 1 & $\odot$ & 4 & 4 & & $\odot .486$ & $\odot .08167$ & -0.138 & $\mathrm{R}$ \\
\hline 1 & 11 & 1 & $\odot$ & 4 & 4 & & 0.556 & $\odot .07081$ & -0.186 & $\mathrm{R}$ \\
\hline 1 & 12 & 1 & $\odot$ & 3 & 3 & & 0.617 & 0.06056 & -0.229 & $\mathrm{R}$ \\
\hline 1 & 13 & 1 & $\odot$ & 3 & 3 & & 0.670 & $\odot .05284$ & -0.269 & $\mathrm{R}$ \\
\hline 1 & 14 & 1 & $\odot$ & 3 & 3 & & 0.716 & $\odot .04656$ & -0.305 & $\mathrm{R}$ \\
\hline 1 & 15 & 1 & 0 & 3 & 3 & & 0.755 & 0.03855 & -0.339 & $\mathrm{R}$ \\
\hline 1 & 16 & 1 & $\odot$ & 3 & 3 & & $\odot .785$ & $\odot .03056$ & -0.368 & $\mathrm{R}$ \\
\hline 1 & 17 & 1 & 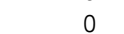 & 4 & 4 & & 0.811 & 0.02519 & -0.395 & $\mathrm{R}$ \\
\hline 1 & 18 & 1 & $\odot$ & 3 & 3 & & $\odot .832$ & 0.02138 & -0.420 & $\mathrm{R}$ \\
\hline 1 & 19 & 1 & $\odot$ & 3 & 3 & & 0.850 & 0.01822 & -0.444 & $\mathrm{R}$ \\
\hline 1 & 20 & 1 & 0 & 3 & 3 & & 0.865 & 0.01489 & -0.467 & $\mathrm{R}$ \\
\hline 1 & 21 & 1 & $\odot$ & 3 & 3 & & $\odot .877$ & $\odot .01201$ & -0.488 & $\mathrm{R}$ \\
\hline 1 & 22 & 1 & 0 & 3 & 3 & & 0.887 & 0.01002 & -0.508 & $\mathrm{R}$ \\
\hline 1 & 23 & 1 & $\odot$ & 3 & 3 & & $\odot .896$ & $\odot .0 \odot 840 \odot$ & -0.527 & $\mathrm{R}$ \\
\hline 1 & 24 & 1 & $\odot$ & 3 & 3 & & 0.903 & $\odot .007123$ & -0.546 & $\mathrm{R}$ \\
\hline 1 & 25 & 1 & 0 & 3 & 3 & & 0.909 & 0.006048 & -0.563 & $\mathrm{R}$ \\
\hline 1 & 26 & 1 & $\odot$ & 3 & 3 & & $\odot .914$ & $\odot .0 \odot 5153$ & -0.581 & $\mathrm{R}$ \\
\hline 1 & 27 & 1 & $\odot$ & 3 & 3 & & 0.918 & 0.004376 & -0.597 & $\mathrm{R}$ \\
\hline 1 & 28 & 1 & $\odot$ & 3 & 3 & & 0.922 & $\odot .003622$ & -0.614 & $\mathrm{R}$ \\
\hline 1 & 29 & 1 & $\odot$ & 3 & 3 & & 0.925 & $\odot . \odot \odot 29 \odot 6$ & $-\odot .629$ & $\mathrm{R}$ \\
\hline 1 & 30 & 1 & 0 & 3 & 3 & & 0.927 & 0.002270 & -0.645 & $\mathrm{R}$ \\
\hline 1 & 31 & 1 & $\odot$ & 3 & 3 & & $\odot .929$ & $\odot .001823$ & -0.660 & $\mathrm{R}$ \\
\hline 1 & 32 & 1 & $\odot$ & 3 & 3 & & $\odot .930$ & $\odot .001442$ & -0.675 & $\mathrm{R}$ \\
\hline 1 & 33 & 1 & $\odot$ & 3 & 3 & & 0.931 & $\odot .001007$ & -0.689 & $\mathrm{R}$ \\
\hline 1 & 34 & 1 & 0 & 3 & 3 & & 0.932 & $\odot .0 \odot \odot 6236$ & -0.704 & $\mathrm{R}$ \\
\hline 1 & 35 & 1 & 0 & 3 & 3 & & 0.932 & 0.0003222 & -0.718 & $\mathrm{R}$ \\
\hline 1 & 36 & 1 & 0 & 3 & 3 & & 0.932 & $2.230 \mathrm{e}-05$ & -0.732 & $\mathbf{R}$ \\
\hline$\overline{1}$ & 37 & 1 & $\theta$ & 3 & 3 & & 0.932 & -0.0002915 & -0.746 & $\overline{\mathrm{R}}$ \\
\hline 1 & 38 & 1 & 0 & 3 & 3 & & 0.931 & -0.0005505 & -0.760 & $\mathrm{R}$ \\
\hline 1 & 39 & 1 & 0 & 3 & 3 & & 0.931 & -๑.๑๑९७7๑7 & -0.774 & $\mathrm{R}$ \\
\hline 1 & 40 & 1 & $\odot$ & 3 & 3 & & 0.930 & -0.0009434 & -0.788 & $\mathrm{R}$ \\
\hline 1 & 41 & 1 & $\odot$ & 3 & 3 & & $\odot .929$ & $-\odot .001085$ & -0.801 & $\mathrm{R}$ \\
\hline 1 & 42 & 1 & $\odot$ & 3 & 3 & & 0.927 & $-\odot .001234$ & -0.815 & $\mathrm{R}$ \\
\hline 1 & 43 & 1 & $\odot$ & 3 & 3 & & 0.926 & -0.001375 & -0.829 & $\mathrm{R}$ \\
\hline 1 & 44 & 1 & $\odot$ & 3 & 3 & & 0.925 & -0.001471 & -0.843 & $\mathrm{R}$ \\
\hline 1 & 45 & 1 & $\odot$ & 3 & 3 & & 0.923 & $-\odot .0 \odot 15 \odot 3$ & -0.857 & $\mathrm{R}$ \\
\hline 1 & 46 & 1 & $\odot$ & 3 & 3 & & $\odot .921$ & $-\odot .001555$ & -0.871 & $\mathrm{R}$ \\
\hline 1 & 47 & 1 & 0 & 3 & 3 & & 0.920 & $-\odot . \odot \odot 1616$ & -0.885 & $\mathrm{R}$ \\
\hline 1 & 48 & 1 & $\Theta$ & 3 & 3 & & 0.918 & -0.001643 & -0.899 & $\mathrm{R}$ \\
\hline 1 & 49 & 1 & $\odot$ & 3 & 3 & & $\odot .917$ & $-\odot .0 \odot 1681$ & -0.913 & $\mathrm{R}$ \\
\hline 1 & 50 & 1 & $\odot$ & 3 & 3 & & $\odot .915$ & $-\odot .0 \odot 185 \odot$ & -0.928 & $\mathrm{R}$ \\
\hline
\end{tabular}

THE ANALYSIS HAS COMPLETED SUCCESSFULLY 


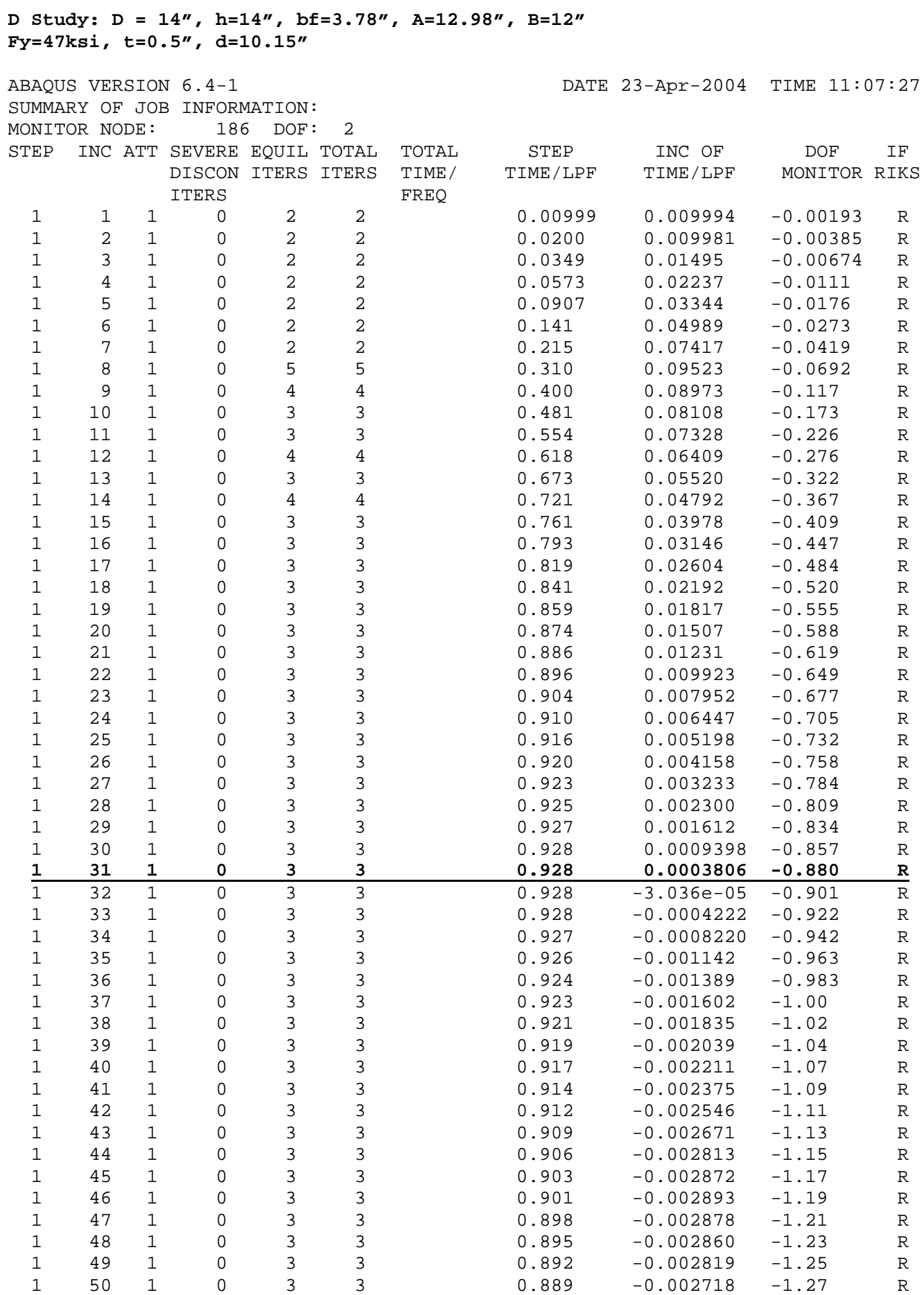

THE ANALYSIS HAS COMPLETED SUCCESSFULLY 


\begin{tabular}{|c|c|c|c|c|c|c|c|c|c|c|}
\hline \multicolumn{10}{|c|}{ D Study: $D=20^{\prime \prime}, h=20^{\prime \prime}, b f=5.4^{\prime \prime}, A=18.54^{\prime \prime}, B=18^{\prime \prime}$} & \\
\hline $\begin{array}{l}\text { ABAQU } \\
\text { SUMMA }\end{array}$ & $\begin{array}{l}S \text { VEF } \\
\text { RY OF }\end{array}$ & $\begin{array}{r}\text { SIOI } \\
\text { JOE }\end{array}$ & $\begin{array}{ll}N & 6.4-1 \\
\text { B } & \text { INFORM }\end{array}$ & MATION : & & & DATE & $23-A p r-2004$ & TIME $11: 2$ & $27: 45$ \\
\hline MONIT & OR NC & E : & 230 & DOF : & 2 & & & & & \\
\hline STEP & INC & АTT & SEVERE & EQUIL & TOTAL & TOTAL & STEP & INC OF & DOF & IF \\
\hline & & & $\begin{array}{l}\text { DISCON } \\
\text { ITERS }\end{array}$ & ITERS & ITERS & $\begin{array}{l}\text { TIME/ } \\
\text { FREQ }\end{array}$ & TIME/LPF & TIME/LPF & MONITOR & RIKS \\
\hline 1 & 1 & 1 & $\odot$ & 2 & 2 & & $\odot . \odot \odot 999$ & $\odot .009991$ & $-\odot .00313$ & $\mathrm{R}$ \\
\hline 1 & 2 & 1 & 0 & 2 & 2 & & $\odot . \odot 2 \odot \odot$ & $\odot . \odot \odot 9974$ & $-\odot .00627$ & $\mathrm{R}$ \\
\hline 1 & 3 & 1 & 0 & 2 & 2 & & $\odot .0349$ & $\odot .01493$ & $-\odot .0110$ & $\mathrm{R}$ \\
\hline 1 & 4 & 1 & $\odot$ & 2 & 2 & & 0.0572 & 0.02232 & -0.0180 & $\mathrm{R}$ \\
\hline 1 & 5 & 1 & $\odot$ & 2 & 2 & & 0.0905 & $\odot .03332$ & $-\odot . \odot 286$ & $\mathrm{R}$ \\
\hline 1 & 6 & 1 & $\odot$ & 2 & 2 & & 0.140 & $\odot .04962$ & $-\odot .0445$ & $\mathrm{R}$ \\
\hline 1 & 7 & 1 & 0 & 3 & 3 & & 0.213 & 0.07325 & -0.0683 & $\mathrm{R}$ \\
\hline 1 & 8 & 1 & $\odot$ & 5 & 5 & & $\odot .306$ & $\odot .09255$ & -0.108 & $\mathrm{R}$ \\
\hline 1 & 9 & 1 & 0 & 4 & 4 & & 0.392 & ๑. 08615 & -0.167 & $\mathrm{R}$ \\
\hline 1 & 10 & 1 & $\odot$ & 3 & 3 & & 0.472 & $\odot .07968$ & -0.234 & $\mathrm{R}$ \\
\hline 1 & 11 & 1 & $\odot$ & 3 & 3 & & 0.544 & $\odot .07246$ & -0.299 & $\mathrm{R}$ \\
\hline 1 & 12 & 1 & 0 & 3 & 3 & & 0.610 & ๑. 06528 & -0.361 & $\mathrm{R}$ \\
\hline 1 & 13 & 1 & $\odot$ & 4 & 4 & & 0.668 & ๑. 05845 & -0.421 & $\mathrm{R}$ \\
\hline 1 & 14 & 1 & 0 & 3 & 3 & & 0.717 & ๑. 04868 & -0.477 & $\mathrm{R}$ \\
\hline 1 & 15 & 1 & $\odot$ & 4 & 4 & & 0.757 & ๑.03984 & -0.530 & $\mathrm{R}$ \\
\hline 1 & 16 & 1 & $\odot$ & 3 & 3 & & $\odot .788$ & $\odot .03166$ & -0.581 & $\mathrm{R}$ \\
\hline 1 & 17 & 1 & 0 & 3 & 3 & & 0.814 & ๑. 02563 & -0.629 & $\mathrm{R}$ \\
\hline 1 & 18 & 1 & $\odot$ & 3 & 3 & & $\odot .835$ & ๑. 02129 & -0.676 & $\mathrm{R}$ \\
\hline 1 & 19 & 1 & 0 & 4 & 4 & & 0.853 & 0.01820 & -0.722 & $\mathrm{R}$ \\
\hline 1 & 20 & 1 & $\odot$ & 4 & 4 & & 0.869 & $\odot .01561$ & -0.766 & $\mathrm{R}$ \\
\hline 1 & 21 & 1 & $\odot$ & 3 & 3 & & $\odot .882$ & $\odot .01303$ & -0.810 & $\mathrm{R}$ \\
\hline 1 & 22 & 1 & 0 & 3 & 3 & & 0.892 & 0.01022 & -0.851 & $\mathrm{R}$ \\
\hline 1 & 23 & 1 & $\odot$ & 3 & 3 & & $\odot .900$ & $\odot .0 \odot 8202$ & -0.891 & $\mathrm{R}$ \\
\hline 1 & 24 & 1 & 0 & 3 & 3 & & 0.907 & $\odot .006681$ & -0.930 & $\mathrm{R}$ \\
\hline 1 & 25 & 1 & 0 & 3 & 3 & & 0.912 & 0.005370 & -0.968 & $\mathrm{R}$ \\
\hline 1 & 26 & 1 & $\odot$ & 3 & 3 & & $\odot .917$ & $\odot .0 \odot 4128$ & $-1.0 \odot$ & $\mathrm{R}$ \\
\hline 1 & 27 & 1 & 0 & 3 & 3 & & 0.919 & $\odot .0 \odot 2927$ & -1.04 & $\mathrm{R}$ \\
\hline 1 & 28 & 1 & 0 & 3 & 3 & & 0.921 & $\odot .001995$ & -1.08 & $\mathrm{R}$ \\
\hline 1 & 29 & 1 & $\odot$ & 3 & 3 & & 0.923 & 0.001194 & -1.11 & $\mathrm{R}$ \\
\hline 1 & 30 & 1 & 0 & 4 & 4 & & 0.923 & 0.0005005 & -1.14 & $\mathbf{R}$ \\
\hline 1 & 31 & 1 & $\theta$ & 6 & 6 & & 0.923 & $-6.688 e-05$ & -1.18 & $\overline{\mathrm{R}}$ \\
\hline 1 & 32 & 1 & 0 & 3 & 3 & & 0.923 & $-\odot .0005203$ & -1.21 & $\mathrm{R}$ \\
\hline 1 & 33 & 1 & 0 & 3 & 3 & & 0.922 & $-\odot .0 \odot \odot 8793$ & -1.24 & $\mathrm{R}$ \\
\hline 1 & 34 & 1 & 0 & 3 & 3 & & 0.920 & $-\odot . \odot \odot 12 \odot 6$ & -1.28 & $\mathrm{R}$ \\
\hline 1 & 35 & 1 & 0 & 3 & 3 & & 0.919 & $-\odot .001479$ & -1.31 & $\mathrm{R}$ \\
\hline 1 & 36 & 1 & $\odot$ & 3 & 3 & & $\odot .917$ & $-\odot .001688$ & -1.34 & $\mathrm{R}$ \\
\hline 1 & 37 & 1 & 0 & 3 & 3 & & 0.915 & $-\odot .001824$ & -1.38 & $\mathrm{R}$ \\
\hline 1 & 38 & 1 & 0 & 3 & 3 & & 0.914 & -0.001951 & -1.41 & $\mathrm{R}$ \\
\hline 1 & 39 & 1 & 0 & 3 & 3 & & 0.912 & $-\odot . \odot \odot 2033$ & -1.44 & $\mathrm{R}$ \\
\hline 1 & 40 & 1 & $\odot$ & 4 & 4 & & 0.909 & $-\odot .0 \odot 2085$ & -1.48 & $\mathrm{R}$ \\
\hline 1 & 41 & 1 & 0 & 4 & 4 & & 0.907 & $-\odot .002120$ & -1.51 & $\mathrm{R}$ \\
\hline 1 & 42 & 1 & $\odot$ & 3 & 3 & & 0.905 & $-\odot . \odot \odot 2112$ & -1.54 & $\mathrm{R}$ \\
\hline 1 & 43 & 1 & 0 & 4 & 4 & & 0.903 & $-\odot .0 \odot 2 \odot 48$ & -1.58 & $\mathrm{R}$ \\
\hline 1 & 44 & 1 & $\odot$ & 3 & 3 & & 0.901 & $-\odot .001979$ & -1.61 & $\mathrm{R}$ \\
\hline 1 & 45 & 1 & 0 & 3 & 3 & & 0.899 & $-\odot .001906$ & -1.64 & $\mathrm{R}$ \\
\hline 1 & 46 & 1 & $\odot$ & 3 & 3 & & 0.897 & -0.001821 & -1.68 & $\mathrm{R}$ \\
\hline 1 & 47 & 1 & 0 & 3 & 3 & & 0.896 & $-\odot . \odot \odot 1742$ & -1.71 & $\mathrm{R}$ \\
\hline 1 & 48 & 1 & $\odot$ & 4 & 4 & & 0.894 & -0.001634 & -1.75 & $\mathrm{R}$ \\
\hline 1 & 49 & 1 & $\odot$ & 3 & 3 & & $\odot .893$ & $-\odot .001498$ & -1.78 & $\mathrm{R}$ \\
\hline 1 & 50 & 1 & $\odot$ & 4 & 4 & & 0.891 & -0.001338 & -1.81 & $\mathrm{R}$ \\
\hline
\end{tabular}

THE ANALYSIS HAS COMPLETED SUCCESSFULLY 


\begin{tabular}{|c|c|c|c|c|c|c|c|c|c|c|}
\hline \multicolumn{11}{|c|}{ D Study: $D=26^{\prime \prime}, h=26^{\prime \prime}, b f=7.2^{\prime \prime}, A=24.1^{\prime \prime}, B=24^{\prime \prime}$} \\
\hline $\begin{array}{l}\text { ABAQU } \\
\text { SUMMA }\end{array}$ & $\begin{array}{l}S \text { VEF } \\
\text { RY OF }\end{array}$ & $\begin{array}{r}\text { SIOI } \\
\text { JOE }\end{array}$ & $\begin{array}{ll}N & 6.4-1 \\
\text { B } & \text { INFORM }\end{array}$ & MATION : & & & DATE & $23-\mathrm{Apr}-20 \odot 4$ & TIME $11: 4$ & $46: 19$ \\
\hline MONIT & $\mathrm{OR} N \mathrm{NC}$ & & 5273 & 3 DOF: & 2 & & & & & \\
\hline STEP & INC & ATT & SEVERE & EQUIL & TOTAL & TOTAL & STEP & INC OF & DOF & IF \\
\hline & & & $\begin{array}{l}\text { DISCON } \\
\text { ITERS }\end{array}$ & ITERS & ITERS & $\begin{array}{l}\text { TIME/ } \\
\text { FREQ }\end{array}$ & TIME/LPF & TIME/LPF & MONITOR & RIKS \\
\hline 1 & 1 & 1 & $\odot$ & 2 & 2 & & $\odot .00999$ & $\odot .009989$ & $-\odot .00420$ & $\mathrm{R}$ \\
\hline 1 & 2 & 1 & 0 & 2 & 2 & & $\odot .020 \odot$ & $\odot . \odot \odot 9966$ & $-\odot .0 \odot 839$ & $\mathrm{R}$ \\
\hline 1 & 3 & 1 & 0 & 2 & 2 & & 0.0349 & $\odot .01491$ & $-\odot .0147$ & $\mathrm{R}$ \\
\hline 1 & 4 & 1 & $\odot$ & 2 & 2 & & 0.0571 & 0.02228 & -0.0241 & $\mathrm{R}$ \\
\hline 1 & 5 & 1 & $\odot$ & 2 & 2 & & $\odot .0904$ & $\odot .03322$ & $-\odot .0383$ & $\mathrm{R}$ \\
\hline 1 & 6 & 1 & $\odot$ & 2 & 2 & & 0.140 & $\odot .04938$ & $-\odot .0596$ & $\mathrm{R}$ \\
\hline 1 & 7 & 1 & 0 & 2 & 2 & & 0.213 & 0.07297 & -0.0915 & $\mathrm{R}$ \\
\hline 1 & 8 & 1 & $\odot$ & 3 & 3 & & $\odot .305$ & $\odot .09256$ & -0.134 & $\mathrm{R}$ \\
\hline 1 & 9 & 1 & 0 & 3 & 3 & & 0.390 & ๑. 08503 & -0.177 & $\mathrm{R}$ \\
\hline 1 & 10 & 1 & $\odot$ & 3 & 3 & & 0.471 & $\odot .08027$ & -0.220 & $\mathrm{R}$ \\
\hline 1 & 11 & 1 & $\odot$ & 4 & 4 & & 0.545 & $\odot .07460$ & -0.270 & $\mathrm{R}$ \\
\hline 1 & 12 & 1 & 0 & 3 & 3 & & 0.612 & ๑. 06698 & -0.324 & $\mathrm{R}$ \\
\hline 1 & 13 & 1 & $\odot$ & 4 & 4 & & 0.673 & $\odot .06050$ & -0.380 & $\mathrm{R}$ \\
\hline 1 & 14 & 1 & 0 & 4 & 4 & & 0.726 & 0.05318 & -0.448 & $\mathrm{R}$ \\
\hline 1 & 15 & 1 & $\odot$ & 3 & 3 & & 0.771 & $\odot .04553$ & -0.514 & $\mathrm{R}$ \\
\hline 1 & 16 & 1 & $\odot$ & 3 & 3 & & $\odot .808$ & $\odot .03676$ & -0.577 & $\mathrm{R}$ \\
\hline 1 & 17 & 1 & 0 & 3 & 3 & & 0.837 & ๑. 02842 & -0.637 & $\mathrm{R}$ \\
\hline 1 & 18 & 1 & 0 & 3 & 3 & & 0.858 & 0.02180 & -0.694 & $\mathrm{R}$ \\
\hline 1 & 19 & 1 & 0 & 3 & 3 & & 0.876 & 0.01744 & -0.749 & $\mathrm{R}$ \\
\hline 1 & 20 & 1 & $\odot$ & 3 & 3 & & 0.890 & $\odot .01400$ & -0.803 & $\mathrm{R}$ \\
\hline 1 & 21 & 1 & $\odot$ & 3 & 3 & & $\odot .901$ & $\odot .01115$ & -0.856 & $\mathrm{R}$ \\
\hline 1 & 22 & 1 & 0 & 3 & 3 & & 0.909 & $\odot .008551$ & -0.907 & $\mathrm{R}$ \\
\hline 1 & 23 & 1 & 0 & 3 & 3 & & 0.916 & $\odot .006230$ & -0.958 & $\mathrm{R}$ \\
\hline 1 & 24 & 1 & 0 & 3 & 3 & & 0.920 & $\odot .004084$ & -1.01 & $\mathrm{R}$ \\
\hline 1 & 25 & 1 & 0 & 3 & 3 & & 0.922 & $\odot .001866$ & -1.06 & $\mathrm{R}$ \\
\hline 1 & 26 & 1 & 0 & 3 & 3 & & 0.922 & 0.0004311 & -1.10 & $\mathbf{R}$ \\
\hline 1 & 27 & 1 & $\theta$ & 3 & 3 & & 0.921 & -0.0009663 & -1.15 & $\bar{R}$ \\
\hline 1 & 28 & 1 & 0 & 3 & 3 & & 0.919 & $-\odot .001942$ & -1.20 & $\mathrm{R}$ \\
\hline 1 & 29 & 1 & $\odot$ & 3 & 3 & & 0.916 & $-\odot . \odot \odot 2829$ & -1.25 & $\mathrm{R}$ \\
\hline 1 & 30 & 1 & $\odot$ & 3 & 3 & & 0.913 & -0.003470 & -1.30 & $\mathrm{R}$ \\
\hline 1 & 31 & 1 & $\odot$ & 3 & 3 & & $\odot .909$ & $-\odot .003809$ & -1.35 & $\mathrm{R}$ \\
\hline 1 & 32 & 1 & 0 & 3 & 3 & & 0.905 & $-\odot .004116$ & -1.40 & $\mathrm{R}$ \\
\hline 1 & 33 & 1 & 0 & 3 & 3 & & 0.901 & $-\odot .0 \odot 4371$ & -1.45 & $\mathrm{R}$ \\
\hline 1 & 34 & 1 & 0 & 3 & 3 & & 0.896 & $-\odot . \odot \odot 45 \odot 6$ & -1.50 & $\mathrm{R}$ \\
\hline 1 & 35 & 1 & 0 & 3 & 3 & & 0.892 & $-\odot .004575$ & -1.55 & $\mathrm{R}$ \\
\hline 1 & 36 & 1 & 0 & 3 & 3 & & 0.887 & $-\odot .004558$ & -1.60 & $\mathrm{R}$ \\
\hline 1 & 37 & 1 & 0 & 3 & 3 & & 0.882 & $-\odot .004462$ & -1.65 & $\mathrm{R}$ \\
\hline 1 & 38 & 1 & 0 & 3 & 3 & & 0.878 & $-\odot .0 \odot 4186$ & -1.70 & $\mathrm{R}$ \\
\hline 1 & 39 & 1 & 0 & 3 & 3 & & 0.874 & $-\odot . \odot \odot 3931$ & -1.75 & $\mathrm{R}$ \\
\hline 1 & $4 \odot$ & 1 & $\odot$ & 3 & 3 & & 0.871 & -0.003585 & -1.80 & $\mathrm{R}$ \\
\hline 1 & 41 & 1 & 0 & 3 & 3 & & 0.868 & $-\odot .003189$ & -1.85 & $\mathrm{R}$ \\
\hline 1 & 42 & 1 & $\odot$ & 3 & 3 & & 0.865 & $-\odot . \odot \odot 2726$ & -1.90 & $\mathrm{R}$ \\
\hline 1 & 43 & 1 & 0 & 3 & 3 & & 0.863 & $-\odot . \odot \odot 2286$ & -1.95 & $\mathrm{R}$ \\
\hline 1 & 44 & 1 & $\odot$ & 3 & 3 & & $\odot .861$ & $-\odot . \odot \odot 1768$ & -2.00 & $\mathrm{R}$ \\
\hline 1 & 45 & 1 & 0 & 3 & 3 & & 0.860 & $-\odot .001304$ & -2.05 & $\mathrm{R}$ \\
\hline 1 & 46 & 1 & 0 & 4 & 4 & & 0.859 & -0.0006799 & -2.10 & $\mathrm{R}$ \\
\hline 1 & 47 & 1 & 0 & 3 & 3 & & 0.859 & $-5.059 e-05$ & -2.15 & $\mathrm{R}$ \\
\hline 1 & 48 & 1 & $\odot$ & 4 & 4 & & 0.859 & $\odot .0 \odot \odot 4676$ & -2.20 & $\mathrm{R}$ \\
\hline 1 & 49 & 1 & $\odot$ & 3 & 3 & & $\odot .860$ & $\odot .0 \odot \odot 9563$ & -2.25 & $\mathrm{R}$ \\
\hline 1 & 50 & 1 & 0 & 3 & 3 & & $\odot .862$ & 0.001648 & -2.30 & $\mathrm{R}$ \\
\hline
\end{tabular}

THE ANALYSIS HAS COMPLETED SUCCESSFULLY 


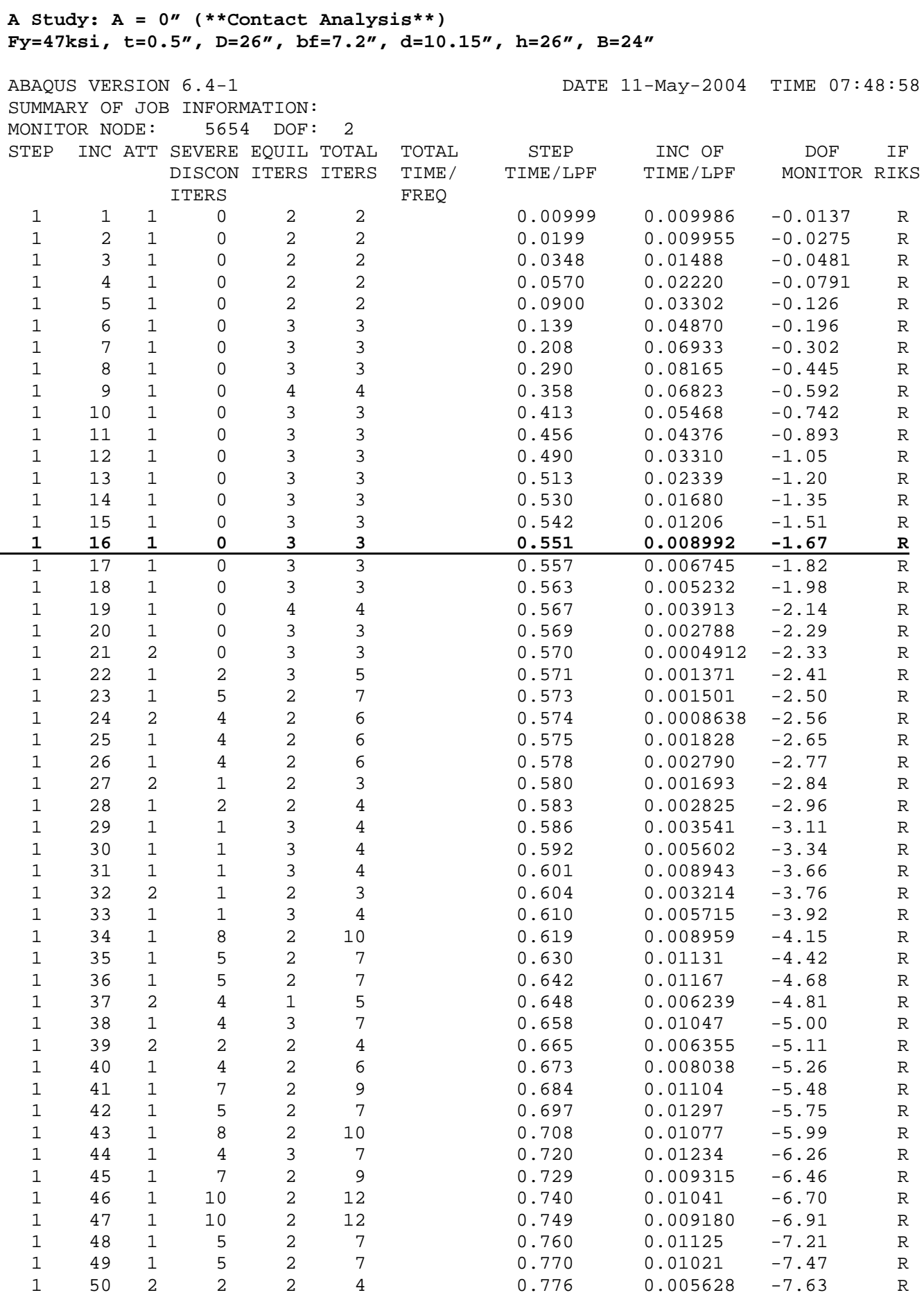

THE ANALYSIS HAS COMPLETED SUCCESSFULLY 


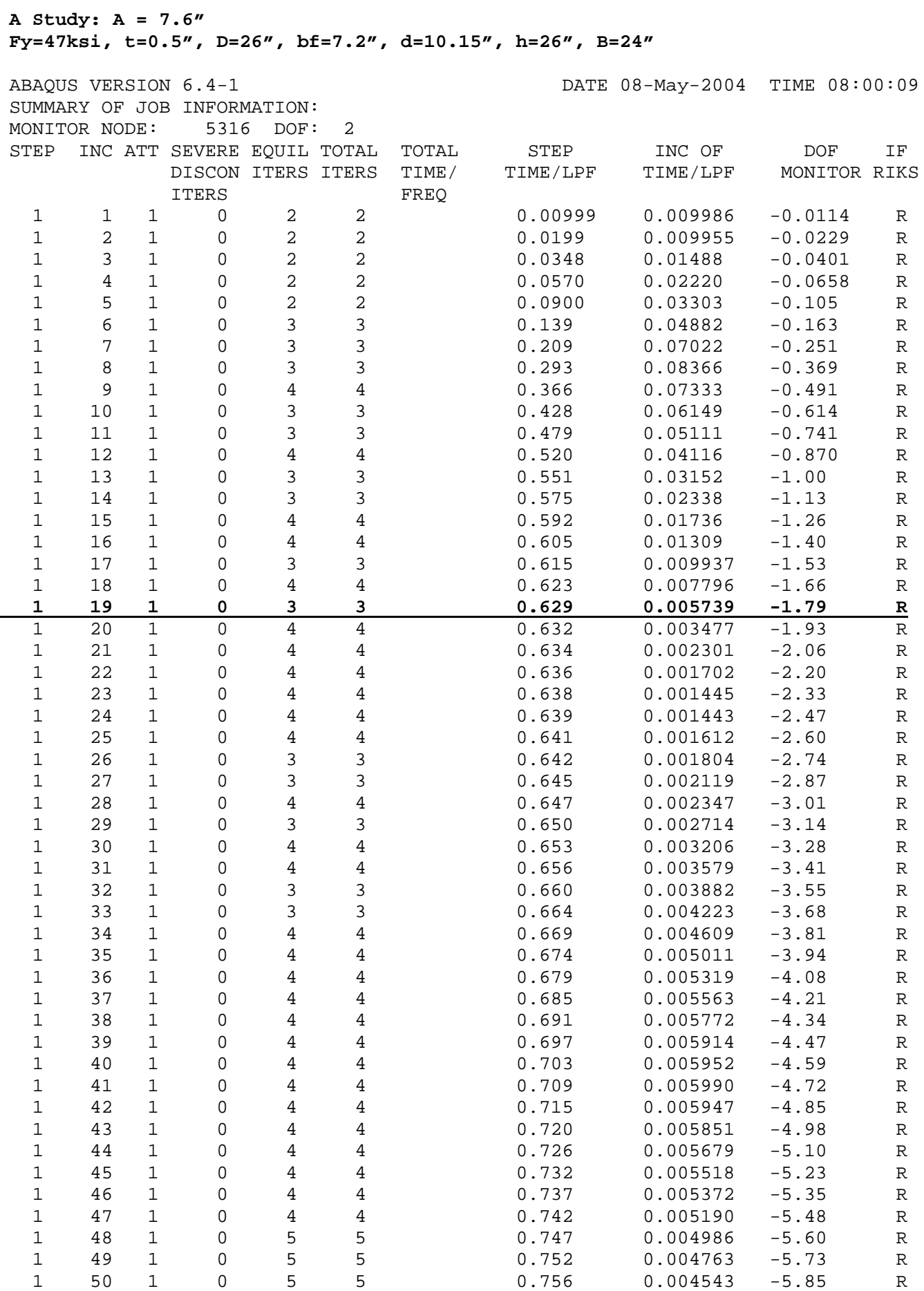

THE ANALYSIS HAS COMPLETED SUCCESSFULLY 


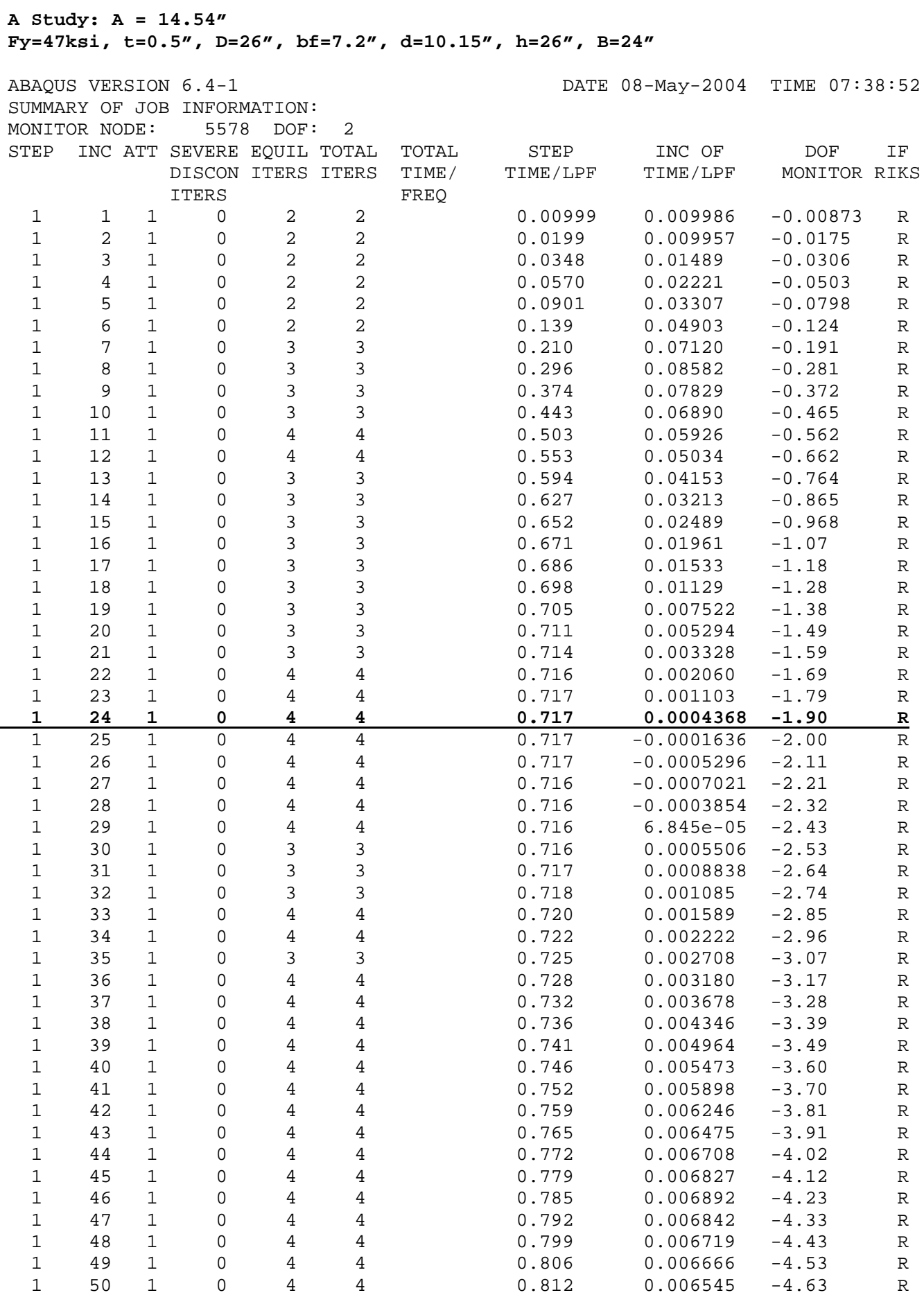

THE ANALYSIS HAS COMPLETED SUCCESSFULLY 


\begin{tabular}{|c|c|c|c|c|c|c|c|c|c|c|}
\hline ABAQU & $S$ VEF & RSION & V 6.4-1 & & & & DATE & $08-$ Мay - 2004 & TIME $08: 3$ & $38: 48$ \\
\hline SUMMA & RY OF & $\mathrm{F} \mathrm{JOB}$ & 3 INFORN & IATION : & & & & & & \\
\hline MONIT & $\mathrm{OR} \mathrm{NC}$ & ODE : & 5895 & DOF : & 2 & & & & & \\
\hline STEP & INC & ATT & $\begin{array}{l}\text { SEVERE } \\
\text { DISCON } \\
\text { ITERS }\end{array}$ & $\begin{array}{l}\text { EQUIL } \\
\text { ITERS }\end{array}$ & $\begin{array}{l}\text { TOTAL } \\
\text { ITERS }\end{array}$ & $\begin{array}{l}\text { TOTAL } \\
\text { TIME/ } \\
\text { FREQ }\end{array}$ & $\begin{array}{c}\text { STEP } \\
\text { TIME/LPF }\end{array}$ & $\begin{array}{c}\text { INC OF } \\
\text { TIME/LPF }\end{array}$ & $\begin{array}{c}\text { DOF } \\
\text { MONITOR }\end{array}$ & $\begin{array}{c}\text { IF } \\
\text { RIKS }\end{array}$ \\
\hline 1 & 1 & 1 & $\odot$ & 2 & 2 & & $\odot .00999$ & $\odot . \odot \odot 9989$ & $-\odot .0 \odot 45 \odot$ & $\mathrm{R}$ \\
\hline 1 & 2 & 1 & $\odot$ & 2 & 2 & & $\odot .0200$ & $\odot .009963$ & $-\odot .00899$ & $\mathrm{R}$ \\
\hline 1 & 3 & 1 & $\odot$ & 2 & 2 & & 0.0349 & 0.01490 & -0.0157 & $\mathrm{R}$ \\
\hline 1 & 4 & 1 & $\odot$ & 2 & 2 & & 0.0571 & $\odot .02226$ & -0.0259 & $\mathrm{R}$ \\
\hline 1 & 5 & 1 & $\odot$ & 2 & 2 & & $\odot .0903$ & $\odot .03319$ & -0.0411 & $\mathrm{R}$ \\
\hline 1 & 6 & 1 & $\odot$ & 2 & 2 & & 0.140 & 0.04931 & -0.0638 & $\mathrm{R}$ \\
\hline 1 & 7 & 1 & $\odot$ & 3 & 3 & & 0.212 & 0.07274 & -0.0981 & $\mathrm{R}$ \\
\hline 1 & 8 & 1 & $\odot$ & 3 & 3 & & 0.305 & ๑.09244 & -0.143 & $\mathrm{R}$ \\
\hline 1 & 9 & 1 & $\odot$ & 3 & 3 & & ๑. 391 & $\odot .08579$ & -0.189 & $\mathrm{R}$ \\
\hline 1 & 10 & 1 & $\odot$ & 3 & 3 & & 0.470 & ๑.07934 & -0.236 & $\mathrm{R}$ \\
\hline 1 & 11 & 1 & $\odot$ & 4 & 4 & & 0.543 & $\odot .07339$ & -0.289 & $\mathrm{R}$ \\
\hline 1 & 12 & 1 & $\odot$ & 3 & 3 & & 0.611 & 0.06774 & -0.346 & $\mathrm{R}$ \\
\hline 1 & 13 & 1 & $\odot$ & 4 & 4 & & 0.673 & $\odot .06164$ & -0.406 & $\mathrm{R}$ \\
\hline 1 & 14 & 1 & $\odot$ & 4 & 4 & & 0.726 & 0.05349 & -0.477 & $\mathrm{R}$ \\
\hline 1 & 15 & 1 & $\odot$ & 3 & 3 & & 0.771 & $\odot .04521$ & -0.547 & $\mathrm{R}$ \\
\hline 1 & 16 & 1 & $\odot$ & 3 & 3 & & 0.808 & 0.03660 & -0.613 & $\mathrm{R}$ \\
\hline 1 & 17 & 1 & $\odot$ & 3 & 3 & & 0.837 & $\odot .02948$ & -0.677 & $\mathrm{R}$ \\
\hline 1 & 18 & 1 & $\odot$ & 3 & 3 & & $\odot .861$ & 0.02364 & -0.739 & $\mathrm{R}$ \\
\hline 1 & 19 & 1 & $\odot$ & 3 & 3 & & 0.880 & ๑. 01910 & -0.800 & $\mathrm{R}$ \\
\hline 1 & 20 & 1 & $\odot$ & 3 & 3 & & $\odot .895$ & 0.01505 & -0.858 & $\mathrm{R}$ \\
\hline 1 & 21 & 1 & $\odot$ & 3 & 3 & & 0.906 & 0.01112 & -0.916 & $\mathrm{R}$ \\
\hline 1 & 22 & 1 & $\odot$ & 3 & 3 & & $\odot .915$ & 0.008132 & -0.971 & $\mathrm{R}$ \\
\hline 1 & 23 & 1 & $\odot$ & 3 & 3 & & 0.920 & $\odot .0 \odot 5238$ & -1.03 & $\mathrm{R}$ \\
\hline 1 & 24 & 1 & $\odot$ & 3 & 3 & & $\odot .922$ & $\odot .0 \odot 2699$ & -1.08 & $\mathrm{R}$ \\
\hline 1 & 25 & 1 & 0 & 3 & 3 & & 0.923 & 0.0006375 & -1.13 & $\underline{\mathbf{R}}$ \\
\hline 1 & 26 & 1 & $\odot$ & 3 & 3 & & 0.922 & $-\odot .0 \odot \odot 9 \odot 77$ & -1.18 & $\overline{\mathrm{R}}$ \\
\hline 1 & 27 & 1 & $\odot$ & 3 & 3 & & 0.920 & $-\odot .002056$ & -1.24 & $\mathrm{R}$ \\
\hline 1 & 28 & 1 & $\odot$ & 3 & 3 & & $\odot .917$ & $-\odot . \odot \odot 3 \odot 73$ & -1.29 & $\mathrm{R}$ \\
\hline 1 & 29 & 1 & $\odot$ & 4 & 4 & & $\odot .913$ & $-\odot . \odot \odot 3672$ & -1.34 & $\mathrm{R}$ \\
\hline 1 & 30 & 1 & $\odot$ & 3 & 3 & & $\odot .909$ & $-\odot .0 \odot 4134$ & -1.40 & $\mathrm{R}$ \\
\hline 1 & 31 & 1 & $\odot$ & 3 & 3 & & 0.905 & $-\odot .0 \odot 4536$ & -1.45 & $\mathrm{R}$ \\
\hline
\end{tabular}




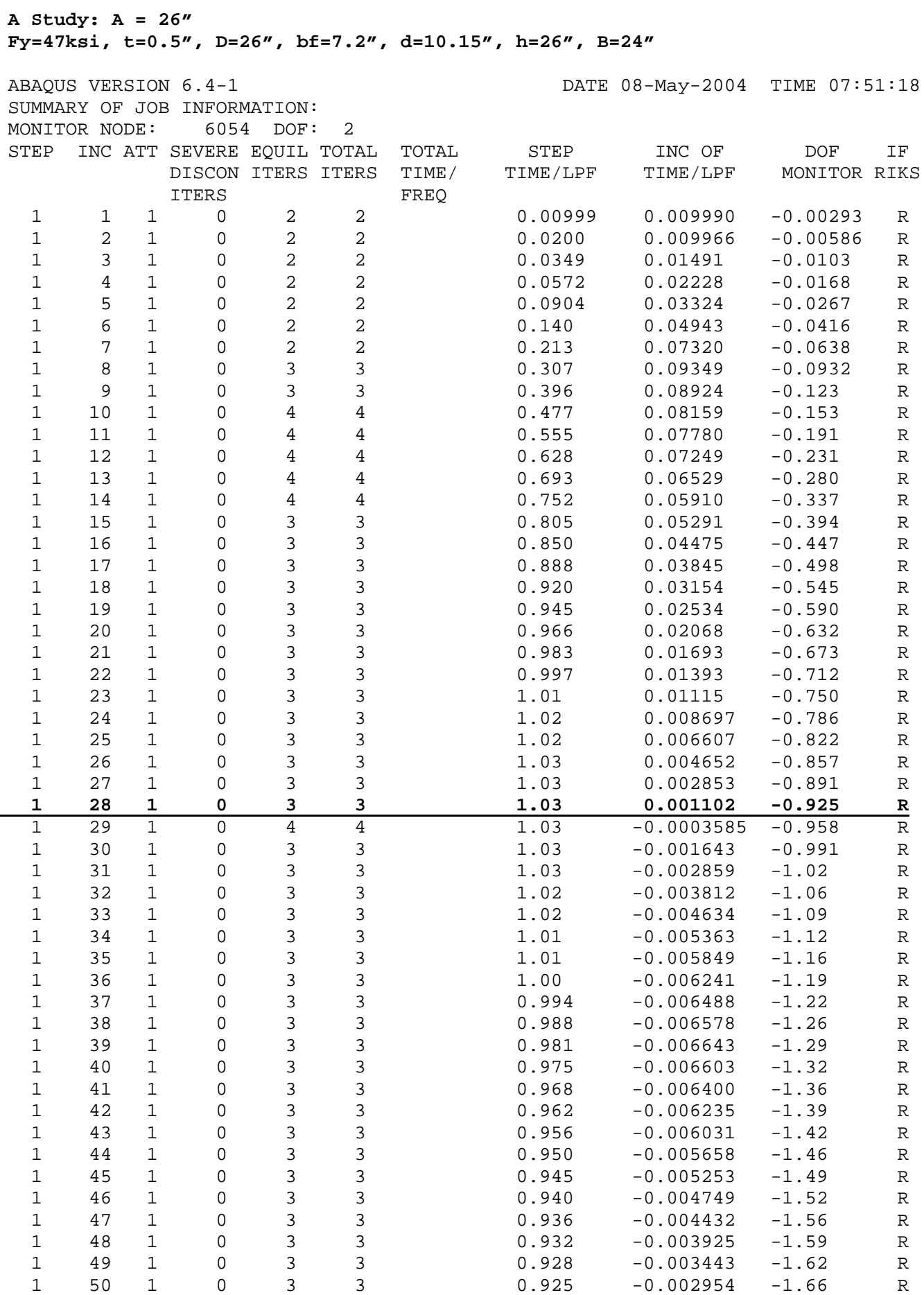

THE ANALYSIS HAS COMPLETED SUCCESSFULLY 


\begin{tabular}{|c|c|c|c|c|c|c|c|c|c|c|}
\hline \multirow{2}{*}{\multicolumn{11}{|c|}{ 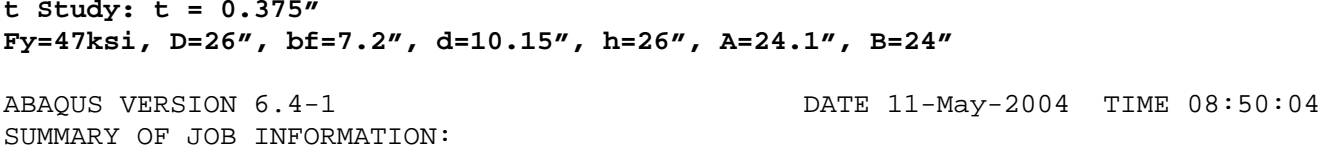 }} \\
\hline & & & & & & & & & & \\
\hline \multicolumn{11}{|c|}{ MONITOR NODE : 5895 DOF : 2} \\
\hline STEP & INC & ATT & SEVERE & EQUIL & TOTAL & TOTAL & STEP & INC OF & DOF & IF \\
\hline & & & $\begin{array}{l}\text { DISCON } \\
\text { ITERS }\end{array}$ & ITERS & ITERS & $\begin{array}{l}\text { TIME/ } \\
\text { FREQ }\end{array}$ & TIME/LPF & TIME/LPF & MONITOR & RIKS \\
\hline 1 & 1 & 1 & 0 & 2 & 2 & & 0.00997 & 0.009974 & -0.00931 & $\mathrm{R}$ \\
\hline 1 & 2 & 1 & $\odot$ & 2 & 2 & & $\odot .0199$ & $\odot .0 \odot 9916$ & $-\odot .0186$ & $\mathrm{R}$ \\
\hline 1 & 3 & 1 & 0 & 2 & 2 & & 0.0347 & $\odot .01478$ & -0.0326 & $\mathrm{R}$ \\
\hline 1 & 4 & 1 & 0 & 2 & 2 & & 0.0566 & 0.02195 & -0.0536 & $\mathrm{R}$ \\
\hline 1 & 5 & 1 & 0 & 2 & 2 & & 0.0891 & 0.03245 & $-\odot .0851$ & $\mathrm{R}$ \\
\hline 1 & 6 & 1 & 0 & 3 & 3 & & 0.136 & 0.04721 & -0.133 & $\mathrm{R}$ \\
\hline 1 & 7 & 1 & 0 & 3 & 3 & & $\odot .202$ & 0.06530 & -0.205 & $\mathrm{R}$ \\
\hline 1 & 8 & 1 & 0 & 3 & 3 & & 0.277 & 0.07517 & -0.302 & $\mathrm{R}$ \\
\hline 1 & 9 & 1 & 0 & 3 & 3 & & 0.342 & 0.06535 & -0.401 & $\mathrm{R}$ \\
\hline 1 & 10 & 1 & $\odot$ & 4 & 4 & & $\odot .397$ & ๑. 05491 & -0.503 & $\mathrm{R}$ \\
\hline 1 & 11 & 1 & 0 & 4 & 4 & & 0.438 & 0.04073 & -0.606 & $\mathrm{R}$ \\
\hline 1 & 12 & 1 & 0 & 4 & 4 & & 0.465 & $\odot .02690$ & -0.713 & $\mathrm{R}$ \\
\hline 1 & 13 & 1 & $\odot$ & 4 & 4 & & 0.482 & 0.01751 & -0.822 & $\mathrm{R}$ \\
\hline 1 & 14 & 1 & 0 & 4 & 4 & & 0.492 & 0.01015 & -0.934 & $\mathrm{R}$ \\
\hline 1 & 15 & 1 & 0 & 4 & 4 & & 0.496 & 0.003492 & -1.05 & $\mathbf{R}$ \\
\hline 1 & 16 & 1 & $\theta$ & 4 & 4 & & 0.495 & -0.0009343 & -1.16 & $\bar{R}$ \\
\hline 1 & 17 & 1 & 0 & 4 & 4 & & 0.491 & -0.003663 & -1.28 & $\mathrm{R}$ \\
\hline 1 & 18 & 1 & $\odot$ & 4 & 4 & & 0.486 & $-\odot .005235$ & -1.40 & $\mathrm{R}$ \\
\hline 1 & 19 & 1 & $\odot$ & 4 & 4 & & 0.480 & $-\odot .005457$ & -1.52 & $\mathrm{R}$ \\
\hline 1 & 20 & 1 & $\odot$ & 4 & 4 & & 0.476 & -0.004748 & -1.64 & $\mathrm{R}$ \\
\hline 1 & 21 & 1 & 0 & 4 & 4 & & 0.472 & $-\odot .003413$ & -1.76 & $\mathrm{R}$ \\
\hline 1 & 22 & 1 & 0 & 4 & 4 & & 0.471 & -0.001554 & -1.88 & $\mathrm{R}$ \\
\hline 1 & 23 & 1 & 0 & 4 & 4 & & 0.472 & ๑. 0008173 & -2.00 & $\mathrm{R}$ \\
\hline 1 & 24 & 1 & $\odot$ & 4 & 4 & & 0.475 & $\odot .003334$ & -2.12 & $\mathrm{R}$ \\
\hline 1 & 25 & 1 & 0 & 4 & 4 & & 0.481 & ๑. 005658 & -2.24 & $\mathrm{R}$ \\
\hline 1 & 26 & 1 & 0 & 4 & 4 & & 0.488 & $\odot .007771$ & -2.35 & $\mathrm{R}$ \\
\hline 1 & 27 & 1 & 0 & 3 & 3 & & 0.498 & $\odot .009308$ & -2.47 & $\mathrm{R}$ \\
\hline 1 & 28 & 1 & 0 & 4 & 4 & & 0.508 & 0.01034 & -2.58 & $\mathrm{R}$ \\
\hline 1 & 29 & 1 & $\odot$ & 4 & 4 & & 0.519 & $\odot .01072$ & -2.70 & $\mathrm{R}$ \\
\hline 1 & 30 & 1 & 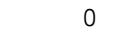 & 4 & 4 & & 0.530 & ๑. 01095 & -2.81 & $\mathrm{R}$ \\
\hline 1 & 31 & 1 & 0 & 4 & 4 & & 0.541 & 0.01105 & -2.93 & $\mathrm{R}$ \\
\hline 1 & 32 & 1 & 0 & 4 & 4 & & 0.552 & 0.01097 & -3.04 & $\mathrm{R}$ \\
\hline 1 & 33 & 1 & 0 & 4 & 4 & & 0.562 & 0.01069 & -3.15 & $\mathrm{R}$ \\
\hline 1 & 34 & 1 & $\odot$ & 4 & 4 & & 0.573 & $\odot .01037$ & -3.26 & $\mathrm{R}$ \\
\hline 1 & 35 & 1 & $\odot$ & 4 & 4 & & 0.583 & $\odot .009939$ & -3.38 & $\mathrm{R}$ \\
\hline 1 & 36 & 1 & 0 & 4 & 4 & & 0.592 & $\odot .009476$ & -3.49 & $\mathrm{R}$ \\
\hline 1 & 37 & 1 & 0 & 4 & 4 & & 0.601 & 0.009061 & -3.59 & $\mathrm{R}$ \\
\hline 1 & 38 & 1 & 0 & 4 & 4 & & 0.610 & $\odot .0 \odot 8687$ & -3.70 & $\mathrm{R}$ \\
\hline 1 & 39 & 1 & 0 & 5 & 5 & & 0.618 & $\odot .008232$ & -3.81 & $\mathrm{R}$ \\
\hline 1 & 40 & 1 & $\odot$ & 5 & 5 & & 0.626 & $\odot .0 \odot 7848$ & -3.92 & $\mathrm{R}$ \\
\hline 1 & 41 & 1 & $\odot$ & 5 & 5 & & 0.633 & $\odot .007482$ & -4.03 & $\mathrm{R}$ \\
\hline 1 & 42 & 1 & 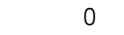 & 4 & 4 & & 0.641 & $\odot .0 \odot 7214$ & -4.13 & $\mathrm{R}$ \\
\hline 1 & 43 & 1 & $\Theta$ & 4 & 4 & & 0.648 & $\odot . \odot \odot 69 \odot 7$ & -4.24 & $\mathrm{R}$ \\
\hline 1 & 44 & 1 & $\odot$ & 4 & 4 & & 0.654 & ๑. 006688 & -4.34 & $\mathrm{R}$ \\
\hline 1 & 45 & 1 & 0 & 4 & 4 & & 0.661 & $\odot .006517$ & -4.45 & $\mathrm{R}$ \\
\hline 1 & 46 & 1 & $\odot$ & 4 & 4 & & 0.667 & $\odot .006390$ & -4.55 & $\mathrm{R}$ \\
\hline 1 & 47 & 1 & $\theta$ & 4 & 4 & & 0.673 & $\odot .006258$ & -4.66 & $\mathrm{R}$ \\
\hline 1 & 48 & 1 & 0 & 4 & 4 & & 0.680 & ๑. 006106 & -4.76 & $\mathrm{R}$ \\
\hline 1 & 49 & 1 & $\odot$ & 4 & 4 & & 0.686 & ๑.๑๑5971 & -4.87 & $\mathrm{R}$ \\
\hline 1 & 50 & 1 & $\odot$ & 4 & 4 & & 0.691 & $\odot .005858$ & -4.97 & $\mathrm{R}$ \\
\hline
\end{tabular}

THE ANALYSIS HAS COMPLETED SUCCESSFULLY 


\begin{tabular}{|c|c|c|c|c|c|c|c|c|c|c|}
\hline ABAQL & $S$ VER & SIOI & N 6.4-1 & & & & DATE &  & TIME ๑८:৫ & $\odot 8: 23$ \\
\hline SUMMA & $\mathrm{RY} O \mathrm{OP}$ & $\mathrm{JOH}$ & B INFORI & MATION & & & & & & \\
\hline MONIT & OR NC & DE : & 589 & 5 DOF & 2 & & & & & \\
\hline STEP & INC & ATT & SEVERE & EQUIL & TOTAL & TOTAL & STEP & INC OF & DOF & IF \\
\hline & & & $\begin{array}{l}\text { DISCON } \\
\text { ITERS }\end{array}$ & ITERS & ITERS & $\begin{array}{l}\text { TIME/ } \\
\text { FREQ }\end{array}$ & TIME/LPF & TIME/LPF & MONITOR & RIKS \\
\hline 1 & 1 & 1 & $\odot$ & 2 & 2 & & $\odot .0 \odot 999$ & $\odot .0 \odot 9989$ & -0.00463 & $\mathrm{R}$ \\
\hline 1 & 2 & 1 & $\odot$ & 2 & 2 & & $\odot .0200$ & $\odot .0 \odot 9963$ & $-\odot .0 \odot 926$ & $\mathrm{R}$ \\
\hline 1 & 3 & 1 & $\odot$ & 2 & 2 & & 0.0349 & ๑. 01490 & $-\odot .0162$ & $\mathrm{R}$ \\
\hline 1 & 4 & 1 & $\odot$ & 2 & 2 & & 0.0571 & 0.02226 & -0.0266 & $\mathrm{R}$ \\
\hline 1 & 5 & 1 & $\odot$ & 2 & 2 & & 0.0903 & 0.03318 & -0.0423 & $\mathrm{R}$ \\
\hline 1 & 6 & 1 & $\odot$ & 2 & 2 & & 0.140 & 0.04929 & -0.0657 & $\mathrm{R}$ \\
\hline 1 & 7 & 1 & 0 & 3 & 3 & & 0.212 & 0.07266 & -0.101 & $\mathrm{R}$ \\
\hline 1 & 8 & 1 & $\odot$ & 3 & 3 & & 0.304 & 0.09213 & -0.148 & $\mathrm{R}$ \\
\hline 1 & 9 & 1 & $\odot$ & 3 & 3 & & $\odot .390$ & 0.08547 & -0.195 & $\mathrm{R}$ \\
\hline 1 & 10 & 1 & $\odot$ & 3 & 3 & & 0.469 & 0.07877 & -0.243 & $\mathrm{R}$ \\
\hline 1 & 11 & 1 & $\odot$ & 4 & 4 & & 0.541 & 0.07271 & -0.297 & $\mathrm{R}$ \\
\hline 1 & 12 & 1 & $\odot$ & 3 & 3 & & 0.609 & 0.06723 & -0.355 & $\mathrm{R}$ \\
\hline 1 & 13 & 1 & $\odot$ & 4 & 4 & & 0.670 & 0.06111 & -0.416 & $\mathrm{R}$ \\
\hline 1 & 14 & 1 & $\odot$ & 4 & 4 & & $\odot .723$ & 0.05300 & -0.489 & $\mathrm{R}$ \\
\hline 1 & 15 & 1 & $\odot$ & 3 & 3 & & 0.767 & 0.04465 & -0.559 & $\mathrm{R}$ \\
\hline 1 & 16 & 1 & $\odot$ & 3 & 3 & & 0.803 & 0.03613 & -0.627 & $\mathrm{R}$ \\
\hline 1 & 17 & 1 & $\odot$ & 3 & 3 & & 0.833 & 0.02920 & -0.693 & $\mathrm{R}$ \\
\hline 1 & 18 & 1 & $\odot$ & 3 & 3 & & $\odot .856$ & 0.02320 & -0.756 & $\mathrm{R}$ \\
\hline 1 & 19 & 1 & $\odot$ & 3 & 3 & & $\odot .874$ & 0.01848 & -0.818 & $\mathrm{R}$ \\
\hline 1 & 20 & 1 & $\odot$ & 3 & 3 & & 0.889 & 0.01458 & -0.879 & $\mathrm{R}$ \\
\hline 1 & 21 & 1 & $\odot$ & 3 & 3 & & $\odot .900$ & 0.01085 & -0.937 & $\mathrm{R}$ \\
\hline 1 & 22 & 1 & $\odot$ & 3 & 3 & & $\odot .908$ & $\odot .007884$ & -0.995 & $\mathrm{R}$ \\
\hline 1 & 23 & 1 & $\odot$ & 3 & 3 & & 0.913 & $\odot .0 \odot 4864$ & -1.05 & $\mathrm{R}$ \\
\hline 1 & 24 & 1 & $\odot$ & 3 & 3 & & $\odot .915$ & $\odot .002395$ & -1.11 & $\mathrm{R}$ \\
\hline 1 & 25 & 1 & 0 & 4 & 4 & & 0.915 & 0.0003808 & -1.16 & $\mathbf{R}$ \\
\hline 1 & 26 & 1 & $\theta$ & 3 & 3 & & 0.914 & -0.001112 & -1.22 & $\bar{R}$ \\
\hline 1 & 27 & 1 & $\odot$ & 3 & 3 & & 0.912 & -0.002335 & -1.27 & $\mathrm{R}$ \\
\hline 1 & 28 & 1 & $\odot$ & 3 & 3 & & 0.909 & -0.003184 & -1.33 & $\mathrm{R}$ \\
\hline 1 & 29 & 1 & $\odot$ & 3 & 3 & & 0.905 & $-\odot .0 \odot 3679$ & -1.38 & $\mathrm{R}$ \\
\hline 1 & 30 & 1 & $\odot$ & 3 & 3 & & 0.901 & -0.004173 & -1.44 & $\mathrm{R}$ \\
\hline 1 & 31 & 1 & $\odot$ & 3 & 3 & & $\odot .896$ & $-0.0 \odot 4492$ & -1.49 & $\mathrm{R}$ \\
\hline 1 & 32 & 1 & $\odot$ & 4 & 4 & & $\odot .892$ & $-\odot .0 \odot 459 \odot$ & -1.55 & $\mathrm{R}$ \\
\hline 1 & 33 & 1 & $\odot$ & 4 & 4 & & 0.887 & -0.004623 & -1.60 & $\mathrm{R}$ \\
\hline 1 & 34 & 1 & $\odot$ & 4 & 4 & & 0.882 & -0.004661 & -1.66 & $\mathrm{R}$ \\
\hline 1 & 35 & 1 & $\odot$ & 3 & 3 & & 0.878 & -0.004576 & -1.72 & $\mathrm{R}$ \\
\hline 1 & 36 & 1 & $\odot$ & 4 & 4 & & 0.874 & -0.004349 & -1.77 & $\mathrm{R}$ \\
\hline 1 & 37 & 1 & $\odot$ & 3 & 3 & & 0.869 & -0.004080 & -1.83 & $\mathrm{R}$ \\
\hline 1 & 38 & 1 & $\odot$ & 3 & 3 & & 0.866 & -0.003847 & -1.89 & $\mathrm{R}$ \\
\hline 1 & 39 & 1 & $\odot$ & 3 & 3 & & 0.862 & -0.003538 & -1.94 & $\mathrm{R}$ \\
\hline 1 & 40 & 1 & $\odot$ & 3 & 3 & & 0.859 & -0.003049 & -2.00 & $\mathrm{R}$ \\
\hline 1 & 41 & 1 & $\odot$ & 3 & 3 & & 0.856 & $-\odot .002574$ & -2.06 & $\mathrm{R}$ \\
\hline 1 & 42 & 1 & $\odot$ & 3 & 3 & & 0.855 & -0.001910 & -2.12 & $\mathrm{R}$ \\
\hline 1 & 43 & 1 & $\odot$ & 4 & 4 & & 0.853 & -0.001069 & -2.17 & $\mathrm{R}$ \\
\hline 1 & 44 & 1 & $\odot$ & 4 & 4 & & 0.853 & $-\odot .0 \odot \odot 2169$ & -2.23 & $\mathrm{R}$ \\
\hline 1 & 45 & 1 & $\odot$ & 4 & 4 & & 0.854 & $\odot .0006789$ & -2.29 & $\mathrm{R}$ \\
\hline 1 & 46 & 1 & $\odot$ & 4 & 4 & & 0.856 & $\odot .001611$ & -2.34 & $\mathrm{R}$ \\
\hline 1 & 47 & 1 & $\odot$ & 3 & 3 & & 0.858 & $\odot .0 \odot 2425$ & -2.40 & $\mathrm{R}$ \\
\hline 1 & 48 & 1 & $\odot$ & 3 & 3 & & 0.861 & 0.003215 & -2.46 & $\mathrm{R}$ \\
\hline 1 & 49 & 1 & $\odot$ & 3 & 3 & & 0.865 & $\odot .004054$ & -2.51 & $\mathrm{R}$ \\
\hline 1 & 50 & 1 & $\odot$ & 3 & 3 & & 0.870 & $\odot .0 \odot 4712$ & -2.57 & $\mathrm{R}$ \\
\hline
\end{tabular}

THE ANALYSIS HAS COMPLETED SUCCESSFULLY 


\begin{tabular}{|c|c|c|c|c|c|c|c|c|c|c|}
\hline ABAQL & $S$ VE & RSIOI & N 6.4-1 & & & & DATE & 11-May-20๑4 & TIME $15: 5$ & $58: 57$ \\
\hline SUMMA & RY 0 & $\mathrm{~F} \mathrm{JOH}$ & B INFORN & MATION : & & & & & & \\
\hline MONIT & & ODE : & 5895 & DOF : & 2 & & & & & \\
\hline STEP & INC & ATT & SEVERE & EQUIL & TOTAL & TOTAL & STEP & INC OF & DOF & IF \\
\hline & & & $\begin{array}{l}\text { DISCON } \\
\text { ITERS }\end{array}$ & ITERS & ITERS & $\begin{array}{l}\text { TIME/ } \\
\text { FREQ }\end{array}$ & TIME/LPF & TIME/LPF & MONITOR & RIKS \\
\hline 1 & 1 & 1 & $\odot$ & 2 & 2 & & 0.0100 & $\odot .009997$ & -0.00170 & $\mathrm{R}$ \\
\hline 1 & 2 & 1 & $\odot$ & 2 & 2 & & 0.0200 & ०. .0०9988 & -0.00340 & $\mathrm{R}$ \\
\hline 1 & 3 & 1 & $\odot$ & 2 & 2 & & 0.0350 & 0.01497 & -0.00595 & $\mathrm{R}$ \\
\hline 1 & 4 & 1 & $\odot$ & 2 & 2 & & 0.0574 & 0.02243 & -0.00978 & $\mathrm{R}$ \\
\hline 1 & 5 & 1 & $\odot$ & 2 & 2 & & 0.0910 & 0.03357 & -0.0155 & $\mathrm{R}$ \\
\hline 1 & 6 & 1 & $\odot$ & 2 & 2 & & 0.141 & 0.05021 & -0.0241 & $\mathrm{R}$ \\
\hline 1 & 7 & 1 & $\odot$ & 2 & 2 & & 0.216 & 0.07498 & -0.0371 & $\mathrm{R}$ \\
\hline 1 & 8 & 1 & $\odot$ & 2 & 2 & & 0.314 & 0.09813 & -0.0541 & $\mathrm{R}$ \\
\hline 1 & 9 & 1 & $\odot$ & 2 & 2 & & 0.412 & ๑. 09744 & -0.0711 & $\mathrm{R}$ \\
\hline 1 & 10 & 1 & $\odot$ & 3 & 3 & & 0.508 & 0.09644 & -0.0882 & $\mathrm{R}$ \\
\hline 1 & 11 & 1 & $\odot$ & 2 & 2 & & 0.603 & ๑. 09528 & -0.105 & $\mathrm{R}$ \\
\hline 1 & 12 & 1 & $\odot$ & 3 & 3 & & 0.695 & ๑. 09172 & -0.122 & $\mathrm{R}$ \\
\hline 1 & 13 & 1 & $\odot$ & 2 & 2 & & 0.781 & 0.08606 & -0.140 & $\mathrm{R}$ \\
\hline 1 & 14 & 1 & $\odot$ & 3 & 3 & & 0.866 & 0.08463 & -0.157 & $\mathrm{R}$ \\
\hline 1 & 15 & 1 & $\odot$ & 3 & 3 & & 0.948 & 0.08209 & -0.175 & $\mathrm{R}$ \\
\hline 1 & 16 & 1 & $\odot$ & 3 & 3 & & 1.03 & ๑. 07871 & -0.192 & $\mathrm{R}$ \\
\hline 1 & 17 & 1 & $\odot$ & 3 & 3 & & 1.10 & 0.07597 & -0.210 & $\mathrm{R}$ \\
\hline 1 & 18 & 1 & $\odot$ & 3 & 3 & & 1.18 & 0.07380 & -0.228 & $\mathrm{R}$ \\
\hline 1 & 19 & 1 & $\odot$ & 3 & 3 & & 1.25 & 0.07058 & -0.246 & $\mathrm{R}$ \\
\hline 1 & 20 & 1 & $\odot$ & 3 & 3 & & 1.31 & 0.06762 & -0.264 & $\mathrm{R}$ \\
\hline 1 & 21 & 1 & $\odot$ & 3 & 3 & & 1.38 & 0.06541 & -0.282 & $\mathrm{R}$ \\
\hline 1 & 22 & 1 & $\odot$ & 3 & 3 & & 1.44 & 0.06187 & -0.300 & $\mathrm{R}$ \\
\hline 1 & 23 & 1 & $\odot$ & 3 & 3 & & 1.50 & 0.05698 & -0.318 & $\mathrm{R}$ \\
\hline 1 & 24 & 1 & $\odot$ & 3 & 3 & & 1.55 & 0.05240 & -0.337 & $\mathrm{R}$ \\
\hline 1 & 25 & 1 & $\odot$ & 3 & 3 & & 1.60 & 0.04863 & -0.355 & $\mathrm{R}$ \\
\hline 1 & 26 & 1 & $\odot$ & 3 & 3 & & 1.64 & 0.04370 & -0.374 & $\mathrm{R}$ \\
\hline 1 & 27 & 1 & $\odot$ & 3 & 3 & & 1.68 & 0.03974 & -0.393 & $\mathrm{R}$ \\
\hline 1 & 28 & 1 & $\odot$ & 3 & 3 & & 1.72 & 0.03629 & -0.411 & $\mathrm{R}$ \\
\hline 1 & 29 & 1 & $\odot$ & 2 & 2 & & 1.75 & 0.03347 & -0.430 & $\mathrm{R}$ \\
\hline 1 & 30 & 1 & $\odot$ & 2 & 2 & & 1.78 & 0.03101 & -0.449 & $\mathrm{R}$ \\
\hline 1 & 31 & 1 & $\odot$ & 2 & 2 & & 1.81 & 0.02879 & -0.468 & $\mathrm{R}$ \\
\hline 1 & 32 & 1 & $\odot$ & 2 & 2 & & 1.84 & ๑. 02655 & -0.487 & $\mathrm{R}$ \\
\hline 1 & 33 & 1 & $\odot$ & 3 & 3 & & 1.86 & 0.02456 & -0.506 & $\mathrm{R}$ \\
\hline 1 & 34 & 1 & $\odot$ & 3 & 3 & & 1.89 & ๑. . 02298 & -0.525 & $\mathrm{R}$ \\
\hline 1 & 35 & 1 & $\odot$ & 3 & 3 & & 1.91 & 0.02131 & -0.545 & $\mathrm{R}$ \\
\hline 1 & 36 & 1 & $\odot$ & 3 & 3 & & 1.93 & 0.01970 & -0.564 & $\mathrm{R}$ \\
\hline 1 & 37 & 1 & $\odot$ & 3 & 3 & & 1.95 & 0.01798 & -0.583 & $\mathrm{R}$ \\
\hline 1 & 38 & 1 & $\odot$ & 2 & 2 & & 1.96 & ๑. 01635 & -0.603 & $\mathrm{R}$ \\
\hline 1 & 39 & 1 & $\odot$ & 3 & 3 & & 1.98 & 0.01486 & -0.622 & $\mathrm{R}$ \\
\hline 1 & 40 & 1 & $\odot$ & 3 & 3 & & 1.99 & ๑. .01336 & -0.641 & $\mathrm{R}$ \\
\hline 1 & 41 & 1 & $\odot$ & 2 & 2 & & 2.00 & ๑ . 01192 & -0.661 & $\mathrm{R}$ \\
\hline 1 & 42 & 1 & $\odot$ & 3 & 3 & & 2.01 & ๑. . 01067 & -0.680 & $\mathrm{R}$ \\
\hline 1 & 43 & 1 & $\odot$ & 3 & 3 & & 2.02 & $\odot .009449$ & -0.699 & $\mathrm{R}$ \\
\hline 1 & 44 & 1 & $\odot$ & 2 & 2 & & 2.03 & ๑. . 008512 & -0.719 & $\mathrm{R}$ \\
\hline 1 & 45 & 1 & $\odot$ & 3 & 3 & & 2.04 & 0.007633 & -0.738 & $\mathrm{R}$ \\
\hline 1 & 46 & 1 & $\odot$ & 3 & 3 & & 2.05 & 0.006733 & -0.758 & $\mathrm{R}$ \\
\hline 1 & 47 & 1 & $\odot$ & 2 & 2 & & 2.05 & ๑. . 005903 & -0.777 & $\mathrm{R}$ \\
\hline 1 & 48 & 1 & $\odot$ & 3 & 3 & & 2.06 & 0.005117 & -0.797 & $\mathrm{R}$ \\
\hline 1 & 49 & 1 & $\odot$ & 3 & 3 & & 2.06 & $\odot .004326$ & -0.816 & $\mathrm{R}$ \\
\hline 1 & 50 & 1 & $\odot$ & 3 & 3 & & 2.06 & 0.003693 & -0.836 & $\mathrm{R}$ \\
\hline 1 & 51 & 1 & $\odot$ & 3 & 3 & & 2.07 & 0.003101 & -0.855 & $\mathrm{R}$ \\
\hline 1 & 52 & 1 & $\odot$ & 2 & 2 & & 2.07 & 0.002578 & -0.875 & $\mathrm{R}$ \\
\hline 1 & 53 & 1 & $\odot$ & 2 & 2 & & 2.07 & 0.002107 & -0.895 & $\mathrm{R}$ \\
\hline 1 & 54 & 1 & $\odot$ & 2 & 2 & & 2.07 & ๑. . 001592 & -0.914 & $\mathrm{R}$ \\
\hline 1 & 55 & 1 & $\odot$ & 2 & 2 & & 2.08 & 0.001103 & -0.934 & $\mathrm{R}$ \\
\hline 1 & 56 & 1 & $\odot$ & 2 & 2 & & 2.08 & 0.0006627 & -0.954 & $\mathrm{R}$ \\
\hline 1 & 57 & 1 & 0 & 2 & 2 & & 2.08 & 0.0002838 & -0.973 & $\mathbf{R}$ \\
\hline 1 & 58 & 1 & 0 & 2 & 2 & & 2.08 & $-1.773 e-05$ & -0.993 & $\overline{\mathrm{R}}$ \\
\hline 1 & 59 & 1 & $\odot$ & 3 & 3 & & 2.08 & $-\odot .0003695$ & -1.01 & $\mathrm{R}$ \\
\hline 1 & 60 & 1 & $\odot$ & 2 & 2 & & 2.07 & -0.0006701 & -1.03 & $\mathrm{R}$ \\
\hline 1 & 61 & 1 & $\odot$ & 3 & 3 & & 2.07 & -0.0009366 & -1.05 & $\mathrm{R}$ \\
\hline 1 & 62 & 1 & $\odot$ & 2 & 2 & & 2.07 & -0.001127 & -1.07 & $\mathrm{R}$ \\
\hline
\end{tabular}




\begin{tabular}{|c|c|c|c|c|c|c|c|c|c|}
\hline 1 & 63 & 1 & $\odot$ & 2 & 2 & 2.07 & $-\odot .00140 \odot$ & -1.09 & $\mathrm{R}$ \\
\hline 1 & 64 & 1 & 0 & 2 & 2 & 2.07 & -0.001684 & -1.11 & $\mathrm{R}$ \\
\hline 1 & 65 & 1 & 0 & 3 & 3 & 2.07 & -0.001955 & -1.13 & $\mathrm{R}$ \\
\hline 1 & 66 & 1 & $\odot$ & 3 & 3 & 2.07 & -0.002140 & -1.15 & $\mathrm{R}$ \\
\hline 1 & 67 & 1 & $\odot$ & 3 & 3 & 2.06 & -0.002317 & -1.17 & $\mathrm{R}$ \\
\hline 1 & 68 & 1 & 0 & 3 & 3 & 2.06 & $-0.0 \odot 249 \odot$ & -1.19 & $\mathrm{R}$ \\
\hline 1 & 69 & 1 & $\odot$ & 3 & 3 & 2.06 & $-0.0 \odot 2681$ & -1.21 & $\mathrm{R}$ \\
\hline 1 & 70 & 1 & $\odot$ & 3 & 3 & 2.06 & -0.002822 & -1.23 & $\mathrm{R}$ \\
\hline 1 & 71 & 1 & $\odot$ & 3 & 3 & 2.05 & -0.003009 & -1.25 & $\mathrm{R}$ \\
\hline 1 & 72 & 1 & 0 & 3 & 3 & 2.05 & -0.003133 & -1.27 & $\mathrm{R}$ \\
\hline 1 & 73 & 1 & 0 & 3 & 3 & 2.05 & -0.003242 & -1.29 & $\mathrm{R}$ \\
\hline 1 & 74 & 1 & $\odot$ & 3 & 3 & 2.04 & -0.003324 & -1.31 & $\mathrm{R}$ \\
\hline 1 & 75 & 1 & $\odot$ & 3 & 3 & 2.04 & -0.003381 & -1.33 & $\mathrm{R}$ \\
\hline 1 & 76 & 1 & $\odot$ & 3 & 3 & 2.04 & -0.003444 & -1.35 & $\mathrm{R}$ \\
\hline 1 & 77 & 1 & 0 & 3 & 3 & 2.03 & -0.003506 & -1.37 & $\mathrm{R}$ \\
\hline 1 & 78 & 1 & 0 & 3 & 3 & 2.03 & -0.003559 & -1.39 & $\mathrm{R}$ \\
\hline 1 & 79 & 1 & $\odot$ & 3 & 3 & 2.03 & -0.003620 & -1.42 & $\mathrm{R}$ \\
\hline 1 & 80 & 1 & $\odot$ & 3 & 3 & 2.02 & -0.003693 & -1.44 & $\mathrm{R}$ \\
\hline 1 & 81 & 1 & 0 & 3 & 3 & 2.02 & -0.003744 & -1.46 & $\mathrm{R}$ \\
\hline 1 & 82 & 1 & 0 & 4 & 4 & 2.01 & -0.003759 & -1.48 & $\mathrm{R}$ \\
\hline 1 & 83 & 1 & $\odot$ & 3 & 3 & 2.01 & -0.003764 & -1.50 & $\mathrm{R}$ \\
\hline 1 & 84 & 1 & $\odot$ & 4 & 4 & 2.01 & -0.003810 & -1.52 & $\mathrm{R}$ \\
\hline 1 & 85 & 1 & $\odot$ & 4 & 4 & 2.00 & -0.003805 & -1.54 & $\mathrm{R}$ \\
\hline 1 & 86 & 1 & 0 & 4 & 4 & 2.00 & -0.003779 & -1.56 & $\mathrm{R}$ \\
\hline 1 & 87 & 1 & $\odot$ & 4 & 4 & 1.99 & -0.003786 & -1.58 & $\mathrm{R}$ \\
\hline 1 & 88 & 1 & $\odot$ & 4 & 4 & 1.99 & -0.003773 & -1.60 & $\mathrm{R}$ \\
\hline 1 & 89 & 1 & $\odot$ & 4 & 4 & 1.99 & -0.003687 & -1.62 & $\mathrm{R}$ \\
\hline 1 & 90 & 1 & 0 & 4 & 4 & 1.98 & -0.003629 & -1.64 & $\mathrm{R}$ \\
\hline 1 & 91 & 1 & 0 & 4 & 4 & 1.98 & -0.003601 & -1.66 & $\mathrm{R}$ \\
\hline 1 & 92 & 1 & $\odot$ & 3 & 3 & 1.98 & -0.003535 & -1.68 & $\mathrm{R}$ \\
\hline 1 & 93 & 1 & 0 & 4 & 4 & 1.97 & -0.003451 & -1.70 & $\mathrm{R}$ \\
\hline 1 & 94 & 1 & 0 & 4 & 4 & 1.97 & -0.003389 & -1.72 & $\mathrm{R}$ \\
\hline 1 & 95 & 1 & 0 & 4 & 4 & 1.97 & -0.003342 & -1.74 & $\mathrm{R}$ \\
\hline 1 & 96 & 1 & $\odot$ & 4 & 4 & 1.96 & -0.003286 & -1.76 & $\mathrm{R}$ \\
\hline 1 & 97 & 1 & $\odot$ & 4 & 4 & 1.96 & -0.003185 & -1.79 & $\mathrm{R}$ \\
\hline 1 & 98 & 1 & $\odot$ & 4 & 4 & 1.96 & -0.003051 & -1.81 & $\mathrm{R}$ \\
\hline 1 & 99 & 1 & $\odot$ & 4 & 4 & 1.95 & $-\odot .0 \odot 29 \odot \odot$ & -1.83 & $\mathrm{R}$ \\
\hline 1 & 100 & 1 & 0 & 4 & 4 & 1.95 & -0.002766 & -1.85 & $\mathrm{R}$ \\
\hline
\end{tabular}

THE ANALYSIS HAS COMPLETED SUCCESSFULLY 


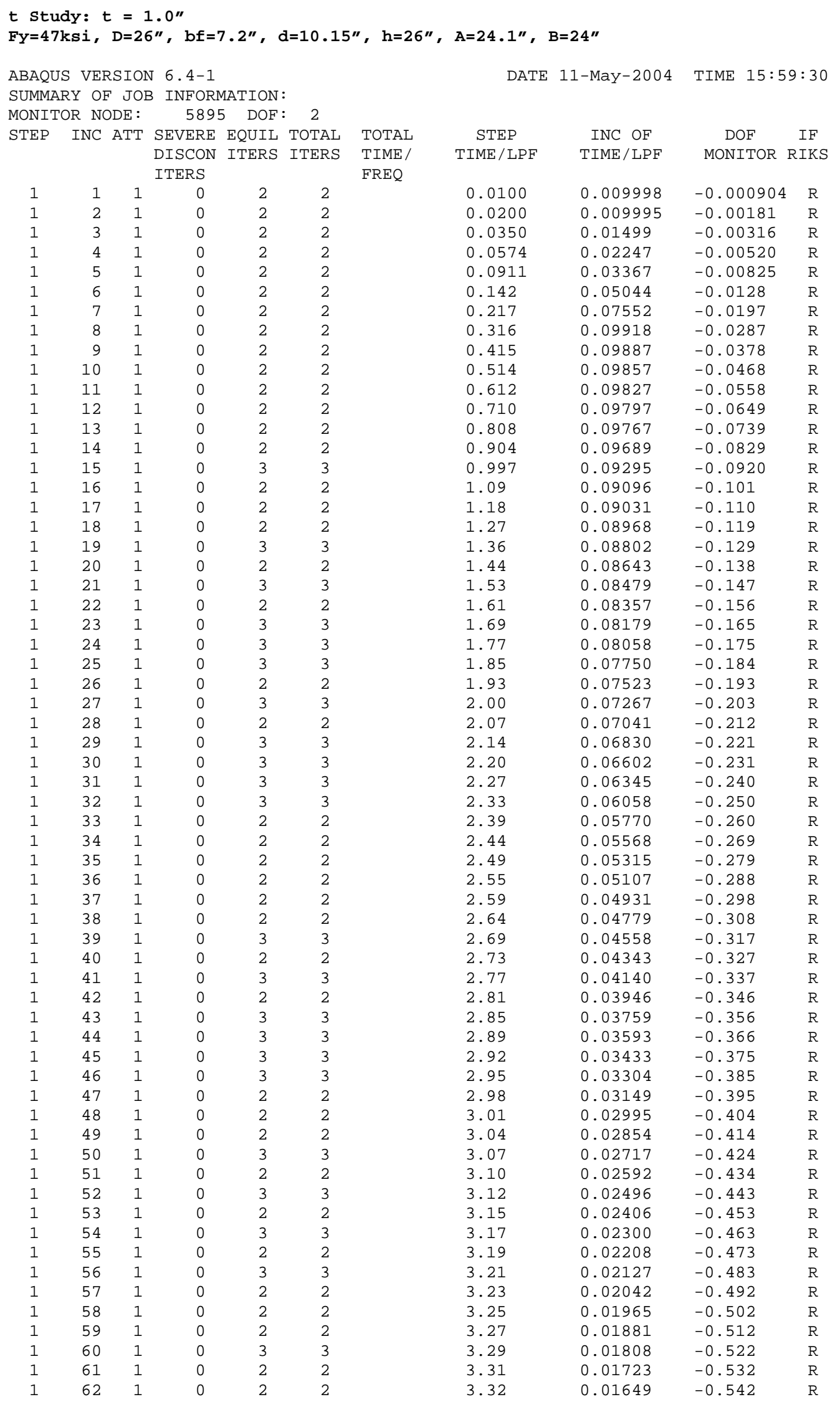




\begin{tabular}{|c|c|c|c|c|c|c|c|c|c|}
\hline 1 & 63 & 1 & $\odot$ & 3 & 3 & 3.34 & $\odot .01572$ & -0.551 & $\mathrm{R}$ \\
\hline 1 & 64 & 1 & 0 & 3 & 3 & 3.35 & 0.01484 & -0.561 & $\mathrm{R}$ \\
\hline 1 & 65 & 1 & $\odot$ & 3 & 3 & 3.37 & $\odot .01399$ & -0.571 & $\mathrm{R}$ \\
\hline 1 & 66 & 1 & $\odot$ & 2 & 2 & 3.38 & 0.01329 & $-\odot .581$ & $\mathrm{R}$ \\
\hline 1 & 67 & 1 & $\odot$ & 2 & 2 & 3.39 & $\odot .01270$ & $-\odot .591$ & $\mathrm{R}$ \\
\hline 1 & 68 & 1 & $\odot$ & 2 & 2 & 3.40 & $\odot .01196$ & -0.601 & $\mathrm{R}$ \\
\hline 1 & 69 & 1 & $\odot$ & 3 & 3 & 3.42 & $\odot .01132$ & -0.611 & $\mathrm{R}$ \\
\hline 1 & 70 & 1 & $\odot$ & 2 & 2 & 3.43 & ๑.01053 & -0.620 & $\mathrm{R}$ \\
\hline 1 & 71 & 1 & $\odot$ & 2 & 2 & 3.44 & 0.01005 & -0.630 & $\mathrm{R}$ \\
\hline 1 & 72 & 1 & $\odot$ & 2 & 2 & 3.45 & $\odot .009526$ & -0.640 & $\mathrm{R}$ \\
\hline 1 & 73 & 1 & $\odot$ & 3 & 3 & 3.46 & $\odot .009 \odot 45$ & -0.650 & $\mathrm{R}$ \\
\hline 1 & 74 & 1 & $\odot$ & 3 & 3 & 3.46 & ๑.0๑8611 & -0.660 & $\mathrm{R}$ \\
\hline 1 & 75 & 1 & $\odot$ & 2 & 2 & 3.47 & 0.008102 & -0.670 & $\mathrm{R}$ \\
\hline 1 & 76 & 1 & $\odot$ & 2 & 2 & 3.48 & $\odot .007620$ & -0.680 & $\mathrm{R}$ \\
\hline 1 & 77 & 1 & 0 & 2 & 2 & 3.49 & $\odot .007205$ & -0.689 & $\mathrm{R}$ \\
\hline 1 & 78 & 1 & $\odot$ & 2 & 2 & 3.49 & 0.006813 & -0.699 & $\mathrm{R}$ \\
\hline 1 & 79 & 1 & $\odot$ & 2 & 2 & 3.50 & 0.006429 & -0.709 & $\mathrm{R}$ \\
\hline 1 & 80 & 1 & $\odot$ & 3 & 3 & 3.51 & 0.006058 & -0.719 & $\mathrm{R}$ \\
\hline 1 & 81 & 1 & $\odot$ & 3 & 3 & 3.51 & $\odot .005738$ & -0.729 & $\mathrm{R}$ \\
\hline 1 & 82 & 1 & $\odot$ & 3 & 3 & 3.52 & $\odot .005459$ & -0.739 & $\mathrm{R}$ \\
\hline 1 & 83 & 1 & $\odot$ & 3 & 3 & 3.52 & $\odot .005100$ & $-\odot .749$ & $\mathrm{R}$ \\
\hline 1 & 84 & 1 & $\odot$ & 3 & 3 & 3.53 & $0.0 \odot 4707$ & -0.759 & $\mathrm{R}$ \\
\hline 1 & 85 & 1 & $\odot$ & 2 & 2 & 3.53 & ๑.0๑4411 & $-\odot .769$ & $\mathrm{R}$ \\
\hline 1 & 86 & 1 & $\odot$ & 3 & 3 & 3.54 & 0.004131 & -0.779 & $\mathrm{R}$ \\
\hline 1 & 87 & 1 & $\odot$ & 3 & 3 & 3.54 & $\odot .0 \odot 3879$ & $-\odot .789$ & $\mathrm{R}$ \\
\hline 1 & 88 & 1 & $\odot$ & 3 & 3 & 3.54 & 0.003667 & $-\odot .799$ & $\mathrm{R}$ \\
\hline 1 & 89 & 1 & $\odot$ & 3 & 3 & 3.55 & $\odot .003405$ & $-\odot .809$ & $\mathrm{R}$ \\
\hline 1 & 90 & 1 & $\odot$ & 3 & 3 & 3.55 & $\odot .003135$ & -0.819 & $\mathrm{R}$ \\
\hline 1 & 91 & 1 & 0 & 3 & 3 & 3.55 & $\odot .0 \odot 2862$ & -0.829 & $\mathrm{R}$ \\
\hline 1 & 92 & 1 & $\odot$ & 3 & 3 & 3.56 & $\odot .0 \odot 2650$ & -0.839 & $\mathrm{R}$ \\
\hline 1 & 93 & 1 & $\odot$ & 3 & 3 & 3.56 & 0.002435 & -0.849 & $\mathrm{R}$ \\
\hline 1 & 94 & 1 & $\odot$ & 3 & 3 & 3.56 & $\odot .0 \odot 2179$ & $-\odot .859$ & $\mathrm{R}$ \\
\hline 1 & 95 & 1 & $\odot$ & 3 & 3 & 3.56 & ๑.001958 & $-\odot .869$ & $\mathrm{R}$ \\
\hline 1 & 96 & 1 & $\odot$ & 3 & 3 & 3.56 & 0.001778 & $-\odot .879$ & $\mathrm{R}$ \\
\hline 1 & 97 & 1 & $\odot$ & 3 & 3 & 3.57 & $\odot .0 \odot 1612$ & $-\odot .889$ & $\mathrm{R}$ \\
\hline 1 & 98 & 1 & $\odot$ & 3 & 3 & 3.57 & $\odot .001480$ & $-\odot .899$ & $\mathrm{R}$ \\
\hline 1 & 99 & 1 & $\odot$ & 3 & 3 & 3.57 & 0.001348 & $-\odot .909$ & $\mathrm{R}$ \\
\hline 1 & 100 & 1 & $\odot$ & 3 & 3 & 3.57 & $\odot .0 \odot 1204$ & $-\odot .919$ & $\mathrm{R}$ \\
\hline 1 & 101 & 1 & $\odot$ & 3 & 3 & 3.57 & 0.001028 & -0.929 & $\mathrm{R}$ \\
\hline 1 & 102 & 1 & $\odot$ & 3 & 3 & 3.57 & 0.0008858 & -0.939 & $\mathrm{R}$ \\
\hline 1 & 103 & 1 & $\odot$ & 3 & 3 & 3.57 & 0.0007363 & -0.949 & $\mathrm{R}$ \\
\hline 1 & 104 & 1 & $\Theta$ & 3 & 3 & 3.57 & $\odot .0006206$ & -0.959 & $\mathrm{R}$ \\
\hline 1 & 105 & 1 & $\odot$ & 3 & 3 & 3.57 & $\odot .0 \odot \odot 4870$ & -0.969 & $\mathrm{R}$ \\
\hline 1 & 106 & 1 & $\odot$ & 3 & 3 & 3.57 & 0.0003803 & $-\odot .979$ & $\mathrm{R}$ \\
\hline 1 & 107 & 1 & $\odot$ & 3 & 3 & 3.57 & $\odot .0 \odot \odot 2650$ & -0.989 & $\mathrm{R}$ \\
\hline 1 & 108 & 1 & 0 & 3 & 3 & 3.57 & $\odot .0001347$ & $-\odot .999$ & $\mathrm{R}$ \\
\hline 1 & 109 & 1 & 0 & 3 & 3 & 3.57 & $2.569 e-05$ & -1.01 & $\mathbf{R}$ \\
\hline 1 & 110 & 1 & $\theta$ & 3 & 3 & 3.57 & $-7.650 \mathrm{e}-05$ & -1.02 & $\overline{\mathrm{R}}$ \\
\hline 1 & 111 & 1 & $\odot$ & 3 & 3 & 3.57 & -0.0001753 & -1.03 & $\mathrm{R}$ \\
\hline 1 & 112 & 1 & $\odot$ & 3 & 3 & 3.57 & $-\odot . \odot \odot \odot 2653$ & -1.04 & $\mathrm{R}$ \\
\hline 1 & 113 & 1 & $\odot$ & 3 & 3 & 3.57 & $-\odot .0003484$ & -1.05 & $\mathrm{R}$ \\
\hline 1 & 114 & 1 & $\odot$ & 3 & 3 & 3.57 & $-\odot .00 \odot 4239$ & -1.06 & $\mathrm{R}$ \\
\hline 1 & 115 & 1 & $\odot$ & 3 & 3 & 3.57 & -๑.๑๑९5315 & -1.07 & $\mathrm{R}$ \\
\hline 1 & 116 & 1 & 0 & 3 & 3 & 3.57 & $-\odot . \odot \odot \odot 6 \odot 79$ & -1.08 & $\mathrm{R}$ \\
\hline 1 & 117 & 1 & $\odot$ & 3 & 3 & 3.57 & -0.0007088 & -1.09 & $\mathrm{R}$ \\
\hline 1 & 118 & 1 & $\odot$ & 3 & 3 & 3.57 & $-\odot . \odot \odot \odot 8 \odot 21$ & -1.10 & $\mathrm{R}$ \\
\hline 1 & 119 & 1 & $\odot$ & 3 & 3 & 3.57 & $-\odot .0 \odot \odot 9168$ & -1.11 & $\mathrm{R}$ \\
\hline 1 & 120 & 1 & $\odot$ & 3 & 3 & 3.57 & $-\odot . \odot \odot 1 \odot \odot 2$ & -1.12 & $\mathrm{R}$ \\
\hline 1 & 121 & 1 & 0 & 3 & 3 & 3.57 & -0.001080 & -1.13 & $\mathrm{R}$ \\
\hline 1 & 122 & 1 & 0 & 3 & 3 & 3.57 & -0.001152 & -1.14 & $\mathrm{R}$ \\
\hline 1 & 123 & 1 & $\odot$ & 3 & 3 & 3.56 & $-\odot .0 \odot 1233$ & -1.15 & $\mathrm{R}$ \\
\hline 1 & 124 & 1 & $\odot$ & 3 & 3 & 3.56 & -0.001308 & -1.16 & $\mathrm{R}$ \\
\hline 1 & 125 & 1 & $\odot$ & 3 & 3 & 3.56 & $-\odot .0 \odot 1371$ & -1.17 & $\mathrm{R}$ \\
\hline 1 & 126 & 1 & 0 & 3 & 3 & 3.56 & $-\odot .001442$ & -1.18 & $\mathrm{R}$ \\
\hline 1 & 127 & 1 & $\odot$ & 3 & 3 & 3.56 & $-\odot .001545$ & -1.19 & $\mathrm{R}$ \\
\hline 1 & 128 & 1 & $\odot$ & 4 & 4 & 3.56 & $-\odot . \odot \odot 1637$ & -1.20 & $\mathrm{R}$ \\
\hline 1 & 129 & 1 & $\odot$ & 4 & 4 & 3.56 & $-\odot .001689$ & -1.21 & $\mathrm{R}$ \\
\hline 1 & 130 & 1 & $\odot$ & 4 & 4 & 3.55 & $-\odot .001741$ & -1.22 & $\mathrm{R}$ \\
\hline 1 & 131 & 1 & $\odot$ & 4 & 4 & 3.55 & $-\odot .001790$ & -1.23 & $\mathrm{R}$ \\
\hline 1 & 132 & 1 & $\odot$ & 4 & 4 & 3.55 & $-\odot .001849$ & -1.24 & $\mathrm{R}$ \\
\hline 1 & 133 & 1 & $\odot$ & 4 & 4 & 3.55 & $-\odot . \odot \odot 1939$ & -1.25 & $\mathrm{R}$ \\
\hline
\end{tabular}




\begin{tabular}{|c|c|c|c|c|c|c|c|c|c|}
\hline 1 & 134 & 1 & $\odot$ & 4 & 4 & 3.55 & $-\odot .001997$ & -1.26 & $\mathrm{R}$ \\
\hline 1 & 135 & 1 & 0 & 4 & 4 & 3.54 & $-\odot .002075$ & -1.27 & $\mathrm{R}$ \\
\hline 1 & 136 & 1 & 0 & 4 & 4 & 3.54 & -0.002143 & -1.28 & $\mathrm{R}$ \\
\hline 1 & 137 & 1 & 0 & 4 & 4 & 3.54 & -0.002191 & -1.29 & $\mathrm{R}$ \\
\hline 1 & 138 & 1 & 0 & 4 & 4 & 3.54 & $-\odot .0 \odot 2223$ & -1.30 & $\mathrm{R}$ \\
\hline 1 & 139 & 1 & 0 & 4 & 4 & 3.54 & $-\odot .002256$ & -1.31 & $\mathrm{R}$ \\
\hline 1 & 140 & 1 & 0 & 4 & 4 & 3.53 & -0.002272 & -1.32 & $\mathrm{R}$ \\
\hline 1 & 141 & 1 & $\odot$ & 4 & 4 & 3.53 & -0.002323 & -1.33 & $\mathrm{R}$ \\
\hline 1 & 142 & 1 & 0 & 4 & 4 & 3.53 & -0.002393 & -1.34 & $\mathrm{R}$ \\
\hline 1 & 143 & 1 & 0 & 3 & 3 & 3.53 & -0.002430 & -1.35 & $\mathrm{R}$ \\
\hline 1 & 144 & 1 & 0 & 4 & 4 & 3.52 & $-0.0 \odot 2478$ & -1.36 & $\mathrm{R}$ \\
\hline 1 & 145 & 1 & 0 & 4 & 4 & 3.52 & -0.002543 & -1.37 & $\mathrm{R}$ \\
\hline 1 & 146 & 1 & 0 & 4 & 4 & 3.52 & -0.002627 & -1.38 & $\mathrm{R}$ \\
\hline 1 & 147 & 1 & 0 & 4 & 4 & 3.52 & -0.002648 & -1.39 & $\mathrm{R}$ \\
\hline 1 & 148 & 1 & 0 & 4 & 4 & 3.51 & -0.002696 & -1.40 & $\mathrm{R}$ \\
\hline 1 & 149 & 1 & 0 & 4 & 4 & 3.51 & $-\odot .002738$ & -1.42 & $\mathrm{R}$ \\
\hline 1 & 150 & 1 & 0 & 4 & 4 & 3.51 & -0.002764 & -1.43 & $\mathrm{R}$ \\
\hline 1 & 151 & 1 & 0 & 4 & 4 & 3.50 & -0.002789 & -1.44 & $\mathrm{R}$ \\
\hline 1 & 152 & 1 & 0 & 4 & 4 & 3.50 & $-\odot .002807$ & -1.45 & $\mathrm{R}$ \\
\hline 1 & 153 & 1 & 0 & 4 & 4 & 3.50 & $-\odot .002821$ & -1.46 & $\mathrm{R}$ \\
\hline 1 & 154 & 1 & 0 & 4 & 4 & 3.50 & $-\odot .002847$ & -1.47 & $\mathrm{R}$ \\
\hline 1 & 155 & 1 & 0 & 4 & 4 & 3.49 & -0.002864 & -1.48 & $\mathrm{R}$ \\
\hline 1 & 156 & 1 & 0 & 4 & 4 & 3.49 & -0.002893 & -1.49 & $\mathrm{R}$ \\
\hline 1 & 157 & 1 & 0 & 4 & 4 & 3.49 & -0.002913 & -1.50 & $\mathrm{R}$ \\
\hline 1 & 158 & 1 & 0 & 4 & 4 & 3.48 & $-\odot .002952$ & -1.51 & $\mathrm{R}$ \\
\hline
\end{tabular}

THE ANALYSIS HAS NOT BEEN COMPLETED 
Fy Study: $\mathrm{Fy}=36 \mathrm{ksi}$

$t=0.5^{\prime \prime}, D=26^{\prime \prime}, b f=7.2^{\prime \prime}, d=10.15^{\prime \prime}, h=26^{\prime \prime}, A=24.1^{\prime \prime}, B=24^{\prime \prime}$

ABAQUS VERSION 6.4-1

DATE 11-May-2004 TIME 17:08:29

SUMMARY OF JOB INFORMATION:

MONITOR NODE: 5895 DOF: 2

$\begin{array}{rrrlcccc}\text { STEP INC ATT SEVERE EQUIL TOTAL } & \text { TOTAL } & \text { STEP } & \text { INC OF } & \text { DOF } & \text { IF } \\ & \text { DISCON } & \text { ITERS ITERS } & \text { TIME/ } & \text { TIME/LPF } & \text { TIME/LPF } & \text { MONITOR RIKS }\end{array}$

\begin{tabular}{|c|c|c|c|c|c|c|c|c|c|}
\hline & & & & ITEK & $\begin{array}{l}\text { 1TERS I MME' } \\
\text { FREQ }\end{array}$ & 11 & IME/LPF & הושל & \\
\hline 1 & 1 & 1 & $\odot$ & 3 & 3 & ๑. 0989 & ๑. 09888 & -0.0445 & $\mathrm{R}$ \\
\hline 1 & 2 & 1 & $\odot$ & 3 & 3 & 0.195 & 0.09615 & -0.0892 & $\mathrm{R}$ \\
\hline 1 & 3 & 1 & $\odot$ & 4 & 4 & $\odot .327$ & 0.1320 & -0.157 & $\mathrm{R}$ \\
\hline 1 & 4 & 1 & $\odot$ & 4 & 4 & $\odot .492$ & $\odot .1649$ & -0.263 & $P$ \\
\hline 1 & 5 & 1 & $\odot$ & 4 & 4 & 0.656 & $\odot .1643$ & -0.428 & $\mathrm{R}$ \\
\hline 1 & 6 & 1 & $\odot$ & 5 & 5 & 0.741 & 0.08493 & -0.691 & $\mathrm{R}$ \\
\hline 1 & 7 & 1 & 0 & 5 & 5 & 0.746 & 0.005056 & -0.960 & $\mathbf{R}$ \\
\hline 1 & 8 & 1 & 0 & 5 & 5 & 0.729 & -0.01712 & -1.23 & $\overline{\mathrm{R}}$ \\
\hline 1 & 9 & 1 & $\odot$ & 5 & 5 & $\odot .709$ & -0.01995 & -1.51 & $\mathrm{R}$ \\
\hline 1 & 10 & 1 & $\odot$ & 5 & 5 & 0.693 & -0.01638 & -1.80 & $\mathrm{R}$ \\
\hline 1 & 11 & 1 & $\odot$ & 5 & 5 & 0.689 & -0.003487 & -2.08 & $\mathrm{R}$ \\
\hline 1 & 12 & 1 & $\odot$ & 5 & 5 & $\odot .702$ & 0.01245 & -2.36 & $\mathrm{R}$ \\
\hline 1 & 13 & 1 & $\odot$ & 5 & 5 & 0.728 & 0.02594 & -2.64 & $\mathrm{R}$ \\
\hline 1 & 14 & 1 & $\odot$ & 4 & 4 & 0.764 & 0.03626 & -2.92 & $\mathrm{R}$ \\
\hline 1 & 15 & 1 & $\odot$ & 4 & 4 & 0.803 & 0.03947 & -3.19 & $\mathrm{R}$ \\
\hline 1 & 16 & 1 & 0 & 4 & 4 & 0.841 & ๑. 03785 & -3.45 & $\mathrm{R}$ \\
\hline 1 & 17 & 1 & $\odot$ & 4 & 4 & $\odot .875$ & $\odot .03417$ & -3.71 & $\mathrm{R}$ \\
\hline 1 & 18 & 1 & $\odot$ & 4 & 4 & 0.906 & 0.03043 & -3.97 & $\mathrm{R}$ \\
\hline 1 & 19 & 1 & $\odot$ & 5 & 5 & 0.933 & 0.02697 & -4.22 & $\mathrm{R}$ \\
\hline 1 & 20 & 1 & $\odot$ & 4 & 4 & 0.957 & 0.02435 & -4.47 & $\mathrm{R}$ \\
\hline 1 & 21 & 1 & 0 & 4 & 4 & 0.980 & ๑. 02254 & -4.72 & $\mathrm{R}$ \\
\hline 1 & 22 & 1 & $\odot$ & 5 & 5 & 1.00 & $\odot .02 \odot 77$ & -4.97 & $\mathrm{R}$ \\
\hline 1 & 23 & 1 & $\odot$ & 5 & 5 & 1.02 & ๑.01956 & -5.21 & $\mathrm{R}$ \\
\hline 1 & 24 & 1 & $\odot$ & 5 & 5 & 1.04 & 0.01868 & -5.45 & $\mathrm{R}$ \\
\hline 1 & 25 & 1 & $\odot$ & 4 & 4 & 1.06 & $\odot .01775$ & -5.68 & $\mathrm{R}$ \\
\hline 1 & 26 & 1 & $\odot$ & 5 & 5 & 1.07 & $\odot .01653$ & -5.92 & $\mathrm{R}$ \\
\hline 1 & 27 & 1 & $\odot$ & 5 & 5 & 1.09 & $\odot .01492$ & -6.15 & $\mathrm{R}$ \\
\hline 1 & 28 & 1 & $\odot$ & 5 & 5 & 1.10 & 0.01258 & -6.38 & $\mathrm{R}$ \\
\hline 1 & 29 & 1 & $\odot$ & 5 & 5 & 1.11 & 0.01006 & -6.61 & $\mathrm{R}$ \\
\hline 1 & 30 & 1 & $\odot$ & 5 & 5 & 1.12 & $\odot . \odot \odot 7263$ & -6.83 & $\mathrm{R}$ \\
\hline 1 & 31 & 1 & $\odot$ & 5 & 5 & 1.12 & 0.005521 & -7.06 & $\mathrm{R}$ \\
\hline 1 & 32 & 1 & $\odot$ & 5 & 5 & 1.13 & $\odot . \odot \odot 4 \odot 55$ & -7.29 & $\mathrm{R}$ \\
\hline 1 & 33 & 1 & $\odot$ & 6 & 6 & 1.13 & $\odot . \odot \odot 2876$ & -7.52 & $\mathrm{R}$ \\
\hline 1 & 34 & 1 & $\odot$ & 6 & 6 & 1.13 & $\odot . \odot \odot 2 \odot \odot \odot$ & -7.74 & $\mathrm{R}$ \\
\hline 1 & 35 & 1 & $\odot$ & 6 & 6 & 1.13 & $\odot . \odot \odot 1517$ & -7.97 & $\mathrm{R}$ \\
\hline 1 & 36 & 1 & $\odot$ & 6 & 6 & 1.14 & 0.001517 & -8.20 & $\mathrm{R}$ \\
\hline 1 & 37 & 1 & $\odot$ & 6 & 6 & 1.14 & $\odot . \odot \odot 1668$ & -8.43 & $\mathrm{R}$ \\
\hline 1 & 38 & 1 & $\odot$ & 5 & 5 & 1.14 & 0.001904 & -8.66 & $\mathrm{R}$ \\
\hline 1 & 39 & 1 & $\odot$ & 5 & 5 & 1.14 & $\odot .0 \odot 2454$ & -8.88 & $\mathrm{R}$ \\
\hline 1 & 40 & 1 & $\odot$ & 5 & 5 & 1.14 & $\odot . \odot \odot 3 \odot 37$ & -9.11 & $\mathrm{R}$ \\
\hline 1 & 41 & 1 & $\odot$ & 5 & 5 & 1.15 & 0.003605 & -9.34 & $\mathrm{R}$ \\
\hline 1 & 42 & 1 & $\odot$ & 5 & 5 & 1.15 & $\odot .0 \odot 4068$ & -9.57 & $\mathrm{R}$ \\
\hline 1 & 43 & 1 & $\odot$ & 5 & 5 & 1.16 & $\odot . \odot \odot 4438$ & -9.80 & $\Omega^{2}>-1$ \\
\hline 1 & 44 & 1 & $\odot$ & 5 & 5 & 1.16 & $0.0 \odot 4747$ & -10.0 & $\mathrm{R}$ \\
\hline 1 & 45 & 1 & $\odot$ & 5 & 5 & 1.17 & $\odot . \odot \odot 4912$ & -10.3 & $\mathrm{R}$ \\
\hline 1 & 46 & 1 & $\odot$ & 6 & 6 & 1.17 & $\odot .005018$ & -10.5 & $\mathrm{R}$ \\
\hline 1 & 47 & 1 & $\odot$ & 5 & 5 & 1.18 & $\odot .005195$ & -10.7 & $\mathrm{R}$ \\
\hline 1 & 48 & 1 & $\odot$ & 5 & 5 & 1.18 & ๑. .๑55438 & -10.9 & $\mathrm{R}$ \\
\hline 1 & 49 & 1 & $\odot$ & 5 & 5 & 1.19 & 0.005613 & -11.2 & $\mathrm{R}$ \\
\hline 1 & 50 & 1 & $\odot$ & 5 & 5 & 1.19 & $\odot . \odot \odot 5719$ & -11.4 & - \\
\hline
\end{tabular}

THE ANALYSIS HAS COMPLETED SUCCESSFULLY 
Fy Study: $F y=47 \mathrm{ksi}$

$t=0.5^{\prime \prime}, D=26^{\prime \prime}, b f=7.2^{\prime \prime}, d=10.15^{\prime \prime}, h=26^{\prime \prime}, A=24.1^{\prime \prime}, B=24^{\prime \prime}$

ABAQUS VERSION 6.4-1

DATE 11-May-2004 TIME 17:04:50

SUMMARY OF JOB INFORMATION:

MONITOR NODE: 5895 DOF : 2

$\begin{array}{lrllcccc}\text { STEP } & \text { INC ATT SEVERE EQUIL TOTAL } & \text { TOTAL } & \text { STEP } & \text { INC OF } & \text { DOF } & \text { IF } \\ & \text { DISCON } & \text { ITERS } & \text { ITERS } & \text { TIME/ } & \text { TIME/LPF } & \text { TIME/LPF } & \text { MONITOR RIKS }\end{array}$

\begin{tabular}{|c|c|c|c|c|c|c|c|c|c|}
\hline & & & $\begin{array}{l}\text { CON } \\
\text { RS }\end{array}$ & 1IERS & $\begin{array}{ll}\text { ITERS } & \text { TME/ } \\
& \text { FREQ }\end{array}$ & IIME/LPF & IIME/LPF & MONIIOR & RIKS \\
\hline 1 & 1 & 1 & 0 & 3 & 3 & $\odot .0989$ & ๑. 09888 & -0.0445 & $\mathrm{R}$ \\
\hline 1 & 2 & 1 & 0 & 3 & 3 & 0.195 & $\odot .09657$ & $-\odot .0892$ & $\mathrm{R}$ \\
\hline 1 & 3 & 1 & 0 & 3 & 3 & 0.332 & 0.1367 & $-\odot .157$ & $\mathrm{R}$ \\
\hline 1 & 4 & 1 & 0 & 5 & 5 & 0.510 & 0.1778 & -0.261 & $\mathrm{R}$ \\
\hline 1 & 5 & 1 & 0 & 4 & 4 & 0.657 & 0.1467 & -0.368 & $\mathrm{R}$ \\
\hline 1 & 6 & 1 & 0 & 4 & 4 & 0.766 & 0.1094 & -0.478 & $\mathrm{R}$ \\
\hline 1 & 7 & 1 & 0 & 4 & 4 & 0.856 & 0.08962 & -0.651 & $\mathrm{R}$ \\
\hline 1 & 8 & 1 & 0 & 5 & 5 & 0.900 & 0.04387 & -0.919 & $\mathbf{R}$ \\
\hline 1 & 9 & 1 & 0 & 6 & 6 & 0.891 & -0.008708 & -1.19 & $\bar{R}$ \\
\hline 1 & 10 & 1 & 0 & 5 & 5 & $\odot .868$ & $-\odot .02277$ & -1.47 & $\mathrm{R}$ \\
\hline 1 & 11 & 1 & 0 & 4 & 4 & 0.847 & $-\odot .02096$ & -1.75 & $\mathrm{R}$ \\
\hline 1 & 12 & 1 & 0 & 5 & 5 & 0.837 & -0.01061 & -2.04 & $\mathrm{R}$ \\
\hline 1 & 13 & 1 & 0 & 4 & 4 & 0.845 & 0.008436 & -2.32 & $\mathrm{R}$ \\
\hline 1 & 14 & 1 & $\odot$ & 5 & 5 & 0.871 & $\odot .02614$ & -2.60 & $\mathrm{R}$ \\
\hline 1 & 15 & 1 & 0 & 4 & 4 & 0.910 & 0.03883 & -2.88 & $\mathrm{R}$ \\
\hline 1 & 16 & 1 & 0 & 5 & 5 & 0.957 & $\odot .04700$ & -3.15 & $\mathrm{R}$ \\
\hline 1 & 17 & 1 & 0 & 4 & 4 & 1.00 & 0.04782 & -3.41 & $\mathrm{R}$ \\
\hline 1 & 18 & 1 & 0 & 4 & 4 & 1.05 & $\odot .04480$ & -3.67 & $\mathrm{R}$ \\
\hline 1 & 19 & 1 & 0 & 4 & 4 & 1.09 & 0.04038 & -3.93 & $\mathrm{R}$ \\
\hline 1 & 20 & 1 & 0 & 4 & 4 & 1.13 & 0.03632 & -4.18 & $\mathrm{R}$ \\
\hline 1 & 21 & 1 & 0 & 4 & 4 & 1.16 & 0.03286 & -4.43 & $\mathrm{R}$ \\
\hline 1 & 22 & 1 & 0 & 4 & 4 & 1.19 & $\odot .02954$ & -4.68 & $\mathrm{R}$ \\
\hline 1 & 23 & 1 & 0 & 4 & 4 & 1.22 & $\odot .02747$ & -4.93 & $\mathrm{R}$ \\
\hline 1 & 24 & 1 & 0 & 4 & 4 & 1.24 & $\odot .02559$ & -5.17 & $\mathrm{R}$ \\
\hline 1 & 25 & 1 & 0 & 4 & 4 & 1.27 & $\odot .02401$ & -5.41 & $\mathrm{R}$ \\
\hline 1 & 26 & 1 & 0 & 4 & 4 & 1.29 & $\odot .02280$ & -5.64 & $\mathrm{R}$ \\
\hline 1 & 27 & 1 & $\odot$ & 4 & 4 & 1.31 & 0.02163 & -5.88 & $\mathrm{R}$ \\
\hline 1 & 28 & 1 & 0 & 4 & 4 & 1.33 & ๑. .01992 & -6.11 & $\mathrm{R}$ \\
\hline 1 & 29 & 1 & 0 & 4 & 4 & 1.35 & ๑. 01753 & -6.34 & $\mathrm{R}$ \\
\hline 1 & 30 & 1 & 0 & 5 & 5 & 1.36 & 0.01425 & -6.57 & $\mathrm{R}$ \\
\hline 1 & 31 & 1 & 0 & 5 & 5 & 1.37 & $\odot .01066$ & -6.80 & $\mathrm{R}$ \\
\hline 1 & 32 & 1 & $\odot$ & 5 & 5 & 1.38 & $\odot .0 \odot 7362$ & -7.02 & $\mathrm{R}$ \\
\hline 1 & 33 & 1 & 0 & 5 & 5 & 1.38 & $\odot .005033$ & -7.25 & $\mathrm{R}$ \\
\hline 1 & 34 & 1 & 0 & 5 & 5 & 1.39 & $\odot .003435$ & -7.48 & $\mathrm{R}$ \\
\hline 1 & 35 & 1 & 0 & 6 & 6 & 1.39 & $\odot .0 \odot 2178$ & -7.70 & $\mathrm{R}$ \\
\hline 1 & 36 & 1 & 0 & 5 & 5 & 1.39 & $\odot . \odot \odot 1529$ & -7.93 & $\mathrm{R}$ \\
\hline 1 & 37 & 1 & 0 & 5 & 5 & 1.39 & $\odot .001619$ & -8.16 & $\mathrm{R}$ \\
\hline 1 & 38 & 1 & 0 & 5 & 5 & 1.40 & $\odot .001863$ & -8.39 & $\mathrm{R}$ \\
\hline 1 & 39 & 1 & 0 & 5 & 5 & 1.40 & $\odot .0 \odot 2509$ & -8.62 & $\mathrm{R}$ \\
\hline 1 & 40 & 1 & 0 & 5 & 5 & 1.40 & $\odot .003346$ & -8.85 & $\mathrm{R}$ \\
\hline 1 & 41 & 1 & $\odot$ & 5 & 5 & 1.41 & $\odot .004183$ & -9.08 & $\mathrm{R}$ \\
\hline 1 & 42 & 1 & 0 & 5 & 5 & 1.41 & $\odot .0 \odot 4916$ & -9.31 & $\mathrm{R}$ \\
\hline 1 & 43 & 1 & 0 & 5 & 5 & 1.42 & $\odot .005569$ & -9.54 & $\mathrm{R}$ \\
\hline 1 & 44 & 1 & 0 & 5 & 5 & 1.42 & $\odot . \odot \odot 6139$ & -9.77 & $\mathrm{R}$ \\
\hline 1 & 45 & 1 & 0 & 5 & 5 & 1.43 & $\odot .006557$ & -10.0 & $\mathrm{R}$ \\
\hline 1 & 46 & 1 & 0 & 5 & 5 & 1.44 & $\odot .0 \odot 70 \odot 7$ & -10.2 & $\mathrm{R}$ \\
\hline 1 & 47 & 1 & 0 & 5 & 5 & 1.44 & $\odot .0 \odot 7182$ & -10.5 & $\mathrm{R}$ \\
\hline 1 & 48 & 1 & $\odot$ & 5 & 5 & 1.45 & $\odot .007277$ & -10.7 & $\mathrm{R}$ \\
\hline 1 & 49 & 1 & 0 & 5 & 5 & 1.46 & $\odot . \odot \odot 7289$ & -10.9 & $\mathrm{R}$ \\
\hline 1 & 50 & 1 & 0 & 5 & 5 & 1.46 & $\odot .007381$ & -11.1 & $\mathrm{R}$ \\
\hline
\end{tabular}

THE ANALYSIS HAS COMPLETED SUCCESSFULLY 
Fy Study: $F y=60 \mathrm{ksi}$

$t=0.5^{\prime \prime}, D=26^{\prime \prime}, b f=7.2^{\prime \prime}, d=10.15^{\prime \prime}, h=26^{\prime \prime}, A=24.1^{\prime \prime}, B=24^{\prime \prime}$

ABAQUS VERSION 6.4-1

DATE 11-May-2004 TIME 17:07:12 SUMMARY OF JOB INFORMATION:

MONITOR NODE: 5895 DOF: 2

$\begin{array}{llllcccc}\text { STEP } & \text { INC ATT SEVERE EQUIL TOTAL } & \text { TOTAL } & \text { STEP } & \text { INC OF } & \text { DOF } & \text { IF } \\ & & \text { DISCON ITERS ITERS } & \text { TIME/ } & \text { TIME/LPF } & \text { TIME/LPF } & \text { MONITOR RIKS }\end{array}$

\begin{tabular}{|c|c|c|c|c|c|c|c|c|c|}
\hline \multicolumn{5}{|c|}{ ITERS } & \multicolumn{2}{|c|}{ FREQ } & & & \\
\hline 1 & 1 & 1 & $\odot$ & 3 & 3 & ๑. 0989 & ๑. 09888 & -0.0445 & $\mathrm{R}$ \\
\hline 1 & 2 & 1 & $\odot$ & 3 & 3 & 0.196 & $\odot .09662$ & - ๑. . $\odot 891$ & $\mathrm{R}$ \\
\hline 1 & 3 & 1 & $\odot$ & 3 & 3 & 0.335 & 0.1399 & $-\odot .156$ & $\mathrm{R}$ \\
\hline 1 & 4 & 1 & 0 & 4 & 4 & 0.525 & 0.1897 & -0.259 & $\mathrm{R}$ \\
\hline 1 & 5 & 1 & $\odot$ & 4 & 4 & 0.760 & 0.2354 & -0.418 & $\mathrm{R}$ \\
\hline 1 & 6 & 1 & $\odot$ & 4 & 4 & 0.996 & 0.2360 & -0.664 & $\mathrm{R}$ \\
\hline 1 & 7 & 1 & $\odot$ & 4 & 4 & 1.09 & $\odot .09075$ & -0.927 & $\mathrm{R}$ \\
\hline 1 & 8 & 1 & 0 & 5 & 5 & 1.11 & 0.01888 & -1.20 & $\mathbf{R}$ \\
\hline 1 & 9 & 1 & $\theta$ & 5 & 5 & 1.09 & -0.01768 & -1.48 & $\bar{R}$ \\
\hline 1 & 10 & 1 & $\odot$ & 5 & 5 & 1.06 & $-\odot .02532$ & -1.76 & $\mathrm{R}$ \\
\hline 1 & 11 & 1 & $\odot$ & 5 & 5 & 1.05 & -0.01583 & -2.05 & $\mathrm{R}$ \\
\hline 1 & 12 & 1 & $\odot$ & 4 & 4 & 1.05 & 0.002930 & -2.33 & $\mathrm{R}$ \\
\hline 1 & 13 & 1 & $\odot$ & 5 & 5 & 1.08 & $\odot .02563$ & -2.61 & $\mathrm{R}$ \\
\hline 1 & 14 & 1 & $\odot$ & 4 & 4 & 1.12 & 0.04349 & -2.88 & $\mathrm{R}$ \\
\hline 1 & 15 & 1 & $\odot$ & 4 & 4 & 1.17 & 0.05435 & -3.15 & $\mathrm{R}$ \\
\hline 1 & 16 & 1 & $\odot$ & 4 & 4 & 1.23 & $\odot .05978$ & -3.42 & $\mathrm{R}$ \\
\hline 1 & 17 & 1 & $\odot$ & 4 & 4 & 1.29 & $\odot .05855$ & -3.68 & $\mathrm{R}$ \\
\hline 1 & 18 & 1 & $\odot$ & 4 & 4 & 1.35 & 0.05494 & -3.94 & $\mathrm{R}$ \\
\hline 1 & 19 & 1 & $\odot$ & 4 & 4 & 1.40 & $\odot .04980$ & -4.19 & $\mathrm{R}$ \\
\hline 1 & 20 & 1 & $\odot$ & 4 & 4 & 1.44 & $\odot .04514$ & -4.44 & $\mathrm{R}$ \\
\hline 1 & 21 & 1 & $\odot$ & 4 & 4 & 1.48 & $\odot .04162$ & -4.69 & $\mathrm{R}$ \\
\hline 1 & 22 & 1 & $\odot$ & 4 & 4 & 1.52 & $\odot .03838$ & -4.93 & $\mathrm{R}$ \\
\hline 1 & 23 & 1 & $\odot$ & 4 & 4 & 1.56 & $\odot .0355 \odot$ & -5.17 & $\mathrm{R}$ \\
\hline 1 & 24 & 1 & $\odot$ & 4 & 4 & 1.59 & ๑. 03359 & -5.41 & $\mathrm{R}$ \\
\hline 1 & 25 & 1 & $\odot$ & 5 & 5 & 1.62 & 0.03179 & -5.65 & $\mathrm{R}$ \\
\hline 1 & 26 & 1 & $\odot$ & 4 & 4 & 1.65 & $\odot . \odot 2977$ & -5.88 & $\mathrm{R}$ \\
\hline 1 & 27 & 1 & $\odot$ & 5 & 5 & 1.68 & $\odot .02808$ & -6.11 & $\mathrm{R}$ \\
\hline 1 & 28 & 1 & $\odot$ & 5 & 5 & 1.71 & $\odot .0255 \odot$ & -6.34 & $\mathrm{R}$ \\
\hline 1 & 29 & 1 & $\odot$ & 5 & 5 & 1.73 & $\odot .02164$ & -6.57 & $\mathrm{R}$ \\
\hline 1 & 30 & 1 & $\Theta$ & 5 & 5 & 1.74 & 0.01689 & -6.80 & $\mathrm{R}$ \\
\hline 1 & 31 & 1 & $\odot$ & 5 & 5 & 1.76 & 0.01148 & -7.02 & $\mathrm{R}$ \\
\hline 1 & 32 & 1 & $\odot$ & 5 & 5 & 1.76 & $\odot .0 \odot 7143$ & -7.25 & $\mathrm{R}$ \\
\hline 1 & 33 & 1 & $\odot$ & 5 & 5 & 1.77 & 0.003852 & -7.48 & $\mathrm{R}$ \\
\hline 1 & 34 & 1 & $\odot$ & 6 & 6 & 1.77 & $\odot .0 \odot 1968$ & -7.70 & $\mathrm{R}$ \\
\hline 1 & 35 & 1 & $\odot$ & 5 & 5 & 1.77 & 0.001636 & -7.93 & $\mathrm{R}$ \\
\hline 1 & 36 & 1 & $\odot$ & 5 & 5 & 1.77 & $\odot .001699$ & -8.16 & $\mathrm{R}$ \\
\hline 1 & 37 & 1 & 0 & 5 & 5 & 1.77 & ๑.002314 & -8.39 & $\mathrm{R}$ \\
\hline 1 & 38 & 1 & $\odot$ & 5 & 5 & 1.78 & 0.003484 & -8.62 & $\mathrm{R}$ \\
\hline 1 & 39 & 1 & $\odot$ & 5 & 5 & 1.78 & $\odot . \odot \odot 4669$ & -8.85 & $\mathrm{R}$ \\
\hline 1 & 40 & 1 & $\odot$ & 5 & 5 & 1.79 & ๑. 005810 & -9.08 & $\mathrm{R}$ \\
\hline 1 & 41 & 1 & $\odot$ & 5 & 5 & 1.80 & $\odot .0 \odot 6874$ & -9.31 & $\mathrm{R}$ \\
\hline 1 & 42 & 1 & $\odot$ & 5 & 5 & 1.80 & $\odot . \odot \odot 7692$ & -9.54 & $\mathrm{R}$ \\
\hline 1 & 43 & 1 & $\odot$ & 4 & 4 & 1.81 & 0.008402 & -9.77 & $\mathrm{R}$ \\
\hline 1 & 44 & 1 & $\odot$ & 4 & 4 & 1.82 & $\odot .009013$ & -10.0 & $\mathrm{R}$ \\
\hline 1 & 45 & 1 & $\odot$ & 4 & 4 & 1.83 & ๑.0०9603 & -10.2 & $\mathrm{R}$ \\
\hline 1 & 46 & 1 & $\odot$ & 5 & 5 & 1.84 & 0.01001 & -10.5 & $\mathrm{R}$ \\
\hline 1 & 47 & 1 & $\odot$ & 4 & 4 & 1.85 & 0.01037 & -10.7 & $\mathrm{R}$ \\
\hline 1 & 48 & 1 & $\odot$ & 5 & 5 & 1.86 & 0.01072 & -10.9 & $\mathrm{R}$ \\
\hline 1 & 49 & 1 & $\odot$ & 4 & 4 & 1.87 & ๑.01085 & -11.1 & $\mathrm{R}$ \\
\hline 1 & 50 & 1 & $\odot$ & 4 & 4 & 1.88 & 0.01082 & -11.4 & $\mathrm{R}$ \\
\hline 1 & 51 & 1 & $\odot$ & 5 & 5 & 1.89 & 0.01072 & -11.6 & $\mathrm{R}$ \\
\hline 1 & 52 & 1 & $\odot$ & 4 & 4 & 1.90 & 0.01058 & -11.8 & $\mathrm{R}$ \\
\hline 1 & 53 & 1 & 0 & 4 & 4 & 1.91 & 0.01053 & -12.0 & $\mathrm{R}$ \\
\hline 1 & 54 & 1 & $\odot$ & 4 & 4 & 1.93 & $\odot .01047$ & -12.3 & $\mathrm{R}$ \\
\hline 1 & 55 & 1 & $\odot$ & 5 & 5 & 1.94 & 0.01038 & -12.5 & $\mathrm{R}$ \\
\hline 1 & 56 & 1 & $\odot$ & 5 & 5 & 1.95 & 0.01052 & -12.7 & $\mathrm{R}$ \\
\hline 1 & 57 & 1 & $\odot$ & 4 & 4 & 1.96 & ๑. 01081 & -12.9 & $\mathrm{R}$ \\
\hline 1 & 58 & 1 & $\odot$ & 5 & 5 & 1.97 & 0.01100 & -13.1 & $\mathrm{R}$ \\
\hline 1 & 59 & 1 & $\odot$ & 5 & 5 & 1.98 & 0.01103 & -13.4 & $\mathrm{R}$ \\
\hline 1 & 60 & 1 & $\odot$ & 5 & 5 & 1.99 & 0.01094 & -13.6 & $\mathrm{R}$ \\
\hline 1 & 61 & 1 & $\odot$ & 5 & 5 & 2.00 & 0.01081 & -13.8 & $\mathrm{R}$ \\
\hline
\end{tabular}

THE ANALYSIS HAS COMPLETED SUCCESSFULLY 


\begin{tabular}{|c|c|c|c|c|c|c|c|c|c|c|}
\hline ABAQU & 5 VER & SION & $N 6.4-1$ & & & & DATE & 24 - Мау - $20 \odot 4$ & TIME 22:1 & $13: 17$ \\
\hline SUMMA & RY OF & $\mathrm{JOB}$ & B INFORM & MATION & & & & & & \\
\hline MONIT & $\mathrm{R} N \mathrm{NC}$ & DE : & 6141 & 1 DOF & 2 & & & & & \\
\hline STEP & INC & ATT & SEVERE & EQUIL & TOTAL & TOTAL & STEP & INC OF & DOF & IF \\
\hline & & & $\begin{array}{l}\text { DISCON } \\
\text { ITERS }\end{array}$ & ITERS & ITERS & $\begin{array}{l}\text { TIME/ } \\
\text { FREQ }\end{array}$ & TIME/LPF & TIME/LPF & MONITOR & RIKS \\
\hline 1 & 1 & 1 & $\odot$ & 2 & 2 & & $\odot .0 \odot 999$ & ๑. 009990 & $-\odot .0 \odot 408$ & $\mathrm{R}$ \\
\hline 1 & 2 & 1 & 0 & 2 & 2 & & $\odot .0200$ & 0.009967 & -0.00816 & $\mathrm{R}$ \\
\hline 1 & 3 & 1 & 0 & 2 & 2 & & 0.0349 & $\odot .01491$ & -0.0143 & $\mathrm{R}$ \\
\hline 1 & 4 & 1 & 0 & 2 & 2 & & 0.0572 & $\odot .02228$ & -0.0235 & $\mathrm{R}$ \\
\hline 1 & 5 & 1 & 0 & 2 & 2 & & $\odot .0904$ & 0.03323 & -0.0373 & $\mathrm{R}$ \\
\hline 1 & 6 & 1 & 0 & 2 & 2 & & 0.140 & 0.04942 & -0.0580 & $\mathrm{R}$ \\
\hline 1 & 7 & 1 & 0 & 2 & 2 & & 0.213 & 0.07308 & $-\odot .0891$ & $\mathrm{R}$ \\
\hline 1 & 8 & 1 & 0 & 3 & 3 & & 0.306 & $\odot .09309$ & -0.130 & $\mathrm{R}$ \\
\hline 1 & 9 & 1 & 0 & 3 & 3 & & 0.392 & ๑. 08608 & -0.173 & $\mathrm{R}$ \\
\hline 1 & 10 & 1 & 0 & 3 & 3 & & 0.471 & 0.07877 & -0.216 & $\mathrm{R}$ \\
\hline 1 & 11 & 1 & 0 & 4 & 4 & & 0.543 & 0.07216 & $-\odot .262$ & $\mathrm{R}$ \\
\hline 1 & 12 & 1 & 0 & 4 & 4 & & 0.608 & $\odot .06502$ & -0.314 & $\mathrm{R}$ \\
\hline 1 & 13 & 1 & 0 & 3 & 3 & & 0.666 & 0.05770 & -0.367 & $\mathrm{R}$ \\
\hline 1 & 14 & 1 & 0 & 3 & 3 & & 0.715 & 0.04930 & -0.422 & $\mathrm{R}$ \\
\hline 1 & 15 & 1 & $\odot$ & 4 & 4 & & 0.755 & 0.04024 & -0.486 & $\mathrm{R}$ \\
\hline 1 & 16 & 1 & 0 & 3 & 3 & & 0.784 & 0.02882 & -0.550 & $\mathrm{R}$ \\
\hline 1 & 17 & 1 & 0 & 3 & 3 & & 0.803 & ๑. 01854 & -0.612 & $\mathrm{R}$ \\
\hline 1 & 18 & 1 & 0 & 3 & 3 & & 0.812 & ๑.0०9124 & -0.674 & $\mathrm{R}$ \\
\hline 1 & 19 & 1 & 0 & 3 & 3 & & 0.813 & 0.001278 & -0.734 & $\mathbf{R}$ \\
\hline 1 & 20 & 1 & $\theta$ & 4 & 4 & & 0.809 & -0.003696 & -0.794 & $\overline{\mathrm{R}}$ \\
\hline 1 & 21 & 1 & 0 & 3 & 3 & & 0.802 & -0.007131 & -0.854 & $\mathrm{R}$ \\
\hline 1 & 22 & 1 & 0 & 3 & 3 & & 0.793 & $-\odot .009271$ & -0.915 & $\mathrm{R}$ \\
\hline 1 & 23 & 1 & 0 & 3 & 3 & & 0.783 & -0.01041 & -0.975 & $\mathrm{R}$ \\
\hline 1 & 24 & 1 & 0 & 3 & 3 & & 0.772 & $-\odot .01075$ & -1.04 & $\mathrm{R}$ \\
\hline 1 & 25 & 1 & 0 & 3 & 3 & & 0.761 & $-\odot .01047$ & -1.10 & $\mathrm{R}$ \\
\hline 1 & 26 & 1 & 0 & 3 & 3 & & 0.752 & -0.009447 & -1.16 & $\mathrm{R}$ \\
\hline 1 & 27 & 1 & 0 & 3 & 3 & & 0.744 & $-\odot .007818$ & -1.22 & $\mathrm{R}$ \\
\hline 1 & 28 & 1 & 0 & 4 & 4 & & 0.738 & $-\odot .005986$ & -1.28 & $\mathrm{R}$ \\
\hline 1 & 29 & 1 & $\odot$ & 3 & 3 & & 0.734 & $-\odot .0 \odot 4134$ & -1.34 & $\mathrm{R}$ \\
\hline 1 & 30 & 1 & 0 & 3 & 3 & & 0.732 & -0.002161 & -1.40 & $\mathrm{R}$ \\
\hline 1 & 31 & 1 & 0 & 3 & 3 & & 0.731 & $-\odot .00 \odot 29 \odot 4$ & -1.46 & $\mathrm{R}$ \\
\hline 1 & 32 & 1 & 0 & 3 & 3 & & 0.733 & $\odot .0 \odot 1272$ & -1.51 & $\mathrm{R}$ \\
\hline 1 & 33 & 1 & 0 & 3 & 3 & & 0.736 & $0.0 \odot 2843$ & -1.57 & $\mathrm{R}$ \\
\hline 1 & 34 & 1 & 0 & 3 & 3 & & 0.740 & ๑.๑०4०36 & -1.63 & $\mathrm{R}$ \\
\hline 1 & 35 & 1 & 0 & 3 & 3 & & 0.745 & ๑.005361 & -1.69 & $\mathrm{R}$ \\
\hline 1 & 36 & 1 & 0 & 3 & 3 & & 0.752 & 0.006597 & -1.75 & $\mathrm{R}$ \\
\hline 1 & 37 & 1 & 0 & 3 & 3 & & $\odot .759$ & ๑.0०7791 & -1.81 & $\mathrm{R}$ \\
\hline 1 & 38 & 1 & 0 & 4 & 4 & & 0.768 & ๑.๑०8697 & -1.87 & $\mathrm{R}$ \\
\hline 1 & 39 & 1 & 0 & 3 & 3 & & 0.778 & ๑.๑๑9855 & -1.92 & $\mathrm{R}$ \\
\hline 1 & 40 & 1 & $\odot$ & 3 & 3 & & 0.789 & 0.01117 & -1.98 & $\mathrm{R}$ \\
\hline 1 & 41 & 1 & 0 & 3 & 3 & & 0.801 & 0.01204 & -2.04 & $\mathrm{R}$ \\
\hline 1 & 42 & 1 & 0 & 3 & 3 & & 0.814 & $\odot .01266$ & -2.10 & $\mathrm{R}$ \\
\hline 1 & 43 & 1 & 0 & 3 & 3 & & 0.827 & $\odot .01322$ & -2.16 & $\mathrm{R}$ \\
\hline 1 & 44 & 1 & $\odot$ & 3 & 3 & & 0.841 & ๑. 01358 & -2.22 & $\mathrm{R}$ \\
\hline 1 & 45 & 1 & 0 & 3 & 3 & & 0.855 & 0.01406 & -2.28 & $\mathrm{R}$ \\
\hline 1 & 46 & 1 & $\odot$ & 3 & 3 & & $\odot .869$ & ๑. 01450 & -2.34 & $\mathrm{R}$ \\
\hline 1 & 47 & 1 & 0 & 3 & 3 & & 0.884 & 0.01443 & -2.40 & $\mathrm{R}$ \\
\hline 1 & 48 & 1 & 0 & 3 & 3 & & $\odot .898$ & 0.01411 & -2.47 & $\mathrm{R}$ \\
\hline 1 & 49 & 1 & 0 & 3 & 3 & & 0.911 & 0.01366 & -2.53 & $\mathrm{R}$ \\
\hline 1 & 50 & 1 & 0 & 3 & 3 & & 0.925 & 0.01322 & -2.59 & $\mathrm{R}$ \\
\hline
\end{tabular}

THE ANALYSIS HAS COMPLETED SUCCESSFULLY 


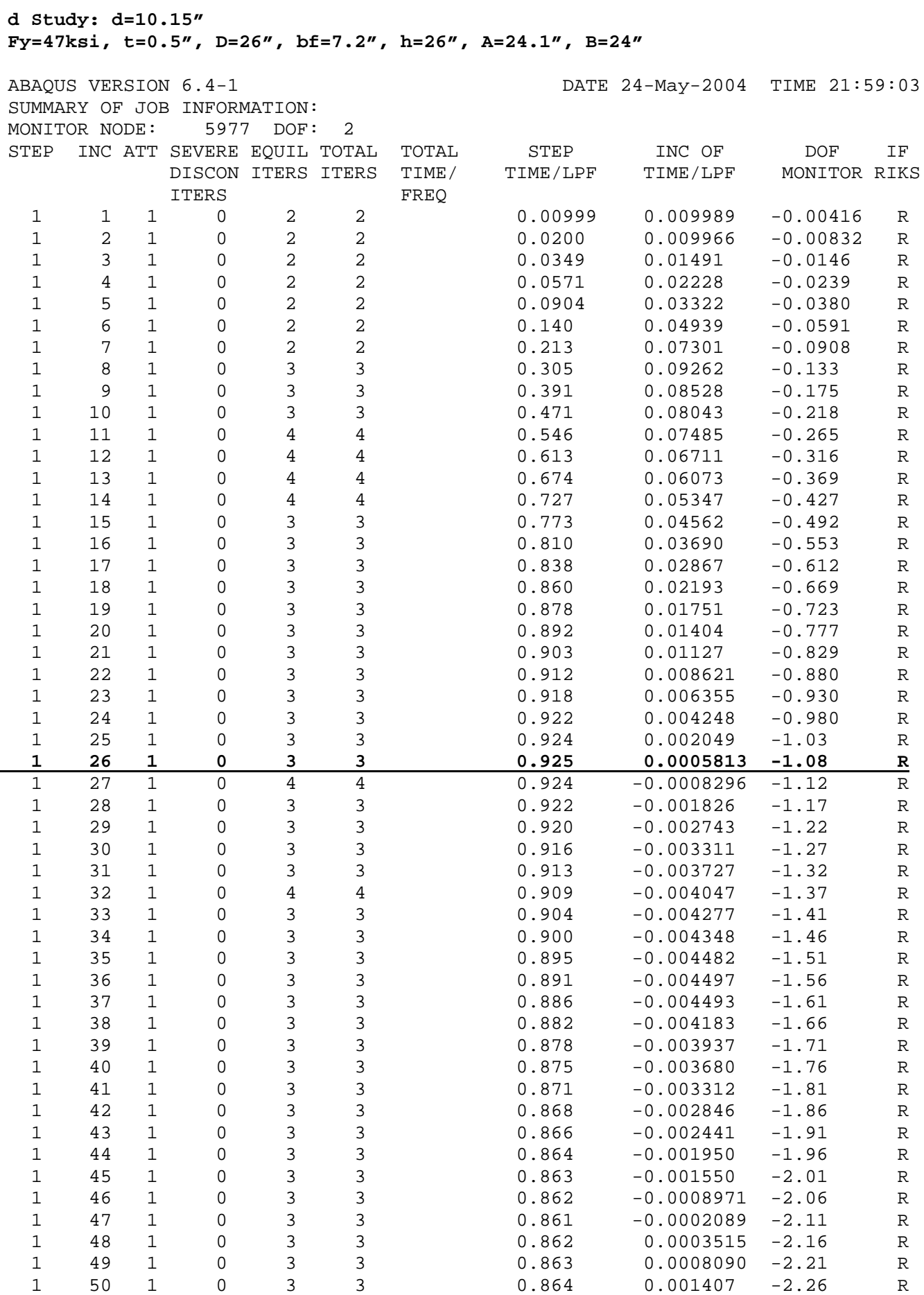

THE ANALYSIS HAS COMPLETED SUCCESSFULLY 


\begin{tabular}{|c|c|c|c|c|c|c|c|c|c|c|}
\hline ABAQU & $S$ VEF & SION & $N 6.4-1$ & & & & DATE & 24-May-2๑๑4 & TIME 22: & $06: 45$ \\
\hline SUMMA & RY OF & $\mathrm{JOB}$ & B INFORN & MATION : & & & & & & \\
\hline MONIT & $\mathrm{OR} \mathrm{NC}$ & DE: & 5833 & 3 DOF: & 2 & & & & & \\
\hline STEP & INC & АTT & SEVERE & EQUIL & TOTAL & TOTAL & STEP & INC OF & DOF & IF \\
\hline & & & $\begin{array}{l}\text { DISCON } \\
\text { ITERS }\end{array}$ & ITERS & ITERS & $\begin{array}{l}\text { TIME/ } \\
\text { FREQ }\end{array}$ & TIME/LPF & TIME/LPF & MONITOR & RIKS \\
\hline 1 & 1 & 1 & 0 & 2 & 2 & & 0.00999 & $\odot .009989$ & -0.00412 & $\mathrm{R}$ \\
\hline 1 & 2 & 1 & 0 & 2 & 2 & & $\odot .0200$ & $\odot . \odot \odot 9964$ & $-0.0 \odot 824$ & $\mathrm{R}$ \\
\hline 1 & 3 & 1 & $\odot$ & 2 & 2 & & 0.0349 & 0.01491 & -0.0144 & $\mathrm{R}$ \\
\hline 1 & 4 & 1 & $\odot$ & 2 & 2 & & 0.0571 & 0.02227 & -0.0237 & $\mathrm{R}$ \\
\hline 1 & 5 & 1 & $\odot$ & 2 & 2 & & 0.0903 & 0.03320 & -0.0376 & $\mathrm{R}$ \\
\hline 1 & 6 & 1 & 0 & 2 & 2 & & 0.140 & 0.04934 & -0.0585 & $\mathrm{R}$ \\
\hline 1 & 7 & 1 & 0 & 2 & 2 & & 0.213 & $\odot .07290$ & $-\odot .0898$ & $\mathrm{R}$ \\
\hline 1 & 8 & 1 & $\odot$ & 3 & 3 & & 0.305 & 0.09235 & -0.131 & $\mathrm{R}$ \\
\hline 1 & 9 & 1 & $\odot$ & 3 & 3 & & 0.390 & 0.08490 & -0.173 & $\mathrm{R}$ \\
\hline 1 & 10 & 1 & $\odot$ & 3 & 3 & & 0.469 & $\odot .07955$ & -0.215 & $\mathrm{R}$ \\
\hline 1 & 11 & 1 & 0 & 4 & 4 & & 0.544 & 0.07420 & -0.263 & $\mathrm{R}$ \\
\hline 1 & 12 & 1 & 0 & 4 & 4 & & 0.610 & $\odot .06661$ & -0.314 & $\mathrm{R}$ \\
\hline 1 & 13 & 1 & $\odot$ & 4 & 4 & & 0.670 & 0.06025 & -0.368 & $\mathrm{R}$ \\
\hline 1 & 14 & 1 & $\odot$ & 4 & 4 & & 0.723 & 0.05279 & -0.432 & $\mathrm{R}$ \\
\hline 1 & 15 & 1 & $\odot$ & 3 & 3 & & 0.769 & 0.04546 & -0.496 & $\mathrm{R}$ \\
\hline 1 & 16 & 1 & 0 & 3 & 3 & & 0.807 & 0.03847 & -0.557 & $\mathrm{R}$ \\
\hline 1 & 17 & 1 & 0 & 3 & 3 & & 0.838 & 0.03128 & -0.614 & $\mathrm{R}$ \\
\hline 1 & 18 & 1 & $\odot$ & 3 & 3 & & 0.863 & 0.02504 & -0.669 & $\mathrm{R}$ \\
\hline 1 & 19 & 1 & $\odot$ & 3 & 3 & & 0.883 & 0.01936 & -0.721 & $\mathrm{R}$ \\
\hline 1 & 20 & 1 & $\odot$ & 3 & 3 & & 0.898 & 0.01507 & -0.772 & $\mathrm{R}$ \\
\hline 1 & 21 & 1 & 0 & 3 & 3 & & 0.911 & 0.01267 & -0.821 & $\mathrm{R}$ \\
\hline 1 & 22 & 1 & 0 & 3 & 3 & & 0.921 & 0.01025 & -0.869 & $\mathrm{R}$ \\
\hline 1 & 23 & 1 & 0 & 3 & 3 & & 0.929 & $\odot .008221$ & -0.916 & $\mathrm{R}$ \\
\hline 1 & 24 & 1 & $\odot$ & 3 & 3 & & 0.935 & $\odot .006043$ & -0.962 & $\mathrm{R}$ \\
\hline 1 & 25 & 1 & 0 & 3 & 3 & & 0.939 & 0.004239 & -1.01 & $\mathrm{R}$ \\
\hline 1 & 26 & 1 & 0 & 3 & 3 & & 0.942 & $\odot .002877$ & -1.05 & $\mathrm{R}$ \\
\hline 1 & 27 & 1 & 0 & 3 & 3 & & 0.944 & $\odot .001874$ & -1.10 & $\mathrm{R}$ \\
\hline 1 & 28 & 1 & 0 & 3 & 3 & & 0.945 & 0.0008703 & -1.14 & $\mathbf{R}$ \\
\hline 1 & 29 & 1 & $\odot$ & 4 & 4 & & 0.945 & $-9.390 \mathrm{e}-05$ & -1.18 & $\bar{R}$ \\
\hline 1 & 30 & 1 & 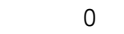 & 3 & 3 & & 0.944 & $-\odot .0 \odot \odot 8075$ & -1.23 & $\mathrm{R}$ \\
\hline 1 & 31 & 1 & 0 & 3 & 3 & & 0.943 & -0.001253 & -1.27 & $\mathrm{R}$ \\
\hline 1 & 32 & 1 & 0 & 3 & 3 & & 0.941 & $-\odot .001592$ & -1.31 & $\mathrm{R}$ \\
\hline 1 & 33 & 1 & 0 & 4 & 4 & & 0.939 & -0.001821 & -1.35 & $\mathrm{R}$ \\
\hline 1 & 34 & 1 & 0 & 3 & 3 & & 0.937 & $-\odot .002009$ & -1.40 & $\mathrm{R}$ \\
\hline 1 & 35 & 1 & 0 & 3 & 3 & & 0.935 & $-\odot .002098$ & -1.44 & $\mathrm{R}$ \\
\hline 1 & 36 & 1 & 0 & 3 & 3 & & 0.933 & $-\odot .002131$ & -1.48 & $\mathrm{R}$ \\
\hline 1 & 37 & 1 & 0 & 4 & 4 & & 0.931 & $-\odot .002127$ & -1.53 & $\mathrm{R}$ \\
\hline 1 & 38 & 1 & 0 & 4 & 4 & & 0.929 & -0.002057 & -1.57 & $\mathrm{R}$ \\
\hline 1 & 39 & 1 & 0 & 3 & 3 & & 0.927 & $-\odot .001974$ & -1.61 & $\mathrm{R}$ \\
\hline 1 & 40 & 1 & 0 & 4 & 4 & & 0.925 & $-\odot .001950$ & -1.66 & $\mathrm{R}$ \\
\hline 1 & 41 & 1 & $\odot$ & 3 & 3 & & 0.923 & -0.001878 & -1.70 & $\mathrm{R}$ \\
\hline 1 & 42 & 1 & 0 & 3 & 3 & & 0.921 & $-\odot .0 \odot 175 \odot$ & -1.74 & $\mathrm{R}$ \\
\hline 1 & 43 & 1 & 0 & 3 & 3 & & 0.920 & -0.001571 & -1.79 & $\mathrm{R}$ \\
\hline 1 & 44 & 1 & $\odot$ & 3 & 3 & & 0.918 & -0.001365 & -1.83 & $\mathrm{R}$ \\
\hline 1 & 45 & 1 & 0 & 3 & 3 & & 0.917 & $-\odot .001139$ & -1.87 & $\mathrm{R}$ \\
\hline 1 & 46 & 1 & $\odot$ & 3 & 3 & & 0.916 & $-\odot .0009466$ & -1.92 & $\mathrm{R}$ \\
\hline 1 & 47 & 1 & 0 & 3 & 3 & & 0.916 & $-\odot . \odot \odot \odot 8168$ & -1.96 & $\mathrm{R}$ \\
\hline 1 & 48 & 1 & $\odot$ & 3 & 3 & & 0.915 & $-\odot .0006925$ & -2.00 & $\mathrm{R}$ \\
\hline 1 & 49 & 1 & $\odot$ & 3 & 3 & & 0.914 & -๑.๑०९6९6९ & -2.04 & $\mathrm{R}$ \\
\hline 1 & 50 & 1 & $\odot$ & 4 & 4 & & 0.914 & $-0.00 \odot 4613$ & -2.09 & $\mathrm{R}$ \\
\hline
\end{tabular}

THE ANALYSIS HAS COMPLETED SUCCESSFULLY 


\section{APPENDIX B}

\section{LOAD-DEFLECTION DATA FROM MOMENT STUDY FEM ANALYSES.}

For the moment study, a concentrated load (P) is applied transversely to the top of the plate and the lateral deflection of this point is monitored. These values are easily converted to moment and rotation at the plate-to-HSS joint. The applied load specified for all models is 100 kips, thus the load at a given increment equals LPF x 100 kips. For this case, the load is specified to follow the nodal rotation so that the moment at the base of the plate always equals $\mathrm{P} \times 36$ ”. The capacity load/deflection for each analysis is shown in boldface type.

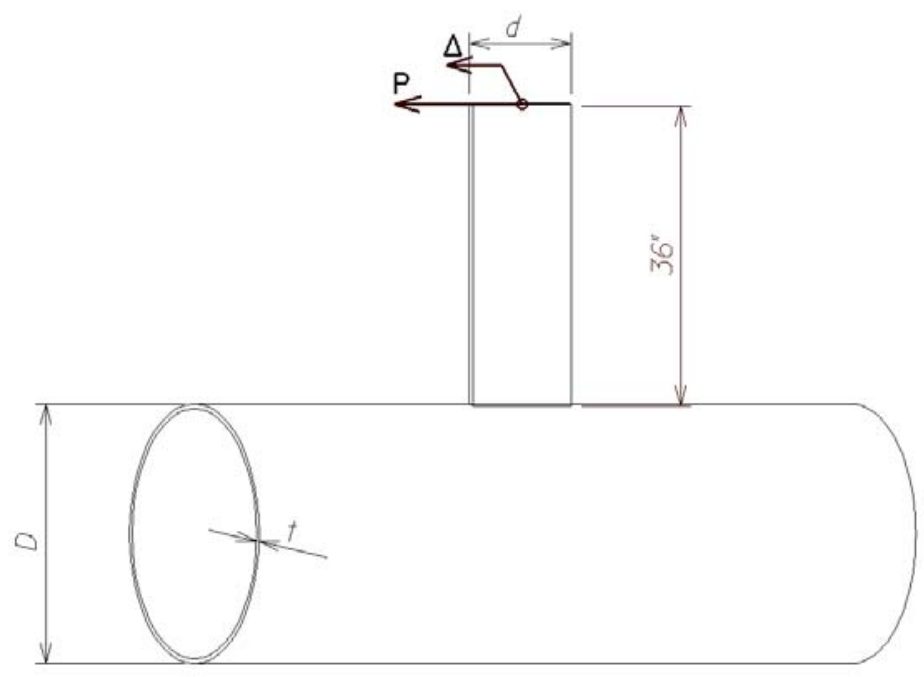

Figure A 2 
Moment Study: $d=5$ "

$F y=47 \mathrm{ksi}, t=0.5^{\prime \prime}, \quad D=26^{\prime \prime}$

ABAOUS VERSION 6.4-1

SUMMARY OF JOB INFORMATION:

MONITOR NODE: 256 DOF: 3

STEP INC ATT SEVERE EQUIL TOTAL

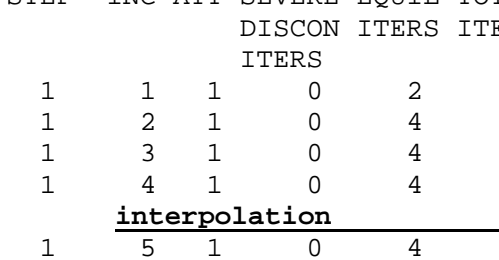

\begin{tabular}{lllll}
1 & \multicolumn{5}{c}{5} & 0 & 4 \\
1 & 6 & 1 & 0 & 4 \\
1 & 7 & 2 & 0 & 4
\end{tabular}

$\begin{array}{lllll}1 & 7 & 2 & 0 & 4\end{array}$

$\begin{array}{llllll}1 & 8 & 1 & 0 & 5 & 5 \\ 1 & 9 & 1 & 0 & 5\end{array}$

$\begin{array}{rrrrrr}1 & 9 & 1 & 0 & 5 & 5 \\ 1 & 10 & 1 & 0 & 5 & 5\end{array}$

$\begin{array}{llllll}1 & 10 & 1 & 0 & 5 & 5 \\ 1 & 11 & 1 & 0 & 5 & 5\end{array}$

$\begin{array}{llllll}1 & 12 & 1 & 0 & 6 & 6\end{array}$

$\begin{array}{llllll}1 & 13 & 1 & 0 & 7 & 7 \\ 1 & 14 & 1 & 0 & 5 & 5\end{array}$

$\begin{array}{llllll}1 & 14 & 1 & \odot & 5 & 5 \\ 1 & 15 & 1 & \odot & 6 & 6\end{array}$

THE ANALYSIS HAS COMPLETED SUCCESSFULLY FREQ
DATE 16-Jul-2004 TIME 07:54:07

$\begin{array}{lcccc}\text { TOTAL } & \text { STEP } & \text { INC OF } & \text { DOF } & \text { IF } \\ \text { TIME/ } & \text { TIME/LPF } & \text { TIME/LPF } & \text { MONITOR RIKS }\end{array}$

\begin{tabular}{llll}
0.0100 & 0.009999 & 0.214 & $R$ \\
0.0194 & 0.009392 & 0.427 & $R$ \\
0.0299 & 0.01051 & 0.746 & $R$ \\
0.0380 & 0.008085 & 1.22 & $R$ \\
0.0428 & & $\mathbf{1 . 8 0}$ & \\
\hline 0.0436 & 0.005618 & 1.92 & $R$ \\
0.0481 & 0.004447 & 2.97 & $R$ \\
0.0495 & 0.001487 & 3.55 & $R$ \\
0.0514 & 0.001875 & 4.43 & $R$ \\
0.0531 & 0.001729 & 5.30 & $R$ \\
0.0549 & 0.001758 & 6.17 & $R$ \\
0.0567 & 0.001841 & 7.03 & $R$ \\
0.0588 & 0.002076 & 7.88 & $R$ \\
0.0612 & 0.002365 & 8.74 & $R$ \\
0.0638 & 0.002616 & 9.58 & $R$ \\
0.0665 & 0.002697 & 10.4 & $R$
\end{tabular}

$\odot .002697$

10.4

$\mathrm{R}$
$\mathrm{R}$
$\mathrm{R}$
$\mathrm{R}$
$\mathrm{R}$
$\mathrm{R}$
$\mathrm{R}$
$\mathrm{R}$
$\mathrm{R}$
$\mathrm{R}$
$\mathrm{R}$
$\mathrm{R}$
$\mathrm{R}$
$\mathrm{R}$
$\mathrm{R}$




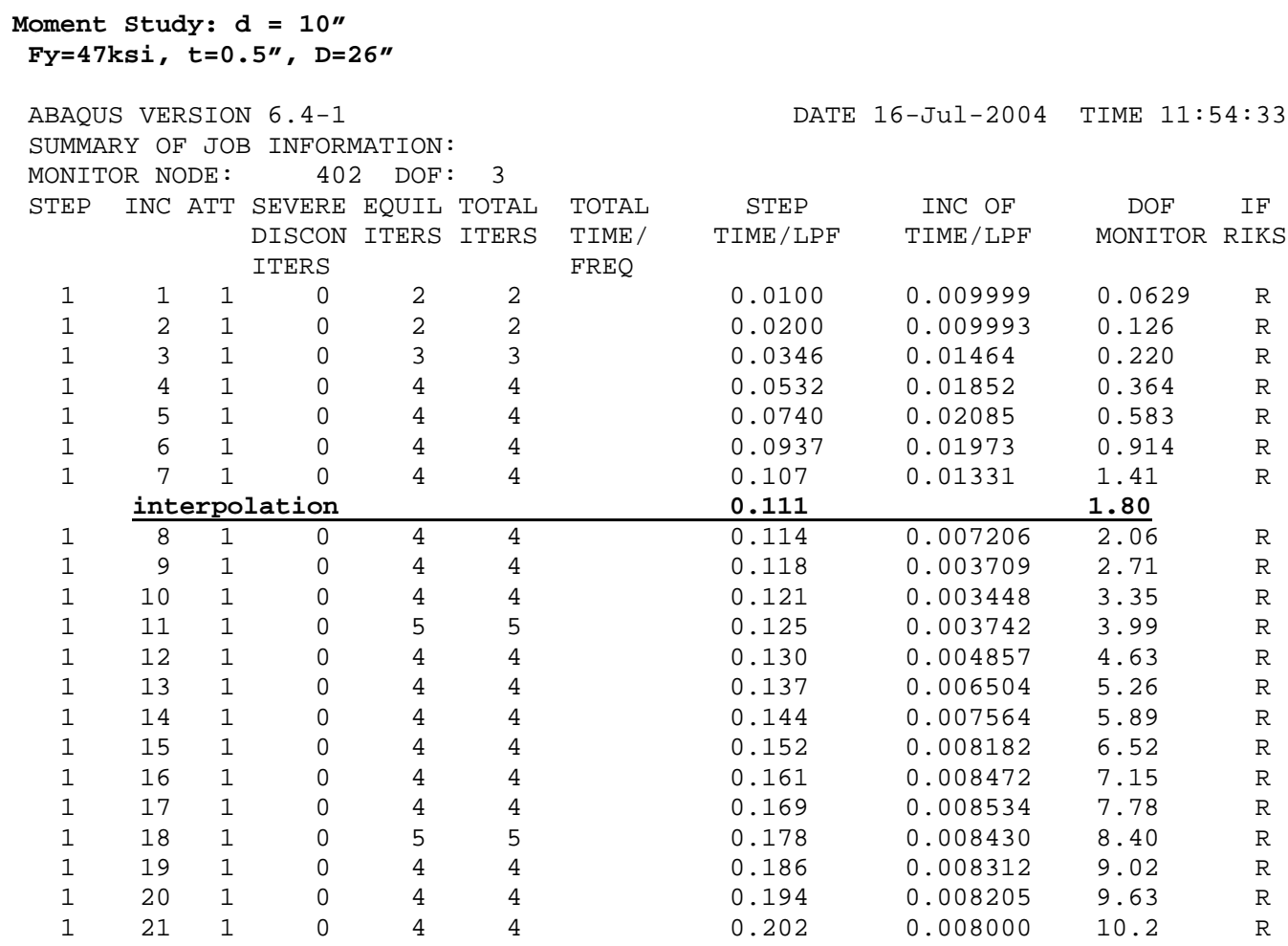

THE ANALYSIS HAS COMPLETED SUCCESSFULLY 


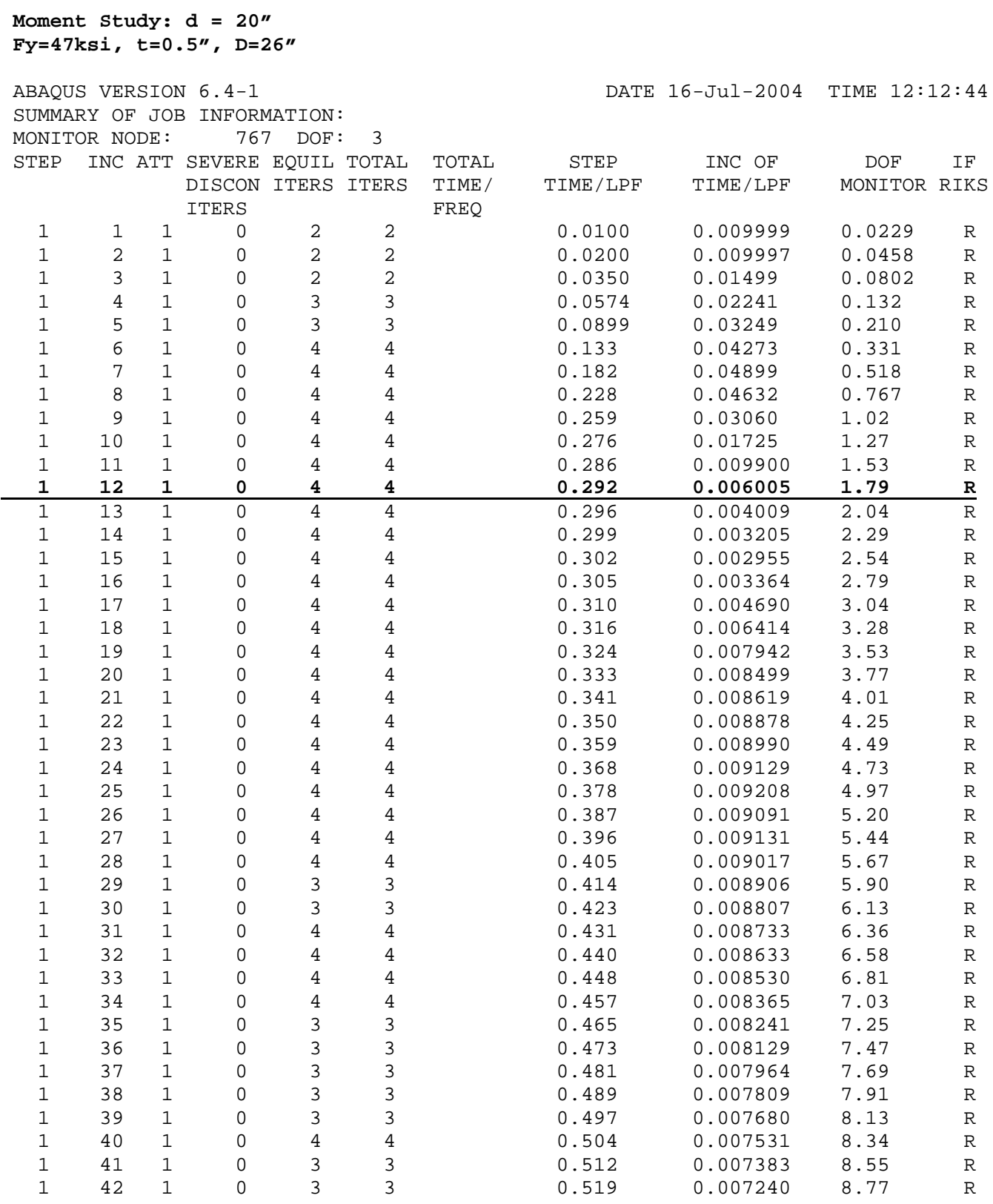




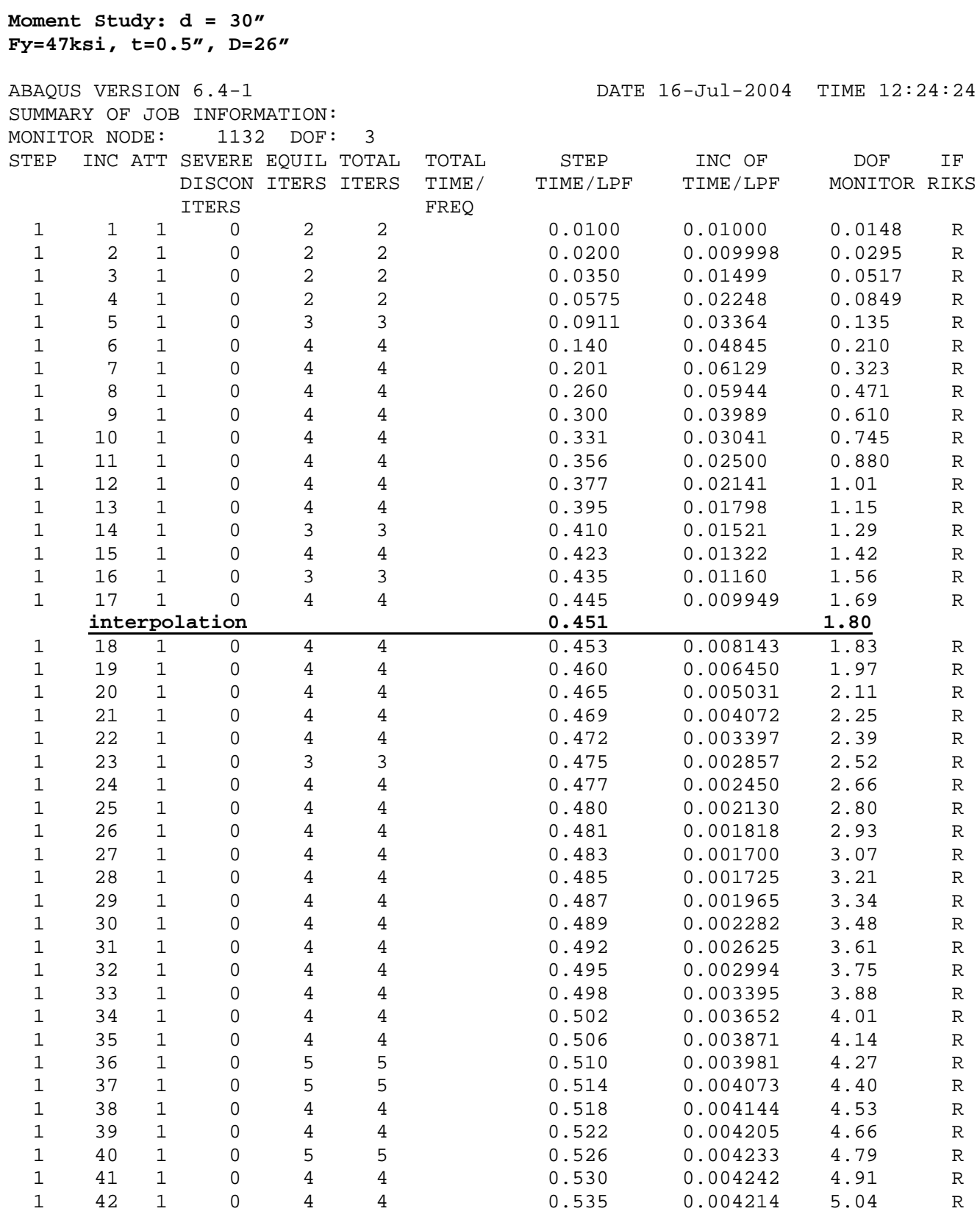




\section{APPENDIX C}

\section{LOAD-DEFLECTION DATA FROM INTERACTION STUDY FEM ANALYSES.}

For the interaction study, a constant moment is first applied, then the concentrated load (P) is applied and the deflection of this point is monitored. The applied load specified for all models is 100 kips, thus the load at a given increment equals LPF x 100 kips. The capacity load/deflection for each analysis is shown in boldface type.

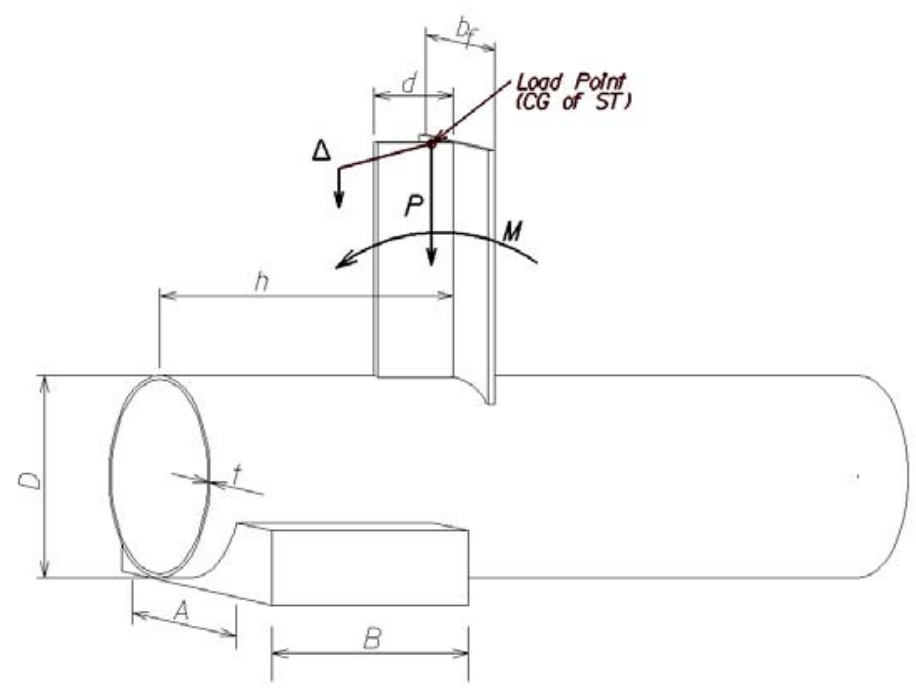

Figure A 3 
Interaction Study: $M=100 \mathrm{k}$ in

Fy=47ksi, $t=0.5^{\prime \prime}, D=26^{\prime \prime}, b f=7.2^{\prime \prime}, d=10.15^{\prime \prime}, h=26^{\prime \prime}, A=24.1^{\prime \prime}, B=24^{\prime \prime}$

ABAQUS VERSION 6.4-1

DATE 31-0ct-2004 TIME 14:32:33

SUMMARY OF JOB INFORMATION:

MONITOR NODE: 5273 DOF: 2

$\begin{array}{ccclcccc}\text { STEP INC ATT SEVERE EQUIL TOTAL } & \text { TOTAL } & \text { STEP } & \text { INC OF } & \text { DOF } & \text { IF } \\ & \text { DISCON } & \text { ITERS } & \text { ITERS } & \text { TIME/ } & \text { TIME/LPF } & \text { TIME/LPF } & \text { MONITOR RIKS }\end{array}$

\begin{tabular}{|c|c|c|c|c|c|c|c|c|c|c|}
\hline \multicolumn{5}{|c|}{ ITERS } & \multicolumn{3}{|c|}{ FREQ } & \multirow[b]{2}{*}{1.000} & \multirow[b]{2}{*}{-0.0151} & \\
\hline 1 & 1 & 1 & $\odot$ & 3 & 3 & 1.00 & 1.00 & & & \\
\hline 2 & 1 & 1 & $\odot$ & 2 & 2 & & $\odot .00997$ & $\odot .0 \odot 9974$ & -0.0198 & $\mathrm{R}$ \\
\hline 2 & 2 & 1 & $\odot$ & 2 & 2 & & $\odot .0199$ & $\odot .0 \odot 9965$ & -0.0245 & $\mathrm{R}$ \\
\hline 2 & 3 & 1 & $\Theta$ & 2 & 2 & & 0.0348 & 0.01491 & -0.0315 & $\mathrm{R}$ \\
\hline 2 & 4 & 1 & $\odot$ & 2 & 2 & & $\odot .0571$ & $\odot .02228$ & $-\odot .0420$ & $\mathrm{R}$ \\
\hline 2 & 5 & 1 & $\odot$ & 2 & 2 & & $\odot .090 \odot$ & 0.03286 & -0.0578 & $\mathrm{R}$ \\
\hline 2 & 6 & 1 & $\odot$ & 2 & 2 & & 0.139 & $\odot .04872$ & $-\odot .0814$ & $\mathrm{R}$ \\
\hline 2 & 7 & 1 & $\odot$ & 3 & 3 & & 0.210 & $\odot .07104$ & -0.117 & $\mathrm{R}$ \\
\hline 2 & 8 & 1 & $\odot$ & 3 & 3 & & $\odot .296$ & $\odot .08650$ & -0.162 & $\mathrm{R}$ \\
\hline 2 & 9 & 1 & $\odot$ & 3 & 3 & & 0.375 & 0.07873 & -0.206 & $\mathrm{R}$ \\
\hline 2 & 10 & 1 & $\odot$ & 3 & 3 & & 0.445 & 0.07030 & -0.250 & $\mathrm{R}$ \\
\hline 2 & 11 & 1 & $\odot$ & 4 & 4 & & 0.507 & $\odot .06138$ & $-\odot .297$ & $\mathrm{R}$ \\
\hline 2 & 12 & 1 & $\odot$ & 4 & 4 & & 0.559 & $\odot .05280$ & -0.344 & $\mathrm{R}$ \\
\hline 2 & 13 & 1 & $\odot$ & 4 & 4 & & 0.605 & $\odot .04507$ & -0.392 & $\mathrm{R}$ \\
\hline 2 & 14 & 1 & $\odot$ & 4 & 4 & & 0.643 & 0.03804 & -0.438 & $\mathrm{R}$ \\
\hline 2 & 15 & 1 & $\odot$ & 4 & 4 & & 0.676 & 0.03340 & $-\odot .486$ & $\mathrm{R}$ \\
\hline 2 & 16 & 1 & $\odot$ & 4 & 4 & & 0.705 & $\odot .02879$ & $-\odot .538$ & $\mathrm{R}$ \\
\hline 2 & 17 & 1 & $\odot$ & 4 & 4 & & 0.729 & $\odot .0244 \odot$ & -0.589 & $\mathrm{R}$ \\
\hline 2 & 18 & 1 & $\odot$ & 4 & 4 & & $\odot .750$ & $\odot .02132$ & -0.638 & $\mathrm{R}$ \\
\hline 2 & 19 & 1 & $\odot$ & 4 & 4 & & 0.769 & 0.01847 & -0.687 & $\mathrm{R}$ \\
\hline 2 & 20 & 1 & $\odot$ & 4 & 4 & & 0.785 & $\odot .01604$ & -0.734 & $\mathrm{R}$ \\
\hline 2 & 21 & 1 & $\odot$ & 4 & 4 & & 0.799 & $\odot .01404$ & -0.780 & $\mathrm{R}$ \\
\hline 2 & 22 & 1 & $\odot$ & 4 & 4 & & 0.811 & 0.01238 & -0.825 & $\mathrm{R}$ \\
\hline 2 & 23 & 1 & $\odot$ & 4 & 4 & & 0.822 & ๑. 01066 & $-\odot .869$ & $\mathrm{R}$ \\
\hline 2 & 24 & 1 & $\Theta$ & 5 & 5 & & 0.831 & $\odot .0 \odot 9221$ & -0.913 & $\mathrm{R}$ \\
\hline 2 & 25 & 1 & $\odot$ & 4 & 4 & & 0.839 & $\odot . \odot \odot 8 \odot 86$ & $-\odot .957$ & $\mathrm{R}$ \\
\hline 2 & 26 & 1 & $\odot$ & 4 & 4 & & 0.847 & $\odot . \odot \odot 7179$ & -1.00 & $\mathrm{R}$ \\
\hline 2 & 27 & 1 & $\odot$ & 4 & 4 & & 0.853 & $\odot .006085$ & -1.04 & $\mathrm{R}$ \\
\hline 2 & 28 & 1 & $\odot$ & 4 & 4 & & 0.858 & $\odot . \odot \odot 4995$ & -1.09 & $\mathrm{R}$ \\
\hline 2 & 29 & 1 & $\Theta$ & 4 & 4 & & 0.862 & 0.004194 & -1.13 & $\mathrm{R}$ \\
\hline 2 & 30 & 1 & $\odot$ & 5 & 5 & & 0.865 & $\odot .0 \odot 3406$ & -1.17 & $\mathrm{R}$ \\
\hline 2 & 31 & 1 & $\odot$ & 5 & 5 & & 0.868 & $\odot . \odot \odot 2692$ & -1.22 & $\mathrm{R}$ \\
\hline 2 & 32 & 1 & $\odot$ & 5 & 5 & & 0.870 & $\odot . \odot \odot 22 \odot 3$ & -1.26 & $\mathrm{R}$ \\
\hline 2 & 33 & 1 & 0 & 5 & $\mathbf{5}$ & & 0.872 & 0.001833 & -1.30 & $\mathbf{R}$ \\
\hline 2 & 34 & 1 & $\theta$ & 5 & 5 & & 0.874 & 0.001636 & -1.35 & $\overline{\mathrm{R}}$ \\
\hline 2 & 35 & 1 & $\odot$ & 5 & 5 & & 0.875 & $\odot .0 \odot 1441$ & -1.40 & $\mathrm{R}$ \\
\hline 2 & 36 & 1 & $\odot$ & 5 & 5 & & 0.876 & $\odot .001110$ & -1.44 & $\mathrm{R}$ \\
\hline 2 & 37 & 1 & $\odot$ & 5 & 5 & & 0.877 & $\odot .0 \odot \odot 8778$ & -1.49 & $\mathrm{R}$ \\
\hline 2 & 38 & 1 & $\odot$ & 5 & 5 & & 0.878 & ๑. $0 \odot \odot 6882$ & -1.54 & $\mathrm{R}$ \\
\hline 2 & 39 & 1 & 0 & 5 & 5 & & 0.878 & 0.0004972 & -1.59 & $\mathrm{R}$ \\
\hline 2 & 40 & 1 & $\odot$ & 5 & 5 & & 0.878 & $\odot .0002821$ & -1.63 & $\mathrm{R}$ \\
\hline 2 & 41 & 1 & $\odot$ & 5 & 5 & & 0.879 & $\odot .0 \odot 01650$ & -1.68 & $\mathrm{R}$ \\
\hline 2 & 42 & 1 & $\odot$ & 5 & 5 & & 0.879 & $\odot .0002003$ & -1.74 & $\mathrm{R}$ \\
\hline 2 & 43 & 1 & $\odot$ & 5 & 5 & & 0.879 & $\odot .0 \odot \odot 2681$ & -1.79 & $\mathrm{R}$ \\
\hline 2 & 44 & 1 & 0 & 5 & 5 & & 0.880 & 0.0004448 & -1.84 & $\mathrm{R}$ \\
\hline 2 & 45 & 1 & $\odot$ & 5 & 5 & & 0.880 & ๑. 0005810 & -1.90 & $\mathrm{R}$ \\
\hline 2 & 46 & 1 & $\odot$ & 6 & 6 & & 0.881 & 0.0007115 & -1.96 & $\mathrm{R}$ \\
\hline 2 & 47 & 1 & $\odot$ & 5 & 5 & & 0.882 & 0.0009562 & -2.01 & $\mathrm{R}$ \\
\hline
\end{tabular}

THE ANALYSIS HAS COMPLETED SUCCESSFULLY 
Interaction Study: $M=200 \mathrm{k}$ in

Fy=47ksi, $t=0.5^{\prime \prime}, D=26^{\prime \prime}, b f=7.2^{\prime \prime}, d=10.15^{\prime \prime}, h=26^{\prime \prime}, A=24.1^{\prime \prime}, B=24^{\prime \prime}$

ABAQUS VERSION 6.4-1

SUMMARY OF JOB INFORMATION:

MONITOR NODE: 5273 DOF: 2

STEP INC ATT SEVERE EQUIL TOTAL

FREQ

\begin{tabular}{|c|c|c|c|c|c|c|c|c|c|c|}
\hline \multicolumn{5}{|c|}{ ITERS } & \multicolumn{3}{|c|}{ FREQ } & \multirow[b]{2}{*}{1.000} & \multirow[b]{2}{*}{$-\odot .0326$} & \\
\hline 1 & 1 & 1 & $\odot$ & 3 & 3 & 1.00 & 1.00 & & & \\
\hline 2 & 1 & 1 & $\odot$ & 3 & 3 & & ๑.0๑944 & $\odot .0 \odot 9440$ & -0.0372 & $\mathrm{R}$ \\
\hline 2 & 2 & 1 & $\odot$ & 2 & 2 & & ๑. 0186 & $\odot .0 \odot 9163$ & -0.0418 & $\mathrm{R}$ \\
\hline 2 & 3 & 1 & $\odot$ & 2 & 2 & & $\odot .0323$ & ๑. 01369 & $-\odot .0486$ & $\mathrm{R}$ \\
\hline 2 & 4 & 1 & $\Theta$ & 2 & 2 & & $\odot .0526$ & 0.02031 & $-\odot .0589$ & $\mathrm{R}$ \\
\hline 2 & 5 & 1 & $\odot$ & 2 & 2 & & ๑.๑826 & 0.03002 & -0.0742 & $\mathrm{R}$ \\
\hline 2 & 6 & 1 & $\odot$ & 3 & 3 & & $\odot .126$ & 0.04363 & -0.0969 & $\mathrm{R}$ \\
\hline 2 & 7 & 1 & $\odot$ & 3 & 3 & & 0.188 & 0.06215 & -0.130 & $\mathrm{R}$ \\
\hline 2 & 8 & 1 & $\odot$ & 3 & 3 & & 0.264 & 0.07546 & -0.173 & $\mathrm{R}$ \\
\hline 2 & 9 & 1 & $\Theta$ & 3 & 3 & & 0.331 & 0.06752 & -0.215 & $\mathrm{R}$ \\
\hline 2 & 10 & 1 & $\Theta$ & 3 & 3 & & 0.390 & 0.05870 & $-\odot .256$ & $\mathrm{R}$ \\
\hline 2 & 11 & 1 & $\odot$ & 4 & 4 & & 0.441 & ๑. 05084 & -0.294 & $\mathrm{R}$ \\
\hline 2 & 12 & 1 & $\odot$ & 3 & 3 & & 0.484 & 0.04332 & -0.334 & $\mathrm{R}$ \\
\hline 2 & 13 & 1 & $\Theta$ & 3 & 3 & & 0.522 & 0.03786 & $-\odot .375$ & $\mathrm{R}$ \\
\hline 2 & 14 & 1 & $\Theta$ & 4 & 4 & & 0.555 & 0.03329 & -0.416 & $\mathrm{R}$ \\
\hline 2 & 15 & 1 & 0 & 4 & 4 & & 0.585 & 0.02940 & -0.457 & $\mathrm{R}$ \\
\hline 2 & 16 & 1 & $\odot$ & 3 & 3 & & 0.610 & 0.02499 & -0.496 & $\mathrm{R}$ \\
\hline 2 & 17 & 1 & $\Theta$ & 4 & 4 & & 0.631 & 0.02153 & -0.535 & $\mathrm{R}$ \\
\hline 2 & 18 & 1 & $\Theta$ & 4 & 4 & & 0.649 & 0.01795 & $-\odot .572$ & $\mathrm{R}$ \\
\hline 2 & 19 & 1 & $\odot$ & 4 & 4 & & 0.665 & 0.01543 & -0.609 & $\mathrm{R}$ \\
\hline 2 & 20 & 1 & 0 & 4 & 4 & & 0.679 & 0.01392 & -0.649 & $\mathrm{R}$ \\
\hline 2 & 21 & 1 & $\odot$ & 4 & 4 & & 0.691 & 0.01239 & -0.688 & $\mathrm{R}$ \\
\hline 2 & 22 & 1 & $\Theta$ & 5 & 5 & & 0.701 & 0.01044 & $-\odot .727$ & $\mathrm{R}$ \\
\hline 2 & 23 & 1 & $\Theta$ & 5 & 5 & & 0.711 & $\odot .0 \odot 9 \odot 87$ & -0.765 & $\mathrm{R}$ \\
\hline 2 & 24 & 1 & $\odot$ & 5 & 5 & & 0.719 & $\odot . ๑ \odot 8 \odot \odot 7$ & $-\odot .802$ & $\mathrm{R}$ \\
\hline 2 & 25 & 1 & $\Theta$ & 4 & 4 & & 0.726 & $\odot .007138$ & -0.840 & $\mathrm{R}$ \\
\hline 2 & 26 & 1 & $\odot$ & 4 & 4 & & 0.732 & $\odot .006579$ & -0.877 & $\mathrm{R}$ \\
\hline 2 & 27 & 1 & $\Theta$ & 4 & 4 & & 0.738 & $\odot .005935$ & $-\odot .914$ & $\mathrm{R}$ \\
\hline 2 & 28 & 1 & $\Theta$ & 4 & 4 & & 0.744 & $\odot .005407$ & -0.951 & $\mathrm{R}$ \\
\hline 2 & 29 & 1 & $\odot$ & 4 & 4 & & 0.749 & $\odot .0 \odot 498 \odot$ & $-\odot .987$ & $\mathrm{R}$ \\
\hline 2 & 30 & 1 & $\Theta$ & 4 & 4 & & 0.753 & 0.004793 & -1.02 & $\mathrm{R}$ \\
\hline 2 & 31 & 1 & $\Theta$ & 4 & 4 & & 0.758 & $\odot .0 \odot 4506$ & -1.06 & $\mathrm{R}$ \\
\hline 2 & 32 & 1 & 0 & 5 & 5 & & 0.762 & $\odot .0 \odot 4557$ & -1.10 & $\mathrm{R}$ \\
\hline 2 & 33 & 1 & $\odot$ & 5 & 5 & & 0.767 & $\odot .0 \odot 4415$ & -1.14 & $\mathrm{R}$ \\
\hline 2 & 34 & 1 & $\odot$ & 5 & 5 & & 0.771 & $\odot .004348$ & -1.18 & $\mathrm{R}$ \\
\hline 2 & 35 & 1 & $\Theta$ & 5 & 5 & & 0.775 & 0.004244 & -1.22 & $\mathrm{R}$ \\
\hline 2 & 36 & 1 & $\Theta$ & 5 & 5 & & 0.780 & $\odot .004248$ & -1.26 & $\mathrm{R}$ \\
\hline 2 & 37 & 1 & 0 & 5 & 5 & & 0.784 & 0.004170 & -1.30 & $\mathbf{R}$ \\
\hline 2 & 38 & 1 & 0 & 5 & 5 & & 0.788 & 0.004146 & -1.35 & $\mathrm{R}$ \\
\hline 2 & 39 & 1 & $\odot$ & 5 & 5 & & 0.792 & $\odot .004143$ & -1.39 & $\mathrm{R}$ \\
\hline 2 & 40 & 1 & $\odot$ & 5 & 5 & & 0.796 & $\odot .0 \odot 4307$ & -1.44 & $\mathrm{R}$ \\
\hline 2 & 41 & 1 & $\odot$ & 5 & 5 & & 0.801 & $\odot .0 \odot 4521$ & -1.48 & $\mathrm{R}$ \\
\hline 2 & 42 & 1 & $\Theta$ & 5 & 5 & & 0.806 & $\odot .0 \odot 4702$ & -1.53 & $\mathrm{R}$ \\
\hline 2 & 43 & 1 & $\odot$ & 5 & 5 & & 0.811 & $\odot .005011$ & -1.58 & $\mathrm{R}$ \\
\hline 2 & 44 & 1 & $\Theta$ & 5 & 5 & & 0.816 & $\odot .005305$ & -1.63 & $\mathrm{R}$ \\
\hline 2 & 45 & 1 & $\odot$ & 5 & 5 & & 0.822 & $\odot .005560$ & -1.68 & $\mathrm{R}$ \\
\hline 2 & 46 & 1 & $\odot$ & 5 & 5 & & 0.827 & $\odot .005730$ & -1.73 & $\mathrm{R}$ \\
\hline 2 & 47 & 1 & 0 & 6 & 6 & & 0.833 & $\odot .005849$ & -1.78 & $\mathrm{R}$ \\
\hline 2 & 48 & 1 & $\odot$ & 5 & 5 & & 0.839 & $\odot .005945$ & -1.84 & $\mathrm{R}$ \\
\hline 2 & 49 & 1 & $\odot$ & 6 & 6 & & 0.845 & ๑.0๑5988 & -1.89 & $\mathrm{R}$ \\
\hline
\end{tabular}

DATE 31-0ct-2004 TIME 14:35:59

STEP INC OF DOF IF $\begin{array}{lccc}\text { STEP } & \text { INC OF } & \text { DOF } & \text { IF } \\ \text { TIME/LPF } & \text { TIME/LPF } & \text { MONITOR } & \text { RIKS }\end{array}$ R R R $\mathrm{R}$ R R R R R $\mathrm{R}$ $\mathrm{R}$ R R , R . R R $\mathrm{R}$ . 
Interaction Study: $M=300 \mathrm{k}$ in

Fy=47ksi, $t=0.5^{\prime \prime}, D=26^{\prime \prime}, b f=7.2^{\prime \prime}, d=10.15^{\prime \prime}, h=26^{\prime \prime}, A=24.1^{\prime \prime}, B=24^{\prime \prime}$

ABAQUS VERSION 6.4-1

SUMMARY OF JOB INFORMATION:

MONITOR NODE: 5273 DOF: 2

DE: SEVERE EQUIL TOTAL

\begin{tabular}{|c|c|c|c|c|c|c|c|c|c|c|}
\hline STEP & INC & ATT & $\begin{array}{l}\text { SEVERE } \\
\text { DISCON } \\
\text { ITERS }\end{array}$ & $\begin{array}{l}\text { EQUIL } \\
\text { ITERS }\end{array}$ & $\begin{array}{l}\text { TOTAL } \\
\text { ITERS }\end{array}$ & $\begin{array}{l}\text { TOTAL } \\
\text { TIME / } \\
\text { FREQ }\end{array}$ & $\begin{array}{c}\text { STEP } \\
\text { TIME/LPF }\end{array}$ & $\begin{array}{l}\text { INC OF } \\
\text { TIME/LPF }\end{array}$ & $\begin{array}{c}\text { DOF } \\
\text { MONITOR }\end{array}$ & $\begin{array}{c}\text { IF } \\
\text { RIKS }\end{array}$ \\
\hline 1 & 1 & 1 & $\odot$ & 4 & 4 & $1.0 \odot$ & 1.00 & 1.000 & -0.0584 & \\
\hline 2 & 1 & 1 & $\odot$ & 3 & 3 & & $\odot .0 \odot 794$ & $\odot .0 \odot 7937$ & -0.0628 & $\mathrm{R}$ \\
\hline 2 & 2 & 1 & $\odot$ & 2 & 2 & & ๑. 0159 & $\odot .0 \odot 7962$ & -0.0671 & $\mathrm{R}$ \\
\hline 2 & 3 & 1 & $\odot$ & 2 & 2 & & 0.0278 & 0.01186 & $-\odot .0737$ & $\mathrm{R}$ \\
\hline 2 & 4 & 1 & $\odot$ & 2 & 2 & & 0.0454 & 0.01766 & -0.0834 & $\mathrm{R}$ \\
\hline 2 & 5 & 1 & $\odot$ & 3 & 3 & & 0.0710 & 0.02559 & -0.0979 & $\mathrm{R}$ \\
\hline 2 & 6 & 1 & $\odot$ & 3 & 3 & & 0.108 & 0.03666 & -0.119 & $\mathrm{R}$ \\
\hline 2 & 7 & 1 & $\odot$ & 3 & 3 & & $\odot .159$ & ๑. 05165 & -0.151 & $\mathrm{R}$ \\
\hline 2 & 8 & 1 & $\odot$ & 3 & 3 & & 0.220 & ๑. .06025 & -0.190 & $\mathrm{R}$ \\
\hline 2 & 9 & 1 & $\odot$ & 3 & 3 & & 0.272 & ๑. 05282 & -0.229 & $\mathrm{R}$ \\
\hline 2 & 10 & 1 & $\odot$ & 3 & 3 & & 0.318 & $\odot .04564$ & -0.265 & $\mathrm{R}$ \\
\hline 2 & 11 & 1 & $\odot$ & 3 & 3 & & 0.357 & ๑. . 03851 & -0.301 & $\mathrm{R}$ \\
\hline 2 & 12 & 1 & $\odot$ & 3 & 3 & & 0.390 & ๑. . 03360 & -0.335 & $\mathrm{R}$ \\
\hline 2 & 13 & 1 & $\odot$ & 3 & 3 & & 0.419 & ๑. . 02925 & -0.368 & $\mathrm{R}$ \\
\hline 2 & 14 & 1 & $\odot$ & 3 & 3 & & 0.444 & 0.02454 & -0.401 & $\mathrm{R}$ \\
\hline 2 & 15 & 1 & $\odot$ & 3 & 3 & & 0.465 & 0.02106 & -0.433 & $\mathrm{R}$ \\
\hline 2 & 16 & 1 & $\odot$ & 3 & 3 & & 0.484 & 0.01866 & -0.465 & $\mathrm{R}$ \\
\hline 2 & 17 & 1 & $\odot$ & 3 & 3 & & 0.499 & 0.01583 & -0.497 & $\mathrm{R}$ \\
\hline 2 & 18 & 1 & $\odot$ & 4 & 4 & & 0.513 & 0.01378 & -0.529 & $\mathrm{R}$ \\
\hline 2 & 19 & 1 & $\odot$ & 4 & 4 & & $\odot .525$ & ๑. . 01142 & -0.560 & $\mathrm{R}$ \\
\hline 2 & 20 & 1 & $\odot$ & 4 & 4 & & 0.534 & ๑. .009226 & -0.590 & $\mathrm{R}$ \\
\hline 2 & 21 & 1 & $\odot$ & 5 & 5 & & 0.541 & $\odot .0 \odot 7368$ & -0.620 & $\mathrm{R}$ \\
\hline 2 & 22 & 1 & $\odot$ & 4 & 4 & & 0.548 & $\odot .0 \odot 6384$ & -0.649 & $\mathrm{R}$ \\
\hline 2 & 23 & 1 & $\odot$ & 4 & 4 & & $\odot .554$ & $\odot .0 \odot 6 \odot 61$ & -0.679 & $\mathrm{R}$ \\
\hline 2 & 24 & 1 & $\odot$ & 4 & 4 & & $\odot .559$ & $\odot .0 \odot 5758$ & -0.709 & $\mathrm{R}$ \\
\hline 2 & 25 & 1 & $\odot$ & 4 & 4 & & 0.565 & $\odot .0 \odot 5 \odot 95$ & $-\odot .739$ & $\mathrm{R}$ \\
\hline 2 & 26 & 1 & $\odot$ & 4 & 4 & & 0.570 & $\odot .0 \odot 5 \odot 53$ & $-\odot .769$ & $\mathrm{R}$ \\
\hline 2 & 27 & 1 & $\odot$ & 4 & 4 & & 0.575 & $\odot .0 \odot 5494$ & -0.801 & $\mathrm{R}$ \\
\hline 2 & 28 & 1 & $\odot$ & 4 & 4 & & $\odot .581$ & ๑. . $\odot 5933$ & -0.832 & $\mathrm{R}$ \\
\hline 2 & 29 & 1 & $\odot$ & 4 & 4 & & 0.587 & $\odot .0 \odot 6087$ & -0.865 & $\mathrm{R}$ \\
\hline 2 & 30 & 1 & $\odot$ & 4 & 4 & & 0.594 & $\odot .0 \odot 6359$ & $-\odot .898$ & $\mathrm{R}$ \\
\hline 2 & 31 & 1 & $\odot$ & 4 & 4 & & 0.600 & $\odot .0 \odot 6658$ & -0.932 & $\mathrm{R}$ \\
\hline 2 & 32 & 1 & $\odot$ & 5 & 5 & & 0.607 & $\odot .0 \odot 6844$ & -0.967 & $\mathrm{R}$ \\
\hline 2 & 33 & 1 & $\odot$ & 4 & 4 & & 0.614 & $\odot .0 \odot 7034$ & -1.00 & $\mathrm{R}$ \\
\hline 2 & 34 & 1 & $\odot$ & 4 & 4 & & 0.621 & $\odot .0 \odot 7258$ & -1.04 & $\mathrm{R}$ \\
\hline 2 & 35 & 1 & $\odot$ & 4 & 4 & & 0.629 & 0.007364 & -1.08 & $\mathrm{R}$ \\
\hline 2 & 36 & 1 & $\odot$ & 4 & 4 & & 0.636 & $\odot . \odot \odot 7587$ & -1.11 & $\mathrm{R}$ \\
\hline 2 & 37 & 1 & $\odot$ & 5 & 5 & & 0.644 & $\odot . \odot \odot 7849$ & -1.15 & $\mathrm{R}$ \\
\hline 2 & 38 & 1 & $\odot$ & 4 & 4 & & 0.652 & 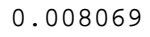 & -1.19 & $\mathrm{R}$ \\
\hline 2 & 39 & 1 & $\odot$ & 5 & 5 & & 0.661 & ๑. . 008576 & -1.23 & $\mathrm{R}$ \\
\hline 2 & 40 & 1 & $\odot$ & 5 & 5 & & 0.670 & $\odot .008999$ & -1.27 & $\mathrm{R}$ \\
\hline 2 & 41 & 1 & 0 & 5 & 5 & & 0.679 & 0.009577 & -1.32 & $\mathbf{R}$ \\
\hline 2 & 42 & 1 & $\Theta$ & 5 & 5 & & 0.689 & 0.01000 & -1.37 & $\mathrm{R}$ \\
\hline 2 & 43 & 1 & $\odot$ & 5 & 5 & & 0.700 & ๑ . 01044 & -1.41 & $\mathrm{R}$ \\
\hline 2 & 44 & 1 & $\odot$ & 5 & 5 & & 0.710 & 0.01065 & -1.46 & $\mathrm{R}$ \\
\hline 2 & 45 & 1 & $\odot$ & 5 & 5 & & 0.721 & ๑ . 01088 & -1.51 & $\mathrm{R}$ \\
\hline 2 & 46 & 1 & $\odot$ & 5 & 5 & & 0.732 & ๑ . 01092 & -1.57 & $\mathrm{R}$ \\
\hline 2 & 47 & 1 & $\odot$ & 5 & 5 & & 0.743 & 0.01102 & -1.62 & $\mathrm{R}$ \\
\hline 2 & 48 & 1 & $\odot$ & 5 & 5 & & 0.754 & 0.01104 & -1.67 & $\mathrm{R}$ \\
\hline 2 & 49 & 1 & $\odot$ & 5 & 5 & & 0.765 & 0.01103 & -1.72 & $\mathrm{R}$ \\
\hline 2 & 50 & 1 & $\odot$ & 5 & 5 & & 0.776 & 0. 01098 & -1.78 & $\mathrm{R}$ \\
\hline
\end{tabular}

DATE 31-0ct-2004 TIME 14:37:59 
Interaction Study: $M=400 \mathrm{k}$ in

Fy=47ksi, $t=0.5^{\prime \prime}, D=26^{\prime \prime}, b f=7.2^{\prime \prime}, d=10.15^{\prime \prime}, h=26^{\prime \prime}, A=24.1^{\prime \prime}, B=24^{\prime \prime}$

ABAOUS VERSION 6.4-1

SUMMARY OF JOB INFORMATION:

MONITOR NODE: 5273 DOF: 2

STEP INC ATT SEVERE EQUIL TOTAL

\section{ITERS}

$\begin{array}{llrrrrr} & & & \text { ITERS } & & & \text { FREQ } \\ 1 & 1 & 1 & \odot & 5 & 5 & 1.0 \odot \\ 2 & 1 & 1 & 0 & 4 & 4 & \\ 2 & 2 & 1 & 0 & 2 & 2 & \\ 2 & 3 & 1 & 0 & 2 & 2 & \\ 2 & 4 & 1 & 0 & 3 & 3 & \end{array}$

$\begin{array}{llllll}2 & 4 & 1 & 0 & 3 & 3 \\ 2 & 5 & 1 & 0 & 3 & 3 \\ 2 & 6 & 1 & 0 & 3 & 3\end{array}$

$\begin{array}{llllll}2 & 7 & 1 & 0 & 3 & 3 \\ 2 & 8 & 1 & 0 & 3 & 3\end{array}$

$\begin{array}{rrrrrr}2 & 9 & 1 & 0 & 3 & 3 \\ 2 & 10 & 1 & 0 & 3 & 3 \\ 2 & 11 & 1 & 0 & 3 & 3\end{array}$

$\begin{array}{lll}2 & 12 & 1\end{array}$

$2 \quad 13 \quad 1$

$2 \quad 14 \quad 1$

$2 \begin{array}{lll}2 & 15 & 1\end{array}$

$2 \quad 16 \quad 1$

$\begin{array}{lll}2 & 17 & 1 \\ 2 & 18 & 1\end{array}$

$\begin{array}{lll}2 & 18 & 1 \\ 2 & 19 & 1\end{array}$

$\begin{array}{lll}2 & 19 & 1 \\ 2 & 20 & 1\end{array}$

$\begin{array}{lll}2 & 21 & 1 \\ 2 & 22 & 1\end{array}$

$\begin{array}{lll}2 & 23 & 1 \\ 2 & 24 & 1\end{array}$

$\begin{array}{lll}2 & 24 & 1 \\ 2 & 25 & 1\end{array}$

$\begin{array}{lll}2 & 25 & 1 \\ 2 & 26 & 1\end{array}$

$\begin{array}{lll}2 & 27 & 1 \\ 2 & 28 & 1\end{array}$

$\begin{array}{lll}2 & 29 & 1 \\ 2 & 30 & 1 \\ 2 & 31 & 1\end{array}$

$\begin{array}{lll}2 & 31 & 1 \\ 2 & 32 & 1 \\ 2 & 33 & 1\end{array}$

$\begin{array}{lll}2 & 33 & 1 \\ 2 & 34 & 1\end{array}$

$\begin{array}{lll}2 & 34 & 1 \\ 2 & 35 & 1\end{array}$

$\begin{array}{lll}2 & 36 & 1 \\ 2 & 37 & 1\end{array}$

$\begin{array}{lll}2 & 37 & 1 \\ 2 & 38 & 1 \\ 2 & 39 & 1\end{array}$

$\begin{array}{lll}2 & 39 & 1 \\ 2 & 4 \odot & 1 \\ 2 & 41 & 1\end{array}$

\begin{tabular}{lllll}
2 & $4 \odot$ & 1 & $\odot$ & 4 \\
2 & 41 & 1 & $\odot$ & 4 \\
$\mathbf{2}$ & $\mathbf{4 2}$ & $\mathbf{1}$ & 0 & $\mathbf{4}$ \\
\hline 2 & 43 & 1 & $\odot$ & 4 \\
2 & 44 & 1 & 0 & 4
\end{tabular}

$\begin{array}{lllll}2 & 44 & 1 & 0 & 4 \\ 2 & 45 & 1 & 0 & 4 \\ 2 & 46 & 1 & 0 & 5\end{array}$

$\begin{array}{lllll}2 & 46 & 1 & 0 & 5 \\ 2 & 47 & 1 & 0 & 4 \\ 2 & 48 & 1 & 0 & 5 \\ 2 & 49 & 1 & 0 & 4\end{array}$

$\begin{array}{lllll}2 & 49 & 1 & \odot & 4 \\ 2 & 5 \odot & 1 & \odot & 5\end{array}$

THE ANALYSIS HAS COMPLETED SUCCESSFULLY
DATE 05-Dec-2004 TIME 23:30:54

STEP INC OF DOF IF

TIME/LPF TIME/LPF MONITOR RIKS

$\begin{array}{lll}1.00 & 1.000 & -0.0999\end{array}$

$0.00561-0.005610-0.104$

$0.0114 \quad 0.005839-0.108$

$0.0201 \quad 0.008670 \quad-0.114$

$\begin{array}{lll}0.0328 & 0.01269 & -0.122\end{array}$

$0.0511 \quad 0.01827 \quad-0.135$

$0.0771 \quad 0.02605 \quad-0.154$

$0.113 \quad 0.03563 \quad-0.181$

0.153

$0.189 \quad 0.03524$

$0.219 \quad 0.03051$

0.244

0.264

0.280

0.292

$\odot .303$

0.312

0.320

$\odot .326$

0.332

0.338

0.344

0.349

0.355

$\odot .361$

0.368

0.375

0.383

0.391

0.400

0.408

0.417

0.427

0.437

0.449

0.461

0.474

0.488

0.503

0.519

0.534

0.551

0.567

0.584

0.600

0.617

0.632

0.648

0.663

0.678

$\odot .692$

0.02515

0.01997

0.01535

0.01256

$\odot .01099$

$\odot .008938$

$\odot .007673$

$\odot .006774$

0.005987

$\odot .006056$

$\odot .005196$

0.005604

$\odot .005986$

0.006227

0.006527

0.007340

0.007863

$\odot .008198$

$\odot .008351$

$\odot .008495$

$\odot .008999$

0.009774

๑. 01040

0.01122

$\odot .01209$

0.01330

$\odot .01395$

0.01493

$\odot .01557$

$\odot .01589$

0.01630

0.01643

0.01649

0.01662

0.01644

0.01578

0.01545

0.01506

0.01477

$\odot .01440$

$-0.216$

$-0.250$

$-0.282$

$-0.313$

$-0.343$

$-0.371$

$-0.399$

$-0.426$

$-0.452$

$-0.479$

$-0.506$

$-0.532$

$-0.560$

$-0.587$

$-0.615$

$-0.643$

$-0.673$

$-0.702$

$-0.733$

$-0.764$

$-0.796$

$-0.828$

$-0.861$

$-0.895$

$-0.930$

$-0.965 \quad R$

$-1.00$

$-1.04$

$-1.08$

$-1.12$

$-1.16$

$-1.20$

$-1.25$

1.29 $-1.34$

$-1.38$

$-1.43$

$-1.48$

$-1.53$

$-1.58$

$-1.63$

$-1.69$

$-1.74$

$R$
$R$
$R$
$R$
$R$
$R$
$R$
$R$
$R$
$R$
$R$
$R$
$R$
$R$
$R$
$R$
$R$
$R$
$R$
$R$
$R$
$R$
$R$
$R$
$R$
$R$
$R$
$R$
$R$
$R$
$R$
$R$
$R$
$R$
$R$
$R$
$R$
$R$
$R$
$R$
$R$
$R$
$R$
$R$
$R$
$R$
$R$
$R$
$R$
$R$
$R$
$R$
$R$
$R$
$R$
$R$
$R$
$R$
$R$
$R$
$R$
$R$
$R$
$R$
$R$
$R$


APPENDIX D

LOAD-DEFLECTION DATA FROM ST-TO-HSS JOINT STUDY FEM ANALYSES. 


\begin{tabular}{|c|c|c|c|c|c|c|c|c|c|c|}
\hline ABAQU & $S$ VEF & SION & $N 6.4-1$ & & & & DATE & $30-0 c t-20 \odot 4$ & TIME $12:$ & $24: 34$ \\
\hline SUMMA & RY OF & $\mathrm{JOB}$ & B INFORN & MATION & & & & & & \\
\hline MONIT & $\mathrm{OR} \mathrm{NC}$ & DE : & 8365 & DOF & 2 & & & & & \\
\hline STEP & INC & ATT & SEVERE & EQUIL & TOTAL & TOTAL & STEP & INC OF & DOF & IF \\
\hline & & & $\begin{array}{l}\text { DISCON } \\
\text { ITERS }\end{array}$ & ITERS & ITERS & $\begin{array}{l}\text { TIME/ } \\
\text { FREQ }\end{array}$ & TIME/LPF & TIME/LPF & MONITOR & RIKS \\
\hline 1 & 1 & 1 & 0 & 2 & 2 & & $\odot .0 \odot 999$ & $\odot .009994$ & -0.00515 & $\mathrm{R}$ \\
\hline 1 & 2 & 1 & $\odot$ & 2 & 2 & & $\odot . \odot 2 \odot \odot$ & $\odot . \odot \odot 998 \odot$ & $-\odot .0103$ & $\mathrm{R}$ \\
\hline 1 & 3 & 1 & $\odot$ & 2 & 2 & & 0.0349 & $\odot .01495$ & $-\odot .0181$ & $\mathrm{R}$ \\
\hline 1 & 4 & 1 & $\odot$ & 2 & 2 & & 0.0573 & 0.02237 & $-\odot .0297$ & $\mathrm{R}$ \\
\hline 1 & 5 & 1 & $\odot$ & 2 & 2 & & 0.0907 & 0.03343 & -0.0471 & $\mathrm{R}$ \\
\hline 1 & 6 & 1 & $\odot$ & 2 & 2 & & 0.141 & 0.04988 & -0.0734 & $\mathrm{R}$ \\
\hline 1 & 7 & 1 & $\odot$ & 2 & 2 & & $\odot .215$ & 0.07419 & -0.113 & $\mathrm{R}$ \\
\hline 1 & 8 & 1 & $\odot$ & 3 & 3 & & $\odot .310$ & 0.09545 & -0.166 & $\mathrm{R}$ \\
\hline 1 & 9 & 1 & $\odot$ & 3 & 3 & & 0.401 & 0.09051 & -0.220 & $\mathrm{R}$ \\
\hline 1 & 10 & 1 & $\odot$ & 4 & 4 & & 0.488 & 0.08690 & -0.276 & $\mathrm{R}$ \\
\hline 1 & 11 & 1 & $\odot$ & 4 & 4 & & 0.570 & 0.08207 & -0.342 & $\mathrm{R}$ \\
\hline 1 & 12 & 1 & $\odot$ & 4 & 4 & & 0.645 & 0.07574 & -0.412 & $\mathrm{R}$ \\
\hline 1 & 13 & 1 & $\odot$ & 4 & 4 & & 0.715 & 0.06984 & $-\odot .497$ & $\mathrm{R}$ \\
\hline 1 & 14 & 1 & $\odot$ & 3 & 3 & & $\odot .777$ & 0.06215 & -0.590 & $\mathrm{R}$ \\
\hline 1 & 15 & 1 & $\odot$ & 3 & 3 & & 0.830 & 0.05298 & $-\odot .683$ & $\mathrm{R}$ \\
\hline 1 & 16 & 1 & $\odot$ & 3 & 3 & & 0.873 & 0.04293 & $-\odot .774$ & $\mathrm{R}$ \\
\hline 1 & 17 & 1 & $\odot$ & 3 & 3 & & 0.906 & 0.03278 & -0.864 & $\mathrm{R}$ \\
\hline 1 & 18 & 1 & $\odot$ & 3 & 3 & & 0.930 & 0.02388 & -0.952 & $\mathrm{R}$ \\
\hline 1 & 19 & 1 & $\odot$ & 3 & 3 & & 0.946 & 0.01581 & -1.04 & $\mathrm{R}$ \\
\hline 1 & 20 & 1 & $\odot$ & 3 & 3 & & 0.954 & $\odot .0 \odot 7872$ & -1.12 & $\mathrm{R}$ \\
\hline 1 & 21 & 1 & 0 & 3 & 3 & & 0.954 & 0.0007201 & -1.21 & $\mathbf{R}$ \\
\hline 1 & 22 & 1 & 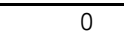 & 4 & 4 & & 0.949 & -0.005607 & -1.29 & $\overline{\mathrm{R}}$ \\
\hline 1 & 23 & 1 & $\odot$ & 4 & 4 & & $\odot .937$ & -0.01167 & -1.38 & $\mathrm{R}$ \\
\hline 1 & 24 & 1 & $\odot$ & 4 & 4 & & 0.922 & -0.01516 & -1.46 & $\mathrm{R}$ \\
\hline 1 & 25 & 1 & $\odot$ & 3 & 3 & & 0.906 & -0.01638 & -1.55 & $\mathrm{R}$ \\
\hline 1 & 26 & 1 & $\odot$ & 3 & 3 & & $\odot .89 \odot$ & $-\odot .01537$ & -1.63 & $\mathrm{R}$ \\
\hline 1 & 27 & 1 & $\odot$ & 3 & 3 & & 0.877 & -0.01330 & -1.72 & $\mathrm{R}$ \\
\hline 1 & 28 & 1 & $\odot$ & 4 & 4 & & 0.866 & -0.01060 & -1.80 & $\mathrm{R}$ \\
\hline 1 & 29 & 1 & $\odot$ & 4 & 4 & & 0.859 & $-\odot .0 \odot 7665$ & -1.89 & $\mathrm{R}$ \\
\hline 1 & 30 & 1 & $\odot$ & 4 & 4 & & 0.854 & -0.004990 & -1.97 & $\mathrm{R}$ \\
\hline 1 & 31 & 1 & $\odot$ & 3 & 3 & & $\odot .851$ & -0.002623 & -2.06 & $\mathrm{R}$ \\
\hline 1 & 32 & 1 & $\odot$ & 3 & 3 & & 0.851 & $-\odot .0 \odot \odot 4376$ & -2.14 & $\mathrm{R}$ \\
\hline 1 & 33 & 1 & $\odot$ & 3 & 3 & & 0.852 & $\odot .001770$ & -2.23 & $\mathrm{R}$ \\
\hline 1 & 34 & 1 & $\odot$ & 3 & 3 & & 0.857 & $\odot .0 \odot 4372$ & -2.31 & $\mathrm{R}$ \\
\hline 1 & 35 & 1 & $\odot$ & 4 & 4 & & 0.864 & $\odot .006955$ & -2.39 & $\mathrm{R}$ \\
\hline 1 & 36 & 1 & $\odot$ & 3 & 3 & & $\odot .873$ & $\odot . \odot \odot 9451$ & -2.48 & $\mathrm{R}$ \\
\hline 1 & 37 & 1 & $\odot$ & 4 & 4 & & 0.885 & 0.01196 & -2.56 & $\mathrm{R}$ \\
\hline 1 & 38 & 1 & $\odot$ & 3 & 3 & & 0.899 & 0.01418 & -2.64 & $\mathrm{R}$ \\
\hline 1 & 39 & 1 & $\odot$ & 4 & 4 & & 0.915 & $0.0160 \odot$ & -2.72 & $\mathrm{R}$ \\
\hline 1 & 40 & 1 & $\odot$ & 4 & 4 & & 0.933 & 0.01723 & -2.81 & $\mathrm{R}$ \\
\hline 1 & 41 & 1 & $\odot$ & 3 & 3 & & $\odot .950$ & $\odot .01786$ & -2.89 & $\mathrm{R}$ \\
\hline 1 & 42 & 1 & $\odot$ & 3 & 3 & & 0.969 & $\odot .01831$ & -2.97 & $\mathrm{R}$ \\
\hline 1 & 43 & 1 & $\odot$ & 4 & 4 & & 0.987 & 0.01850 & -3.06 & $\mathrm{R}$ \\
\hline
\end{tabular}

THE ANALYSIS HAS COMPLETED SUCCESSFULLY 
Interior Cross Connection:

Fy=47ksi, $t=0.5^{\prime \prime}, D=26^{\prime \prime}, b f=7.2^{\prime \prime}, d=10.15^{\prime \prime}, h=26 ", L=60^{\prime \prime}$

ABAQUS VERSION 6.4-1

SUMMARY OF JOB INFORMATION:

MONITOR NODE: 12689 DOF: 2

STEP INC ATT SEVERE EQUIL TOTAL DISCON ITERS ITERS

\begin{tabular}{rrrrr} 
& & \multicolumn{3}{r}{ ITERS } \\
1 & 1 & 1 & 0 & 2 \\
1 & 2 & 1 & 0 & 2 \\
1 & 3 & 1 & 0 & 2 \\
1 & 4 & 1 & 0 & 2 \\
1 & 5 & 1 & 0 & 2 \\
1 & 6 & 1 & 0 & 2 \\
1 & 7 & 1 & 0 & 3 \\
1 & 8 & 1 & $\odot$ & 3 \\
1 & 9 & 1 & 0 & 3 \\
1 & 10 & 1 & 0 & 4 \\
1 & 11 & 1 & 0 & 4 \\
1 & 12 & 1 & 0 & 4 \\
1 & 13 & 1 & 0 & 4 \\
1 & 14 & 1 & 0 & 3 \\
1 & 15 & 1 & 0 & 3 \\
1 & 16 & 1 & 0 & 4 \\
1 & 17 & 1 & 0 & 3 \\
1 & 18 & 1 & 0 & 3 \\
1 & 19 & 1 & 0 & 3 \\
1 & 20 & 1 & 0 & 3 \\
\hline 1 & 21 & 1 & 0 & 6 \\
1 & 22 & 1 & 0 & 4
\end{tabular}

$\begin{array}{lllll}1 & 21 & 1 & 0 & 6 \\ 1 & 22 & 1 & 0 & 4 \\ 1 & 23 & 1 & 0 & 4\end{array}$

$\begin{array}{lllll}1 & 23 & 1 & 0 & 4\end{array}$

$124 \quad 1$

$1 \quad 25 \quad 1$

$1 \quad 26 \quad 1$

$\begin{array}{lll}1 & 27 & 1\end{array}$

$\begin{array}{lll}1 & 28 & 1\end{array}$

$\begin{array}{lll}1 & 29 & 1\end{array}$

$1 \quad 30 \quad 1$

$1 \quad 31 \quad 1$

$\begin{array}{lll}1 & 32 & 1\end{array}$

1331

$\begin{array}{lll}1 & 34 & 1 \\ 1 & 35 & 1\end{array}$

\begin{tabular}{l}
2 \\
2 \\
2 \\
2 \\
2 \\
2 \\
3 \\
3 \\
3 \\
4 \\
4 \\
4 \\
4 \\
3 \\
3 \\
4 \\
3 \\
3 \\
3 \\
3 \\
6 \\
4 \\
4 \\
4 \\
4 \\
4 \\
4 \\
4 \\
3 \\
4 \\
5 \\
6 \\
4 \\
4 \\
4 \\
\hline
\end{tabular}

DATE 31-0ct-2004

TIME $07: 51: 51$

TOTAL

TIME/
FREQ

$\begin{array}{cccc}\text { STEP } & \text { INC OF } & \text { DOF } & \text { IF } \\ \text { TIME } & & & \\ & \text { TIME } & & \end{array}$ $\begin{array}{lll}0.00999 & 0.009992 & -0.00685\end{array}$

$\begin{array}{llll}0.0200 & 0.009974 & -0.0137 & R\end{array}$

$\begin{array}{llll}0.0349 & 0.01493 & -0.0240 & R\end{array}$

$0.0572 \quad 0.02233 \quad-0.0394 \quad R$

$0.0906 \quad 0.03333 \quad-0.0626 \quad R$

$\begin{array}{llll}0.140 & 0.04965 & -0.0975 & R\end{array}$

$\begin{array}{llll}0.214 & 0.07336 & -0.150 & R\end{array}$

$\begin{array}{llll}0.307 & 0.09320 & -0.220 & R\end{array}$

$\begin{array}{llll}0.394 & 0.08726 & -0.292 & R\end{array}$

$\begin{array}{llll}0.477 & 0.08280 & -0.365 & R\end{array}$

$\begin{array}{llll}0.553 & 0.07631 & -0.447 & R\end{array}$

$\begin{array}{llll}0.622 & 0.06931 & -0.534 & R\end{array}$

$\begin{array}{llll}0.684 & 0.06112 & -0.629 & R\end{array}$

$\begin{array}{llll}0.735 & 0.05139 & -0.734 & R\end{array}$

$\begin{array}{llll}0.777 & 0.04243 & -0.839 & R\end{array}$

$\begin{array}{llll}0.811 & 0.03313 & -0.944 & R\end{array}$

$\begin{array}{llll}0.834 & 0.02384 & -1.05 & R\end{array}$

$\begin{array}{llll}0.851 & 0.01639 & -1.15 & R\end{array}$

$0.860 \quad 0.009095 \quad-1.25 \quad \mathrm{R}$

$\begin{array}{llll}0.862 & 0.002449 & -1.35 & R\end{array}$

$\begin{array}{llll}0.859 & -0.003247 & -1.43 & R\end{array}$

$\begin{array}{llll}0.846 & -0.01279 & -1.42 & R\end{array}$

$\begin{array}{llll}0.827 & -0.01968 & -1.40 & R\end{array}$

$\begin{array}{llll}0.809 & -0.01763 & -1.39 & R\end{array}$

$\begin{array}{llll}0.797 & -0.01168 & -1.37 & R\end{array}$

$\begin{array}{llll}0.791 & -0.005921 & -1.37 & R\end{array}$

$\begin{array}{llll}0.790 & -0.001181 & -1.37 & R\end{array}$

$\begin{array}{llll}0.794 & 0.003822 & -1.37 & R\end{array}$

$\begin{array}{llll}0.803 & 0.008584 & -1.38 & R\end{array}$

$\begin{array}{llll}0.816 & 0.01293 & -1.39 & R\end{array}$

$\begin{array}{llll}0.830 & 0.01437 & -1.45 & R\end{array}$

$\begin{array}{llll}0.824 & -0.006171 & -1.62 & R\end{array}$

$\begin{array}{llll}0.808 & -0.01543 & -1.77 & R\end{array}$

$\begin{array}{llll}0.793 & -0.01535 & -1.92 & R \\ 0.782 & -0.01067 & -2.06 & R\end{array}$

THE ANALYSIS HAS COMPLETED SUCCESSFULLY 


\section{BIBLIOGRAPHY}

1. ABAQUS, (2003) ABAQUS Theory Manual, Hibbitt, Karlsson \& Sorensen, Inc., Pawtucket, Rhode Island, USA.

2. AASHTO (2001) Standard Specifications for Structural Supports for Highway Signs, Luminaires and Traffic Signals, $4^{\text {th }}$ Edition, American Association of State Highway and Transportation Officials, Inc., Washington D.C.

3. AISC (2000) Load and Resistance Factor Design Specification for Steel Hollow Structural Sections, American Institute of Steel Construction, Chicago, Illinois, November 10.

4. AISC (2001) Manual of Steel Construction - Load and Resistance Factor Design $3^{\text {rd }}$ Edition, American Institute of Steel Construction, Chicago, Illinois, November.

5. AISC (1997a) Hollow Structural Sections Connections Manual, American Institute of Steel Construction, Chicago, Illinois.

6. AISC (1997b) Specification for the Design of Steel Hollow Structural Sections, American Institute of Steel Construction, Chicago, Illinois, April 15.

7. AWS (2004) D1.1 Structural Welding Code - Steel $19^{\text {th }}$ Edition, American Welding Society, Miami, Florida, October 15.

8. Bathe, K.J. (1996) Finite Element Procedures, Prentice-Hall, Inc., Upper Saddle River, New Jersey.

9. Boyle, R., Earls, C.J., (2004) "Full-Scale Testing of Tri-Chord Sign Structure Connections” Report No. CE/ST 28, Department of Civil and Environmental Engineering, University of Pittsburgh, Pittsburgh, Pennsylvania.

10. Chen, W.F., Ross, D.A. (1977), “Tests of Fabricated Tubular Columns,” Journal of the Structural Division, ASCE, Volume 103, No. ST3.

11. Clough, R.W., (1965), The Finite Element Method in Structural Mechanics, in O.C. Zienkiewicz et al. ( $1^{\text {st }}$ Ed), Stress Analysis, John Wiley and Sons, London.

12. Dieter, G. E. (1986), Mechanical Metallurgy $3^{\text {rd }}$ Ed., McGraw Hill, ISBN 0-07-016893-8. 
13. Galambos, T. (1998), Guide to Stability Design Criteria for Metal Structures, $5^{\text {th }}$ Ed., Wiley, ISBN 0471127426.

14. Greco, N., Earls, C.J., (2003) "Structural Ductility in Hybrid High Performance Steel Beams,” Journal of Structural Engineering, Vol. 129, No. 12, American Society of Civil Engineers, Reston, Virginia, pp.1584-1595.

15. Kosteski, N., Packer, J.A., (2003) "Longitudinal Plate and Through Plate-to-Hollow Structural Section Welded Connections,” Journal of Structural Engineering, Vol. 129, No. 4, American Society of Civil Engineers, Reston, Virginia.

16. Kurobane, K., Makino, Y., Mitsui, Y. (1976) “Ultimate Strength Formulae for Simple Tubular Joints.” IIW Doc. XV-385-76. Dept. of Architecture, Kumamoto Univ.

17. Kurobane, K., Makino, Y., Mitsui, Y. (1980) "Re-Analysis of Ultimate Strength Data For Truss Connections in Circular Hollow Sections.” IIW Doc. XV-461-80. Dept. of Architecture, Kumamoto Univ.

18. Kurobane, K. (1981), “New Developments and Practices in Tubular Joint Design.” IIW Doc. XV-488-81. Dept. of Architecture, Kumamoto Univ.

19. Li, Y., Earls, C.J. (2002), “Design Recommendations for the Proportioning and Detailing of Long-Span Tri-Chord Sign Structures, Phase I,” Report No. CE/ST 24, Department of Civil and Environmental Engineering, University of Pittsburgh, Pittsburgh, Pennsylvania.

20. Marshall, P.W. (1992), Design of Welded Tubular Connections - Basis and Use of AWS Code Provisions, Elsevier, Amsterdam, ISBN 0444882014.

21. Packer, J.A., Henderson, J.E. (1997), Hollow Structural Section Connections and Trusses, second edition, Design Guide, Canadian Institute of Steel Construction, Willowdale, Ontario, Canada, June.

22. Prion, H.G.L., Birkemoe, P.C. (1988), "Experimental Behaviour of Unstiffened Fabricated Tubular Steel Beam-Columns,” Publ. No. 88-3, Department of Divil Engineering, University of Toronto, Toronto, Ontario, Canada.

23. PENNDOT (2003a) "Overhead Sign Structures - 2-Post \& 4-Post Tri-chord Truss Spans From 18288 to 73152 (60' to 240') Notes and Design Criteria”, Standard Drawings for Bridge Design - BD 644-M, Commonwealth of Pennsylvania Department of Transportation, Harrisburg, Pennsylvania.

24. PENNDOT (2003b) “Overhead Sign Structures - 2-Post \& 4-Post Tri-chord Truss Spans From 18288 to 73152 (60’ to 240') Notes and Design Criteria”, Standard Drawings for Bridge Construction - BC 744- $M$, Commonwealth of Pennsylvania Department of Transportation, Harrisburg, Pennsylvania. 
25. Popov, E.P., Zayas, V.A., Mahin, S.A. (1979), “Cyclic Inelastic Buckling of Thin Tubular Columns,” Journal of the Structural Division, ASCE, Volume 105, No. ST11.

26. Soh, C.K., Chan, T.K., Yu, S.K., (2000) "Limit Analysis of Ultimate Strength of Tubular X-Joints," Journal of Structural Engineering, Vol. 126, No. 7 American Society of Civil Engineers, Reston, Virginia.

27. Stamenkovic, A., Sparrow, K. (1983), "Load Interaction in T-Joints of Steel Circular Hollow Sections,” Journal of Structural Engineering, ASCE, Volume 109, No. 9.

28. Thomas, S., Earls, C.J., (2003) "Cross Sectional Compactness and Bracing Requirements for HPS483W Girders," Journal of Structural Engineering, Vol. 129, No. 12 American Society of Civil Engineers, Reston, Virginia, pp. 1569-1583.

29. Toma, S., Chen, W.F. (1979), “Analysis of Fabricated Tubular Columns,” Journal of the Structural Division, ASCE, Volume 105, No. ST11.

30. Wardenier, J. (1982), Hollow Section Joints, Delft University Press, Delft, ISBN 90.6275.084.2.

31. Wardenier, J., Kurobane, Y., Packer, J.A., Dutta, D., and Yeomans, N. (1991) Design Guide for Circular Hollow Section (CHS) Joints Under Predominantly Static Loading. CIDECT (ed.) and Verlag TUV Rheinland GmbH, Koln, Federal Republic of Germany.

32. Young, W. (1989), Roark's Formulas for Stress and Strain $6^{\text {th }}$ Edition, McGraw-Hill, New York, ISBN 0-07-072541-1. 